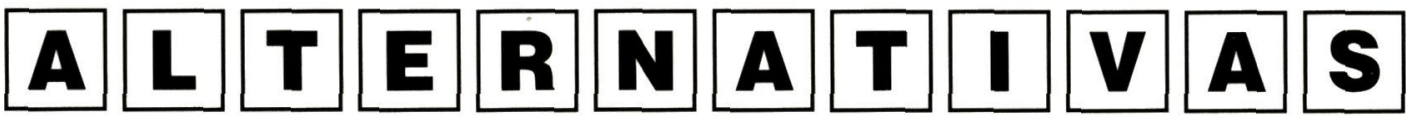

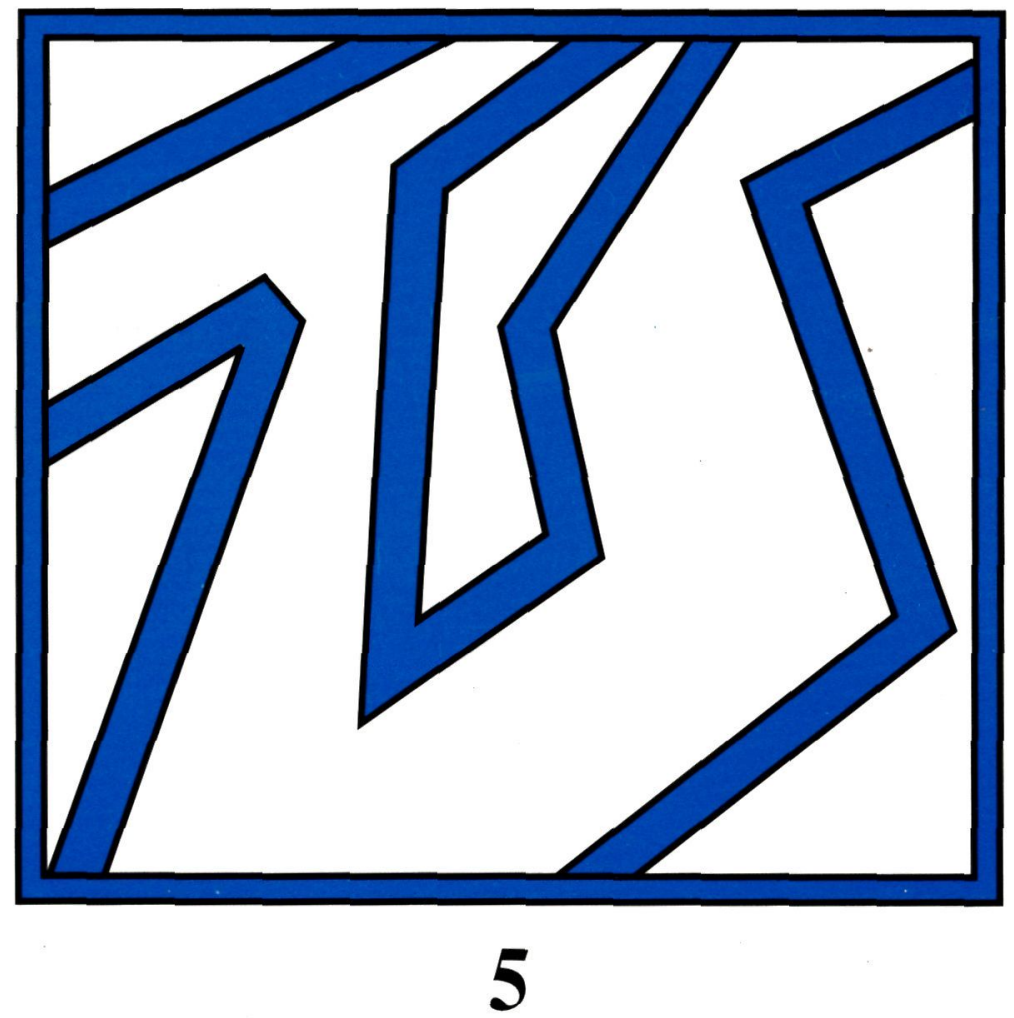

CUADERNOS DE TRABAJO SOCIAL 




\section{ALTERNATIVAS}

\section{CUADERNOS}

DE

TRABAJO SOCIAL 
ALTERNATIVAS. CUADERNOS DE TRABAJO SOCIAL. N. ${ }^{\circ}$ 5. Octubre 1997.

CONSEJO EDITORIAL:

Directora técnica:

Esperanza Suárez Soto

Secretaria:

Manuela Palomar Villena

M. ${ }^{\mathrm{a}}$ José Escartín Caparrós

Hortensia Redero Bellido

M. ${ }^{a}$ Dolores Díez García

\section{EDICIÓN Y ADMINISTRACIÓN:}

Escuela Universitaria de Trabajo Social. Universidad de Alicante.

03690 San Vicente del Raspeig. Alicante.

Telf.: (96) 59037 70. Fax: (96) 5903572.

Depósito Legal: M. 37.152-1992.

I.S.S.N.: $\quad 1133-0473$.

Impresión:

ROMGRAFIC, S.L.

Martínez de Velasco, 17. 03013 Alicante (España).

Encuadernación:

Encuadernaciones Alicante, S.L.

Precio del ejemplar: 2.000 ptas.

Reservados todos los derechos

Suscripciones y venta:

Librería Compás-Universidad, S.L.

Centro de Servicios Universitarios. Universidad de Alicante.

03690 San Vicente del Raspeig. Alicante. España.

Apdo. de correos $\mathrm{n} .0203$.

Telf.: (96) 59093 90. Fax: (96) 5909391.

PRÓXIMA SECCIÓN MONOGRÁFICA:

El marco actual de la Acción Social. ¿Servicios Sociales públicos o privados?

Plazo para la presentación de artículos: 1 de julio de 1998. 


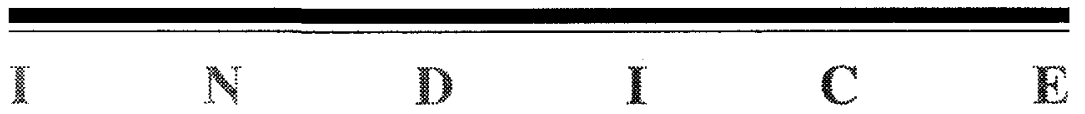



Esperanza Suárez Soto. Directora técnica del consejo editorial de la revista «Alternativas. Cuadernos de Trabajo Social».

Presentación

\section{Trabajos sobre violencia}

M. a Asunción Martínez Román. Departamento de Trabajo Social y Servicios Sociales. Universidad de Alicante.

"Pobreza y exclusión social como formas de violencia estructural". La lucha contra la pobreza y la exclusión social es la lucha por la paz.

Gonzalo Musitu Ochoa. Profesor y director del Area de Psicología Social. Facultad de Psicología. Universidad de Valencia.

Violencia y terrorismo: Un análisis desde la perspectiva ecológica.

E. Bosch-Fiol, M. Gili-Planas y V.A. Ferrer-Pérez. Departamento de Psicología. Universidad de las Islas Baleares.

La violencia doméstica como una forma de expresión de actitudes misóginas.

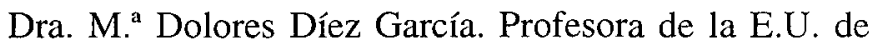
Trabajo Social. Universidad de Alicante.

Dr. Sergio Quesada Rettschlag. Profesor de la E.U. de Trabajo Social. Universidad de Alicante.

M. ${ }^{a}$ Dolores Sala Bonmatí. Trabajadora social.

El maltrato a menores en la provincia de Alicante en el periodo 1980-1997. 
Agustín Bueno Bueno. Profesor de Psicología Social. Universidad de Alicante.

El maltrato psicológicolemocional como expresión de violencia hacia la infancia.

Javier Domínguez, José R. Brocal, José J. Cases, Virginia Tovar y Agustín Bueno.

Análisis del programa de seguimiento de medidas judiciales de régimen abierto en la ciudad de Alicante durante 1996.

José Conrado Moya Mira. Psicólogo. Jefe de la Sección de Familia, Infancia y Juventud de la Dirección Territorial de Bienestar Social de Alicante

Organización de los Servicios de Protección a la Infancia en la Comunidad Valenciana. Análisis normativo y funcional.

M. ${ }^{a}$ José Escartín Caparrós. Profesora Titular de Trabajo Social. Departamento de Trabajo Social y Servicios Sociales. Universidad de Alicante.

Los niños maltratados y sus familias. Algunas indicaciones para la intervención del trabajador social.

\section{Tribuna libre}

Salvador Amigó Borrás. Profesor asociado de la Facultad de Psicología. Universidad de Valencia.

El "problema de la droga" y la prevención del consumo de drogas: mitos y alternativas, con una especial referencia al consumo de cannabis.

M. José Salvador Pedraza, Eva Domínguez Sánchez, Raquel Carracedo Manzanera. Técnicos de la Consejería de Sanidad y Bienestar Social de la Junta de Castilla y León.

Marco operativo de las intervenciones de inserción asociadas a la percepción de rentas mínimas. 
Jesús Moragón Nava. Trabajador Social. Centro de Salud de Atención Primaria. INSALUD. Albacete.

La realidad rural: situación en una región. La organización de equipamientos.

Trinidad Banda Gallego. Profesora titular de la Escuela Universitaria de Trabajo Social. Universidad de Huelva.

El debate sobre la provisión pluralista de los Servicios Sociales.

Víctor M. Giménez Bertomeu. Trabajador Social. Coordinador del Centro Social n. ${ }^{\circ}$ 4. Servicios Municipales del Ayuntamiento de Alicante.

El trabajador social en la dirección de un Centro de Servicios Sociales.

Enrique di Carlo. Equipo E.I.E.M. Universidad Nacional de Mar del Plata. Argentina.

El paradigma humanista como sustancia del Trabajo Social. El Trabajo Social y el paradigma humanista dialéctico. Alternativa de reorganización teorética y metodología del trabajo social profesional

\section{Libros}

M. José Escartín Caparrós. Profesora Titular del Departamento de Trabajo Social y Servicios Sociales. Universidad de Alicante.

Título: «Violencia. Memoria amarga». Siglo XXI de España Editores, S.A. Madrid, 1997, 303 páginas. Autor: Javier Urra Portillo. Defensor del Menor en la Comunidad de Madrid.

M. ${ }^{a}$ Asunción Martínez Román. Departamento de Trabajo Social y Servicios Sociales. Universidad de Alicante.

Título: «Los Modelos en Trabajo Social. Intervención con personas y familias». Siglo XXI de España Editores, S.A. 
Madrid, 1996, 405 páginas. Autora: Mathilde du Ranquet.

M. ${ }^{a}$ Victoria Molina Sánchez. Catedrática de Trabajo Social. Universidad Complutense de Madrid.

Título: «Introducción al Trabajo Social II. Trabajo Social con individuos y familias». Editorial Aguaclara. Alicante, 1997, 287 páginas. Autoras: Escartín Caparrós, M.J., Palomar Villena, M., Suárez Soto, E.

\section{Números publicados}

Número 1 (1992)

Número 2 (1993)

328

Número 3 (1995)

331

Número 4 (1996) 


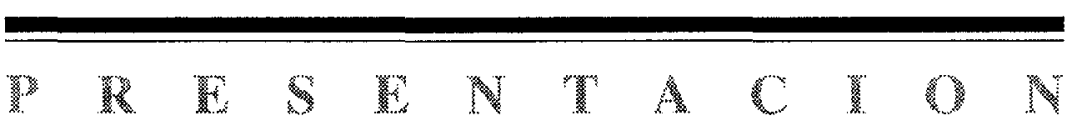





\section{ESPERANZA SUÁREZ SOTO.}

Directora técnica del consejo editorial de la revista « Alternativas. Cuadernos de Trabajo Social».

Me complace presentar el número 5 de la revista «Alternativas. Cuadernos de Trabajo Social» que editamos desde la Escuela de Trabajo Social de la Universidad de Alicante.

La sección monográfica de este número aborda, tal y como estaba anunciado, el tema de la violencia en nuestra sociedad, con interesantes aportaciones sobre el mismo, siendo los menores el grupo que ha ocupado el grueso de la revista, tanto en la reflexión teórica como en experiencias de investigación y de acción aportadas por los/as autores/as.

Se ofrecen también en este número interesantes artículos sobre pobreza y terrorismo como formas extendidas y agudas de violencia social. En ellos, se sugieren nuevos parámetros de análisis, necesarios, para la articulación de nuevas medidas sociales realmente tendentes a la eliminación de estos problemas sociales.

El problema de malos tratos a mujeres se presenta mediante una reflexión de las causas profundas, que, en última instancia, hacen que, situaciones como éstas pervivan en las llamadas sociedades avanzadas y en las puertas del siglo XXI.

La violencia hacia los menores ocupa, tal y como decíamos, un extenso lugar en esta sección monográfica. La razón de ello se debe, sin lugar a dudas, a la creciente preocupación sobre esta realidad, que, por el momento, no está suficientemente interiorizada en la conciencia social.

Así, entre los trabajos presentados para esta sección, se incluye una investigación sobre el maltrato a menores en la provincia de Alicante en el periodo 1980-1997, un análisis sobre la incidencia de los malos tratos psicológicos a la infancia, una evaluación sobre el programa de seguimiento de las medidas judiciales, un panorama de la organización de los servicios de protección a la infancia en la Comunidad Va- 
lenciana $y$, por último, algunas indicaciones para la intervención de los trabajadores sociales en este ámbito de problemas.

La sección abierta es, asimismo, numerosa en aportaciones variadas, realizadas desde distintos contextos geográficos, profesionales y académicos sobre temas como la droga, el debate actual en los Servicios Sociales, los análisis sobre determinadas realidades rurales y marcos de intervención para la inserción social. La sección se cierra, por último, con dos propuestas de reflexión y actualización en la concepción teórica y práctica del Trabajo Social, como son el papel del trabajador/a social en la dirección de los Centros de Servicios Sociales y la incidencia de los valores y paradigmas humanistas y dialécticos en los contenidos centrales del trabajo social.

En nombre del Consejo Editorial, y en el mío propio, quiero mostrar nuestra satisfacción y agradecimiento a la colaboración obtenida para este nuevo número de la revista.

Aprovecho la ocasión para comunicar mi despedida y la de algunos compañeros y compañeras del consejo editorial, reiterando nuestra gratitud a autores/as y colaboradores/as y, de manera especial, al servicio de distribución y venta y a los encargados de las tareas de impresión, todos los cuales han contribuido de manera decisiva a que estos números de la revista vieran la luz.

Dado el interés mostrado a lo largo de los últimos números acerca de los cambios que se vienen produciendo en nuestras sociedades en el contexto de la Acción social, el Consejo Editorial ha decidido incorporar estas reflexiones en la sección monográfica del próximo número de la revista bajo el tema «El marco actual de la Acción Social. ¿Servicios Sociales públicos o privados?», por lo que ponemos de nuevo este medio de comunicación a disposición de todas aquellas reflexiones que, sin duda, pueden contribuir a encontrar nuevas vías de mejora y bienestar social. 
1. TRABAJOS

SOBRE

VIOLENCIA 



\section{POBREZA Y EXCLUSIÓN SOCIAL COMO FORMAS DE VIOLENCIA ESTRUCTURAL \\ LA LUCHA CONTRA LA POBREZA Y LA EXCLUSIÓN SOCIAL ES LA LUCHA POR LA PAZ}

\section{M. ${ }^{a}$ ASUNCIÓN MARTÍNEZ ROMÁN}

Departamento de Trabajo y Servicios Sociales. Universidad de Alicante.

\section{INTRODUCCIÓN}

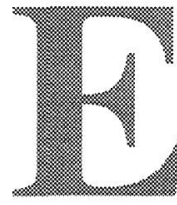

1 aumento de la pobreza, considerado globalmente, es un problema mundial de tal envergadura que ha pasado a ser un objetivo prioritario de Naciones Unidas. En el último Informe sobre Desarrollo Humano se constata que la pobreza «ya no es inevitable», tanto en el plano nacional como en el internacional, entendiendo la pobreza no sólo como pobreza de ingreso sino, en la perspectiva del desarrollo humano, «como denegación de opciones y oportunidades para vivir una vida tolerable» (vivir una vida larga, sana y creativa y disfrutar de un nivel decente de vida, libertad, dignidad, respeto por sí mismo y de los demás). El Informe destaca los avances logrados en todos los países del mundo en cuanto al ingreso y también en cuanto a la esperanza de vida y al acceso a los servicios sociales básicos, pero advierte que los adelantos han sido desiguales, con retrocesos, y que la pobreza sigue siendo generalizada (PNUD, 1997).

Si la pobreza es evitable, resulta ser más injusta la persistencia de situaciones como las destacadas en el Informe: más de la cuarta parte de la población del mundo en desarrollo sigue viviendo en la pobreza; alrededor de un tercio de la población (1.300 millones de personas) vive con un ingreso inferior a un dólar diario; la mayor cantidad de personas afectadas se encuentran en Asia meridional y Africa subsahariana; en América Latina y el Caribe la pobreza de ingreso afecta a unos 110 millones de personas y sigue creciendo; en Europa Oriental y los países de la Comunidad de Estados Independientes (CEI) se ha experimentado el mayor deterioro en los últimos diez años (120 millones de personas).

El problema también afecta a los países industrializados, en los que se calcula que más de 100 millones de personas viven por debajo 
de la pobreza de ingreso, siendo 37 millones las personas que carecen de empleo. Actualmente, en Estados Unidos, una cuarta parte de los niños viven en hogares que están por debajo de la línea de la pobreza. Este fenómeno de la «infantilización» de la pobreza se constata también en otros países industrializados. Así, alrededor de la mitad de los niños que viven en hogares con un sólo padre se hallan por debajo de la línea de pobreza en Australia, Canadá, Reino Unido y Estados Unidos, pero sólo el 5\% en Finlandia y el 8\% en Suecia (PNUD, 1997:87).

La pobreza y la exclusión social, en cuanto denegación de opciones y de oportunidades para vivir una vida tolerable, se analizan a continuación como una forma evidente de violencia estructural que puede y debe ser evitada.

\section{HAY VIOLENCIA CUANDO LAS PERSONAS ENCUENTRAN OBSTÁCULOS PARA SU DESARROLLO PERSONAL Y SOCIAL.}

Galtung, experto en temas de investigación para la paz, partiendo de una definición generalista de la paz como ausencia de violencia, sostiene una concepción amplia de la violencia, más allá de la mera violencia física, en la que se relacionan directamente paz y desarrollo. La paz, en sentido amplio, es la ausencia tanto de violencia directa como de violencia estructural entre los Estados y dentro de los Estados, lo que supone la posibilidad de lograr la satisfacción de las necesidades básicas: la supervivencia, el bienestar, la identidad y la libertad para todos. El desarrollo, en sentido restringido, es igual a crecimiento económico y, en sentido amplio, es igual a la satisfacción de las necesidades humanas básicas: supervivencia, bienestar, identidad y libertad para todos (Galtung, 1985:107).

Es decir, la ausencia de paz, la violencia, está directamente relacionada con obstáculos o impedimentos a las posibilidades de desarrollo humano. En consecuencia, este autor considera que «la violencia está presente cuando los seres humanos se ven influidos de tal manera que sus realizaciones efectivas, somáticas y mentales, están por debajo de sus realizaciones potenciales», de modo que «cuando lo potencial es mayor que lo efectivo, y ello es evitable, existe violencia» (Galtung, 1995:314-315).

La pobreza (miseria), según Galtung, es una forma de sufrimiento, es la privación de las necesidades básicas implantada en la estructura y justificada por la cultura. Según la tipología del autor, la pobreza puede considerarse una forma de violencia estructural o indirecta, situación en la que la violencia se genera y está implantada dentro de la 
estructura y se manifiesta como un poder desigual y, consiguientemente, como oportunidades de vida distintas. La pobreza se apoya en la violencia cultural, es decir, la religión, la ideología, la lengua, el arte, la ciencia o la cosmología pueden servir para justificar y legitimar la existencia de la pobreza, considerándola algo inevitable (Galtung, 1996) y hasta, incluso, necesario (Tortosa, 1993:53).

En consecuencia, la pobreza es una forma de violencia institucionalizada e interiorizada, de ahí las dificultades para luchar contra ella, ya que cualquier intento de erradicarla producirá fuertes resistencias, tanto por parte de las estructuras sociales que se resistirán a los cambios, como por parte de los propios sujetos afectados. Las personas que carecen de poder de decisión sobre la distribución de los recursos existentes no tienen las mismas oportunidades de acceso a los medios precisos para desarrollar sus potencialidades personales. Esta diferencia de oportunidades origina una permanente situación de desigualdad que puede calificarse como violencia estructural o injusticia social, violencia que, a su vez, puede ser manifiesta o latente (Galtung, 1995:320).

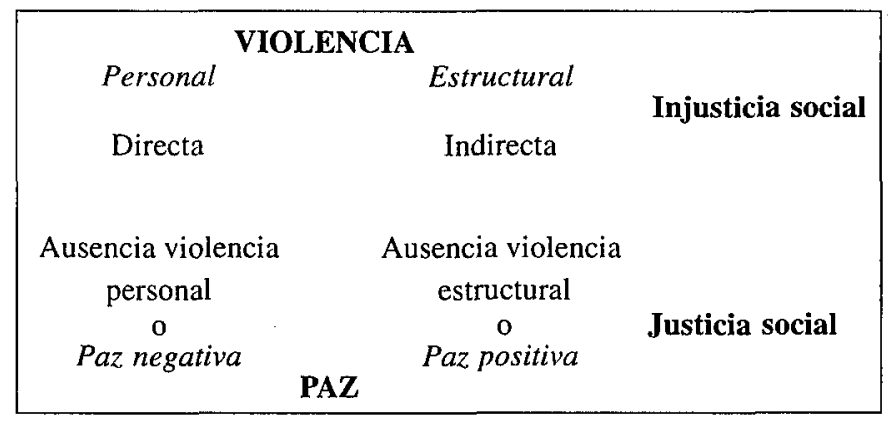

FUENTE: Galtung, J. (1995) Investigaciones teóricas. Sociedad y Cultura contemporáneas. Madrid, Tecnos-Instituto de Cultura «Juan Gil-Albert», pág. 348.

Así, la ausencia de violencia estructural o paz estructural (paz positiva) sería la existencia de justicia social, es decir, una distribución igualitaria del poder y de los recursos, lo que lleva al autor a destacar la estrecha relación entre este tipo de paz y la teoría del desarrollo, tal como la más reconocida relación entre la ausencia de violencia personal (paz negativa) y la teoría del conflicto. Por lo tanto, en la investigación para la paz tiene un lugar necesario la investigación del desarrollo.

Desde diferentes organismos internacionales, se destaca, en los últimos años, tanto la existencia en el mundo de la pobreza, la injusticia social y el deterioro ambiental como la ausencia de su justificación, 
estableciendo la relación causal entre pobreza y crecimiento económico e, incluso, con los conflictos bélicos. Situación que, si bien afecta en mayor medida a países en proceso de desarrollo, afecta también a los países industrializados.

En la Conferencia sobre Población y Desarrollo de El Cairo se reconocía que «la pobreza generalizada sigue siendo el principal problema con que se tropieza al efectuar actividades de desarrollo. $\mathrm{La}$ pobreza suele ir acompañada de desempleo, malnutrición, analfabetismo, el bajo nivel social de la mujer, riesgos ambientales y un acceso limitado a servicios sociales y sanitarios, incluidos los servicios de salud reproductiva, que a su vez, incluye la planificación de la familia. Todos estos factores contribuyen a elevar los niveles de fecundidad, morbilidad y mortalidad, así como a reducir la productividad económica. La pobreza también está íntimamente relacionada con la inadecuada distribución espacial de la población, el uso insostenible y la distribución no equitativa de recursos naturales tales como la tierra y el agua y una grave degradación del medio ambiente» (Naciones Unidas, 1994:18).

Asimismo, la Comisión Sudamericana de Paz destaca que «la pobreza, la exclusión social y el desempleo son factores de inestabilidad económica, política, social y cultural que generan violencia y amenazan la seguridad de las personas» (Comisión Sudamericana de $\mathrm{Paz}$, Seguridad y Democracia, 1994). El Informe sobre Desarrollo Humano de 1994 destaca el interés de la ONU por un desarrollo humano sostenible, resaltando que el programa de paz y el programa de desarrollo deben ser integrados en última instancia: «sin paz no puede haber desarrollo; pero sin desarrollo la paz puede estar amenazada» (PNUD, 1995). Una condición imprescindible para que se dé la paz es el hecho de que los seres humanos tengan seguridad en sus vidas cotidianas, más allá de la clásica concepción de la seguridad como protección del territorio nacional ante un posible conflicto bélico contra otro país. Esta nueva concepción de la seguridad humana no es un concepto meramente defensivo sino integrador, que reconoce la preocupación de las personas ante sus condiciones de vida diarias, lo que les lleva a entender la seguridad como la protección ante acontecimientos que pueden tener gran trascendencia en sus vidas, tales como la enfermedad, el hambre, el desempleo, etc.

Por lo tanto, al pensar en la seguridad no hay que pensar sólo en la seguridad militar sino también en la seguridad humana o, en lo que es lo mismo, preocuparse por la seguridad de la población entendiendo por tal las condiciones de vida y la dignidad humanas. En el primer caso, se busca protección ante posibles riesgos que pondrían en peligro a seres humanos, en el segundo, hay que preocuparse de las con- 
diciones de vida que impiden a las personas su desarrollo humano, se centra en el ser humano. La seguridad es un concepto integrador y globalizador en el que se pueden distinguir siete categorías: seguridad económica, seguridad alimentaria, seguridad en materia de salud, seguridad ambiental, seguridad personal, seguridad de la comunidad y seguridad política.

De todo lo dicho se desprende la interdependencia existente entre seguridad humana y desarrollo humano, si bien hay que distinguir las diferencias: el desarrollo humano es un concepto más amplio, como un proceso de ampliación de la gama de opciones de las que dispone la gente; la seguridad humana «hace posible que la gente pueda ejercer esas opciones en forma segura y libre y que pueda tener relativa confianza en que las oportunidades que tiene hoy no desaparecerán totalmente mañana» (PNUD, 1995:26-27). Las limitaciones o déficits del desarrollo humano tienen como consecuencia la pérdida o inexistencia de la seguridad humana. A su vez, la existencia de inseguridad humana puede ser una causa de generación de violencia por parte de las personas que se ven privadas de su seguridad y ven mermadas o anuladas sus oportunidades de desarrollo personal, de lo que se pueden encontrar ejemplos en todos los países (Rifkin, 1996:249-258).

Esta falta de seguridad humana no sólo afecta a los países en proceso de desarrollo sino que, dadas las características del sistema mundial, cuando la inseguridad puede traspasar las fronteras nacionales también puede verse amenazada la seguridad humana a escala mundial. Las amenazas contra la seguridad humana mundial del siglo XXI, como crecimiento descontrolado de la población; disparidad de oportunidades económicas; migración internacional excesiva; deterioro del medio ambiente; producción y tráfico de estupefacientes; y terrorismo internacional, plantean la necesidad de actuar conjuntamente todos los países, al no ser posible para ninguno de ellos permanecer aislado del resto.

Resulta nuevo el mensaje de Naciones Unidas sobre lo injustificado de la existencia de situaciones de pobreza humana cuando, durante años, se ha venido justificando la existencia de situaciones de pobreza como el costo inevitable de todo proceso de desarrollo económico argumentándose que, cuando se lograse dicho desarrollo, los beneficios alcanzarían a los más pobres que se beneficiarían también de ello. Sin embargo, el tiempo ha demostrado que dicho planteamiento sólo asegura el beneficio de unos pocos en los que se acaban concentrando las ganancias, mientras que, por el contrario, un número mucho mayor de personas no llegan a alcanzar las mejoras logradas e, incluso, pueden ver empeorar sus condiciones de vida como precio de la mejora del primer grupo. 
La situación resulta más injusta, socialmente hablando, cuando las ganancias económicas se concentran cada vez en menos manos, en proporciones escandalosas que suponen una seria amenaza social. Así, en 1994, la relación entre el ingreso del $20 \%$ más rico del mundo y el ingreso del $20 \%$ más pobre era de 78 a 1 , en comparación con 61 a 1 en 1991 y con 30 a 1 en 1960 (PNUD, 1997:29).

\section{III.POBREZA Y EXCLUSIÓN SOCIAL COMO FORMAS DE VIOLENCIA ESTRUCTURAL.}

Desde 1990, el Programa de Naciones Unidas para el Desarrollo viene proponiendo un nuevo paradigma de desarrollo por el que se sitúa al ser humano en el centro del proceso de desarrollo, destacando que el crecimiento económico no es un fin sino un medio necesario para el desarrollo humano. El Informe sobre el Desarrollo de 1994, señala que un desarrollo humano significa la posibilidad de que toda persona amplíe plenamente su capacidad humana y la aproveche al máximo en todas las esferas (económica, social, cultural y política), protegiendo las opciones de las generaciones futuras (desarrollo sostenido) y asignando prioridad a la reducción de la pobreza, promoción de empleo productivo, promoción de la integración social y regeneración del medio ambiente (PNUD, 1995:5).

Se define el Desarrollo Humano como el proceso de ampliación de opciones de la gente, siendo las opciones fundamentales: vivir una vida larga, sana y creativa; tener educación (conocimientos y capacidad de comunicación); y disfrutar de un nivel de vida decente. Además, son necesarias otras opciones como: libertad política; garantía de otros derechos humanos; respeto por sí mismo, así como recibir el respeto de los demás (PNUD, 1997:17-18).

Cuando hay privación de estas opciones hay pobreza humana y ello es socialmente injusto, dado que otras personas sí disponen de esas opciones y, por lo tanto, de un desarrollo humano. Al hablar de pobreza humana se alude a privación de capacidades básicas, es decir, la privación en años de vida, salud, vivienda, conocimientos, participación social, seguridad personal y medio ambiente. Desde la perspectiva de la capacidad, la pobreza de una vida se basa no sólo en la situación empobrecida en la que una persona vive efectivamente, sino también en la carencia de oportunidad real, determinada por limitaciones sociales y por circunstancias personales para vivir una vida «valiosa y valorada». Esta otra cara de la pobreza es la que nos muestra las dificultades de integración social que encuentran muchas personas, lo que nos sitúa en la esfera de la exclusión social. 
Siguiendo a Rodgers, podemos considerar la exclusión social como una característica de los individuos o como una característica de las sociedades. En el primer caso, la exclusión social se centra en las condiciones de vida que la gente tiene. Una persona socialmente excluida está socialmente aislada en algún sentido; puede tener desventaja en cuanto al reconocimiento de sus derechos legales o respecto a su capacidad para ejercerlos efectivamente, entrando en una dinámica de causalidad acumulativa, de efectos negativos que refuerzan la desventaja y que pueden hacerla irreversible. En el segundo caso, se puede considerar la exclusión social con un enfoque institucional (instituciones, normas etc.), el marco en el que los individuos se relacionan. En este sentido, hay exclusión social cuando la sociedad permite diferentes formas de discriminación, cuando se niega a individuos y a grupos el acceso a los bienes, servicios, mercados y recursos que se asocian a la ciudadanía. En resumen, puede verse la exclusión social como un concepto multidimensional de pobreza que introduce aspectos de participación social y de realización de derechos como seguridad (física, de sustento y de protección ante contingencias, protección, identidad y plena ciudadanía) en su conceptualización (Rodgers, 1995:43-55).

La exclusión social es también una forma de violencia estructural en cuanto entre las causas de la exclusión encontramos fenómenos estructurales, tal como se reconoce desde las Comunidades Europeas: la persistencia del desempleo de larga duración; las consecuencias para el mercado laboral de las mutaciones industriales (especialmente para los trabajadores menos cualificados); el deterioro de las estructuras familiares; la evolución del sistema de valores, en particular, el hundimiento de la cohesión y de las formas tradicionales de solidaridad; la tendencia a la fragmentación social y, como consecuencia, la reducida participación en las instituciones representativas tradicionales; y la evolución de los fenómenos migratorios. El Comité Económico y Social considera que el problema de la exclusión social en Europa es un problema de grandes dimensiones, que supone una amenaza al progreso social y económico europeo, a la unidad europea y nacional e, incluso, para la propia democracia (Comunidades Europeas, 1993).

De la serie de fenómenos citados como factores estructurales generadores de la exclusión social, hay que destacar por su importancia el desempleo de larga duración y la inestabilidad/precariedad laboral, que han dado lugar a la aparición de nuevos grupos de población en situación de precariedad y de pobreza, afectando especialmente a jóvenes, mujeres, minorías étnicas y mayores de 45 años. Un reciente informe de la OIT estima que, en 1996, un 30\% de la población acti- 
va mundial estaba en desempleo o sub-empleada y que el número de los trabajadores pobres (insuficientemente remunerados) aumentaba sin cesar (OIT, 1997).

La Unión Europea no está libre de fenómenos como la mundialización de la economía y la globalización de la tecnología que han originado, por una parte, la demanda de una mayor cualificación laboral y, por otra, la desvalorización de los trabajadores no cualificados con la consiguiente desaparición de gran número de empleos. En consecuencia, en los países industrializados ha tenido lugar una situación generalizada de desempleo estructural que ha perdurado durante los 80 , con un alto costo social para muchas personas que han pasado a ser pobres o tienen gran peligro de serlo por su vulnerabilidad.

La novedad es que estas personas que han pasado a estar en peligro de llegar a ser pobres pertenecen a las clases medias formadas por trabajadores que se habían beneficiado de los modos de crecimiento económico anteriores cualificándose y empleándose, con lo que contribuían a mantener los sistemas de protección social diseñados precisamente para evitar que se llegaran a encontrar en una situación de pobreza.

Engelhard señala tres consecuencias de esta situación mundial:

a) las personas son valoradas socialmente en función de su capacidad de ser productivas y de su poder de consumo y ahorro, por lo que las personas que no pueden acceder a un empleo pasan a estar en riesgo o en situación de exclusión social;

b) la competitividad y la eficacia tecno-económica son los criterios financieros dominantes, buscándose la máxima ganancia a pesar de los costes sociales;

c) el debilitamiento de lo político, como resultado de la primacía de lo económico sobre lo social y de lo financiero sobre lo económico (Engelhard, 1996:36-41).

El desempleo es, además, un factor generador de una nueva categoría de personas pobres denominados por Castel «los válidos invalidados por la coyuntura» que, si no trabajan, no es porque no quieran hacerlo sino porque no encuentran trabajo y a los que tampoco se les puede «rehabilitar» en cuanto que no son encuadrables en las categorías clásicas de la ayuda social. Hay que ayudarles a encontrar un lugar «normal» en la sociedad y ello sólo será posible a través de un empleo (Castel, 1995).

Castel destaca la necesidad de analizar el trabajo como el medio actual de situarse en la estructura social, ya que existe una fuerte correlación entre el lugar ocupado en la división social del trabajo y la participación en las redes sociales y en los sistemas de protección que cubren a un individuo ante las contingencias a lo largo de su existen- 
cia. El aumento de la vulnerabilidad de la población general supone un aumento de la fragilidad de las personas que ya eran antes vulnerables, encontrándose una correlación entre la degradación del status concedido por el trabajo y la fragilización de los soportes relacionales familiares, vecinales y sociales (Castel, 1995:415). Para representar esta situación, el autor recurre a establecer unas «zonas» de cohesión social en las que se situarían las personas en función de su situación laboral y social, con la posibilidad de sub-zonas y variaciones en función de las situaciones personales y sociales.

Son tres las zonas en que se pueden encuadrar a las personas en relación a la cohesión social: una primera zona, denominada de «integración» en la que se encuentran las personas que disfrutan plenamente de los derechos de ciudadanía; una segunda zona en la que se encuentran las personas que se encuentran en situación de «vulnerabilidad», con grave riesgo de empobrecimiento y exclusión social y, finalmente, la zona en la que se encuentran las personas en situación de «exclusión social» (Castel, 1995:474).

Partiendo de esta propuesta de Castel, podemos sintetizar la situación de las personas en función de las características diferenciales que implican la adscripción a cada una de las zonas:

1. Zona de INTEGRACIÓN.
empleo estable,
relaciones familiares y sociales fuertes.
Ingresos económicos, status social, protección social, apoyo redes sociales, opor-
tunidades de participación en la vida social, cultural, económica y política, junto
con habilidades para ejercerla efectivamente.
2. Zona de VULNERABILIDAD.
empleo precario,
soportes familiares y sociales frágiles.
Inestabilidad laboral, paro recurrente, ingresos insuficientes, débil protección so-
cial, «vivir al día» o solamente sobrevivir, peligro de endeudamiento, debilita-
miento de las redes sociales primarias, inicio del sentimiento de inutilidad social y
de un proceso de desvalorización personal y social.
3. Zona de EXCLUSIÓN.
ausencia de participación en actividad productiva,
aislamiento familiar y social.
Sentimiento de inutilidad social («normales inútiles») y pérdida de la autoestima,
«desafiliación», ausencia de oportunidades y/o incapacidad de ejercer los dere-
chos sociales y no participación en la vida social, cultural, económica y política.


En resumen, el trabajo es el principal fundamento de la ciudadanía, en tanto comporta una dimensión económica y una dimensión social, es el medio concreto sobre el que se construyen los derechos y los deberes sociales. Hay que destacar la denominada zona de «vulnerabilidad», caracterizada por la situación de precariedad laboral y social, en la que se podría encuadrar a un importante grupo de población. El hecho de que sea situable en esta zona una parte importante de la población, debería convertirla en diana para la intervención de las políticas sociales si se deseara evitar la exclusión social.

En el caso español, se observa un fenómeno similar al descrito por Castel: el desempleo y el subempleo son uno de los principales problemas sociales actuales, existiendo un gran grupo de personas con graves dificultades para subsistir y, otros muchos, en precaria situación (Martínez Román, 1996a). Entre los distintos factores explicativos de la agravación del desempleo español en los últimos años hay que citar: por una parte, la disminución del consumo privado debido a la fuerte moderación salarial, el aumento del paro y los recortes en las prestaciones por desempleo, con efectos agravados por los recortes del gasto público; por otra, una serie de efectos estructurales como la destrucción de millones de puestos de trabajo consecuencia de la reestructuración industrial y factores estructurales de la economía española que la sitúan en débil posición en el contexto mundial. En opinión de Recio, las políticas laborales adoptadas al primar el recorte de salarios y la progresiva reducción de los derechos laborales, pueden haber acentuado las deficiencias del mercado laboral español y de su sistema productivo, potenciando crecientes desigualdades sociales que han generado un clima de tensión social (Recio, 1997:276-277).

Como se ha visto anteriormente, la exclusión social no es consecuencia, únicamente, de la falta de medios económicos; en el fenómeno inciden factores de muy diversa índole, entre los cuales juega un papel fundamental la dificultad para incorporarse al mercado de trabajo, la posibilidad de lograr el pleno desarrollo como persona y la satisfacción de las necesidades de forma autónoma y por medios lícitos. El hecho de llevar tiempo fuera del sistema de producción implica una cierta desadaptación al sistema de vida normalizado, con dificultad para acceder a los servicios, a la participación en la vida social y con un lógico desfase en la preparación necesaria para encontrar nuevamente trabajo; además de la pérdida de conocimientos y habilidades para el trabajo, se produce una frustración y un deterioro progresivo de la actitud frente al trabajo.

Los aspectos personales del paro «tienen repercusiones físicas (consumo de alcohol, incremento de suicidios y para-suicidios, alteraciones psicopatológicas, etc), también deja huella en las relaciones 
familiares y en las sociales, tales como la disminución del uso de habilidades sociales que provoca, la disminución de posibilidades de contacto interpersonal o la carencia de la fuente de estima pública que reporta el ejercicio laboral» (Quevedo, 1990: 211). La prolongación de esta situación provoca un sentimiento de pérdida de confianza en uno mismo y en la sociedad, que puede traer consigo problemas adicionales de salud y sociales que pueden empujar, cada vez más, a mantenerse al margen de la sociedad. A falta de estudios conocidos en nuestro país, hay que recordar, por ejemplo, la correlación entre crecimiento de desempleo y violencia criminal que queda demostrada en el estudio de Merva y Fowles, en Estados Unidos, encontrando que un crecimiento de un $1 \%$ en el desempleo supone un crecimiento del $6,7 \%$ en los homicidios, de un 3,4\% en los crímenes violentos y de un 2,4\% en los crímenes contra la propiedad (Merva y Fowles, 1992).

En opinión de Cáritas Española, dos causas importantes del aumento del grupo de personas excluidas han sido «la flexibilización del mercado de trabajo, con la apertura constante de «huecos», que no ha conseguido que el grupo de los parados de larga duración encuentre un lugar en él y el recorte de los subsidios que provoca que un grupo de trabajadores en paro caigan en situaciones de exclusión, sin posibilidades de incorporarse al mundo laboral» (Pérez, 1996:15). Opinión que coincide con otras realizadas por otras organizaciones, entre ellas los sindicatos. Un caso especial es la aparición de los nuevos demandantes de ayuda económica, sin historia previa de necesidad económica, que como consecuencia de la crisis económica «de la noche a la mañana» pierden sus fuentes de ingresos y, con ellos, un nivel de bienestar, pasando a no saber cómo subsistir. Cáritas cifra esta cara de la pobreza entre un $10 \%$ y un $14 \%$ de las demandas, registradas a través de sus servicios, que corresponden a personas de clase media, y que llegan muchas veces derivados desde los Servicios Sociales públicos, impotentes para ayudarles. Para Cáritas es importante destacar la peculiaridad de estas situaciones, que quedarían superadas con la posibilidad de un empleo (no hay historia previa de marginación), por lo que, en su opinión, estas situaciones tienen su origen en los desequilibrios estructurales inherentes al modelo económico actual (generador de paro y de inestabilidad social) y en las carencias de una política social incapaz de prevenir la aparición de nuevos grupos de desprotegidos (Cáritas Española, 1997).

Resumiendo, el desempleo y el subempleo han llegado a ser en estos momentos la mayor preocupación de los españoles, en unos casos, por estar sufriendo directamente sus consecuencias y, en otros, por la pérdida generalizada de la seguridad asociada, tradicionalmente, a muchos empleos o por la dificultad de acceder a un primer em- 
pleo. En este contexto difícil para el conjunto de la población, hay que destacar las especiales dificultades de las personas incluidas en la categoría de los «vulnerables» (Tortosa, 1993:61-64), aquellas categorías sociales producto de la desigualdad, con menos poder, que suponen, en este contexto de dificultad general de empleo, un aumento de la vulnerabilidad de determinados grupos de población como son la edad, el género, la existencia de discapacidades, inmigración, minoría cultural, etc. Por razones de espacio tan sólo podemos comentar, brevemente, la situación en razón de edad y género.

En relación a la edad, un caso especial es el de los jóvenes españoles cuyo mayor problema es el desempleo o el subempleo, estimándose en 1.120.000 los jóvenes sin empleo, las cifras más altas de la Unión Europea (Centro de Estudios del Cambio Social, 1997: XXIII). En 1995, se constató una disminución del número de jóvenes protegidos ante el desempleo (16-34 años). Del total de 177.316 perceptores menos en media anual perceptores de subsidio, 144.588 fueron jóvenes, entre los perceptores de prestaciones contributivas el descenso del número de perceptores no presenta variaciones por grupos de edad (CES, 1996:309-310). En 1996, los parados menores de 30 años son la mitad del total de los que, a su vez, la mitad llevaba más de un año buscando empleo; de los que han logrado trabajo, un tercio ha conocido cuatro trabajos o más (CES, 1997:86-190).

Estos problemas deben analizarse en el contexto de la situación general del empleo y, por tanto, no se trata de exigir simplemente a los jóvenes un cambio por su parte. La mayoría de las ofertas a las que los jóvenes ha podido optar en los últimos años han sido temporales, de corta duración y con escasas o nulas posibilidades de protección social, ocupando muchas veces empleos de inferior cualificación con lo que, además, se relega a otros jóvenes sin cualificación que ven disminuidas sus oportunidades. En opinión de los sindicatos mayoritarios uno de los factores que explica esta situación de los jóvenes es la implantación, en la reforma laboral de 1993, de la figura del contrato de aprendizaje, que ha degradado las condiciones laborales de los jóvenes sin garantizar realmente la formación, y la deslaboralización de los contratos de menos de $48 \mathrm{~h}$./mes o de menos de $12 \mathrm{~h} . / \mathrm{semana}$ (Comisión de Trabajo y Seguridad Social del Senado, 1994:10-19; Elvira, 1994:38). La gravedad del problema ha sido causa de importantes modificaciones aprobadas en la última reforma laboral de este mismo año, sin embargo, dada su reciente implantación, es prematuro hacer valoraciones.

Desde el punto de vista del desarrollo humano de estos jóvenes, esta falta de opciones de trabajo, con la consiguiente carencia de ingresos, tiene repercusiones importantes en cuanto a las posibilidades 
de independencia de la familia de origen retrasando la formación de la propia familia y cambiando los roles de padres y abuelos que se ven obligados a seguir manteniendo a los hijos y, en muchas ocasiones, también a los nietos. Además, es fuente de problemas sociales como delincuencia, drogadicción, etc., por lo que el desempleo y subempleo juvenil puede calificarse de despilfarro de recursos humanos y amenaza para la cohesión económica y social (Comunidades Europeas, 1995).

En cuanto a la variable género, el colectivo de las mujeres es uno de los más castigados por el desempleo, lo que guarda estrecha relación con la situación social de la mujer española (Fernández Viguera, 1990:65-86). No hay que olvidar que, hasta hace relativamente poco, el nivel de estudios era muy bajo y la cualificación profesional prácticamente inaccesible para la mujer, las familias primaban la cualificación de los hijos varones como futuros «cabezas de familia», de la mujer se esperaba que se dedicara a «sus labores» familiares, abandonando el trabajo, si es que lo tenía, al contraer matrimonio. La consecuencia es que estas mujeres no han estado cotizando, su trabajo ha sido «invisible», por lo que han quedado dependientes de los ingresos del marido y desprotegidas cuando esta fuente de ingresos les fallaba: sin derecho a prestaciones sociales o éstas les resultan insuficientes, sin empleo cuando hay exceso de demanda, sin cualificación y, con frecuencia, con menores a su cargo.

Expertas/os de inserción laboral de las mujeres señalan, entre los obstáculos que estas encuentran: la alta precariedad en el empleo, su baja cualificación profesional, la absorción mayoritaria de empleos femeninos en la economía sumergida, los salarios inferiores a los hombres en el mismo puesto laboral, la elevada dificultad para acceder a puestos de responsabilidad, la acumulación del pluriempleo derivado de la doble jornada y la falta de autovaloración personal y profesional (Cáritas, 1995).

Las mujeres han venido estando sub-representadas en las cifras de beneficiarios de prestaciones sociales por desempleo, persistiendo en 1995 esta menor presencia femenina entre los beneficiarios de prestaciones, y, además, con menor nivel de protección ya que, en el caso de la prestaciones contributivas, la proporción es de una mujer por cada dos varones (CES, 1996:310-311). La menor protección social tiene relación con el mayor número de contratos a tiempo parcial, el subempleo y la discriminación de la mujer en caso de embarazo (Comisión de Política Social y Empleo del Congreso de los Diputados, 1994:8796), a pesar de los esfuerzos realizados por el Instituto de la Mujer. 
Especialmente difícil puede llegar a ser la situación de las mujeres solas cabezas de familia. En 1991, un 51\% de las mujeres separadas con hijos menores a su cargo, tenían ingresos anuales inferiores al millón de pesetas, así como dificultades de acceso a un empleo «normalizado» (Cáritas, 1991:62-66). Lo que explica que estas mujeres son uno de los grupos sobre-representados entre los que perciben las modalidades de renta mínima: «suponen entre 35 y un $45 \%$ del total, lo que resulta desproporcionado sobre su peso relativo en el conjunto de los hogares (alrededor del 10\%); parecen responder a dos grupos: mayores de 40-45 años, con más hijos y sin relación laboral anterior y otras mujeres más jóvenes (20-40) con menos hijos, con cierta experiencia laboral precaria y estudios primarios» (Aguilar, 1995:224).

Se acumulan, por una parte, todos los factores generales descritos que hacen muy difícil la inserción laboral de la mujer en general (mentalidad social tradicional del rol de ama de casa, la falta de cualificación profesional, el no tener experiencia laboral previa, etc.), a lo que se añaden otras dificultades ocasionadas por la asunción de rol de cabeza de familia, como la soledad ante la doble necesidad de conseguir ingresos para mantener el hogar y el cuidado de los menores a su cargo. En estas circunstancias, cuando la mujer se encuentra sin apoyos para el cuidado de los menores, se encuentra atrapada, ya que no puede capacitarse profesionalmente y/o no puede salir a trabajar por tener que encargarse de sus hijos. Por todo ello, la monoparentalidad es para la mujer un grave riesgo de inicio de un proceso de empobrecimiento y exclusión social.

Este mismo problema es extensivo a las mujeres que se ven obligadas a dedicarse al cuidado de las personas mayores dependientes de la familia, lo que resulta de gran actualidad ante el progresivo envejecimiento de la población, con las consiguientes mayores probabilidades de dependencia. Como señalan López de Lera e Izquierdo, «es necesario prevenir y evitar el aumento de la exclusión social en el ámbito de las mujeres ancianas, situación que en las grandes áreas metropolitanas es causa de un preocupante incremento de situaciones de abandono y pobreza entre este colectivo» (López de Lera e Izquierdo, 1995:25).

Esto es altamente injusto cuando tradicionalmente la mujer española ha tenido que asumir por imperativo sociocultural el cuidado de los miembros del hogar, lo que ha supuesto un importante ahorro al gasto público. El problema resulta de gran actualidad cuando la tendencia es fomentar la permanencia de estas personas en el hogar, lo que acaba queriendo decir que lo cuide la mujer de la casa, sin contar con su consentimiento (Rodríguez, 1994; Forster, 1994; Cerati, 1994). La mujer debe tener la oportunidad de elegir libremente si quiere ejer- 
cer ese rol de cuidadora, contando con apoyos públicos y, en el caso de que elija ese papel, el sistema de protección social debe compensarla suficientemente con vistas a su futuro, para prevenir posibles situaciones de pobreza o exclusión social.

\section{IV.EDUCANDO PARA LA PAZ, LUCHANDO CONTRA LA POBREZA Y LA EXCLUSIÓN SOCIAL.}

Como se ha venido diciendo, la pobreza y la exclusión social son formas de violencia estructural que pueden y deben ser evitadas y erradicadas. Las personas que carecen de oportunidades para su desarrollo personal y social sufren distintas formas de violencia directa que afectan directamente a su calidad de vida, violencia que se debe a la injusticia social perpetrada por el resto del grupo social que sí dispone de las oportunidades necesarias para su desarrollo humano.

A su vez, la pobreza y la exclusión social son factores de inestabilidad económica, política, social y cultural que pueden generar violencia física, siendo una amenaza real para las personas, tal como se está constatando en todo el mundo. No es de extrañar que las personas que se encuentran sin oportunidades o inseguros ante su futuro inmediato actúen violentamente cuando observan el contraste de las condiciones de vida de otras personas que, por tener poder de decisión, disponen de mucho más de lo necesario.

La respuesta ante este aumento de la violencia desde las políticas públicas y las élites de la sociedad no ha sido, hasta ahora, un cambio en las políticas macroeconómicas con el fin de mejorar la situación de las personas en situación de pobreza o exclusión social y prevenir el empeoramiento del problema. Por el contrario, se ha venido respondiendo a la violencia con más violencia desde las fuerzas de seguridad e incluso aumentando estas, en vez de atacar las causas que han generado esa ola de inseguridad personal a la que la gente sin acceso al poder no tiene más armas para responder que con la propia violencia. Las élites sociales reaccionan recurriendo a cuerpos privados de seguridad y exigiendo a los poderes públicos mayor represión y control de las fuerzas de seguridad pública.

Hay que recordar que, el verdadero desarrollo social, no es posible si no se favorece la plena integración social de TODAS las personas y que la exclusión y la discriminación no se producen solamente por problemas económicos sino también por diferencias de género, raciales, étnicas, físicas, psicológicas, sensoriales, etc.

Para que dicha integración social sea posible se precisan dos condiciones, por una parte, que el contexto social sea favorable a di- 
cha integración y, por otra, que las personas sean capaces de participar en la vida social, cultural, económica y política. Ambas están estrechamente relacionadas de tal manera que, si las personas no han tenido la oportunidad de desarrollar sus habilidades, no podrán aprovechar sus oportunidades de participar, por lo que se debe ofrecer las necesarias oportunidades, protegiendo a los más débiles y reconociendo el derecho a la diferencia para crear e innovar. Hay que capacitar a la población para poder vivir en común, respetar la dignidad de cada cual, primando la no violencia y la solidaridad.

Según Naciones Unidas, una «sociedad socialmente integrada» es: «Una sociedad capaz de dar cabida a aspiraciones individuales y de grupos diferentes y divergentes dentro de una estructura flexible de valores básicos compartidos e intereses comunes. Vista en el contexto del desarrollo humano sostenible, la integración social es sinónimo de más justicia, más igualdad, más bienestar material y más libertad democrática, lo que entraña igualdad de oportunidades y derechos para todos. En el seno de la sociedad se manifiesta como solidaridad, interdependencia, respeto a la diversidad cultural, tolerancia de los estilos de vida distintos de lo general y valor para sustituir sistemas que son inoperantes por otros más equitativos» (Naciones Unidas, 1994).

El desarrollo humano es interdependiente del crecimiento económico, pero este crecimiento debe tener las siguientes características: generar empleo y seguridad en los medios de ganarse el sustento; propiciar la libertad de las personas; distribuir equitativamente los beneficios; promover la cohesión social y la cooperación; salvaguardar el desarrollo humano futuro (PNUD, 1996:63). Este es un modelo de crecimiento muy diferente del modelo imperante, que al disociar los aspectos sociales y económicos del desarrollo esta generando pobreza y exclusión social, tal como se ha comentado, sin que ello sea inevitable (Riechman y Recio, 1997).

Concluyendo, la lucha contra la pobreza y la exclusión social implica la sensibilización de la sociedad sobre la existencia de las situaciones de violencia en que están inmersas las personas que se encuentran ante la pobreza o la exclusión social. Porque la mayoría de estas situaciones son ignoradas por resultar invisibles al resto de la población, unas veces por vergüenza de los que las sufren y otras veces por intereses políticos en invisibilizarlas. Si se desconocen, difícilmente se puede reconocer la injusticia social que comportan y menos ayudarles a reivindicar el reconocimiento de sus derechos.

Por lo tanto, es importante, en primer lugar, la investigación para conocer y hacer visibles estas situaciones que impiden a algunas personas su desarrollo humano. En segundo lugar, hay que actuar. La pobreza y la exclusión social pueden y deben evitarse, para lo que hay 
que plantear la lucha contra la pobreza o la exclusión como un tema de derechos humanos y de justicia social, lo que resituaría el debate sobre las políticas sociales y el papel del Estado. En todo ello, la Universidad, en su conjunto, no puede permanecer al margen. Y, en particular, el Trabajo Social debe replantear su rol ante los nuevos desafíos (Macarov, 1991:114-116), por ejemplo, con un mayor acercamiento entre lo económico y lo social (Midgley, 1996:13-25), para lo que se sugiere incidir en la formación de los futuros profesionales de ambos ámbitos desde la docencia universitaria (Martínez Román, 1996b).

Las políticas públicas no han sabido anticiparse ni responder a los nuevos problemas sociales, en particular, los Servicios Sociales deben replantear su rol (Martínez Román, 1997). Como señala la ONU, «lo que falta no son los recursos ni las soluciones económicas sino el impulso político para enfrentar directamente la pobreza» (PNUD, 1997:106), con tres elementos esenciales: potenciación política de los pobres, unión de actores sociales para el cambio y un Estado propicio y responsable.

Ante causas estructurales, no se puede recurrir a culpabilizar a las víctimas o a plantear actuaciones meramente asistenciales «in extremis» (Martínez Román y Guillén, 1996:334). El Estado no puede eludir su responsabilidad, aún cuando se reconozca la corresponsabilidad de la sociedad y se le reconozca su importante protagonismo. Los pobres deben organizarse para hacerse visibles y participar en la toma de decisiones que afectan directamente a sus vidas; el resto de la sociedad a través de las asociaciones de interés social, partidos políticos, los sindicatos, medios de comunicación, universidad, empresas, etc., necesitan unirse para potenciar un desarrollo humano. Pero todo este esfuerzo social precisa el apoyo de un Estado «activo y fuerte, que use su fuerza en favor de los pobres y no en su contra», que propicie espacios democráticos en los que la población «pueda articular sus demandas, actuar colectivamente y luchar por una distribución más equitativa del poder», asegurando que «las prácticas y los principios democráticos lleguen a todos los niveles y dimensiones de la sociedad» (PNUD, 1997:114-119).

\section{BIBLIOGRAFÍA}

AGUILAR, M. et al. La caña y el pez. Estudio sobre los salarios sociales en las Comunidades Autónomas. Fundación FOESSA, Madrid, 1995.

CÁRITAS ESPAÑOLA. «Pobreza y Desarrollo. Las condiciones de la nueva pobreza». Dossier, 1991, nº 25. 
CÁRITAS ESPAÑOLA. III Jornadas Estatales «Mujer y Trabajo». Programa de Mujer de los Servicios Sociales Generales. Cercedilla (Madrid) $17-$ 19 febrero, 1995.

CÁRITAS ESPAÑOLA. «Políticas contra la exclusión social». Documentación Social. Revista de Estudios Sociales y de Sociología Aplicada, 1997, $\mathrm{n}^{\circ} 106$, monográfico.

CASTEL, R. Les métamorphoses de la question sociale. Fayard, París, 1995.

CENTRO DE ESTUDIOS DEL CAMBIO SOCIAL. Informe España 1996, una interpretación de su realidad social. Fundación Encuentro, Madrid, 1997.

CERATI, C. La mala hija. Anaya \& Mario Muchnik, Barcelona, (1994).

CES. España 1995. Economía, Trabajo y Sociedad. Memoría sobre la situación socioeconómica y laboral. Consejo Económico y Social, Madrid, 1996.

CES. España 1996. Economía, Trabajo y Sociedad. Memoría sobre la situación socioeconómica y laboral. Comité Económico y Social, Madrid, 1997.

COMISIÓN DE POLÍTICA SOCIAL Y EMPLEO DEL CONGRESO DE LOS DIPUTADOS, 4 de octubre de 1994. Diario de Sesiones del Congreso de los Diputados, V Legislatura, Comisiones, $\mathrm{n}^{\circ} 297$.

COMISIÓN SUDAMERICANA DE PAZ, SEGURIDAD Y DEMOCRACIA. «Propuestas emanadas de los «Foros Regionales de Actores sociales para promover una Agenda social en América Latina», Santiago de Chile, 5-6 diciembre, 1994.

COMISIÓN DE TRABAJO Y SEGURIDAD SOCIAL DEL SENADO, 19 de abril de 1994. Diario de Sesiones del Senado, V Legislatura, Comisiones, $n^{\circ} 95$.

COMUNIDADES EUROPEAS. Comité Económico y Social. «Dictámen del Comité Económico y Social sobre la «Exclusión Social». Bruselas. SOC/ 257. CES 1014/93, 1993.

COMUNIDADES EUROPEAS. Comité Económico y Social. «El paro Juvenil». Dictámen de Iniciativa de la Sección de Asuntos Sociales, Familia, Educación y Cultura. SOC/293, 1995.

ELVIRA, S. «Contrato de aprendizaje, así no». El País, 5 de febrero de 1994.

ENGELHARD, P. L'Homme Mondial. Les sociétés humaines peuvent-elles survivre. Arléa, Paris, 1996.

FERNÁNDEZ VIGUERA, B. «Pobreza femenina y estructura social», en VV.AA. Cuestiones en torno al Trabajo Social. Popular, Madrid, 1990, págs. 65-86.

FORSTER, M. Los hombres primero. Ediciones B., Barcelona, 1994.

GALTUNG, J. Sobre la paz. Fontamara, Barcelona, 1985. 
GALTUNG, J. Investigaciones teóricas. Sociedad y Cultura contemporáneas. Tecnos-Instituto de Cultura «Juan Gil-Albert», Madrid, 1995.

GALTUNG, J. Peace by peaceful means. Peace and Conflict, Development and Civilization. Sage-Prio, Londres, 1996.

LÓPEZ DE LERA, D. e Izquierdo Escribano, A. «Transformaciones demográficas y nuevas formas de convivencia en la población española». Sociedad y Utopía. Revista de Ciencias Sociales, 1995, nº 6, pág. 25.

MACAROV, D. Certain Change. Social Work practice in the future. NASW Press, Silver Spring-MD, 1991.

MARTÍNEZ ROMÁN, $\mathrm{M}^{\mathrm{a}}$ A. Exclusión y Política social: respuestas públicas a las nuevas necesidades sociales en España y Reino Unido. (Tesis Doctoral becada por el Instituto de Estudio Juan Gil-Albert). Universidad de Alicante, Alicante, 1996a.

MARTÍNEZ ROMÁN, Mª A. «Algunos problemas de las políticas públicas de empleo dirigidas a los colectivos con mayores dificultades de inserción». IV Encuentro Internacional sobre Servicios Sociales «Exclusión e Intervención social», Valencia 29-31 de octubre, 1996b.

MARTÍNEZ ROMÁN, $M^{a}$ A. «Los Servicios Sociales públicos y la exclusión social», La Cristalera. Revista de Asuntos Sociales, Dirección General de Bienestar Social-Murcia, 1997, nº 7.

MARTÍNEZ ROMÁN, Ma A. y GUILLÉN, E. «Estado de Bienestar y Servicios Sociales: problemas, reacciones y medidas necesarias» en Casilda, $\mathbf{R}$. y Tortosa, J.M. (Editores) Pros y contras del Estado de Bienestar. Tecnos, Madrid, 1996, págs. 313-336.

MERVA, M. y FOWLES, R. Effects of disminished economic opportunities on social stress: heart attacks, strokes and crime. Economic Policy Institute, Washington, DC, 1992.

MIDGLEY, J. «Involving Social Work in economic development». International Social Work, 1996, vol. 39, n 1, págs. 13-25.

NACIONES UNIDAS. «Hacía una Sociedad para Todos». Documento de Antecedentes $n^{\circ} 3$ de la Cumbre Mundial sobre Desarrollo Social, Copenhague, 6-12 marzo, 1995.

NACIONES UNIDAS. «Conferencia Internacional sobre la Población y el Desarrollo», El Cairo, 5-13 septiembre 1994. A/CONF:171/13.

OIT. El empleo en el mundo 1996-97: las políticas nacionales a la hora de la mundialización. Organización Internacional del Trabajo, Ginebra, 1997.

PÉREZ, E. «Trabajadores de segunda categoría». Cáritas, 1996, n 58.

PNUD. Informe sobre Desarrollo Humano 1994. Fondo de Cultura Económica, México, 1995.

PNUD. Informe sobre Desarrollo Humano 1996. Mundi-Prensa, Madrid, 1996. 
PNUD. Informe sobre Desarrollo Humano 1997. Mundi- Prensa, Madrid, 1997.

QUEVEDO AGUADO, M.P. «La propuesta de la Renta Mínima y el Salario Ciudadano desde un modelo constructivista de la personalidad en el medio psicosocial». Documentación Social, 1990, n 78, enero-marzo.

RECIO, A. Trabajo, personas, mercados. Manual de Economía Laboral. Icaria-FUHEM, Barcelona, 1997.

RIECHMAN, J. y RECIO, A. Quien parte y reparte... El debate sobre la reducción del tiempo del trabajo. Icaria, Barcelona, 1997.

RIFKIN, J. El fin del trabajo. Nuevas tecnologias contra puestos de trabajo: el nacimiento de una nueva era. Paidós, Barcelona, 1996.

RODGERS, G. «What is special about a «social exclusion» approach?», en Rodgers, G., Gore, C. y Figuereido, J.B. Social Exclusion: Rhetoric, Realty, Responses. ILO, Ginebra, 1995.

RODRÍGUEZ, J.A. Envejecimiento y familia. CIS, Madrid, 1994.

TORTOSA, J.M. La pobreza capitalista. Tecnos, Madrid, 1993. 


\title{
VIOLENCIA Y TERRORISMO: UN ANÁLISIS DESDE LA PERSPECTIVA ECOLÓGICA
}

\author{
GONZALO MUSITU OCHOA
}

Profesor y Director del Area de Psicología Social de la «Universitat de València».

\section{SUMMARY}

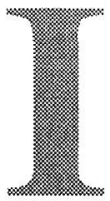

$\mathrm{n}$ this article, the issues of violence and terrorism are analyzed from an ecological perspective. Thus, terrorism is viewed as something more than the manifestation of some sort of psychopathology or the consequence of frustration or social unfairness. Terrorism is considered to result from the confluence of multiple factors, such as individual factors, family and school factors, factors related to the peer group, as well as sociohistorical factors and, finally, the mass media. In the last part, I underline the advantages of this ecological approach and the relevance of analyzing all the contexts if a long-term solution to this social problem wants to be found.

\section{SUMARIO}

En este artículo se analizan la violencia y el terrorismo desde una perspectiva ecológica. Se considera que el terrorismo es algo más que la manifestación de algún tipo de psicopatología o la consecuencia de la frustración o de los desequilibrios sociales. Se considera que el terrorismo es el resultado de la confluencia de múltiples factores, tales como factores individuales, familiares y escolares, factores relacionados con el grupo de iguales, así como también factores sociohistóricos y finalmente los medios de comunicación. Finalmente, se subrayan las ventajas del acercamiento ecológico y la importancia de analizar todos los contextos en el análisis de este problema social.

\section{INTRODUCCIÓN}

La violencia, en sentido amplio, y el terrorismo son dos términos íntimamente relacionados aunque con una cierta asimetría en sus rela- 
ciones. Así, sabemos que no toda violencia es terrorismo, pero sí que todo terrorismo es violencia. $\mathrm{Si}$ analizamos algunas de sus múltiples formas, los actores que las protagonizan y las motivaciones que la impulsan, constatamos la tremenda complejidad de la violencia en este final del milenio.

Asumiendo los riesgos que por defecto o por exceso lleva implícita toda clasificación, me atrevo a sugerir tres grandes categorías que aglutinan una parte importante de la multiplicidad de expresiones de violencia en nuestros días: 1. Violencia del Estado, la cual podría categorizarse a su vez en violencia ilegal, violencia ilegítima y la violencia como instrumento; 2. Violencia de grupos cívicos, en la que se integrarían la violencia de los grupos alzados en armas contra particulares, crimen organizado y violencia de particulares organizados y 3 . Violencia insurgente en la que se incluirían las revoluciones, las guerrillas y el terrorismo. Esta última forma de violencia la encontramos generalmente impregnada de otras formas de violencia previas y es, a mi juicio, la forma más característica y dramática de los últimos tiempos, fundamentalmente, por la brutalidad de sus argumentos, la irracionalidad de sus demandas y la incertidumbre social que generan. Mi postura es que la violencia, sea cual fuere su origen, la forma de su expresión y sus objetivos, es siempre negativa, es, como dice Cortina (1996), negativa y por tanto rechazable. La violencia no es ni debe ser el recurso al que deben acudir los hombres para solucionar sus problemas y conflictos, porque de su uso no se deriva una mejor calidad de las relaciones humanas y de la vida social en general.

Definiría la violencia como todo acto intencional de uno o más seres humanos haciendo uso ilegítimo o amenaza de uso de la fuerza, dirigido a otro u otros seres humanos con la finalidad de ocasionarles daño físico o psicológico y es, además, percibido como intencional por el receptor, receptores o potenciales receptores. Es, también, el comportamiento humano más obstructor para la realización personal y para la convivencia social. Esta definición integra la intencionalidad, el daño físico o psicológico, el uso ilegítimo de la fuerza y la percepción de la intencionalidad por el receptor o receptores reales o potenciales y personas próximas. En esta definición, en primer lugar, no se excluye ningún contexto o realidad psicosocial y, en segundo lugar, se soslayan, no se excluyen, las connotaciones afectivas. A la violencia política, en la que se integrarían las ideas previas, habría que añadir aquellas expresadas en la definición de Dowse y Hughes (1979): «actos de desorganización, destrucción o daño que tienden a modificar el comportamiento de otros con consecuencias para el sistema social y político». El terrorismo lo definiría como el uso sistemático de una estrategia de violencia extrema cuya característica más significativa 
es el terror y la incertidumbre que genera en la sociedad en general y se sustenta en la creencia de que con ello se obtendrán determinados resultados socio-políticos. En este sentido, Reinares (1993) añade al uso sistemático de la violencia, el que éste sea por el poder o contra el poder. La violencia política, a diferencia del terrorismo, tiene entre sus objetivos unas personas o unas instituciones muy delimitadas, concretas, «selectivas», lo que no quiere decir que no haya alguna arbitrariedad en la última selección de la víctima. Pero el terrorismo pretende, además de inspirar terror, socializar el miedo (Elzo, 1996:2).

El terrorismo, independientemente de las fuentes y de las formas, tiene una serie de características que podríamos considerar universales: la utilización permanente del asesinato, la destrucción y el daño físico y psicológico a través de la intimidación pública y el terror con una finalidad política -pensemos que el terrorismo es un modo deliberado de desatar el terror con fines políticos-; la utilización cada vez más frecuente de instrumentos sofisticados de tortura y muerte -no podemos soslayar el hecho de que los avances tecnológicos en armas, explosivos, transporte y comunicaciones también mejoran el potencial destructor del terrorismo-; es racionalizado y justificado por alguna filosofía, teoría o ideología, no importa lo cruel que sea ésta; es la creación de atmósferas de terror, desesperación e impotencia en su imaginario enemigo con la finalidad de someterlo a sus propias demandas; en sus efectos, es indiscriminado, lo que ayuda a diseminar el terror y el miedo, puesto que todos podemos ser víctimas, lo cual infunde un profundo sentimiento de vulnerabilidad personal generalizada (Wilkinson, 1987; O'Sullivan, 1987).

El terrorismo no surge espontáneamente; tampoco por convulsiones económicas y sociales o por una necesidad irreprimible de unos jóvenes radicales con graves problemas de ajuste psicosocial que pierden el control y el raciocinio; se trata, a mi juicio, de una compleja confluencia de fuerzas psico-socio-políticas que es necesario integrar y analizar si de verdad queremos comprender y afrontar en toda su complejidad este grave problema social. El terrorismo, desde una perspectiva psicosocial, es más que una manifestación de alguna psicopatología o el resultado de frustraciones e injusticias sociales. Es, a mi entender, el resultado de la convergencia de factores individuales, familiares, escolares, sociales e históricos íntimamente relacionados. Asumir la interdependencia de esos factores -perspectiva ecológicaque proceden en su mayoría de los diferentes contextos significativos que configuran el desarrollo humano -microsistema, mesosistema, exosistema y macrosistema- tiene significativas implicaciones teóricas y prácticas. 


\section{EL ACERCAMIENTO ECOLÓGICO}

Entre los principios de este acercamiento se encuentran, en primer lugar, la necesidad de estudiar los fenómenos como un sistema total y no considerarlos como entidades independientes y, en segundo lugar, el análisis debe centrarse en las distintas interrelaciones que existen tanto entre los elementos del sistema como entre los distintos sistemas o, lo que es lo mismo, en la complejidad organizada.

Estos dos principios tienen importantes implicaciones para el análisis de los problemas sociales entre los que se encuentra también el terrorismo. Son los siguientes: 1 . El investigador y analista social, al trascender en sus análisis al individuo o grupo para situarse en sus interrelaciones, pierde toda posible inclinación o tentación de estigmatización o etiqueta, puesto que el problema no se sitúa en uno u otro lado del conflicto, o lo que es lo mismo, en los actores emisores o en los actores receptores, sino en sus interrelaciones, lo que supone asumir el principio de la circularidad -no hay relaciones diferenciadas ni claras de causa-efecto, las relaciones son circulares- sobre el de la causalidad -hay una relación de causa-efecto-; 2 . Toda intervención o actuación que no se centre en los contextos y sus interrelaciones tiene una alta probabilidad de que fracase; 3 . Se integrarían en un modelo comprensivo las diferentes perspectivas teóricas o formas de acercarse al análisis de ese drama social; 4 . Se darían soluciones al problema no desde los actores, que sería más violencia, sino desde la compleja red configurada por todos y cada uno de esos contextos.

En este artículo, me voy a centrar en el análisis, desde la perspectiva ecológica, de esos contextos y de sus relaciones, defendiendo la idea de que el terrorismo es la punta de un iceberg en el que la parte oculta está configurada por las interacciones de los contextos individual, familiar-escolar, los iguales, los medios de comunicación y el contexto histórico y, en consecuencia, que cualquier análisis o programa de actuación debe considerar todos y cada uno de esos contextos.

\subsection{Contexto individual}

Hay investigadores y académicos, posiblemente estimulados por políticos y circunstancias políticas, que comparten la teoría conservadora del «control del delito» fundamentada a su vez en el modelo clínico o psiquiátrico, cuyo principio básico consiste en que individuos enfermos o perversos -no las desigualdades sociales ni los conflictos sociopolíticos- son responsables de la violencia y el terrorismo (Turk, 1996). En este sentido, los estudios clínicos, a través de historias personales, psico-biografías y entrevistas, no han identifica- 
do ninguna característica psicopatológica común a los terroristas (Ferracuti, 1982; Ministerio del Interior de Alemania Occidental, 198182-83-84).

En general, numerosos problemas provienen de enfocar la atención de forma exclusiva en la propia psicopatología, o bien de una definición demasiado restringida de la misma y, entonces, sucede que los árboles no nos permiten ver el bosque. Sin embargo, no creo que se pueda afirmar hoy, con la información de que disponemos, que el terrorismo sea el producto de personas con serias perturbaciones mentales. El amplio espectro de la actividad terrorista no puede categorizarse como «irracional»y, por tanto, como patológico, ilógico o inexplicable. Recurrir al terrorismo no tiene por qué ser, siempre y necesariamente, una aberración. Puede constituir, como afirma Reich (1992), una respuesta racional y calculada a las circunstancias. Tenemos constancia de como, a lo largo de la historia y en la actualidad, con igual o mayor intensidad, personas con una vida normal y responsable han perpetrado actos abominables y atroces en nombre de principios religiosos, ideologías supuestamente justas y demandas nacionalistas, lo cual nos invita a pensar en el hecho de que las atrocidades del terrorismo requieren condiciones sociales favorables, antes que personas enfermas o monstruosas para cometer esas atrocidades. Con condiciones sociales apropiadas, a personas supuestamente normales, de convivencia grata, se les puede inducir a actos espantosamente crueles (Wilkinson, 1985, 1987; Ver tb. los experimentos de Milgram, 1974).

\subsubsection{Mecanismos individuales}

Tampoco parecen tener fundamento otros intentos que se han llevado a cabo por atribuir automáticamente los comportamientos terroristas a mecanismos, procesos o características psicológicas particulares. Por ejemplo, es improbable, como indica Corrado (1981), que el «narcisismo» explique el terrorismo de incluso un número pequeño de grupos ideológicamente radicales (vit. Lasch, 1979 y Morf, 1970), o que en su defecto lo trate de explicar el deseo de morir (Cooper, 1977 y 1978; Reich., 1992).

Cierto es que para pasar de ser una persona con unos principios éticos, entre los que se encuentra el respeto al otro y a la vida del otro, a otra, en la que la vida del otro no cuenta y donde no hay escrúpulos ni autocensura, se requiere, al menos, dar un gran paso que psicológicamente consiste en una reestructuración cognoscitiva del significado de asesinar, de manera que este acto pueda ejecutarse libre de la autocensura (Bandura, 1992), lo cual ocurre no sólo en los terroristas, sino también en los gobernantes y en otros ámbitos de la vida social. 
En conjunción con este mecanismo psicológico, operan otros como la comparación siguiendo el principio del contraste y el desplazamiento de la responsabilidad que brevemente paso a describir. La comparación, siguiendo el principio del contraste, consiste en utilizar un referente de comparación extremadamente negativo, de manera que los actos de uno parezcan insignificantes o incluso loables. El individuo, en este caso el individuo terrorista, minimiza sus asesinatos como la única arma defensiva de que disponen para reprimir las crueldades generalizadas que sufren elementos de su grupo. Es más, ante sus grupos de pertenencia y apoyo, los ataques dirigidos contra el «aparato represor»-no importa que haya víctimas- son actos de desprendimiento y martirio. Lo mismo sucede con aquellas personas y sectores sociales víctimas de actos terroristas para quienes los actos de represalia contra los terroristas son insignificantes y aplaudidos si los comparan con las atrocidades cometidas por los terroristas.

Bajo condiciones de desplazamiento de la responsabilidad, la gente ve sus acciones como si surgieran de los dictados de las autoridades, y no de su propia voluntad. El desplazamiento de la responsabilidad no sólo debilita las restricciones sobre las propias reacciones perjudiciales sino que también, como indica Bandura, elimina la preocupación social por el bienestar de la gente maltratada por otros (Tilker, 1970; Bandura, 1992).

Otra forma de debilitar las reacciones de autodisuasión es a través de la desconsideración o falsa representación de las consecuencias de la acción. Cuando los terroristas deciden realizar actividades que son perjudiciales para los demás evitan confrontación o minimizan el daño causado. Recuerdan fácilmente la información que reciben previamente sobre los beneficios potenciales del comportamiento pero no son capaces de recordar sus efectos perjudiciales (Wilkinson, 1987). Naturalmente que, junto con la falta de atención selectiva y de una alteración cognoscitiva de los efectos, la representación social distorsionada conlleva con frecuencia esfuerzos activos para desacreditar las pruebas del daño que causan. Así, mientras se ignoren, minimicen, distorsionen o se perciban con frialdad e incredulidad los resultados perjudiciales de la propia conducta, hay pocas razones, si alguna, para activar la autocensura.

Estos y otros mecanismos de desconexión no transforman en un instante a una persona respetuosa en otra «despiadada», capaz de asesinar a otros seres humanos, más bien es un proceso que opera a través de un amplio entrenamiento de desconexión moral y destreza, en este caso destreza terrorista. Posiblemente, el aspecto más importante para comprender a los terroristas es el asumir que estos tienen la sen- 
sación de estar defendiéndose contra un mundo agresivo, malvado, intruso y sanguinario (Kellen, 1992).

Tengamos presente también que la desconexión opera sobre los objetivos de los actos violentos. Sabemos que percibir a la víctima como un ser humano intensifica las reacciones empáticas merced a la similitud percibida. Las alegrías y los sufrimientos de los semejantes despiertan sentimientos más similares que las alegrías o sufrimientos de personas extrañas o a las que se ha despojado de sus cualidades humanas. Así, es fácil referirse a las víctimas con nombres tales como gusanos, ratas, etc.

En resumen, la mayoría de los terroristas no muestra una psicopatología grave. Aunque los datos indican que muchos terroristas no han tenido éxito en su vida personal, educativa y vocacional (Post, 1992 y Bandura, 1992), aspectos que, por otra parte, tienen que ver poco con la esquizofrenia y la locura y los impulsos asesinos, la manera menos sesgada de entender los actos terroristas desde la perspectiva individual es acudiendo a los mecanismos que estos utilizan para justificar sus actos terroristas, así como sus intenciones y naturalmente, las reacciones de la población. La gran transformación personal que tiene lugar en gran parte de los terroristas que, en muchos casos los conduce al nihilismo, a la desesperación y al temor extremo ante el castigo del grupo, puede arrastrarlos al suicidio (Sprinzak, 1992) además de sentir que es imposible regresar a una situación cognitiva y social que podríamos llamar normal. A esto hay que añadir el hecho de que el terrorista convencido cree profundamente que sus fines justifican cualquier medio y desecha cualquier argumento a favor del respeto de los derechos humanos.

\subsection{Contexto familiar}

La familia es el entorno fundamental en la determinación de las actividades y la estructura de relaciones del niño y adolescente, pero obviamente no es el único. A medida que el sujeto crece, la normativa cultural determina su ingreso y participación en otros entornos de socialización, de manera que el ambiente social se amplía gradualmente con la edad. La participación en entornos múltiples es consecuencia del desarrollo, puesto que la cultura dicta ciertas transiciones ambientales a ciertas edades; pero también es causa y condicionante del desarrollo, ya que incrementa la densidad, la complejidad y la flexibilidad en la experiencia y la representación del mundo social. Para comprender, pues, el proceso de socialización hay que ir más allá del microsistema familiar y abordar el análisis del mesosistema, del «con- 
junto de relaciones entre los entornos en los que la persona en desarrollo participa de forma activa» (Bronfenbrenner, 1977).

La familia es, desde la infancia a la adolescencia, el referente fundamental del sujeto, y esto en dos sentidos: por un lado, es el ambiente más estable y duradero desde el nacimiento hasta el fin de la adolescencia, mientras el sujeto atraviesa todas esas transiciones contextuales normativas. Es el entorno que, en condiciones normales, permanece, aunque por supuesto se va modificando. Y las transformaciones que sufre proceden en gran parte de la interacción con otros contextos que constituyen el mesosistema del sujeto. Y por otro lado, es el principal determinante de la "ubicación social" del niño y adolescente, por tanto, de las características concretas -e incluso de la presencia o ausencia- de los demás entornos. A medida que el sujeto crece, su autonomía social y la capacidad de seleccionar sus propios ambientes se incrementan paralelamente, pero aún entonces siempre tendrá que construir su mundo desde el "lugar social" originario que su familia le proporcionó (Musitu y Allatt, 1994; Gracia, Herrero y Musitu, 1995).

En la familia tiene lugar uno de los procesos más importantes para la salud mental y física de los seres humanos. Me estoy refiriendo a la socialización. Tradicionalmente, se ha entendido la socialización familiar como aquellos procesos de interacción que se producen en el contex to familiar y que tienen como objetivo inculcar en los hijos un determinado sistema de valores, normas y creencias (Molpeceres, 1991; Musitu et al., 1988; Musitu y Allatt, 1994). A través de esos procesos, los hijos aprenden cómo comportarse y afrontar las diferentes situaciones sociales y transmiten a sus hijos su concepción del mundo, así como una representación global del funcionamiento de la realidad social. Este proceso incluye tanto demandas explícitas -la verbalización de normas de conducta- como elementos mucho más sutiles, tales como la percepción de las expectativas que los otros significativos, fundamentalmente los padres, tienen en torno a él. Es decir, hay una transmisión sutil, en muchas ocasiones no consciente, de todo un sistema de valores y creencias.

Es, por lo tanto, en el contexto familiar donde el niño, por primera vez, se le indica qué es lo bueno, lo valioso, lo deseable, y en donde comienza a construir su propio sistema de valores. Evidentemente, el proceso de «construcción» de este sistema no sólo se ve influido por estos otros significativos; no es un sistema inmutable y, a lo largo de la vida, son diversas las influencias que se adivinan en la organización de nuestro sistema de creencias - la escuela, los iguales, el contexto laboral y la propia experiencia personal-. Sin embargo, aunque la familia no determine totalmente el sistema de valores del individuo, 
sienta las bases de lo que a lo largo de su vida tendrá por central o altamente deseable.

Una socialización negativa dificulta a lo largo de la vida el establecimiento de lazos con los demás y está relacionada con niveles bajos de confianza en las relaciones sociales y con una excesiva dependencia en las adhesiones sociales -o políticas-como mecanismo compensatorio. Las duras experiencias físicas y emocionales producen poderosos sentimientos de culpabilidad y ansiedad que son luego reprimidos o externalizados y proyectados sobre otros. Los trabajos de Volkan (1968), Fornari (1975) y Gartner (1996) estiman que los grupos y los individuos identificados con dichas representaciones negativas pueden fácilmente convertirse en agresores potenciales.

Las experiencias derivadas de una socialización negativa en la infancia y adolescencia tienen efectos en los adultos, quienes son más agresivos y están más predispuestos a implicarse en conflictos abiertos. Por último, varios estudios interculturales reflejan una correlación positiva entre las prácticas negativas de socialización y la agresión física, el desajuste psicosocial, el consumo de drogas, la belicosidad y la lucha armada (Levinson y Malone, 1980; Zigler y Child, 1969; Musitu y Allatt, 1994; Rollins y Thomas, 1979).

Las prácticas educativas infantiles afectivas y cálidas no deben considerarse sin más como lo contrario de lo que se entiende por socialización negativa, ya que dichas prácticas tienen en la conducta agresiva efectos independientes. Esta distinción guarda quizá una cierta similitud con la diferenciación entre permisividad y castigo en la socialización de la agresión, puesto que éstos, según Sears, Maccoby y Levin (1958), tienen efectos independientes en la conducta agresiva. Una manifestación del afecto más abierta hacia los niños, un mayor énfasis en valores tales como la confianza, la honestidad y la generosidad, y unos lazos más íntimos entre padre e hijo, por ejemplo, son prácticas todas que estimulan a los individuos a desarrollar las habilidades sociales necesarias para resolver los conflictos sin recurrir a la violencia (Ross, 1981; 1991).

Estudios antropológicos muestran igualmente que una socialización cálida y afectiva se relaciona con una baja conflictividad, tanto dentro de la sociedad como en el trato con extraños. Las representaciones sociales de los otros suelen ser relativamente de apoyo, de confianza, de cooperación y de ayuda. Cuando las expectativas son mutuas, se desarrollan unas secuencias reforzantes y, una vez que han comenzado, se mantienen unos patrones bajos de conflictividad (Montagú, 1978).

En relación con el terrorismo, los trabajos científicos que relacionan las prácticas de socialización con el terrorismo son muy escasos. 
Uno de los estudios más serios, realizado hasta la fecha sobre los aspectos psicosociales del terrorismo, es el realizado por un grupo de científicos alemanes patrocinado por el ministerio del Interior alemán y publicado en cuatro volúmenes (Vls. 1981, 82, 83 y 84). Estos científicos analizan la vida de 250 terroristas de Alemania Occidental, 227 de izquierda y 23 de derecha de familias fragmentadas; se descubrió que la pérdida del padre tenía hondas repercusiones. El 79\% de las personas investigadas informó que tenían conflictos graves con los padres (33\%), y describieron en términos hostiles al padre, cuando todavía estaba presente en sus vidas. Uno de cada tres había sido previamente condenado en un tribunal de menores. En general, la conclusión de los autores fue que el grupo de terroristas cuyas vidas habían estudiado mostraban una pauta de fracaso tanto educativo como vocacional. Al considerar a los terroristas como «orientados hacia el progreso y propensos al fracaso», los investigadores caracterizaron sus carreras como «el punto terminal de una serie de intentos de adaptación abortados» (Post, 1992). Parece que la infancia infeliz característica de muchos terroristas alemanes los ha convertido en gente iracunda, negativa y frustrada. A juzgar por los materiales fragmentarios de que se dispone, eso parece ser especialmente cierto de aquellos que proceden del ambiente estricto e intolerablemente rígido tan típico de la burguesía alemana, con sus numerosas compulsiones y pretensiones (Kellen, 1992). La ansiedad que han experimentado la mayoría de los miembros de la Facción del Ejército Rojo con respecto a sí mismos, y atribuible a su pasado emocional, también fue atestiguada por Baumann (1979), especialista en explosivos del grupo. No obstante, sería deseable más información relativa a los procesos de socialización en la infancia y adolescencia en los miembros de grupos terroristas, puesto que la información de que se dispone no es suficiente como para llegar a conclusiones rigurosas.

\subsection{Contexto escolar}

La Escuela es una institución social que refleja la cultura de la que forma parte y transmite a los jóvenes que están educándose en ella no sólo conocimientos y habilidades específicas, sino un modo determinado de ver el mundo. El contenido y valores de la educación, la organización física y social de la escuela, el estilo de enseñanza, son subsistemas de la escuela que se encuentran regidos de algún modo por el macrosistema y que tienen gran incidencia en la formación del alumno (Musitu et al., 1996; Musitu y Allatt, 1994). Por ejemplo, un caso extremo de utilización de la escuela como plataforma en la formación de guerrilleros es la Madraza o escuela coránica a donde acuden los niños más pobres, aprenden de memoria el Corán, se sociali- 
zan en un ambiente draconiano y luego los fundamentalistas afganos, entre ellos los Talibanes, acuden a estos centros para nutrir sus filas de ideólogos, jueces islámicos, y milicianos dispuestos a dar la vida por un modelo de Islam más propio de la época de Mahoma que de finales de este siglo.

La concepción de la escuela como contexto donde tienen lugar otros procesos, además del aprendizaje de conocimientos, se inicia en los años cincuenta con los trabajos de orientación ecológica de Barker y sus colaboradores, centrando su atención en el entorno y la situación para explicar y comprender la conducta humana. El ajuste en la escuela, la aceptación de profesores y alumnos son determinantes importantes en el ajuste psicosocial de los jóvenes e incluso en su vida adulta. (Barker et al., 1953; Molpeceres, 1991; Ovejero, 1990). Los datos indican que muchos terroristas no han tenido éxito educativo y vocacional y tampoco una integración escolar adecuada (Post, 1992 y Bandura, 1992).

En todas las aulas encontramos grupos de alumnos con una pobre identificación con el centro educativo, con problemas de integración y con muy baja motivación -esto se incrementa significativamente allí donde el alumnado procede de estratos socio-económicos bajos-, hasta el punto de que toda su ilusión es llegar a los 16 años para abandonar el centro educativo. Una parte importante de estos niños se organiza en pandillas y va creando y recreando una cultura de clase y de grupo - los colegas- con la que tratan de dejar constancia de quiénes son, de su idiosincrasia, y enfrentarse o soportar menos dolorosamente las exigencias de la cultura escolar oficial «legítima», cuando no también enemiga.

Los «colegas» construyen, día a día, una verdadera contracultura dentro de una institución claramente representativa de la cultura dominante, oficial. Estas penetraciones, o conductas, en ningún momento previstas como objetivo por las personas que planifican el curriculum, ni por el profesorado, se producen en el mismo corazón de la escuela, la institución encargada de la difusión y salvaguardia de unos valores antagónicos a esas desviaciones marginales. Tal grupo de alumnos tratará de aprovechar cualquier mínima posibilidad para hacerse con el control de la situación, arrebatándoselo, por tanto, a sus profesores y profesoras.

El grupo de iguales: La implicación en grupos terroristas. Pertenecer al grupo terrorista puede representar para muchos de estos muchachos y muchachas la primera vez que se sienten formar parte de algo, que se sienten realmente importantes, que tienen la impresión de que lo que hacen cuenta para algo. Integrarse en un grupo terrorista puede representar para estos jóvenes un intento por consolidar una 
autoestima quebrantada, por resolver una división y ser uno con uno mismo y con la sociedad. Muchos de sus miembros provienen de sectores marginales de la sociedad, y la pertenencia a estos grupos fundamentalistas o nacionalistas contribuye poderosamente a la consolidación de la identidad psicosocial en un momento de gran inestabilidad y flujo social (Post, 1992). Satisfacen, además, ciertas necesidades personales, como el apoyo y la aprobación de otros miembros del grupo, oportunidades para ejercer la violencia, rebelarse contra el mundo de los padres, y muchas otras de las que como dice Reich (1992) nosotros no nos sentiríamos orgullosos. En este sentido, Ali Tunsi responsable de seguridad en el Ministerio del Interior de Argel, considera que hoy son legión los argelinos de menos de 30 años que corresponden al personaje de la película de Merzak Alluache, «Omar Gatlato», un muchacho sin trabajo que vive a costa de sus padres, que duerme en la cocina de la vivienda familiar y que se pasa el día en el café, o «sosteniendo los árboles de las aceras». En este contexto, pocas son las personas que se extrañan de la facilidad con que los cabecillas integristas prometen el paraíso y una mejor existencia terrenal a sus jóvenes reclutas.

Pero hay otras cosas que la vida del terrorismo puede aportar, como poder, identidad, prestigio, privilegios, puede suministrar un camino para avanzar, una oportunidad para la gloria, la excitación y el riesgo, para alcanzar renombre mundial, una forma de demostrar la osadía que se tiene, e incluso un medio de acumular riqueza y también pertenencia y aprobación social. Pero, sobre todo, los terroristas se perciben en ocasiones como «héroes y salvadores» de realidades imaginarias y de enemigos imaginarios; una percepción que es reforzada por una compleja y densa red de apoyo no terrorista configurada por familiares, amigos, instituciones que les refuerzan sus creencias y sus propias autopercepciones. Por eso, más que combatir y perseguir al terrorista, hay que intervenir y actuar desde la concordia sobre su red o redes de apoyo. Según ha observado Crenshaw (1992): «El grupo es vital como seleccionador e intérprete de la ideología». Por ejemplo, el retrato robot del terrorista argelino es, según el responsable de Interior de ese país, un muchacho entre los dieciocho y los treinta años que «no tiene nada que perder» fanatizado por el extremismo de grupos religiosos que le apoyan moral y materialmente y que a cambio le piden que dé su vida.

Para Laitin (1996), el reclutamiento de jóvenes terroristas requiere de dos condiciones: 1 . Debe haber un estrato social en que la violencia sea parte del repertorio de la cultura habitual. Los estudios criminológicos se han concentrado en la clase media baja y en los jóvenes de clase obrera en barrios urbanos, en pequeñas ciudades y en 
sociedades rurales (Mardin, 1978; Laitin, 1996) y 2. Entre los jóvenes que son miembros de los grupos sociales (en contraposición con los políticos y económicos) locales es donde más éxito tiene la banda violenta en el reclutamiento. Una proposición inicial es que una condición necesaria para la acción guerrillera nacionalista contra la autoridad estatal es una sociedad rural rica en grupos sociales de pertenencia (Laitin, 1996).

Post (1992) considera, desde una orientación psicoanalítica, que la obsesión del terrorista de que hay que destruir el establishment deriva de la búsqueda de identidad por parte del terrorista y por el hecho de que al golpear al establishment está intentando destruir al enemigo que lleva dentro.

Como unidad social, el grupo terrorista clandestino está aislado del mundo exterior, pero construye una realidad propia y todo un nuevo conjunto de pautas morales y de comportamiento que se imponen de forma estricta, además de una ferviente creencia compartida que es la que verdaderamente mantiene cohesionado al grupo. Se ha de hablar de una autonomía e independencia grupales donde priman la solidaridad, la dependencia, la obediencia y la subordinación. Los miembros del grupo se encuentran tan íntimamente relacionados los unos con los otros que todo acto individual tiene un significado colectivo de la máxima importancia (Bandura, 1992 y Post, 1992). El grupo terrorista necesita a su vez de un grupo de apoyo que puede estar constituido a su vez por una facción, una clase social, un grupo religioso o un grupo político, que buscan un tipo particular de cambio político. Para Gurr (1992), las dos vías principales para que el grupo terrorista pase a la acción son la radicalización -que caracteriza a grupos con objetivos orientados hacia el futuro- y la reacción -cuando un grupo ve amenazado su estatus o sus derechos-. Estos últimos afirman actuar en defensa de una comunidad más amplia cuya integridad y bienestar se encuentran en peligro. Este terrorismo de base comunitaria -ETA, IRA - despierta con frecuencia algún apoyo entre la comunidad debido a resentimientos latentes por viejas injusticias y desigualdades actuales.

Es decir, se supone que los beneficios -fundamentalmente psicológicos- de una campaña terrorista llevada a cabo con éxito, serían compartidos por todos aquellos que apoyan individualmente y colectivamente los fines del grupo, sin importar en qué medida participen activamente (Reich, 1992). Por ello, no es fácil encontrar una solución de corto alcance para el problema del terrorismo. Una vez que un individuo se encuentra, en términos de Post (1992), «metido en la olla a presión» del grupo terrorista, resulta prácticamente imposible influir en él. A largo plazo, la política antiterrorista más efectiva es 
aquella que inhibe a los reclutas potenciales para que no se integren al grupo (Post, 1992).

Los actos terroristas, supuestamente políticos, llevados a cabo por el grupo se justifican de manera colectiva, reflejando en esa justificación valores sociales predominantes de manera que el comportamiento individual y el grupal se encuentran intimamente unidos, una idea que los expertos soslayan con suma facilidad. La cohesión de grupo así generada se ve aumentada por el peligro externo, que tiende a reducir la división interna y a producir unidad contra el «enemigo externo».

\subsection{Contexto histórico}

El contexto histórico forma parte del macrosistema dentro del modelo ecológico. No hay que ignorar cuando se analiza el terrorismo político o étnico nacionalista, el proceso histórico de desarrollo de una conciencia nacional que bien se ignora, o bien se intenta bloquear desde el Estado. Ahora bien, con palabras de Unzueta (1984, pág.. 22), no es cuestión de recrearse en el pasado, pero cuidado de empeñarse en ignorarlo o en hacer creer que una huella de esta naturaleza, testarudamente urdida, puede desaparecer de la noche a la mañana. Pueden olvidarse los episodios concretos, pero la huella queda. De la misma manera que nuestra psicohistoria define nuestro presente, así sucede con la psico-socio-historia de pueblos y comunidades. Ignorarlo supone despreciar la esencia de un pueblo, es decir, sus creencias, sus valores, sus hábitos, en una palabra, su concepción del mundo y de la vida.

El desarrollo de esta conciencia nacional no se basa sólo en una historia, en unas bases étnicas, sino también, y fundamentalmente hoy, en la respuesta a la búsqueda por parte de la colectividad de preguntas sobre su futuro, su identidad, en definitiva a la búsqueda de sí mismo para dar respuesta a estos interrogantes (Ruiz de Pinedo, 1984).

\subsection{Medios de comunicación}

Los medios de comunicación de masas son parte integrante de ese macrosistema y a su vez un microcontexto fundamental en el análisis del terrorismo. Yo creo que convergemos en la idea de que los terroristas tienen en los mass media uno de sus grandes aliados. En primer lugar, porque aprenden de las experiencias de los demás, conocidas con frecuencia a través de los medios de comunicación y, en segundo lugar, porque detectan los estados de opinión y las diferentes actuaciones de la policía. En ocasiones, obtienen información hasta de sus futuras víctimas. 
En este sentido, los países occidentales son los mayores impulsores de los terroristas, no sólo porque se les presta tanta atención en los medios, sino todavía más porque los líderes políticos hacen declaraciones mesiánicas sobre sus intenciones de destruir el terrorismo hasta sus mismas raíces, rindiéndoles de esa manera un alto tributo. Claro que, como esto no es posible de ninguna de las maneras, los terroristas obtienen como consecuencia de ello, grandes beneficios publicitarios. Con estos refuerzos se convierten en los grandes actores en los escenarios mundiales más significativos: juegos olímpicos, reuniones de jefes de estado, reuniones científicas, etc., con lo cual el incremento de su autoestima y sentimiento de pertenencia al grupo se activan en progresión geométrica.

\section{III.A MODO DE CONCLUSIÓN}

Un análisis del terrorismo requiere integrar todas aquellas variables que se consideran cruciales en cada uno de los contextos del desarrollo humano. Es decir, al individuo en su red. Así, no debería soslayarse en los análisis, los contextos familiares y escolares, íntimamente relacionados. La socialización familiar y escolar son contextos determinantes en la transmisión de valores, en la autoestima y en el ajuste. Desde la óptica de la intervención, considero que ante las dificultades que tenemos de intervenir en el medio familiar, se debería atender con mimo el medio escolar, a través de un curriculum atractivo, dinámico, con mayor protagonismo del alumno y, sobre todo, flexible. Un curriculum que se adapte a las circunstancias especiales y a las demandas de amplios sectores de la sociedad.

Un sistema educativo sancionador genera violentos absentismos y rechazos a la escuela, fuente a su vez de la génesis de pandillas y de desencantos en donde se nutre el terrorismo. Insisto en la educación por encima de todo, puesto que creo en ella más que en cualquier otra medida, bien sea o no coercitiva. Porque centrarse en la psicopatología para explicar los comportamientos terroristas es un recurso demasiado fácil y, además, o, posiblemente por ello, muy poco efectivo. Junto con las medidas educativas, deben funcionar otras medidas como las sociales y económicas. Es cada vez mayor el desencanto y la frustración de los jóvenes de hoy ante unas perspectivas de futuro desalentadoras; la creación de nuevos estímulos y perspectivas supondrían un revulsivo frente a una vida con dificultades excesivas y alicientes escasos.

Creo que la amenaza externa y una política reactiva de represalias son insuficientes para intimidar a los líderes de la organización terro- 
rista e inducirles a abandonar sus actos de violencia política. Quiero decir que la política de represalias puede que a corto plazo tenga su efecto disuasorio. Pero, a largo plazo, los testigos jóvenes de esta violencia serán más tarde parte activa de esta violencia terrorista. Por eso también sugiero no ignorar la historia, pues hacer historia es actualizar el presente.

Paul Wilkinson (1987) pone de relieve el carácter de «cabeza de hidra» del fenómeno terrorista contemporáneo, en el sentido de que, cuando se piensa que se ha cortado la cabeza al movimiento terroris$\mathrm{ta}$, inmediatamente surge otra en su lugar. Para hacerle justicia, insiste Wilkinson con razón, es necesario aceptar en primer lugar que «el contexto lo es todo en el análisis de la violencia política». Aunque la exigencia de sensibilidad al contexto sólo puede ser plenamente satisfecha por una adecuada perspectiva histórica, es esta perspectiva, precisamente, la que, según el citado autor, ha estado ausente demasiado a menudo de la literatura sobre el tema. Intentar al menos una rectificación parcial de esta situación parece importante, pues es principalmente la dimensión histórica la que distingue el estudio académico del terrorismo de los enfoques periodísticos que exageran la novedad del fenómeno, ignorando las tradiciones y los contextos dispares en los que aparece.

A la larga, fórmulas efectivas podrían ser el quebrantar la red de apoyo externa al terrorismo, para lo cual se requieren de profundas medidas sociales y económicas: flexibilizar al máximo las vías de salida del terrorismo, para lo cual las vías del diálogo entre las diferentes fuerzas políticas es conditio sine quanon para que se pueda llevar a cabo; se sabe que el retorno del terrorista al desempeño de roles legítimos y no violentos en una sociedad democrática es muy problemática y personalmente peligrosa. No obstante, hay que hacer todo lo posible para que así sea con todas las fuerzas sociales apoyando la iniciativa; de aquí se sugeriría la recomendación de que se reduzca la atracción que ejercen los grupos terroristas, para lo cual, la vía educativa con las reformas necesarias en forma y contenido, junto con las medidas políticas y económicas, podrían ser los grandes amortiguadores y obstructores del terrorismo. Todo ello en colaboración con los medios de comunicación de masas que deben tener la función de transmitir a todos los sectores de la población, de forma adecuada e insistente esas medidas y los objetivos que se persiguen, más que dramatizar y publicitar los actos terroristas, pues no hay que olvidar que eso también forma parte de sus objetivos, en este caso, psicológicos. 


\section{BIBLIOGRAFÍA}

BANDURA, A.: «Mecanismos de desconexión moral». En Reich, W. (ed.), Origenes del terrorismo. Pomares-Corredor. Barcelona, 1992; 173-205.

BARKER, R.G. y otros: Adjustment to physical handicap and illness, $2 \mathrm{~d}$ ed. Social Science Research Council. New York, 1953.

BAUMANN, M.: Terror or love: Bommi Baumann's own story of his life as a west german urban guerrilla. Grove Press. New York, 1979. 19-24.

BRONFENBRENNER, U.: "Toward an experimental ecology of human development». American Psychologist, 32, 1977; 513-531.

COOPER, H.H.A.: «Psychopath as terrorist: A psychological perspective», Legal Medical Quarterly, 2, 1978; 188-197.

COOPER, H.H.A.: «What is a terrorist: A psychological perspective», Legal Medical Quarterly, 1, 1977; 16-32.

CORRADO, R.R.: «A critique of the mental disorder perspective of political terrorism», International Journal of Law and Psychiatry, 4, 1981, 293310.

CORTINA A. «Etica y violencia política». Sistema, 1996; 132-133:57-71.

CRENSHAW, M.: «La lógica del terrorismo: comportamiento terrorista como producto de una elección estratégica». En Reich, W. (ed.), Orígenes del terrorismo. Pomares-Corredor. Barcelona,1992; 17-35.

CRENSHAW, M.: «Preguntas a responder, conocimientos a aplicar, investigaciones pendientes». En Reich, W. (ed.), Orígenes del terrorismo. Pomares-Corredor. Barcelona, 1992; 265-280.

DODD C.: «La contención del terrorismo: la violencia en la política turca, 1965-80". En O’Sullivan, N. (ed.), Terrorismo, ideología y revolución. Alianza. Madrid, 1987; 165-186.

ELZO, J.: «Euskalerria en la encuesta europea de valores: ¿son los vascos diferentes?». Universidad de Deusto. Bilbao, 1992.

ELZO, J.: The problem of violence in the basque country. International Meeting: Biology and Sociology of Violence, Septiembre 1966. Fundación Valenciana de Estudios Avanzados. Valencia, 1966.

FERRACUTI, F: «A sociopsychiatric interpretation of terrorism», Annals of the American Academy of Sciences, 463, septiembre de 1982; 136-137.

FERRACUTI, F.: «Ideología y arrepentimiento: el terrorismo en Italia». En Reich, W (ed.), Orígenes del terrorismo. Pomares-Corredor. Barcelona, 1992; 73-78.

FORNARI, F.: The psychoanalysis of war. Indiana University Press. Bloomington, 1975. 
GARTNER, R.: Cross-cultural aspects of violence. International Meeting: Biology and Sociology of Violence, Septiembre 1966. Fundación Valenciana de Estudios Avanzados. Valencia, 1966.

GOTTESMAN, I.: Genetics and human aggression. International Meeting: Biology and Sociology of Violence, Septiembre 1966. Fundación Valenciana de Estudios Avanzados. Valencia, 1966.

GRACIA, E.; HERRERO, J. y MUSITU, G.: Apoyo Social. PPU. Barcelona, 1995.

GURR, T.R.: «El terrorismo en las democracias: sus bases sociales y políticas». En Reich, W. (ed.), Orígenes del terrorismo. Pomares-Corredor. Barcelona, 1992; 100-118.

HINDE, R.: The diversity of aggression. International Meeting: Biology and Sociology of Violence, Septiembre 1966. Fundación Valenciana de Estudios Avanzados. Valencia, 1966.

KELLEN K. «Ideología y rebelión: terrorismo en Alemania occidental». En Reich, W. (ed.), Orígenes del terrorismo. Pomares-Corredor. Barcelona, 1992; 55-72.

LAITIN, D.D.: «Resurgimientos nacionalistas y violencia». Sistema, 1996; 132-133:193-229.

LASCH, CH.: The culture of narcissism. W.W. Norton. New York, 1979.

LEVINSON, D. y MALONE, M.J.: Toward explaining human culture: A critique of the findings of worlwide cross-cultural research. HRAF Press. New Haven, 1980.

MARDIN, S.: "Youth and violence in Turkey». Arch. Europ. Sociol., XIX, 1978; 229-254.

MILGRAM, S.: Obedience to authority: An experimental view. Harper \& Row. New York, 1974.

MINISTERIO DEL INTERIOR DE ALEMANIA OCCIDENTAL: Analysen zum terrorismus, 1-4. Deutscher Verlag. Darmstadt, 1981, 1982, 1983, 1984.

MOLPECERES, M.A.: Sistemas de valores, estilos de socialización y colectivismo familiar. Tesis de Licenciatura. Dir. Gonzalo Musitu. Facultad de Psicología. Universidad de Valencia,1991.

MONTAGU, A. (comp.): Learning non-aggression. Oxford University Press. New York, 1978.

MORF, G.: Terror in Quebec: Case studies of the F.L.W. Clarke, Irwin. Toronto, 1970.

MUSITU, G. y ALLATT, P.: Psicosociología de la familia. Albatros. Valencia, 1994. 
MUSITU, G.; ROMAN, J.M. y GRACIA, E.: Familia y educación: Prácticas educativas de los padres y socialización de los hijos. Labor. Barcelona, 1988.

MUSITU, G.; ROMAN, J.M. y GUTIERREZ, M.: Educación familiar y socialización de los hijos. Idea Books. Barcelona, 1996.

O'SULLIVAN, N.: «Terrorismo, ideología y democracia». En O'Sullivan, N. (ed.), Terrorismo, ideología y revolución. Alianza. Madrid, 1987; 19-46.

O'SULLIVAN, N.: Terrorismo, ideología y revolución. Alianza. Madrid, 1987.

OVEJERO, A.: El aprendizaje cooperativo. PPU. Barcelona, 1990.

POST, J.M.: «Psicología terrorista: el comportamiento terrorista como producto de fuerzas psicológicas». En Reich, W. (ed.), Orígenes del terrorismo. Pomares-Corredor. Barcelona, 1992; 36-52.

REICH, W.: «Límites y oportunidades de la investigación psicológica». In: Reich, W. (ed.), Orígenes del terrorismo. Pomares-Corredor. Barcelona, 1992; 281-298.

REICH, W: Orígenes del terrorismo. Pomares-Corredor. Barcelona, 1992.

REINARES, F.: «Fundamentos para una politica gubernamental antiterrorista en el contexto de regímenes democráticos». Sistema, 1996; 132-133:111127.

REINARES, F.: Violencia y política en Euskadi. Descleé de Brouwer. Bilbao, 1984.

REINARES, F.: "Características y formas de terrorismo político en sociedades industriales avanzadas». Revista Internacional de Sociología, 5, MayoAgosto. Madrid, 1993; 35-67.

ROLLINS, B.C. y THOMAS, D.L.: «Parental support, power, and control techniques in the socilization of children». En W.R. Burr, R. Hill, F.I. Nye y I.L. Reiss (eds.), Contemporary theories about the family, vol.1, Free Press. New York, 1979; 317-364.

ROSS, M.H.: «Socioeconomic complexity, socialization, and political differentiation». Ethos, 9, 1981; 217-247.

ROSS, M.H.: "The role of evolution in ethnocentric conflict and its management». Journal of Social Issues, 47, 1991; 167-185.

RUIZ DE PINEDO, I.: «Euskadi, cuestión de estado». En Reinares, F. (ed.), Violencia y política en Euskadi. Descleé de Brouwer. Bilbao, 1984; $55-$ 70.

SEARS, R.R.; MACCOBY, E.E. y LEVIN, H.: «The socialization of aggression». En E.E. Maccoby, T. Newcomb y E.L. Hartley (comps.), Reading in social psychology, Holt, Rinehart \& Winston. New York, 1958, $2 \gg$ ed; $350-358$. 
SPRINZAK, E.: «La formación psicopolítica del terrorismo de extrema izquierda en una democracia: el caso de los Weathermen». En Reich, W. (ed.), Orígenes del terrorismo. Pomares-Corredor. Barcelona, 1992; 7999.

TILKER, H.A.: «Socially responsible behavior as a function of observer responsibility and victim feedback». Journal of Personality and Social Psychology, 14, 1970; 95-100.

TURK. A.T.: «La violencia política desde una perspectiva criminologica». Sistema, 1996; 132-133:41-55.

UNZUETA, M.: «Claves para comprender una situación». En Reinares, F. (ed.), Violencia y política en Euskadi. Descleé de Brouwer. Bilbao, 1984; 15-36.

VOLKAN, V.D.: The need to have enemies and allies: From clinical practice to international relationships. Jason Aronson. New York, 1968.

WILKINSON, P.: «La lucha contra la hidra: el terrorismo internacional y el imperio de la ley». En O'Sullivan, N. (ed.). Terrorismo, ideología y revolución. Alianza. Madrid, 1987; 251-269.

WILKINSON, P.: «Las leyes de la guerra y del terrorismo». En Rapoport, D.C. (ed.), La moral del terrorismo. Ariel. Barcelona, 1985; 115-137.

ZIGLER, E. y CHILD, I.L.: «Socialization». En G. Lindzey y E. Aronson (comps.), Handbook of social psychology, 2» ed. Addison-Wesley. Reading, Mass., 1969. 


\section{LA VIOLENCIA DOMÉSTICA COMO UNA FORMA DE EXPRESIÓN DE LAS ACTITUDES MISÓGINAS}

E. BOSCH FIOL

M. GILI PLANAS

V.A. FERRER PÉREZ

Departamento de Psicología de la Universidad de las Islas Baleares.

\section{RESUMEN}

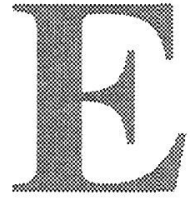

1 problema de la violencia doméstica es una gran fuente de preocupación en nuestro entorno. Dentro de este problema, por otra parte tan amplio, en nuestra Comunidad Autónoma hay un clima de especial sensibilidad en relación a la violencia doméstica hacia las mujeres. Esta situación tiene que ver, entre otras cosas, con la muerte de varias mujeres en el espacio de pocos meses debido a los ataques de sus cónyuges respectivos.

A pesar de este interés, resulta difícil establecer medidas para hacer frente al problema, entre otras cosas, porque se carece de datos fiables sobre el número de casos. El único número real es el de denuncias, y la práctica totalidad de expertos coinciden en afirmar que sólo un $10 \%$ de las mujeres que sufren violencia doméstica denuncian esta situación.

En el trabajo que se propone se presentan los datos recogidos en nuestra comunidad sobre el tema de la violencia doméstica a mujeres y se discute la metodología empleada para ello.

\section{PALABRAS CLAVE}

Violencia doméstica, denuncias.

\section{INTRODUCCIÓN}

En la IV Conferencia Mundial de la Mujer, celebrada en Beijing en septiembre de 1995, se reconoció que la violencia contra las mujeres 
es un obstáculo para la igualdad, el desarrollo y la paz de los pueblos, impidiendo que las mujeres disfruten de sus derechos humanos y libertades fundamentales.

El artículo 1 de la "Declaración sobre la eliminación de la violencia contra las mujeres" de las Naciones Unidas dice que "la violencia contra las mujeres es todo acto de violencia basado en la pertenencia al sexo femenino que tenga o pueda tener como resultado un daño o sufrimiento físico, moral o psicológico para las mujeres, inclusive la amenaza de tales actos, la coacción o la privación arbitraria de libertad, tanto si se produce en la vida pública o privada".

Desde un punto de vista clínico, el término maltrato o violencia doméstica se emplea para referirse a las agresiones físicas, psíquicas, sexuales o de otro tipo, llevadas a cabo reiteradamente por parte de un familiar (habitualmente el marido o pareja) y que causan daño físico y/ o psíquico y vulneran la libertad de otra persona (habitualmente la mujer) (Echeburúa et al., 1990).

Cuantificar este problema no es fácil. Es importante tener en cuenta que estamos hablando de algo que ocurre en el ámbito privado y, normalmente, en ausencia de testigos. Además, sigue existiendo todavía gran cantidad de barreras psicológicas y culturales que tienden a encubrir estas situaciones. Así, el miedo de la víctima hacia las consecuencias que para ella y/o para sus hijos puede suponer la denuncia, considerar que se trata de un problema doméstico y que debe resolverse en privado, las presiones familiares y sociales, etc., hacen que todavía su cuantificación sea difícil. Es decir, los malos tratos se configuran como un delito oculto y los estudiosos del tema suelen sugerir que tan sólo entre un $10 \%$ y un $30 \%$ de los malos tratos reales llegan a conocerse y/o denunciarse (Sarasua et al., 1994; Zubizarreta et al., 1994).

Pero, además, tampoco se dispone de datos concluyentes sobre las denuncias, puesto que, al menos en España, los delitos de malos tratos se encuentran en las estadísticas judiciales dispersos entre los apartados relativos a otros delitos, faltas, delitos contra las personas, faltas contra las personas, etc. (Larrauri, 1994; Larrauri y Varona, 1995; Vázquez, 1993).

Así, aunque se calcula que entre 250.000 y 300.000 mujeres son maltratadas en España (Pérez del Campo, 1995), estimaciones proporcionadas por el Ministerio del Interior (Instituto de la Mujer, 1994, p. 93) señalan que el número de denuncias de mujeres por malos tratos de sus parejas en España entre 1985 y 1992 es de 122.298, distribuidas como se observa en la Figura 1. 


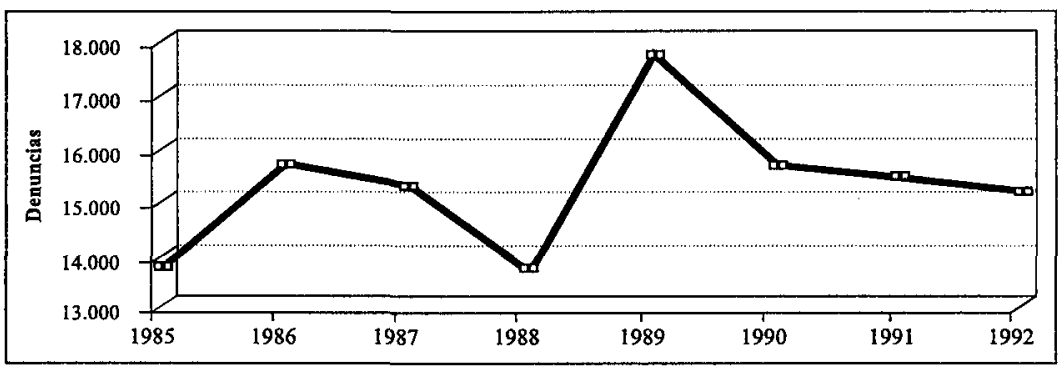

FIGURA 1: Número de denuncias de mujeres por malos tratos entre 1985 y 1992.

Durante el curso 1993-94, la "Comissió Interdepartamental de la Dona del Govern Balear" nos encargó la realización de un estudio sobre la situación de la mujer en las Islas Baleares. Este estudio (Bosch, Ferrer, Gili y Manassero, 1996) estaba financiado conjuntamente por esta comisión y por el Instituto de la Mujer, dependiente del Ministerio de Asuntos Sociales.

Para la realización del mencionado estudio, se seleccionó, mediante un muestreo estratificado por municipios y cuotas (sexo y edad), una muestra representativa de los residentes en la Comunidad Autónoma de las Islas Baleares. Dicha muestra estaba compuesta por 1.800 personas, mayores de 18 años y menores de 80 años, residentes en Baleares e incluía tanto hombres como mujeres, puesto que uno de los objetivos propuestos era no sólo conocer la situación de las mujeres sino poder compararla con la de los hombres de esta Comunidad. A las personas integrantes de dicha muestra se les administró, mediante entrevistas domiciliarias llevadas a cabo por un equipo de 40 entrevistadores previamente entrenados para tal fin, una encuesta elaborada por nosotras (Bosch et al., 1996) que analiza diferentes aspectos de la realidad social, incluyendo datos socio-demográficos, hábitos familiares, estudios, etc.

Entre los temas analizados en dicha encuesta había un apartado destinado a victimología. Los datos obtenidos en este sentido indican que los delitos más citados son los robos, mientras que otros delitos, como aquellos contra la libertad sexual o los malos tratos, aparecen en un porcentaje mínimo. Cabe destacar también el hecho de que todas las mujeres que afirman haber sido víctimas de malos tratos lo han denunciado (véanse tablas 1 y 2 en página siguiente).

En nuestra opinión, las características de la encuesta administrada (leída por el encuestador, en el domicilio de la persona, etc.) hacen que estos resultados sean simplemente orientativos, pero no proporcionan información fiable sobre el estado de la cuestión. 


\begin{tabular}{|l|c|c|}
\hline & Mujeres & Hombres \\
\hline Accidente de circulación & 0,4 & 0,3 \\
Amenazas & - & 1 \\
Delitos contra el honor & - & - \\
Delitos contra la libertad sexual & 2,1 & - \\
Estafa & 0,4 & 2,1 \\
Lesiones & 0,8 & 1,7 \\
Malos tratos & 0,4 & - \\
Peleas & - & - \\
Robos & 95,4 & 94,2 \\
Otros & 0,4 & 0,3 \\
\hline
\end{tabular}

TABLA 1: En caso de haber sido víctima de un delito, ¿cuál fue?

\begin{tabular}{|l|c|c|c|c|c|c|}
\hline & Muj. & Hom. & Muj. & Hom. & Muj. & Hom. \\
\hline Accidente de circulación & - & - & 0,4 & 0,4 & - & - \\
Amenazas & - & - & - & 0,4 & - & 0,4 \\
Delitos contra el honor & - & - & - & - & - & - \\
Delitos contra la libertad sexual & - & - & 0,8 & - & 1,3 & - \\
Estafa & - & - & 0,4 & 1,3 & - & 0,9 \\
Lesiones & - & 0,4 & 0,8 & 1,3 & - & - \\
Malos tratos & - & - & 0,4 & - & - & - \\
Robos & 2,1 & 1,3 & 67,5 & 52,4 & 25,7 & 40,6 \\
Otros & - & - & 0,4 & 0,4 & - & - \\
\hline
\end{tabular}

TABLA 2: Tipo de delito/ ¿Conocía al agresor?

A la vista de las dificultades metodológicas derivadas de uso de una encuesta, y relacionado con la ocurrencia en nuestra Comunidad Autónoma de varios casos de violencia doméstica hacia las mujeres con resultado de muerte, en marzo de 1995 pusimos en marcha, con la colaboración de la "Comissió Interdepartamental de la Dona" del "Govern Balear" un estudio piloto para intentar recoger información más exacta sobre el número de mujeres que padecen este problema en nuestro entorno.

Dadas las dificultades para acceder a esta información, antes comentadas, consideramos que podía ser una opción adecuada poner a disposición de las mujeres afectadas un teléfono gratuito donde, garantizando el absoluto anonimato, pudieran llamar para facilitarnos datos sobre su problema de malos tratos.

Dicho teléfono era atendido por un contestador automático que explicaba la finalidad del estudio, solicitando los datos necesarios con el mensaje que se incluye en el Cuadro 1. 
"Está vd. hablando con el contestador automático destinado a recoger información sobre malos tratos. Los datos que vd. nos va a proporcionar son absolutamente anónimos.

Esta inciativa está dirigida a mujeres que hayan sido víctimas de malos tratos por parte de sus parejas o ex-parejas durante 1994.

Por favor, después de oír la señal, indique:

a) Su edad,

b) Si ha sido víctima de malos tratos físicos, psíquicos o de ambos tipos.

c) Si denunció o no los hechos.

d) Y, en caso afirmativo, cuántas veces.

e) Y cuándo empezaron los malos tratos.

Muchas gracias por su colaboración"

CUADRO 1: Mensaje contenido en el contestador del teléfono puesto a disposición de las mujeres

El teléfono estuvo en funcionamiento durante 6 semanas y, con anterioridad a ese periodo, se realizó una amplia distribución de carteles explicando su existencia en asociaciones de mujeres, centros públicos, etc., así como una amplia campaña en la prensa local explicando su existencia y los propósitos del estudio.

\section{RESULTADOS}

En total, se recogieron un total de 17 cintas que contenían 307 llamadas distribuidas de la manera que se observa en la Tabla 3.

\begin{tabular}{|c|c|c|}
\hline Número de cinta & Fechas & Núm. de llamadas \\
\hline Cinta.$^{\circ} 1$ & 13 marzo & 14 \\
\hline Cinta $n^{\circ} 2$ & 14-15 marzo & 17 \\
\hline Cinta $n^{\circ} 3$ & 16-17 marzo & 16 \\
\hline Cinta $n^{\circ} 4$ & 18-20 marzo & 16 \\
\hline Cinta $n^{\circ} 5$ & 21-27 marzo & 13 \\
\hline Cinta n. ${ }^{\circ} 6$ & 28 marzo & 8 \\
\hline Cinta $n^{\circ} 7$ & 29 marzo & 19 \\
\hline Cinta $n^{\circ} 8$ & 30 marzo & 27 \\
\hline Cinta.$^{\circ} 9$ & 1-2 abril & 34 \\
\hline Cinta $n^{\circ} 10$ & 3 abril & 17 \\
\hline Cinta n..$^{\circ} 11$ & 4-5 abril & 19 \\
\hline Cinta.$^{\circ} 12$ & 6-9 abril & 15 \\
\hline Cinta n..$^{\circ} 13$ & 10-11 abril & 14 \\
\hline Cinta $n .^{\circ} 14$ & 12-17 abril & 34 \\
\hline Cinta $n .^{\circ} 15$ & 18-20 abril & 13 \\
\hline Cinta $\mathrm{n}^{\circ} 16$ & 21-23 abril & 19 \\
\hline Cinta n..$^{\circ} 17$ & 24 abril & 12 \\
\hline Total llamadas & & 307 \\
\hline
\end{tabular}

TABLA 3: Distribución de las llamadas telefónicas recibidas. 
Gracias a la localización física del contestador, se pudo determinar que una gran parte de las llamadas se efectuaron durante la tarde-noche y raramente en horario laboral. Además, el análisis realizado ha permitido determinar que la práctica totalidad de ellas fueron realizadas desde cabinas telefónicas.

El análisis del contenido de las llamadas recibidas permite clasificarlas tal y como se observa en la Tabla 4.

\begin{tabular}{|l|c|c|}
\hline & Núm. de Ilamadas & $\%$ \\
\hline Llamadas válidas & 105 & 34,2 \\
Llamadas de comentarios & 28 & 9,12 \\
Llamadas masculinas de contenido & & \\
insultante-amenazante hacia las mujeres & 123 & 40,07 \\
Llamadas infantiles (bromas,...) & 51 & 16,61 \\
Total de llamadas & 307 & 100 \\
\hline
\end{tabular}

TABLA 4: Caracterización de las llamadas recibidas.

En relación a las llamadas válidas es posible extraer un perfil característico de las mujeres víctimas de malos tratos que aparece descrito en la Tabla 5.

\begin{tabular}{|l|c|}
\hline & Características \\
\hline Edad media & 36,4 años \\
Tipo de malos tratos: & $7,62 \%$ \\
- Físicos & $7,62 \%$ \\
- Psíquicos & $84,76 \%$ \\
- Físicos y psíquicos & \\
Denuncia: & $8,57 \%$ \\
- Denunciados & $91,43 \%$ \\
- No denunciados & Datos no especificados \\
Duración media &
\end{tabular}

TABLA 5: Perfil de las mujeres maltratadas.

\section{III.CONCLUSIONES}

En primer lugar, cabe señalar que la mayoría de la llamadas válidas corresponden a mujeres que no denunciaron las agresiones sufridas. Esto confirmaría que el número de denuncias es muy inferior al número real de víctimas, aún cuando en este estudio piloto no podemos determinar la magnitud real de la diferencia. 
Por otra parte, la mayoría de los casos corresponden a mujeres que han sufrido tanto malos tratos físicos como psíquicos, coincidiendo con los resultados hallados por autores como Sarasua y cols. (1994).

Al valorar la duración del maltrato, la respuesta más frecuente es que éste se remonta al inicio de la relación y/o el nacimiento del primer hijo. Este resultado coincide con diferentes análisis sobre el tema (Zubizarreta et al., 1994).

Las llamadas de comentario han sido realizadas tanto por hombres como por mujeres (incluyendo algunos/as profesionales del derecho) que expresaban su opinión sobre el tema de los malos tratos, aportaban lo que ellos/as consideraban como soluciones al problema, etc.

Es importante señalar el elevado número de llamadas incluyendo comentarios, amenazas, insultos (4 cintas estaban totalmente llenas de este tipo de llamadas) que han tenido prácticamente bloqueado el teléfono de denuncia durante una parte importante del tiempo de funcionamiento, de forma que, a nivel afectivo, el teléfono no ha estado disponible las 24 horas inicialmente previstas. Cabe suponer que de haber sido mayor la disponibilidad el número de denuncias habría sido sensiblemente mayor.

Se constata, pues, que un tema como la violencia doméstica no sólo es fruto de, sino que suscita, aún hoy en día, actitudes fuertemente misóginas que se traducen en frivolizar, insultar, amenazar, etc., aprovechando la impunidad que proporciona el anonimato. Y, aunque estos comportamientos han llevado literalmente a boicotear una iniciativa como la que se ha pretendido desarrollar con este estudio, indirectamente, nos han ofrecido una información que no estaba previsto recoger y que nos proporciona una cierta perspectiva sociológica sobre la posición de ciertos hombres en nuestra Comunidad (todas las llamadas insultantes han sido realizadas por varones).

Vistos los resultados, debemos concluir sugiriendo que los estudios sobre la violencia doméstica deberían ser planteados mediante técnicas tradicionales (encuestas o entrevistas individualizadas) que, aún teniendo un coste económico mucho mayor que el tipo de investigación aquí propuesto, evitarían las dificultades con las que nosotras nos hemos encontrado.

Aún a pesar de todas las dificultades con las que nos encontramos, lo cierto es que en los últimos tiempos en nuestra Comunidad ha aumentado progresivamente la concienciación sobre este tema por parte de las instituciones públicas y las organizaciones de diversa índole. Así, y relacionado con el análisis que hemos presentado, poco tiempo después (durante el año 1996) el Colegio Oficial de Psicólogos de Baleares puso en marcha un programa de atención inmediata a muje- 
res víctimas de malos tratos, subvencionado por la "Comissió Interdepartamental de la Dona" del Govern Balear", y organizó diversos cursos de formación para psicólogos/as y otros/as profesionales en contacto con esta problemática.

\section{BIBLIOGRAFÍA}

BOSCH, E., FERRER, V.A., GILI M. y MANASSERO, M.A.: Estudio sobre la situación de las mujeres en Baleares / Estudi sobre la situació de les dones a Balears. Govern Balear. Palma. 1996.

ECHEBURÚA, E., CORRAL, P., SARASÚA, B., ZUBIZARRETA, I. y SAUCA, D.: Malos tratos y agresiones sexuales: Lo que la mujer debe saber y puede hacer. Servicio Vasco de la Mujer. Vitoria. 1990.

INSTITUTO DE LA MUJER: La mujer en cifras (Una década 1982-1992). Instituto de la Mujer. Ministerio de Asuntos Sociales. Madrid. 1994.

LARRAURI, E. (Comp): Mujeres, derecho penal y criminología. Siglo XXI. Madrid. 1994.

LARRAURI, E. y VARONA, D.: Violencia doméstica y legítima defensa. EUB. Barcelona. 1995.

PÉREZ DEL CAMPO, A.M.: Una cuestión incomprendida. El maltrato a la mujer. Horas y horas. Madrid. 1995.

SARASÚA, B., ZUBIZARRETA, I., ECHEBURÚA, E. y CORRAL, P.: Perfil psicológico del maltratador a la mujer en el hogar. E. ECHEBURÚA. Personalidades violentas. Pirámide. Madrid. 1994. pp. 111-178.

VÁZQUEZ, B.: La violencia familiar y la agresión sexual como objeto de la pericial psicológica. En J. URRA y B. VÁZQUEZ (Comps.). Manual de psicología forense. Siglo XXI. Madrid. 1993. pp. 273-318.

ZUBIZARRETA, I., SARASÚA, B., ECHEBURÚA, E., CORRAL, P., SAUCA, D. y EMPERANZA, I.: Consecuencias psicológicas del maltrato doméstico. E. ECHEBURÚA. Personalidades violentas. Pirámide. Madrid. pp. 129-152. 


\section{EL MALTRATO A MENORES EN LA PROVINCIA DE ALICANTE EN EL PERIODO 1980 -1997}

DRA. M DOLORES DÍEZ GARCÍA

Prof. E.U. de Trabajo Social. Universidad de Alicante.

DR. SERGIO QUESADA RETTSCHLAG

Prof. E.U. de Trabajo Social. Universidad de Alicante.

$\mathrm{M}^{\mathrm{a}}$ DOLORES SALA BONMATÍ

Trabajadora Social.

\section{RESUMEN}

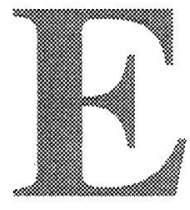

n los últimos años se está tomando conciencia acerca de un problema que necesita de la intervención de la Sociedad y, en particular, de los profesionales que actúan en el campo social. Nos estamos refiriendo al tratamiento de situaciones problemáticas relacionadas con los malos tratos a menores. Se requiere una intervención que contemple las tres áreas de actuación: individual, grupal y comunitaria, con especial atención a la prevención de estos problemas.

Este hecho nos ha llevado a plantearnos la realización de un estudio empírico que nos permita detectar el estado real del problema en un estrato concreto de la sociedad, a la vez que sustentara cuantas conclusiones y posibles vías de actuación se pudieran realizar a partir de dicho conocimiento.

\section{PALABRAS CLAVE}

Maltrato, menores, físico, emocional, prevención.

\section{INTRODUCCIÓN}

El tema de los malos tratos en los menores es una cuestión desgraciadamente de creciente actualidad cuya única cara positiva radica en la posibilidad de concienciar a la sociedad, a los agentes sociales y a la Administración, para que, aunando esfuerzos, la situación de estos niños pueda mejorar, al mismo tiempo que se desarrolla una labor más eficaz en los aspectos de prevención. 
Cuando se habla del maltrato, habitualmente (tal vez por la influencia de los medios de comunicación, que a menudo nos presentan los casos más dramáticos y escabrosos de maltrato hacia menores), pensamos en el niño que presenta cualquier tipo de agresión física, pero no podemos olvidar que existe otro tipo de agresión que no se detecta tan fácilmente, y puede crear un daño tal vez mayor. Nos estamos refiriendo a las agresiones psicológicas, «es fácil considerar que se puede dar maltrato psicológico sin que haya maltrato físico; pero no es tan sencillo separarlo a la inversa: cuando hay maltrato físico se puede afirmar que casi siempre hay daño psicológico»'. Se está proponiendo el concepto de maltrato emocional por ser una concepción más amplia, y así evitar que exista una separación entre la terminología referida al maltrato físico y psicológico.

El mismo autor señala en el trabajo citado que el maltrato emocional puede ser entendido como «aquellas conductas dirigidas intencionalmente por un adulto hacia otra persona (niño o adulto) que producen en ésta daño interno a través de sentimientos negativos (desvalorización, desestima) hacia su propia persona sin justificación ni necesidad».

Es importante también reseñar que en los primeros años de vida cualquier tipo de maltrato tiene unas consecuencias que revisten mayor gravedad, debido a la fragilidad y la indefensión del niño. Según diferentes autores, «el $60 \%$ de las muertes que ocurren por conducta abusiva paterna y el $50 \%$ de los casos que resultan con daños permanentes, principalmente por lesiones en la cabeza, se producen entre los menores de 2 años» ${ }^{2}$, igualmente, otro dato apunta a que «en nuestro país las muertes producidas por maltrato se detectan generalmente entre niños de menos de 3 años. Por tanto, el maltrato en los primeros años de vida representa un grave peligro para la vida del niño, por lo que se debe desarrollar una labor en los diversos aspectos, pero, principalmente, en el aspecto informativo, y sobre todo en el ámbito de prevención»3.

La legislación vigente acerca de los derechos del menor, Ley 1/96 en su Título I, referente a los derechos de los menores (al honor, a la intimidad, a la información, a la libertad ideológica, de participación,

BUENO BUENO, A. Aspectos psicológicos del maltrato infantil. III Jornadas de reflexión Menores. 28-febrero-1997. Escuela Universitaria de Trabajo Social. Pág. 2 y 3.

2 NEWBERG. (1.982). Citado en: El maltrato fisico y emocional en la primera infancia. Bienestar y Protección Infantil. Edit. F.A.P.M.I. (Federación de A sociaciones para la Prevención del Maltrato Infantil). $\mathrm{N}^{\circ} 4$ diciembre-96. Madrid.

3 CASCALES HILLA, C. Derechos del niño y protección al menor. III Jornadas de reflexión Menores. 28-febrero-1997. Escuela Universitaria de Trabajo Social. Pág. 3. 
a ser oído, a expresarse libremente....), y en su Título II, de las actuaciones en situación de desprotección social del menor e instituciones de protección de menores, incorpora las nuevas necesidades de una sociedad que a la vez que evoluciona es cambiante en sus demandas.

A su vez, «el sistema de protección social del menor está encaminado a prevenir $e$ intervenir en situaciones que comporten riesgo o desamparo de estos menores, actuando en cada caso con las medidas correspondientes, bien desde los servicios sociales de base (ayudas puntuales) o bien en la asunción de la tutela en los casos de desamparo» ${ }^{4}$.

Otro factor importante a tener en cuenta, a la hora de analizar los malos tratos, es la situación de riesgo que afecta tanto a los menores, como a las familias donde está integrado el menor maltratado. En estas situaciones de riesgo se puede destacar, en líneas generales, los problemas que afectan a un porcentaje alto de estas familias, dentro de las que padecen riesgo de carácter social: familias monoparentales, la mayoría numerosas, con vivienda precaria, de bajo nivel económico, convertido, en algunos casos, en situaciones de pobreza (obligando a sus miembros a practicar la mendicidad), subempleo y bajo nivel educativo. Otro tipo de causa, en estas conductas, son las asociadas al consumo de alcohol y otras drogas por llevar coligado el modo violento de los que las consumen. Este compendio de problemas hace que en familias en las que no se asumen situaciones de desequilibrio se desarrolle la violencia (física y/o emocional) hacia los menores o hacia la totalidad de sus miembros.

Todos estos motivos demuestran la necesidad de una mayor concienciación sobre un problema cuya solución requiere la participación de toda la sociedad y, más concretamente, de los profesionales que actúan en el campo social, dentro de los cuales los trabajadores sociales tienen un papel fundamental en el tratamiento de estas situaciones-problemas. Se requiere, pues, por parte de estos profesionales, una intervención que contemple las tres áreas de actuación: individual, grupal y comunitaria, y que a su vez preste una especial atención a la prevención.

Este conjunto de consideraciones nos llevaron a plantearnos la realización de un estudio empírico que nos permitiera conocer el estado real del problema en el estrato social objeto de estudio, a la vez que sustentara cuantas conclusiones y comentarios pudiéramos realizar a partir de dicho conocimiento.

4 RODRÍGUEZ BONGIL, J.El drama del menor en España. Ediciones B.J.A. 1993 Barcelona. Pág. 31 . 
Por ello, la finalidad de este estudio es múltiple. Por una parte, nos interesa concretar qué tipos de maltrato se dan con mayor frecuencia en los menores de nuestra comunidad, qué edades tienen estos niños y cómo les afecta física y/o emocionalmente el problema. Otro objetivo es conocer la relación que tiene el menor con su familia de origen, la existencia de otros hermanos, la situación de los mismos y el lugar de residencia (si es la residencia familiar o no, en régimen de acogimiento, o si reside en un centro de acogida).

\section{METODOLOGÍA}

Para la realización de nuestro estudio, escogimos dentro del Servicio de Programas de Asuntos Sociales, la Sección de Medidas Judiciales y Reforma de Menores de la antigua Consellería de Trabajo y Asuntos Sociales en su delegación de Alicante (de cuyos miembros queremos hacer público reconocimiento por su amabilidad y facilidades dadas). Seleccionamos una muestra aleatoria de 100 expedientes de menores, de entre los correspondientes a los diecisiete últimos años. Este tamaño de muestra, bajo la hipótesis de $\mathrm{p}=50 \%$, conlleva un margen de confianza del 95 '5\%.

Después de obtener y clasificar los datos, se realizó un análisis estadístico de ellos, cuyos resultados vienen sintetizados en los gráficos que presentamos, así como en los comentarios sobre los mismos. El estudio se ha centrado en conocer aspectos generales del menor y de los padres biológicos, e igualmente aspectos concretos de los malos tratos de los que son víctimas estos menores.

En consecuencia, además de los datos sociológicos relativos a los menores objeto de estudio, y de los motivos por los que ingresan en un centro, se abordan problemas que les afectan directa e indirectamente. También se han incluido las tipologías tanto de la madre biológica como del padre biológico, su situación sanitaria, sociolaboral y estado civil, entre otros.

\section{III.RESULTADOS}

\section{3.l. Aspectos generales del menor.}

En función de una mayor facilidad interpretativa, describiremos, con un carácter eminentemente gráfico, los principales resultados obtenidos. Comenzaremos, para ello, con cuestiones relativas al menor. 


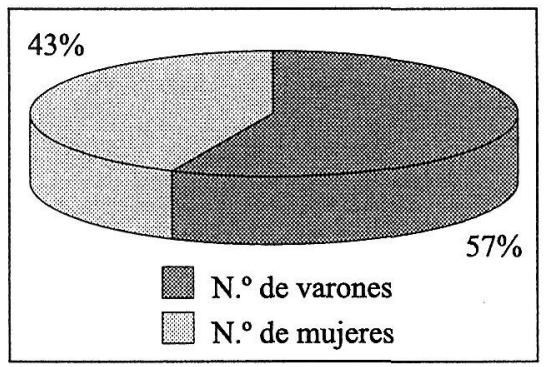

GRÁFICO 1: Distribución de los menores por sexo.

En el Gráfico 1, observamos que el sexo no parece ser determinante en los malos tratos al menor, a pesar de que existe un diferencial de porcentaje entre varones y mujeres de un $14 \%$.

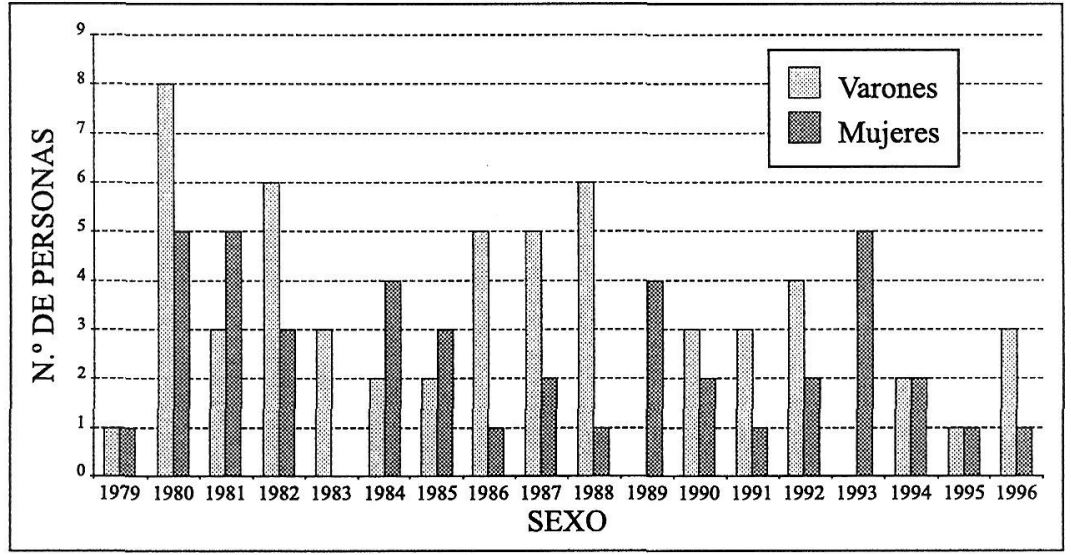

GRÁFICO 2: Distribución del menor por edad y sexo.

En el Gráfico 2, relativo al año de nacimiento y sexo de los menores objeto de malos tratos, podemos apreciar:

- Que en el año 1979 existe un $n^{\circ}$ mínimo atípico de malos tratos cuyas causas, si bien podrían estar asociadas a la edad, habría realmente que determinarlas. A partir de 1980 hay una ligera disminucion global de los mismos.

- Determinados años presentan una gran diferencia a favor de un sexo, destacando 1989 y 1993 en los que los malos tratos afectaron solamente a las mujeres.

- Los menores de 3 años presentan situación de maltrato en un 10\% de los casos, sin diferencias importantes a favor de un sexo. 


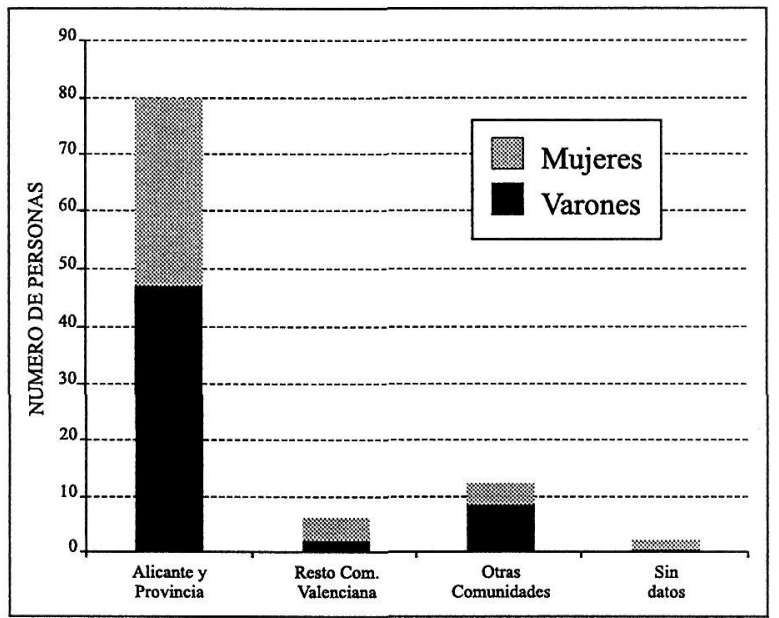

GRÁFICO 3: Localidad de nacimiento y sexo del menor

El Gráfico 3 muestra la existencia de un mayor número de menores nacidos en Alicante y provincia atribuible a que el estudio ha sido elaborado a partir de los datos recogidos en esta provincia. Se observa la existencia de menores de otras provincias como Madrid, Barcelona, Málaga, etc., debido a la movilidad geográfica de algunas familias.

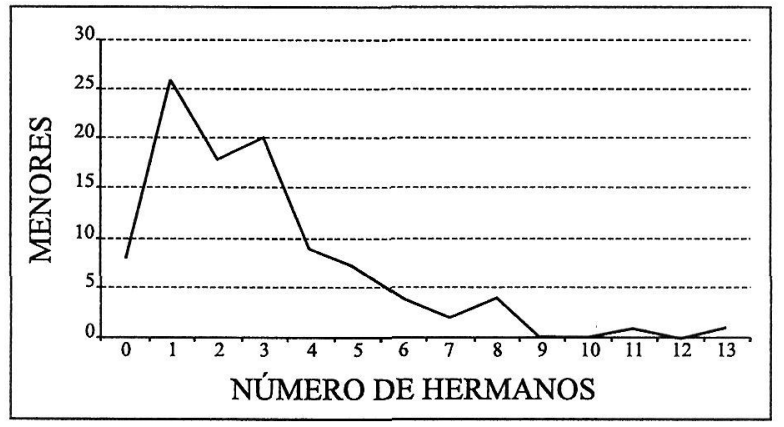

GRÁFICO 4: Número de hermanos del menor.

En el Gráfico 4, podemos apreciar como un 92\% de los menores estudiados tiene algún hermano, entre ellos destaca como máxima frecuencia el valor 26, correspondiente a aquellos menores que tienen un solo hermano. Por otra parte, entre uno y tres hermanos se encuentra el $64 \%$ de la muestra, mientras que con más de cuatro hermanos se halla el $19 \%$ de los menores. El máximo valor corresponde a un niño que cuenta con trece hermanos. 


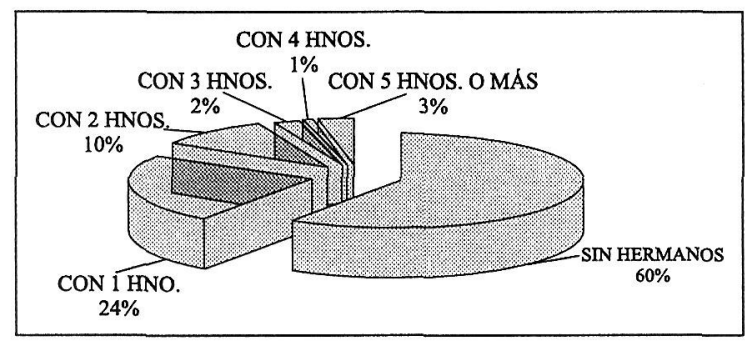

GRÁFICO 5: Hermanos del menor con medidas de protección.

Nos interesaba conocer no sólo si estos menores tenían otros hermanos sino, además, cuál era su situación. El Gráfico 5 refleja que un $60 \%$ de los menores no tienen hermanos con medidas de protección. Existe un $24 \%$ de menores con un hermano atendido en alguna institución. Llama la atención la existencia de un menor, que de trece hermanos tiene nueve con expediente abierto.

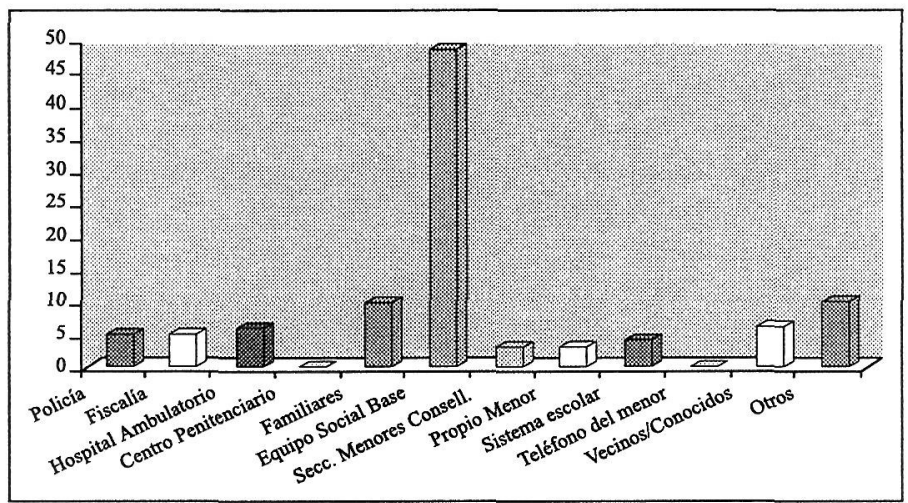

GRÁFICO 6: Vía de detección.

Los resultados relativos a la vía de detección del problema se aprecian en el Gráfico 6, indicando las personas, los centros o instituciones donde llega el problema que sufre el menor, derivando el caso cuando no se tienen competencias para una primera actuación. Destaca sobre todos los demás el Equipo Social de Base Municipal con un $48 \%$ de casos detectados. Curiosamente, aparece un dato acerca de uno de los servicios de implantación reciente en esta ciudad, el teléfono del menor, con un porcentaje de utilización $(0 \%)$, posiblemente debido a la falta de información que el usuario tiene de su existencia.

Por otra parte, era importante conocer las posibles vías de entrada de estos menores. Este hecho se muestra en el Gráfico 7 donde queda reflejado que el $61 \%$ de los casos entran a través de la Sección de la 


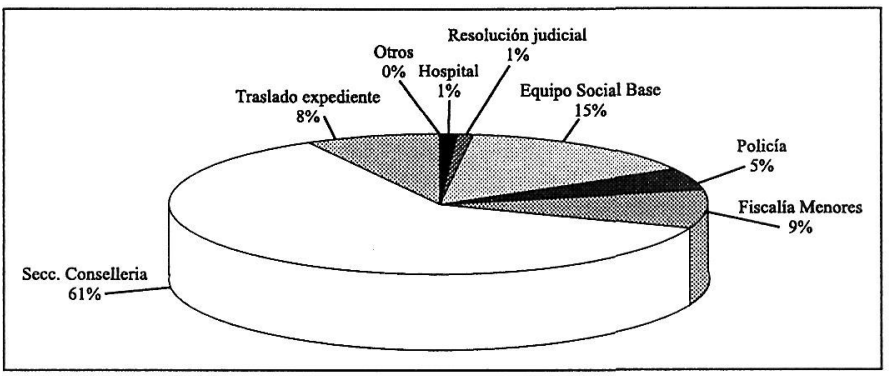

GRÁFICO 7: Vía de entrada.

Consellería, seguido en un $15 \%$ por el Equipo Social de base, mientras que la entrada a través de un hospital o por resolución judicial es un porcentaje muy pequeño. Esto nos hace intuir que o bien no se puede hablar de un número alto de menores que sufran castigo físico severo o bien, si existen, en estos casos no se realiza la tramitación directa al hospital, sino que se derivan a las dos vías de entrada citadas. Comparando los Gráficos 6 y 7 deducimos que, de los detectados por el Equipo Social Base, sólo un 15\% de los casos es tramitado por el propio equipo para su posterior estudio y resolución, derivando un $33 \%$ de los casos hacia la Sección de la Consellería relativa al menor.

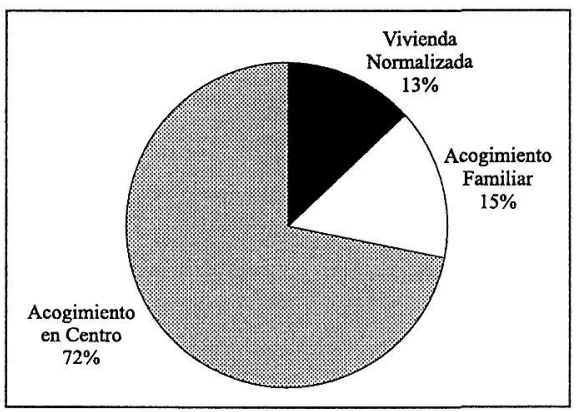

GRÁFICO 8: Tipo de vivienda del menor.

En el Gráfico 8 es fácil observar que la mayoría de los niños, un $72 \%$, están ingresados en Centros de acogimiento, esto indica que, aunque existen más recursos, el tipo de vivienda más utilizada donde se acoge al menor es la de una institución.

En cuanto a datos relativos a su educación, el Gráfico 9 nos indica un hecho importante, que la mayoría de menores, aun presentando problemas, tienen un grado de escolarización medio. La mayor frecuencia, un $63 \%$, corresponde a los que estudian E.G.B./E.S.O./F.P. $\mathrm{y}$, en cuanto al sistema escolar, destaca con un $43 \%$ la normalidad en 


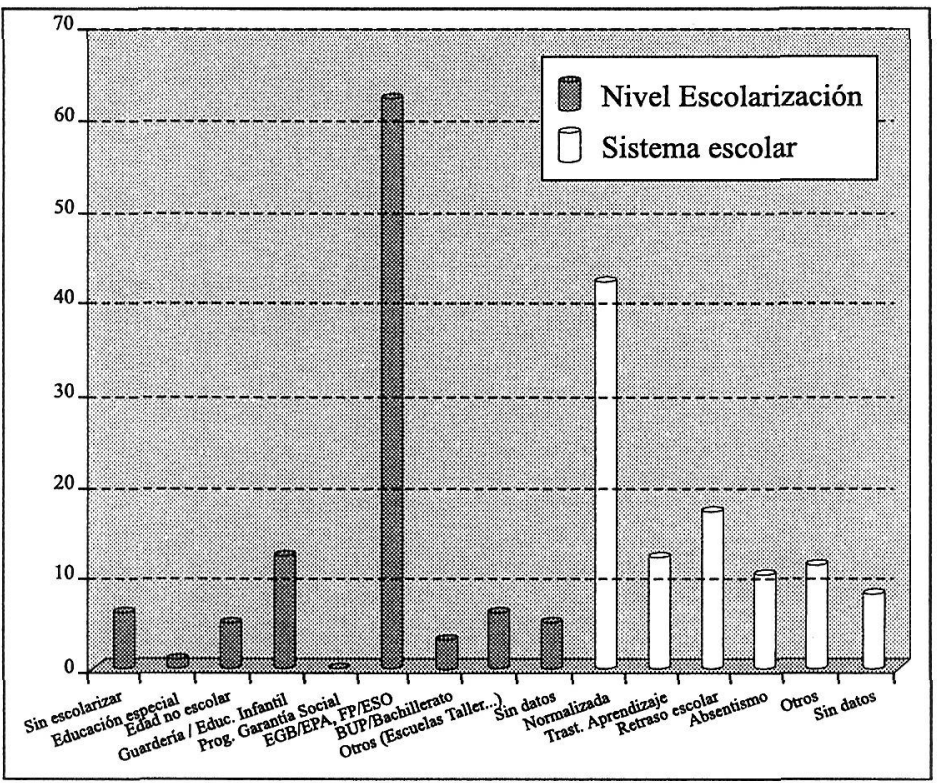

GRÁFICO 9: Datos de Educación.

el sistema escolar, seguido, a gran distancia, por alumnos con retraso escolar manifiesto en un $18 \%$ de casos o transtornos de aprendizaje en un $12 \%$.

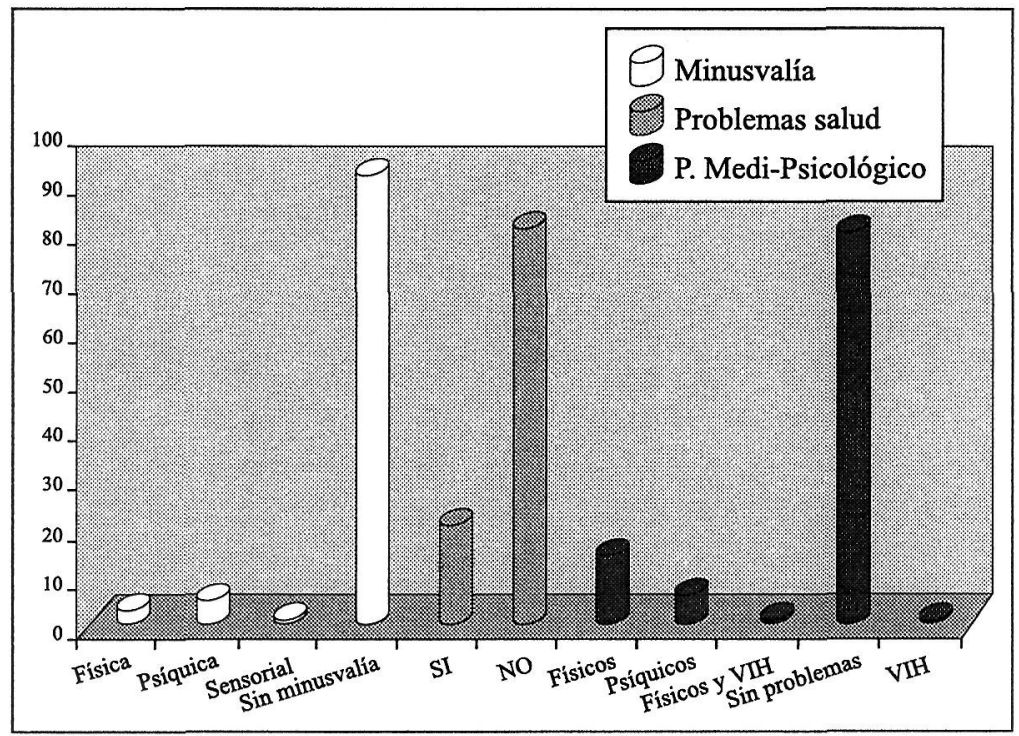

GRÁFICO 10: Problemas de salud de los menores. 
Por último, en el Gráfico 10 observamos que, afortunadamente, los menores no presentan en su mayoría problemas sanitarios, ni problemas de minusvalía, sólo existe un $28 \%$ que presenta problemas de salud, de los cuales el $18 \%$ corresponde a problemas físicos y el resto a problemas psíquicos.

\subsection{Aspectos generales de los padres biológicos.}

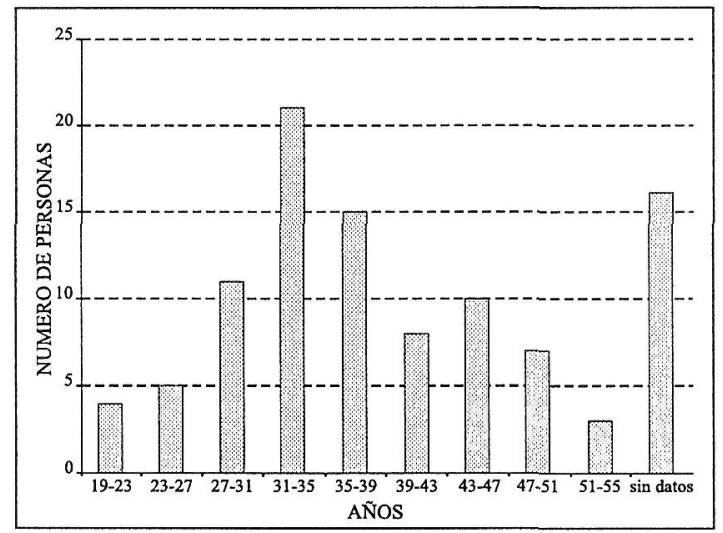

GRÁFICO 11: Edad de la madre biológica.

A partir de la tabla relativa al Gráfico 11, se ha obtenido 36 años como edad media de la madre biológica del menor, siendo el intervalo modal el comprendido entre 31 y 35 años. Análogamente, con la tabla del Gráfico 12, se obtuvo como edad media del padre biológico 43 años. Estos resultados indican que no es la juventud uno de los factores de mayor riesgo que suele aparecer en los padres que maltratan. Es de destacar el elevado porcentaje, un $30 \%$, de los padres de los que no se dispone de datos.

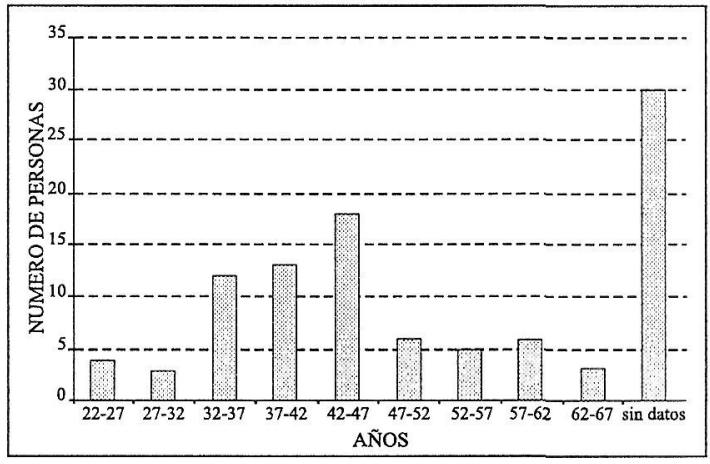

GRÁFICO 12: Edad del padre biológico 


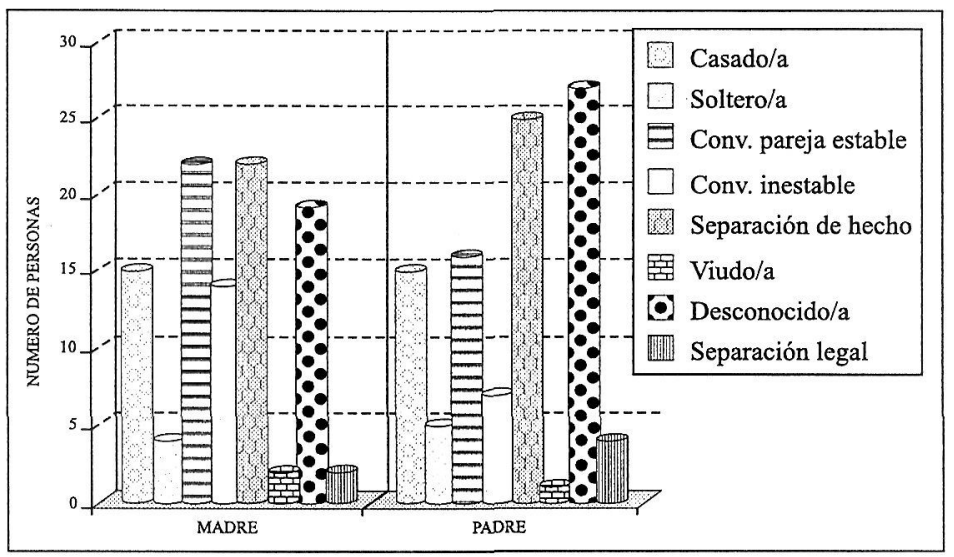

GRÁFICO 13: Estado civil del padre/madre biológicos.

El Gráfico 13 nos muestra que, en el caso concreto de la madre, existe el mismo número con separación de hecho, $22 \%$, que conviviendo con pareja estable. Respecto al padre, hemos encontrado que de un $27 \%$ de ellos se desconoce su estado civil, lo cual puede dar lugar a diferentes interpretaciones: o el padre no es necesariamente quien convive con la madre o éste no mantiene ningún contacto con los responsables de la guarda o custodia del menor. Le sigue en importancia los padres que tienen separación de hecho con un $24 \%$.

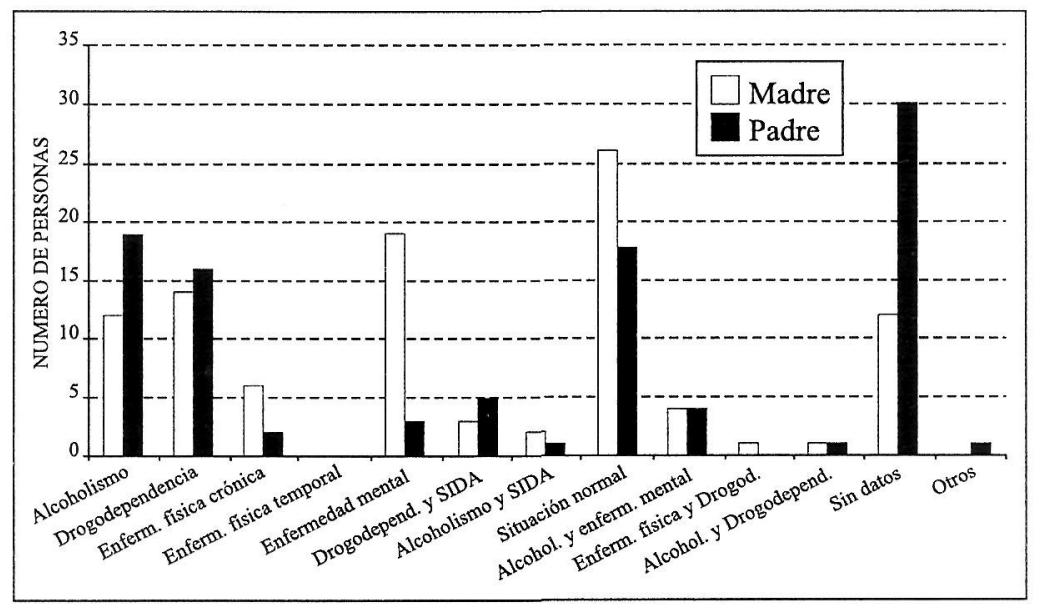

GRÁFICO 14: Situación sanitaria de los padres biológicos.

La situación sanitaria se aborda en el Gráfico 14. Pasamos a destacar la incidencia que pueden tener ciertas situaciones sanitarias en el comportamiento de los padres hacia los menores. 
- En el caso de la madre, existe un $26 \%$ en situación de normalidad, seguida en importancia en un $18 \%$ por las madres que padecen alguna enfermedad mental y alrededor de un $14 \%$ que son drogodependientes, lo cual crea un factor de riesgo añadido en los menores.

- En cuanto al padre, uno de los problemas más repetidos es el alcoholismo, con un $19 \%$, seguido de los drogodependientes en un $16 \%$, existiendo un alto porcentaje de expedientes, el $29 \%$, sin datos en este apartado. El sida no es una situación detectada en los casos estudiados.

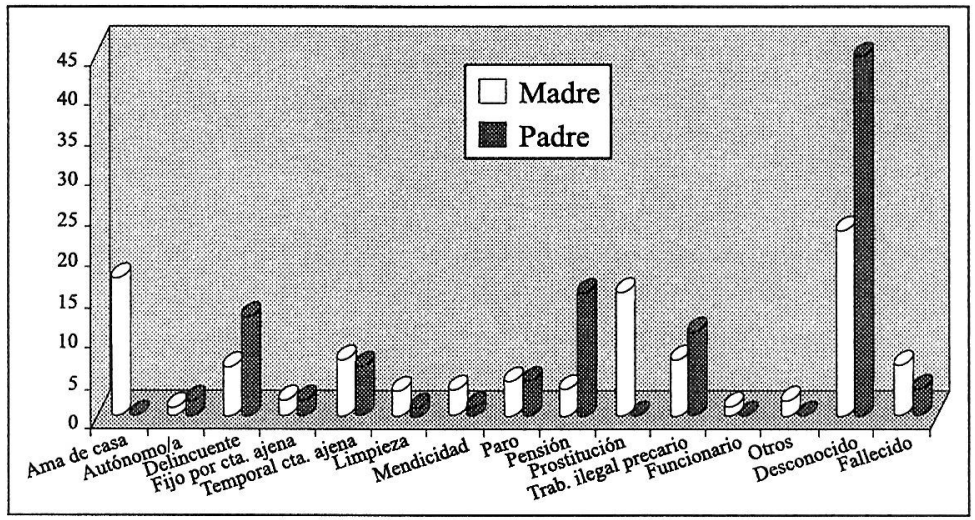

GRÁFICO 15: Situación laboral de los padres biológicos.

Respecto a la situación laboral de los padres biológicos, el dato más significativo, correspondiente al $44 \%$ de los expedientes y que se muestra en el Gráfico 15, es el desconocimiento de la situación laboral del padre, los demás valores nos indican que existe un mayor índice de pensionistas, trabajos ilegales y temporales por cuenta ajena, lo cual induce a pensar que el nivel económico familiar es bastante bajo. En la madre aparece un grupo, $20 \%$, cuya situación es la de ama de casa, en contraposición con las dedicadas a la prostitución que son el $18 \%$ de ellas. En el extremo opuesto encontramos el caso de los padres funcionarios como situación mínima. No existe una gran incidencia de mortalidad en los datos relativos a los padres, un $7 \%$ de las madres ha fallecido frente a un $3 \%$ de los padres del total de la muestra.

En cuanto a la vivienda, los Gráficos 16 y 17 muestran, como dato significativo a tener en cuenta, la normalidad, un $40 \%$ para las madres y un $55 \%$ para los padres, en el tipo de vivienda de los padres biológicos en la Comunidad Valenciana. Los acogimientos en algún centro asistencial, penitenciario o con familiares es mínimo. En el caso del 


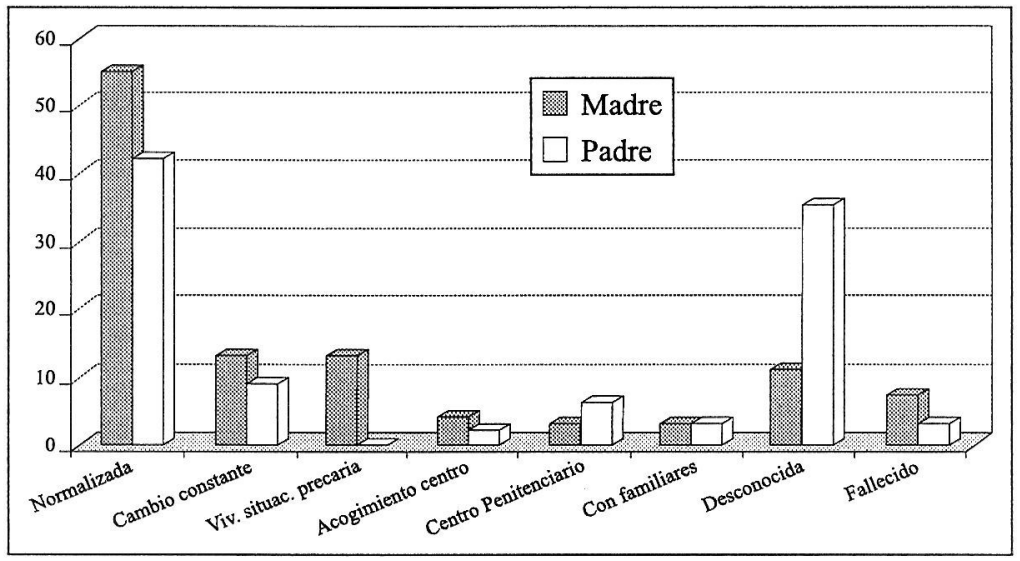

GRÁFICO 16: Tipo de vivienda de los padres biológicos.

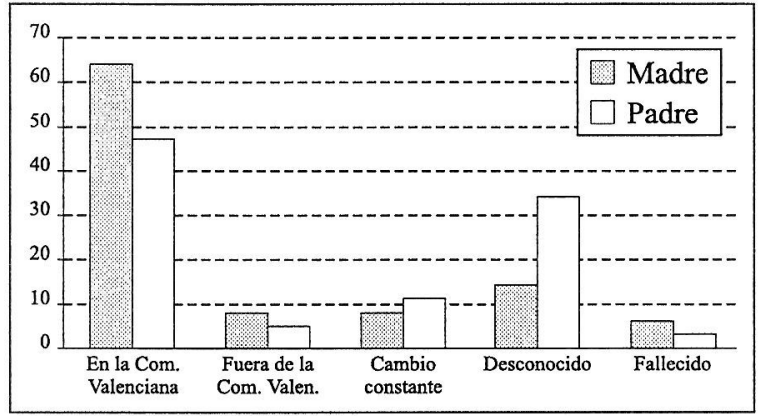

GRÁFICO 17: Domicilio de los padres biológicos.

padre vuelve a ser elevado, un $34 \%$, el porcentaje relativo al desconocimiento del lugar de residencia.

\subsection{Aspectos generales de los malos tratos en los menores.}

Siguiendo con otros aspectos importantes hemos estudiado los tipos de maltrato, la representación gráfica 18 señala este tipo de maltrato o abandono sufrido por los menores en Alicante y provincia, indicando además cuál es la tipología de maltrato más frecuente en los expedientes estudiados.

El gráfico descubre que en un $73 \%$ de los casos se da el abandono físico como causa de maltrato o como motivo de ingreso del menor en el sistema de protección. Este tipo de maltrato se desagrega en distintas situaciones apareciendo éstas de forma aislada o asociadas y con sus correspondientes porcentajes. 


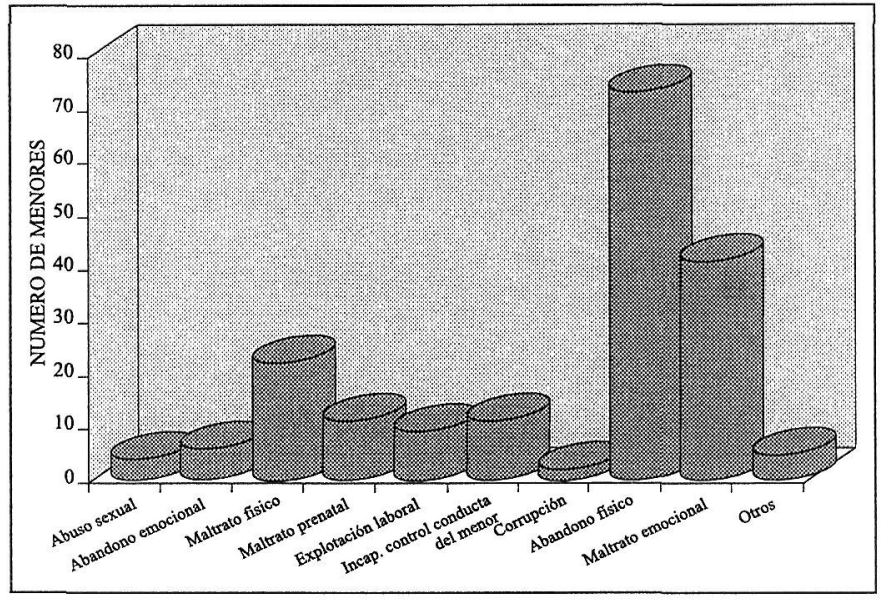

GRÁFICO 18: Comparativa del tipo de maltrato

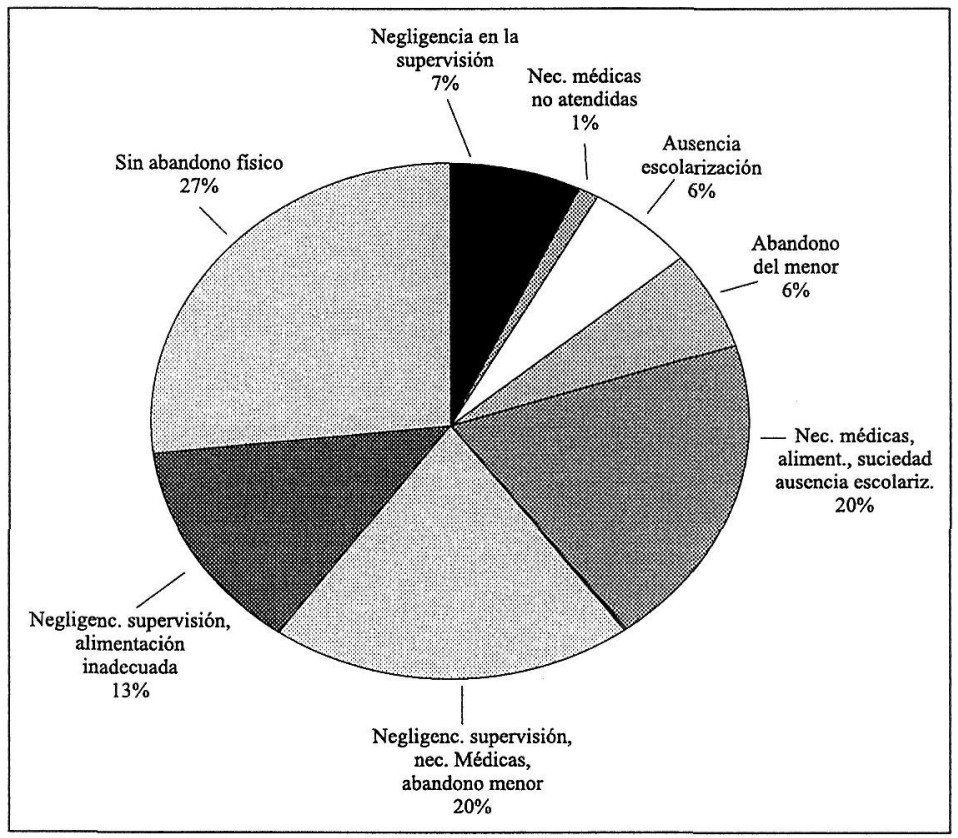

GRÁFICO 19: Abandono físico del menor.

- negligencia en la supervisión, 7\%,

- necesidades médicas - sanitarias no atendidas, $1 \%$,

- escasez o ausencia de escolarización, 6\%,

- abandono del menor en un lugar, 6\%,

- negligencia en la supervisión y alimentación, $13 \%$, 
- negligencia en la supervisión junto con necesidades médicas no atendidas y abandono del menor, 20\%,

- necesidades médicas no atendidas, alimentación inadecuada, suciedad muy llamativa y ausencia de escolarización, $20 \%$.

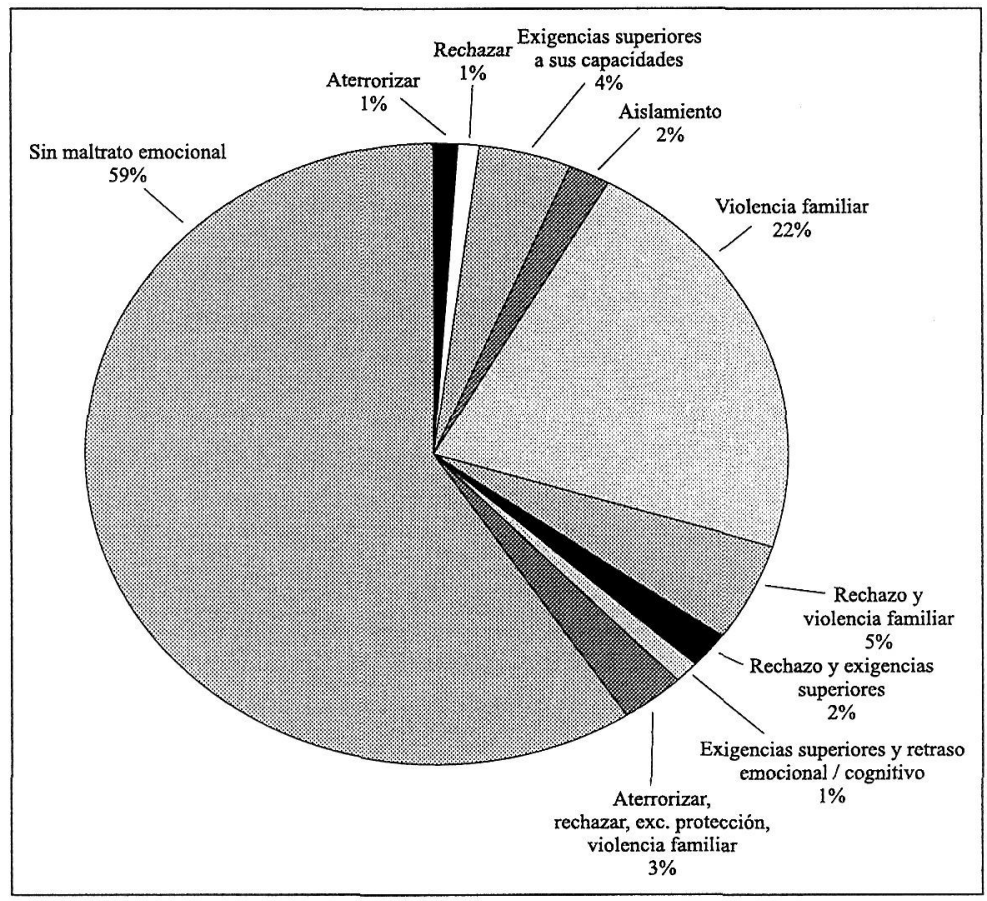

GRÁFICO 20: Maltrato emocional del menor.

Como segundo tipo del maltrato se refleja el emocional con un $41 \%$, que contempla las siguientes situaciones y porcentajes

- aterrorizar con un castigo extremo que le generará un miedo intenso, $1 \%$,

- rechazarlo, ridiculizarlo o insultarlo, $1 \%$,

- exigencias superiores a su capacidad, $4 \%$,

- aislamiento (privación de relaciones sociales), $2 \%$,

- violencia familiar, $22 \%$,

- rechazo y violencia familiar, $5 \%$,

- rechazo y exigencias superiores a su capacidad, $2 \%$,

- exigencias superiores a su capacidad con retraso en su desarrollo emocional y cognitivo, $1 \%$,

- aterrorizar, rechazar, excesiva protección junto con violencia familiar, $3 \%$. 
Al comprobar que los tipos de maltrato más comunes entre los menores eran el abandono físico y el maltrato emocional, se aplicó un test estadístico que permitiera analizar la independencia o relación entre estos dos caracteres. Concluimos, a un nivel del $5 \%$, que no se puede aceptar la hipótesis de Independencia, o lo que es lo mismo, que los menores que sufren abandono físico no tienen porqué recibir necesariamente un maltrato emocional.

\section{IV.CONCLUSIONES.}

A través de los resultados obtenidos en este estudio estamos en disposición de conocer más de cerca la problemática que afecta a los menores que sufren cualquier tipo de maltrato o abandono en nuestra provincia.

A primera vista, se puede decir que efectivamente influyen los diferentes factores de riesgo en la conducta de los padres maltratadores, ya que se han detectado como situaciones de riesgo las derivadas de enfermedades (alcoholismo, enfermedad mental, drogodependencias) o situaciones de bajo nivel económico, con trabajo precario o ilegal, así como problemas estructurales en la familia biológica.

En los datos referidos a los menores observamos que el sexo no es determinante en estas situaciones. Del estudio de los expedientes, se deduce que un $32 \%$ de niños tiene edades comprendidas entre 15 y 18 años, estando 10 de ellos sujetos a medidas de protección antes de 1990. En el otro extremo de la distribución por edades están los menores de 3 años, un $10 \%$ del total, a los que se les ha abierto expediente en el año 96 . En cuanto al número de hermanos, existe un $39 \%$ con familia numerosa, siendo un hermano el hecho más común para un $26 \%$ de ellos. Si bien un $60 \%$ de los menores no tiene ningún hermano atendido a través del sistema de protección, un $3 \%$ de ellos tiene más de cinco hermanos en esta situación.

No existe una gran incidencia de problemas sanitarios que les afectan, y en lo concerniente al sistema educativo están casi la mitad de ellos integrados con normalidad, aunque en un $28 \%$ existen transtornos de aprendizaje o retraso escolar. El mayor número de situaciones de maltrato o abandono son detectadas por el Equipo Social de Base $(48 \%)$, residiendo en un centro un amplio espectro de la muestra (el $72 \%$ en centros de acogida, el $15 \%$ en régimen de acogimiento familiar y el $13 \%$ con su familia de origen).

Pasando a analizar los tipos de maltrato más frecuentes, en los menores de nuestra provincia, podemos resumir que, aunque existe maltrato físico en un $28 \%$, lo que más se detecta es el abandono físico 
en un $73 \%$ de casos. Coincidimos con los estudios hechos con anterioridad, por autores ya citados, en el hecho de que el maltrato emocional, enmarcado tanto por las muestras de hostilidad verbal crónica, en forma de insulto, burla, desprecio, crítica o amenaza de abandono y/o constante bloqueo de las iniciativas infantiles, como por el vacio emocional creado por una persistente falta de respuestas paternas a las demandas de afecto y proximidad hechas por el menor, se observa, en un $41 \%$ de los casos, como el segundo en importancia. Esto último puede significar que se empieza a tener cierto control sobre el problema, existiendo, sin embargo, dificultad en su detección, posiblemente debido a las carencias de medios y recursos, tanto materiales como humanos disponibles en materia de prevención.

En cuanto a la aplicación de estos recursos, se debería estudiar si la Institucionalización del menor maltratado es la medida adecuada o si se debe potenciar otros recursos: acogimiento familiar o permanencia en su familia de origen en los casos que sea posible. En este aspecto, otros estudios ${ }^{5}$ concluyen que, en los programas incluidos dentro del Plan Integral de Protección de Menores de la Xunta de Galicia, es bastante significativo ver como medidas destinadas a potenciar un ambiente familiar normalizado, promoviendo la acción social a través de servicios que procuren que el menor permanezca en su ambiente familiar y comunitario, proporcionando las ayudas correspondientes, tienen un presupuesto netamente inferior a las que pretenden institucionalizar al menor.

Por lo tanto, y en resumen, es necesario potenciar la información y prevención dirigida a las familias afectadas por los problemas citados, además de las que presenten algunos de los factores de riesgo descritos. A su vez, es necesario una actuación inmediata e individualizada del menor, desarrollada por un equipo multidisciplinar, capaz de aplicar el recurso más adecuado a la problemática de cada uno de ellos y del modo más objetivo.

Y por último, creemos que es necesario promover el acogimiento bien dentro de la familia extensa del menor o en otra familia, pero siempre de la forma más normalizada posible, para lograr así una mejor adaptación del menor a su propio medio. 



\section{EL MALTRATO PSICOLÓGICO / EMOCIONAL COMO EXPRESIÓN DE VIOLENCIA HACIA LA INFANCIA}

\section{AGUSTÍN BUENO BUENO}

Profesor de Psicología Social de la Universidad de Alicante.

\section{RESUMEN}

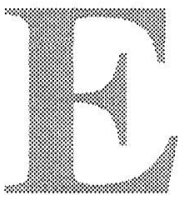

1 presente trabajo se centra en el concepto de maltrato emocional, o psicológico, en contraste con los otros tipos de maltrato a la infancia. Propone una clasificación dentro del maltrato emocional y analiza las distintas categorías propuestas.

\section{PALABRAS CLAVE:}

Maltrato, maltrato emocional, infancia, familia, intervención social.

\section{INTRODUCCIÓN}

El maltrato, sea del aspecto que sea, físico o psicológico, personal, familiar o institucional, paterno-filial, de pareja o senil, es una forma negativa y agresiva de relación personal violenta, que tiene una honda repercusión en el desarrollo psicológico. Si cabe, esta afirmación inicial es aún más taxativa durante todo el periodo de infancia y adolescencia.

Pero esta afirmación inicial sobre la trascendencia del maltrato en la infancia puede quedar oscurecida por las dificultades para determinar qué se entiende por maltrato y las posibles manifestaciones del mismo. Es comúnmente aceptado que "existe una cierta dificultad para aproximarse al concepto de maltrato infantil de una manera objetiva y analítica" (San Juan, C. y De Paúl, J., 1996). Ocurre algo semejante al concepto de agresión en la literatura psicológica más sólida, que hace falta introducir los matices de intencionalidad o de calificación social para que un mismo acto pase de ser una agresión a ser una acción benéfica (Bandura, 1973). Determinadas actuaciones educativas, o correctivas, encuentran en esta ambivalencia su clave de discusión. 
Inicialmente, el maltrato infantil estuvo totalmente identificado con el maltrato físico. R.S. Kempe y C.H. Kempe (1979), en su obra emblemática sobre el maltrato infantil, afirman: "el maltrato infantil supone la existencia de un niño golpeado", aunque, luego, al hacer el análisis central del problena considera, efectivamente, entre las conductas de maltrato, la violencia física, el abandono físico o negligencia, el maltrato emocional y los malos tratos sexuales. Idéntica clasificación hacen E. Gracia y G. Musitu (1994). Por su parte, C. Moya (1993), en un tratamiento del tema desde los mismos servicios de protección a la infancia, desdobla el abandono en físico y emocional, sin ampliar éste al nivel de maltrato. Para finalizar este breve recorrido conceptual por el maltrato, es inevitable referirnos a la obra de A. Martínez y J. De Paúl (1993), que hace una primera distinción entre maltrato intra y extrafamiliar y abre la tipología del maltrato intrafamiliar a las siguientes categorías: maltrato físico, maltrato por negligencia, abandono (como grado extremo de la negligencia), maltrato o abuso emocional, abuso sexual, maltrato prenatal y síndrome de Münchhausen por poderes. Es la variante mayor de todas las clasificaciones encontradas, si bien podríamos decir que las diferencias entre algunas categorías son más funcionales que conceptuales y no todas excluyentes entre sí.

Continuando con esta matización de conceptos y entrando en lo específico de nuestro tema, encontramos el término maltrato psicológico, acuñado en contraposición al de maltrato físico, como una denominación muy poco feliz. En primer lugar, porque la contraposición entre maltrato físico y psicológico es una contraposición sólo aparente, pero que además acarrea graves consecuencias tanto en investigación, como en intervención y quizás también en legislación.

Es fácil considerar que se puede dar maltrato psicológico sin que haya maltrato físico, pero no es tan sencillo separarlos a la inversa: cuando hay maltrato físico se puede afirmar que casi siempre hay daño psicológico. Esta superposición con frecuencia enturbia los estudios sobre prevalencia, etiología y consecuencias del maltrato. Esta realidad queda claramente reflejada en los resultados del análisis discriminante de E. Gracia y G. Musitu (1994): "La categoría Negligencia queda relativamente bien definida a partir de las variables anteriores, con un $82,35 \%$ de los casos correctamente clasificados por la función discriminante. Sin embargo, y por otra parte, la función discriminante no permite distinguir con la misma precisión los grupos de Maltrato Físico y Emocional, (...)" (p. 63). Igualmente, confunde o disminuye el alcance de los programas de prevención e intervención.

Parece, pues, más acertado hablar de maltrato emocional. Esta denominación evita la contraposición terminológica y a través de ella la 
conceptual. Además, así se facilita la consideración conjunta del problema del maltrato, su diagnóstico psicológico y las estrategias de intervención, sin que induzca a pensar que son fenómenos autoexcluyentes.

\section{II. ¿QUÉ SE ENTIENDE POR MALTRATO EMOCIONAL?}

Kempe y Kempe (1979) indican a este respecto "que son actos nocivos, sobre todo verbales, diciéndole constantemente al niño que es odioso, feo, antipático, estúpido, o se le hace ver que es una carga indeseable. Puede incluso no llamársele por su nombre, sino que se le trata simplemente como 'tú', o 'idiota' o de otro modo insultante (...)" (p. 36). Se trata de una descripción muy concreta de lo que pueden ser algunas conductas expresivas del rechazo emocional, pero, a poco que reflexiones sobre realidades y vivencias, el fenómeno del maltrato emocional puede ser mucho más amplio. Ya estos autores apuntaban que los malos tratos emocionales desempeñan un cierto papel en todos los abusos y negligencias físicas y su presencia en casi todos los casos que observamos resulta muy evidente.

Una concepción más elaborada, dentro de la gran dificultad que representa cualquier fenómeno emocional, la encontramos en M.I. Arruabarrena y J. De Paúl (1994) que consideran el maltrato emocional como "la hostilidad verbal crónica en forma de insulto, desprecio, crítica o amenaza de abandono, y constante bloqueo de las iniciativas de interacción infantiles (desde la evitación hasta el encierro o confinamiento) por parte de cualquier miembro adulto del grupo familiar" (p. 31). Como complemento, definen el abandono emocional como "la falta persistente de respuesta a las señales (llanto, sonrisa), expresiones emocionales y conductas procuradoras de proximidad e interacción iniciadas por el niño y la falta de iniciativa de interacción y contacto, por parte de una figura adulta estable". Podemos decir que son las dos vertientes activa y pasiva de una relación emocional negativa.

Pero lo que no resulta tan claro es que la actividad emocional de signo negativo (maltrato emocional) sea exclusivamente de carácter verbal. La forma de vestir a un niño, la forma de reprenderle o castigarle, las actividades que se le obliga o induce a hacer, etc., pueden tener un marcado signo de rechazo emocional.

J. Garbarino (1986) matizaba el concepto de maltrato emocional en cuatro subgrupos: rechazo, aterrorizar, aislamiento e ignorar. Pero exigiendo para que se pueda hablar de maltrato emocional en esos cuatro supuestos, el que se den con persistencia y continuidad y el que sean acciones claramente perceptibles. 
Todavía no llegan los cuatro subtipos de Garbarino a cubrir toda la gama de conductas posibles productoras de maltrato emocional, y quizás sea un objetivo inalcanzable e incluso no deseable el pretender matizar con detalle las formas concretas de maltrato emocional. J. Giovannoni (1991), tras constatar la pluralidad de fenómenos que se engloban en el maltrato psicológico intrafamiliar, defiende distintas clasificaciones según que se esté pensando en objetivos de diagnóstico, de intervención o de diseños de política social. En este último extremo, Giovannoni constata la dificultad de actuación por la intromisión y cruce de poderes que supone el marcar unas determinadas pautas educativas, que en realidad es donde aparecen los episodios de maltrato psicológico o emocional.

En nuestro caso, hablamos de maltrato emocional refiriéndonos a aquellas conductas dirigidas intencionalmente por un adulto hacia un niño, que producen en él daño interno a través de sentimientos negativos (desvalorización, desestima) hacia su propia persona sin justificación ni necesidad.

Supuesto esto y puesto a discusión, vamos a constatar dos elementos característicos del maltrato emocional, aunque no del todo ajenos también al maltrato físico.

El impacto emocional de la conducta de una persona sobre otra es muy relativo. Va a depender, sobre todo, de la forma en que esa conducta sea percibida por el niño, por el receptor.

Podemos decir que el impacto emocional es cognitivo y, por lo tanto, no tiene valor universal ni constante. Es susceptible de interpretaciones diversas como cualquier conducta verbal en función del tono, de matices y contexto de la frase; o como una conducta no-verbal en términos de captación del significado y alcance de los gestos.

$\mathrm{Al}$ mismo tiempo, el impacto emocional de una conducta adulta en un niño adquiere valoración negativa en función de los términos de comparación de conductas que utilice el sujeto.

Los términos de comparación a utilizar por el sujeto pueden ser de dos clases:

- Las conductas habituales de trato a los otros niños en ese mismo medio social y cultural.

- Las conductas habituales de trato a ese niño por otras personas.

Esta relatividad de la interpretación de las conductas es lo que hace especialmente difícil la intervención y prevención en los casos de impacto emocional negativo.

Puede decirse que esta dificultad es también inherente a los malos tratos físicos, pero su alcance es sensiblemente menor. Podemos encontrar niños para los cuales el acostarse sin cenar, o el recibir una 
paliza de su padre, no sea vivido como maltrato, y, en cambio, acuse de ofensor al profesor que le ha dado un empujón al entrar a clase ("porque a mí sólo me pega mi padre"). Esta vivencia es absolutamente real y no algo anecdótico y extraño. Pero si se quieren investigar las palizas, o la desnutrición, hay mejores vías que éstas para clarificar el desprecio íntimo que supone decirle a un niño sucio, o sentarle a él sólo en una esquina de la clase, o mandarle fregar el suelo que ha ensuciado.

La dificultad para objetivar el impacto emocional se hace mayor cuando se refiere a conductas que representan formas culturales establecidas y aceptadas. En la sociedad occidental, el niño está adquiriendo cotas de respeto y dignidad perfectamente justificadas pero impensables todavía para otras culturas. Por ello, no debe extrañarnos que los/as niños/as procedentes de esas culturas, y recién insertados aquí, no vivan como daño emocional lo que para nosotros sí lo es.

Esto, evidentemente, debe cuestionarnos nuestros modelos de intervención en casos procedentes de otras culturas. No hay que ignorar el problema, pero tampoco hay que creárselo a ellos de manera forzada. Los procesos paulatinos de inmersión cultural -sin perder su origen- es lo que hará cambiar el concepto de normalidad y el de daño. Cuando esta concienciación vaya apareciendo es cuando el profesional puede actuar de manera directa.

Otra situación completamente distinta es la que se da en el maltrato emocional vivido por un niño respecto de su profesor o respecto de un familiar, porque su/s vínculo/s afectivo/s anterior/es le han tratado con tal miramiento que es incapaz de soportar una broma o un reproche, o una conducta del adulto entre el desprecio y el reproche. En estos casos podemos hablar de daño emocional pero no de maltrato.

Como ocurre en el daño físico, si un alimento es dañino para un niño, y el responsable del comedor no lo sabe, lo que le ocurra al niño al tomarlo será un daño físico, pero el responsable del comedor no ha sido un maltratador. Situaciones equivalentes hay muchas, que calificamos por lo general como desgracias o hipersensibilidad del niño/a.

A la inversa también es analizable la relatividad del maltrato emocional, así como la del físico, aunque éste en menor grado. Un niño muy acostumbrado a los malos tratos, procedentes, física o emocionalmente, de las figuras iniciales de apego, puede demandar un trato agresivo o humillante como forma satisfactoria para él de relacionarse con otros adultos. Lógicamente, estamos ante casos de contenido patológico importante en el desarrollo de esa persona.

No obstante, la actuación aquí es menos compleja de analizar. Salvo que el nuevo adulto tenga una patología complementaria o una 
ignorancia acusada, no tiene sentido entrar en el juego relacional de ese niño. Un trato positivo continuado será el mejor antídoto y el mejor acompañante de cualquier proceso terapéutico.

\section{III.CLASIFICACIÓN DEL MALTRATO EMOCIONAL}

Ya hemos visto en el apartado anterior las clasificaciones de Arrubarrena y De Paúl (1994), así como los subtipos de Garbarino (1986), ahora vamos a representar inicialmente en esquema los distintos tipos de maltrato emocional que, a nuestro juicio, se pueden dar en la relación adultos-niños. El hilo conductor nos lo facilita el maltrato físico por la sencilla razón de que es difícil pensar en un auténtico y claro maltrato de tipo físico que no lleve emparejado un maltrato emocional.

Con frecuencia, la acción violenta que produce el daño físico es la misma que produce el impacto emocional. Diríamos que en muchas ocasiones hay daño emocional en un niño porque ha habido violencia física, aunque no haya mediado palabra ultrajante, ni despreciativa. Por ejemplo, una simple y seca bofetada de un adulto, sin más comentarios ni gestos, pero dada a un/a adolescente en presencia de amigos y amigas será considerada por él más como dolor emocional que como daño físico.

Por otra parte, es incuestionable el hecho de que pueden haber sentimientos de rechazo, hastío, burla, desprecio, etc., hacia el menor, que se expresen de manera exclusiva con palabras o gestos no-verbales, pero sin violencia física de ningún tipo. Incluso este tipo de maltrato exclusivamente emocional puede ser el más frecuente en niveles socioculturales medios y medios altos, donde el empleo de la fuerza física como instrumento disciplinar no es tan frecuente, como no lo es tampoco como medio de vida.

El otro criterio de clasificación es la frecuencia con la que ocurre el maltrato emocional. Podemos encontrarnos con acciones desvalorizantes del adulto hacia el menor que constituyen el tono habitual de la convivencia entre ambos, son como el estilo de vida de esa familia o de esa relación institucional. En cambio, puede haber comportamientos puntuales del adulto muy cargados de daño emocional, pero diluidos entre otros de carácter neutro e incluso muy positivos. El impacto emocional resultante puede ser de cualquier signo, y sería inútil pretender fórmulas combinatorias. Lo que sí es sabido es que la ambivalencia emocional de un persona adulta, y sobre todo referida a una faceta concreta de la conducta del niño, puede tener repercusio- 
nes negativas para el desarrollo del autoconcepto infantil y de sus aptitudes.

\begin{tabular}{|l|l|}
\hline \multirow{2}{*}{$\begin{array}{l}\text { MALTRATO EMOCIONAL } \\
\text { PARALELO ABANDONO O }\end{array}$} & $\begin{array}{l}\text { A) De carácter general } \\
\text { No están cubiertas sus necesidades básicas, ni } \\
\text { las físicas ni las afectivas: abandonos, desam- } \\
\text { paros, desidia alimenticia, (...), la agresión fí- } \\
\text { sica es forma habitual de relación. }\end{array}$ \\
\cline { 2 - 2 } & $\begin{array}{l}\text { B) De carácter concreto } \\
\text { Hay agresión física: palizas, heridas, etc., pero } \\
\text { unidas a insultos, desprecios, humillaciones, } \\
\text { (...), y ocurridas de manera puntual, aunque con } \\
\text { mayor o menor frecuencia. }\end{array}$ \\
\hline \multirow{3}{*}{$\begin{array}{l}\text { MALTRATO EMOCIONAL } \\
\text { ABANDONO NI } \\
\text { MALTRATO FÍSICO }\end{array}$} & $\begin{array}{l}\text { C) De carácter general. } \\
\text { Forma habitual de vida en la cual no hay agre- } \\
\text { sión física ni carencias básicas, pero hay trato } \\
\text { de inferioridad para el o los maltratados: en } \\
\text { comidas, vestuario, tareas, insultos, (...) (sín- } \\
\text { drome de la Cenicienta). }\end{array}$ \\
\cline { 2 - 3 } & $\begin{array}{l}\text { D) De carácter específico } \\
\text { Aparecen actuaciones determinadas en una si- } \\
\text { tuación concreta: humillaciones, vejaciones, } \\
\text { desprecios, o insultos, (...), pero esporádicos. }\end{array}$ \\
\hline
\end{tabular}

TIPOS DE MALTRATO EMOCIONAL

Se podrían introducir otros criterios clasificatorios del maltrato emocional infantil, tales como distinguir los posibles agentes dentro del ámbito familiar (padre, padrastro, madre, madrastra, hermano, etc.), del ámbito institucional más cercano al menor (profesores, educadores u otros profesionales) e incluso de las grandes instituciones (judicatura, administración local, autonómica,...)'.

Dentro del contexto familiar podríamos distinguir aún el maltrato físico y/o emocional como exclusivo hacia uno de los miembros -es lo que hemos llamado síndrome de la Cenicienta - frente al maltrato físico y/o emocional hacia el conjunto del grupo familiar, como característica del clima de familia.

1 Puede ser interesante apuntar aquí el contrasentido en el que se cae al hacer coincidir el defensor o comisionado del menor en una persona de la administración que, a su vez, puede ser la responsable directa o indirecta de situaciones de maltrato. 


\section{IV.ANÁLISIS DE LOS TIPOS DE MALTRATO EMOCIONAL}

De cada uno de los cuatro tipo de maltrato emocional que hemos señalado antes en el esquema, podemos hacer un pequeño desglose.

En primer lugar, el maltrato emocional de tipo A es el que con más facilidad salta a la vista. Se localiza en las zonas más deterioradas de las poblaciones, en condiciones de vida y vivienda por lo general muy bajas. Suelen ser casos conocidos suficientemente por los vecinos y por los técnicos de la intervención social. Es frecuente que sea toda la familia la que viva en tales condiciones, afectando especialmente al grupo infantil; pero puede darse sólo en alguno o algunos de los miembros $^{2}$. Es fácilmente denunciable por ir unido al maltrato físico, y su comprobación resulta así más objetiva.

Otra cosa es que el niño/a no sea consciente de ese maltrato porque no conoce otra forma de vivir. Si pervive en ese ambiente lo lógico es que lo acabe interiorizando como una forma normal de relacionarse y que más adelante lo reproduzca en sus etapas juvenil y adulta.

Sólo en la medida en que esos menores conozcan a fondo otra forma de vivir, y la conozcan antes de que el deterioro ambiental haya cristalizado como deterioro personal, podrán entrar en crisis por comparación de ambientes y estilos de vida, y podrán generar -con ayuda- mecanismos de cambio.

El tipo B de maltrato emocional que hemos señalado se caracteriza, además de por su vinculación con el maltrato físico y por el hecho de que no es la forma habitual de vida, por el hecho de que ambos se pueden reforzar recíprocamente. El daño emocional incrementa el dolor físico y ciertos daños físicos acentúan el sufrimiento interior de la persona.

Según el tipo de violencia física que se produzca, la humillación puede ser mayor. Tal es el caso de la agresión sexual, o el obligar a comer sobras o alimentos en relativas malas condiciones. En cambio, hacer dormir a un niño en el suelo puede ser tomado por el niño como poco amenazante.

Por el contrario, un castigo físico liviano, como puede ser una bofetada sin más añadidos, puede adquirir un significado de gran gravedad para el niño/a si se la ha propinado en presencia de colegas o rivales. Igualmente, unos azotes en las nalgas, poco dolorosos físicamente, pueden suponer un gran dolor emocional si se le dan haciéndole desnudar esas partes previamente. 
En estos episodios de maltrato físico y emocional conjunto pero circunstancial, es cuando se pueden producir las consecuencias imprevisibles más graves. Es fácil que haya una pérdida de control en el agresor, y que se vaya produciendo in crescendo la violencia hasta llegar a límites lamentables.

Es en este tipo de casos donde con más frecuencia se buscan desencadenantes causales de la violencia. Puede ser que se atribuya a una conducta inicial del niño: obstinada, insolente, absurda, etc., que resulta insoportable y provoca las iras del adulto. Una vez que el adulto airado inicia la reacción de agresión, ambas conductas (la del niño y la del adulto) se potencian circularmente: -llanto infantil-ira del adulto-llanto obstinado del niño-reacción agresiva del adulto-incremento de la obstinación infantil-incremento de la agresión adulta - ...

Cuando la atribución de causalidad se hace sobre el adulto, su descontrol suele explicarse, en primer lugar, por el consumo de alcohol o de drogas de otro tipo, que le han llevado a una baja resistencia a la frustración y a una desinhibición de los impulsos agresivos.

En los casos -no tan infrecuentes- en los que no se puede aducir el consumo de drogas por el adulto, se explica la agresión por el elevado grado de estrés y cansancio acumulado que ha convertido en insoportables las reacciones del niño/a. Esta explicación es la más frecuente cuando la agresión procede de la madre biológica del menor maltratado.

Por último, dentro de este apartado, se podría incluir, aunque salvando las distancias, lo que podríamos denominar malos tratos rituales. Son esos casos en los que se realizan daños físicos, lesiones graves y aún la muerte, unido a vejaciones, llevado el adulto/s de un rechazo emocional previo y global hacia el menor: la posesión diabólica o algún otro tipo de maleficio. Diríamos que aquí el maltrato emocional precede al físico, además de acompañarle, y está implícito en el diagnóstico previo que el adulto hace de la conducta del niño.

El maltrato emocional de tipo $\mathrm{C}$ puede ser generalizado hacia todo el grupo familiar o escolar o institucional, pero no es lo más frecuente. Cuando se da tal situación estamos o ante un planteamiento educativo absolutamente negativista o bien estamos ante una persona de autoridad totalmente engreída o amargada. No descartamos tales situaciones, pero el prototipo del modelo $\mathrm{C}$ es el menor -hijo/a, alumno/a, etc.- no querido, no deseado, rechazado, por las razones que sea, dentro del contexto al que nos referimos.

Se trata de un maltrato que, sin grandes estridencias externas, y por ello a veces ignorado por las figuras de autoridad superior, afecta 
de manera más honda al individuo y puede producirle a largo plazo un fuerte daño psicológico.

Este tipo $\mathrm{C}$ significa que, dentro del grupo familiar o del grupo escolar o institucional, este menor es considerado de inferior categoría y tratado como tal por la/s figura/s de mayor autoridad, sin que encuentre un contrapeso suficiente en el grupo para significarse de manera positiva.

Si nos centramos en el grupo familiar hay que presuponer que en esta situación, si hay pareja, los dos miembros desprecian al menor, o bien que uno desprecia y el otro consiente. Por eso lo hemos caracterizado como sindrome Cenicienta. Es frecuente que el menor con este tipo de maltrato sea hijo/a de una pareja estable anterior de la madre, o hijo de madre soltera inicialmente aceptado por su actual pareja. La madre en esta situación no se atreve a frenar a su compañero actual por miedo a perder cualquier beneficio percibido por ella. Hasta hace unos años, en nuestro país, y aún ocurre en países latinoamericanos, estos niños van, inicialmente y por bien de paz doméstica, a un centro de menores, y acaban siendo abandonados allí por pérdida de contactos.

Mirando a la intervención en este tipo de casos, es sin duda la terapia familiar la opción indicada, en ventaja frente a cualquier otro tratamiento de carácter individual.

El maltrato emocional de tipo D, que, como el anterior, ya dijimos que son los más frecuentes en personas de clase media y por tanto los más frecuentes, acentúa aún más su incidencia por la sencilla razón de que no se trata de una conducta extrema ni continua. El hecho de que no se trate de una conducta continuada no quiere decir que sea algo aislado, más bien diríamos que nos referimos a un goteo despreciativo discontinuo pero alargado durante gran parte de la infancia y adolescencia.

La puerta de acceso al conocimiento de este tipo de problemas difícilmente será antes de la adolescencia si se trata del ámbito familiar, y se producirá a través de la manifestación directa del propio menor a una persona de confianza (familiar, profesional o amiga) en un momento de crisis.

El alcance de este maltrato emocional puede variar en función no sólo de la frecuencia de los episodios, sino también según el número y cualidad de los adultos maltratantes y de las facetas respecto a de las que se de el maltrato. No va a ser lo mismo que padre y madre adopten de vez en cuando este tipo de conductas, o que lo haga sólo uno de ellos mientras el otro/a contrarresta con valoraciones positivas o mientras el otro/a permanece indiferente. 
Va a ser difícil en estos casos hacer un diagnóstico preciso del maltrato emocional como algo global. Más bien va a ser interesante y útil hacer un estudio del autoconcepto del menor y de las imágenes que guarda de los adultos referenciales.

Antes de finalizar este epígrafe hay que señalar la proximidad que hay entre este maltrato emocional de tipo D y el chantaje afectivo: si haces lo que yo quiero eres bueno y te valoro; si haces lo que no quiero, eres malo y te desprecio.

\section{CONSECUENCIAS PSICOLÓGICAS DEL MALTRATO EMOCIONAL}

Las consecuencias psicológicas de cualquier proceso o hecho traumático son polimórficas y difíciles de precisar. La dificultades principales radican, en primer lugar, porque un mismo síntoma puede responder a varias causas o determinantes, los cuales con frecuencia se entrecruzan en la vida de las personas; $y$, en segundo lugar, la dificultad aumenta porque algunas consecuencias no aparecen hasta después de muchos años, en concreto, cuando el menor ha alcanzado una edad en la cual los aprendizajes vicarios interiorizados facilitan la inversión de los papeles del maltrato.

Los estudios sobre repercusiones del maltrato están referidos exclusivamente al maltrato físico, entre otras razones por la dificultad que hemos apuntado al principio de aislar lo físico de lo psicológico o emocional. Por esta misma razón, la mayor parte de las repercusiones que se constatan en el maltrato físico son aplicables al emocional, quizás con la excepción de la violencia física, pero aún esto habría que comprobarlo de manera más precisa.

A este respecto, Kempe y Kempe (1979), que siguen siendo la referencia más directa en este punto, indican las siguientes alteraciones sintomáticas del maltrato en general:

- Sumisos y ansiosos de agradar ante desconocidos (médicos, ATS, Trabajadores Sociales).

- Síntoma de demonio: negativistas, agresivos y con frecuencia hiperactivos.

- En ocasiones, mezcla de los dos grupos anteriores.

- Dificultad para reconocer sus propios sentimientos y para hablar de los mismos: inclinaciones, simpatías, su soledad, su angustia, sus gustos. No se permiten bromas, alegrías,...

- Tienen una deficitaria imagen de sí mismos, como consecuencia de lo anterior. 
- Comportamiento autopunitivo, relacionado con la deficiente imagen de sí mismos. No se permiten la diversión.

Centrándonos en la repercusión primaria, la que se puede apreciar en los mismos años de infancia y adolescencia, podemos afirmar que la consecuencia más generalizada del maltrato es el deterioro del autoconcepto y la pérdida de autoestima.

Cuando la pérdida de autoestima llega a niveles extremadamente bajos, estamos ante una persona en repliegue total sobre sí misma, y por tanto en depresión grave, que puede llevar a la necesidad de construir espontánea o artificialmente un mundo de fantasía donde pueda desempeñar un papel distinto al que desempeña en la vida real.

Otra derivación de una historia de maltrato fuerte que llega a niveles severos de desestima es la pérdida de la propia dignidad. Cuando la experiencia interiorizada de dolor, humillación, desprecio, es tan grande como para no poder revelarse, ni cuestionarse su situación, ni para pedir ayuda de superación -no de subsistencia- estamos ante un individuo dispuesto a todo. Desconfía de todos, porque si él no se aprecia a sí mismo ¿quién lo va a estimar? No tiene miedo a lo que le pueda ocurrir, porque ya le ha ocurrido de todo. No le importa el dolor ajeno, porque la vida es así, dolor, desprecio... Y una vez que se ha perdido la dignidad, la conciencia de ser persona y vivir entre personas, con derechos y obligaciones, da igual todo y el individuo es refractario a cualquier ayuda que suponga superación, dignificación.

He querido señalar primero el cuadro fuerte de las repercusiones porque hasta llegar a ahí cada individuo puede recorrer y aparcar en mil vericuetos del camino. Los más suaves serán sentimientos de inferioridad, de culpa, porque ha interiorizado que él/ella es malo/a y merecedor/a de todo lo que le han dicho o hecho; reacciones de retraimiento y desconfianza inicial hacia los adultos, de agresividad fácil hacia personas y objetos; reacciones de suspicacia, de hipersensibilidad a comentarios y actitudes ajenas hacia él o ella.

A continuación, presentamos un cuadro realizado conjuntamente con los educadores y educadoras del Centro de Vida de Nazaret en un proceso habitual de investigación-acción, en el cual aparecen agrupadas algunas consecuencias del maltrato infantil detectadas en la intervención educativa con los menores. 


\section{VI.REPERCUSIONES OBSERVADAS EN LOS CASOS DE MALTRATO}

\begin{tabular}{|l|l|}
\hline RESPECTO A SÍ MISMO/A & $\begin{array}{l}\text { - Sentimiento de inferioridad. } \\
\text { - Baja autoestima. } \\
\text { - Resistencia a reconocer sus fallos y a asu- } \\
\text { mir responsabilidades. }\end{array}$ \\
\hline RESPECTO A OTROS NIÑOS/AS & $\begin{array}{l}\text { - Tendencia a ir con niños más pequeños. } \\
\text { - Retraimiento en la convivencia. } \\
\text { - Mentiras fantásticas. }\end{array}$ \\
\hline RESPECTO A ADULTOS & $\begin{array}{l}\text { - Desconfianza en el adulto. } \\
\text { - Refugiarse en la mentira y mentir sobre } \\
\text { su propia familia. }\end{array}$ \\
\hline - Ocultación de sentimientos.
\end{tabular}

Ofrecemos la anterior sintomatología a título indicativo, no demostrativo. Ni cuando encontremos alguno de esos rasgos podemos afirmar, sin más, que estamos ante un caso de mal trato emocional ni, al contrario, cuando estemos ante un caso de maltrato tenemos por qué esperar todo ese cuadro de reacciones. La agrupación que ofrecemos nos puede ayudar, cuando en un niño o niña se dé un grupo importante de estos síntomas nos puede inducir a profundizar en un diagnóstico confirmatorio o no de maltrato emocional y/o físico.

\section{VII.LÍNEAS DE INTERVENCIÓN}

No pretendo dar aquí recetas de intervención. Intentarlo requeriría más espacio y profundidad, pero es evidente que si estudiamos el problema de los malos tratos es pensando en generar caminos de actuación.

No obstante, y a modo de síntesis, habrá que distinguir procesos de intervención según sea la situación del menor y de la familia. En cualquier caso, y siempre que el niño o el joven mantenga contacto con la familia, la intervención habrá de hacerse sobre todo el núcleo familiar. Los objetivos de esta intervención habrán de tener dos grandes áreas de incidencia: la educativa, de cambio de creencias, modelos educativos, pautas, actitudes; y la terapeútica, buscando la revisión de los sentimientos, lazos afectivos y vivencias antiguas tanto de índole personal como grupal. 
El objetivo general en la intervención directa con el menor, sea en el seno del grupo familiar o sea de manera individual por las circunstancias que lo acompañen, siempre estará en la constelación de la autoestima, la revalorización de la persona desprestigiada, pasando por experiencias y valoraciones que clarifiquen el autoconcepto del niño o adolescente.

Por otra parte, y en términos más globales, la lucha contra el maltrato es signo elocuente de la evolución de una sociedad, y más aún si miramos al maltrato emocional independiente del físico. Esa lucha es en primer lugar una toma de conciencia de derechos y obligaciones propios y ajenos, de grandes y pequeños. Pero inmediatamente hay que empeñarse en la búsqueda de modelos de relación interpersonal que sean facilitadores del crecimiento total de la persona: del niño y de la niña, y también de los adultos.

En última instancia podemos plantear que la lucha contra el maltrato tiene su mejor camino en la promoción del buen trato.

\section{BIBLIOGRAFÍA}

ARRUABARRENA, M.I. y DE PAÚL, J. (1994): Maltrato a los niños en la familia. Madrid, Pirámide.

BANDURA, A. (1973): Social learning theory of aggression. En J.F. Knutson (comp.): The control of aggresion. Chicago, Aldine.

GARBARINO, J. (1986): The psychologically battered child. San Francisco, Jossey Bass Inc. Pub.

GIOVANNONI, J. (1991): Social policy considerations in defining psychological maltreatment. Development and Psychopathology, 3, 51 59.

GRACIA, E. y MUSITU, G. (1994): Tipología del maltrato: una conceptualización empírica. Revista de Psicología Social Aplicada, 4, 1, p. 53 - 72.

KEMPE, R. S. y KEMPE, C. H. (1979): Niños maltratados. Madrid, Morata.

MARTÍNEZ, A. y DE PAÚL, J. (1993): Maltrato y abandono en la infancia. Barcelona, Martínez Roca.

MOYA, C. (1993): Algunas cuestiones relativas al proceso de toma de decisiones en los casos de malos tratos a la infancia. Revista de Psicología Social Aplicada. 3, 1, p. 73 - 83.

SAN JUAN, C. y DE PAÚL, J. (1996): La representación social de los malos tratos infantiles: Un estudio de casos. Revista de Psicología Social Aplicada, 6, 1, p. $39-56$. 


\title{
ANÁLISIS DEL PROGRAMA DE SEGUIMIENTO DE MEDIDAS JUDICIALES DE RÉGIMEN ABIERTO EN LA CIUDAD DE ALICANTE DURANTE 1.996
}

\author{
JAVIER DOMÍNGUEZ \\ JOSÉ R. BROCAL \\ JOSÉ J. CASES \\ VIRGINIA TOVAR \\ AGUSTÍN BUENO
}

\section{RESUMEN}

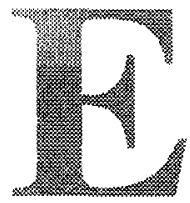

n este trabajo se presentan los datos correspondientes a la problemática presentada en los casos de menores con aplicación de medidas judiciales en medio abierto en la ciudad de Alicante en 1996 y la intervención efectuada en los mismos: características de población, medidas judiciales empleadas y distribución de las mismas por delitos, sexo y edad, objetivos según las medidas, recursos utilizados y niveles de logro apreciados. Se incluye una proyección del programa hacia el futuro.

\section{PALABRAS CLAVE}

Jóvenes infractores, medidas judiciales, intervención social, medio abierto.

I. AMBIENTACIÓN DEL PROGRAMA DE SEGUIMIENTO DE MEDIDAS JUDICIALES DE RÉGIMEN ABIERTO EN LA CIUDAD DE ALICANTE.

Consideramos necesario contextualizar el Programa de Seguimiento de las Medidas Judiciales de Régimen Abierto antes de entrar en el

Este programa se realiza dentro del convenio de colaboración entre Nazaret y el Excmo. Ayuntamiento de Alicante. 
análisis de los datos correspondientes al año 1996. Pretendemos con ello darles el alcance que se les puede pedir, que es el de primerizos, aunque herederos de una larga historia de hacer sin hacer, o de estar en la Ley pero no en la realidad social. Podemos afirmar sin reparos que 1996 es el primer año natural completo en el que hay seguimiento real de una gama de medidas judiciales de régimen abierto en la ciudad de Alicante.

En la antigua Ley de Tribunales Tutelares de Menores de 1948 se establecían como posibles medidas a ser tomadas por el juez respecto a un menor de edad: el internamiento en un centro y la libertad vigilada. A ésta se reducían, pues, las medidas de régimen abierto, y de hecho no significaba intervención ni ejecución salvo de carácter administrativo.

En aquel contexto legal, que ha durado hasta hace muy poco, el menor era llamado al Tribunal Tutelar de Menores y allí recibía la amonestación correspondiente y se le informaba que se le había abierto un expediente. Ahí quedaba todo, el expediente en su archivo y el menor haciendo la misma vida que antes. Si volvía a delinquir y era cogido por la policía entonces se repetía la misma función. Así, hasta que ingresaba en un centro o superaba la edad penal y pasaba a la jurisdicción ordinaria. Para informar sobre los expedientes de libertad vigilada el Ministerio de Justicia tenía en cada provincia entre dos y cuatro delegados, que emitían sus informes si el juez se lo requería -y que si los hubiera requerido en todos los casos, no habría sido posible materialmente realizarlos-.

El 5 de junio de 1992 es aprobada la Ley 4/92, sobre reforma de la Ley Reguladora de la Competencia y Procedimiento de los Juzgados de Menores. Esta ley, promulgada por inconstitucionalidad de la de 1948, modifica importantes artículos de la anterior. En concreto, el Artículo Segundo, apartado cuatro, dice así:

"El artículo 17 de la Ley de Tribunales Tutelares de Menores, aprobada por Decreto de 11 de junio de 1948, tendrá la siguiente redacción:

El Juez de menores podrá acordar, con respecto a éstos, las medidas siguientes:

1. amonestación o internamiento por tiempo de uno a tres fines de semana.

2. ${ }^{a}$ Libertad vigilada.

3. Acogimiento por otra persona o núcleo familiar.

4. ${ }^{a}$ Privación del derecho a conducir ciclomotores o vehículos de motor.

$5{ }^{\text {a }}$ Prestación de servicios en beneficio de la Comunidad. 


\section{6. ${ }^{a}$ Tratamiento ambulatorio o ingreso en un Centro de carácter terapéutico.}

7. Ingreso en un Centro en régimen abierto, semiabierto o cerrado.

En el ejercicio de la facultad de enjuiciar las faltas a que se refiere el apartado $2^{\circ}$ del artículo 9 se aplicarán las penas señaladas en el Código Penal". ${ }^{2}$

Así mismo, establece un nuevo procedimiento de actuación de los juzgados de menores, con informe del fiscal, asesorado por un equipo técnico, y se concreta que "la ejecución de las medidas adoptadas por los Juzgados de Menores corresponden a las Entidades Públicas competentes en la materia" (disposición adicional tercera de la citada Ley 4/92). La Entidad Pública, en nuestro caso, es la Comunidad Autónoma, que delega esta función en los Ayuntamientos.

El Ayuntamiento de Alicante concierta con la Fundación Nazaret -P. Fontova - la ejecución del Programa de Seguimiento de Medidas Judiciales de Régimen Abierto. Esto se produce en el curso escolar 93/94, incluye un único profesional (los delegados del Ministerio de Justicia habían desaparecido) y alcanza solamente a la medida de libertad vigilada porque las otras no están todavía diseñadas en la Comunidad Valenciana.

En este momento, cabía un modelo burocrático y de control del menor, o un modelo educativo con intención de incidir positivamente en el proceso socializador del menor. Este segundo modelo era el que se planteaba desde la dirección del programa, aunque fuera con los mínimos recursos materiales y personales que se ofrecían. Curiosamente, coincide la puesta en marcha del programa con una larga vacante del titular del Juzgado de Menores en la provincia de Alicante.

El 5 de diciembre de 1994 es aprobada por las Cortes Valencianas la Ley 7/94 de la Infancia ${ }^{3}$ en la cual se concretizan, dentro del capítulo de programas de reinserción, las medidas judiciales de todo tipo que puede imponer el juez a los menores (Cfr. Artículo 29 y ss. de la Ley 7/94 de la Generalitat Valenciana) y cuya ejecución es competencia de la Generalitat ${ }^{4}$.

Completado así el marco legal, aunque sin ninguna otra infraestructura administrativa o de especial capacidad de gestión de recursos,

Cfr. BOE, $\mathrm{N}^{\circ}$ 140, de 11 de junio de 1992.

Cfr. DOGV, $\mathrm{N}^{\circ} 2.408$ de 16 de diciembre de 1994.

4 Un desarrollo del diseño de esos programas de reinserción puede consultarse en: MOYA, C; GALVAÑ. F. y NIETO, C.: "Programas de ejecución de medidas judiciales". En A. BUENO (Coord.): Intervención social con menores. Alicante, Secretariado de Publicaciones de la Universidad de Alicante, 1996, pp. 293 - 318. 1: Cfr. BOE, No 140, de 11 de junio de 1992. 
a comienzos del curso 1995/96 se amplía el concierto del Ayuntamiento de Alicante a tres educadores (titulados en Trabajo Social, Psicología y Profesorado de EGB, respectivamente) y a toda la gama de medidas judiciales de régimen abierto que de hecho pone en ejecución la Comunidad Valenciana, que son: libertad vigilada, internamiento de fin de semana, prestación de servicios en beneficio de la comunidad.

Todo este largo proceso legislativo-administrativo es lo que explica que el año 1996 sea el primer año natural completo que permite un análisis del programa. Es el primer año completo, aunque tiene un largo precedente bastante irregular, por lo cual el análisis no permite todavía comparaciones retrospectivas ni prospecciones de evolución.

\section{SITUACIÓN GENERAL DEL RECURSO}

- Número de medidas: 76.

- Número de menores: 73.

- Menores con más de una medida: 3 (tres menores con dos medidas cada uno). Uno de ellos con post-medida, al no haber sido conseguidos los objetivos planteados durante la medida, y con total voluntariedad por parte del menor y su familia.

- Menores que han causado baja durante 1996: 49.

- Medidas que han causado baja durante 1996: 50.

- Medidas iniciadas en 1996: 53.

\section{III.ESTUDIO DE VARIABLES DE LA POBLACIÓN ATENDIDA}

3.1. Distribución de menores por sexo $(n=73)$.

\begin{tabular}{|c|c|c|c|c|}
\hline CHICOS & $\%$ & CHICAS & $\%$ & TOTAL \\
\hline 63 & 86,3 & 10 & 13,7 & 73 \\
\hline
\end{tabular}

TABLA 1

Como podemos observar, el grupo de hombres con medida judicial durante el año 1996 es significativamente mayor que el grupo de mujeres. Por cada chica con medidas judiciales de régimen abierto hay seis varones en la misma consideración.

\subsection{Distribución de menores por año de nacimiento y sexo $(n=73)$.}

El rango de edad donde se sitúan la mayoría de los casos se encuentra entre los años de nacimiento 1980 y $1982(82,2 \%)$, entre 14 y 


\begin{tabular}{|c|c|c|c|c|c|c|}
\hline \multirow[b]{2}{*}{ AÑO NACIM. } & \multicolumn{4}{|c|}{ SEXO } & \multirow[b]{2}{*}{ TOTAL } & \multirow[b]{2}{*}{$\%$} \\
\hline & CHICOS & $\%$ & CHICAS & $\%$ & & \\
\hline Año 78 & 1 & 1,6 & 1 & 10 & 2 & 2,7 \\
\hline Año 79 & 9 & 14,3 & 0 & 0 & 9 & 12,3 \\
\hline Año 80 & 28 & 44,4 & 3 & 30 & 31 & 42,5 \\
\hline Año 81 & 13 & 20,6 & 2 & 20 & 15 & 20,5 \\
\hline Año 82 & 10 & 15,9 & 4 & 40 & 14 & 19,2 \\
\hline Año 83 & 2 & 3,2 & 0 & 0 & 2 & 2,7 \\
\hline TOTAL & 63 & 100 & 10 & 100 & 73 & 100 \\
\hline
\end{tabular}

TABLA 2

16 años. En este grupo destaca el grupo de hombres nacidos durante 1980, frente al grupo de mujeres, más numeroso, nacidas durante 1982. El hecho de que el grupo de hombres tenga, en conjunto y como promedio, más edad que el grupo de mujeres puede apuntar a la mayor precocidad madurativa de las chicas, si bien el volumen de infracciones judicializadas o sancionadas son sensiblemente menores.

Los casos de edades superiores a los 16 años (15\%) corresponden a delitos que se cometieron cuando los menores no habían cumplido aún esa edad.

El número de menores que poseen menos de 14 (2,7\%) es muy bajo y son en su totalidad hombres. Este dato tanto nos puede informar de la edad paradigmática del comienzo general de la actividad delictiva, como la consideración social -tanto formal como informal- de la misma.

3.3. Distribución de medidas por año y trimestre del hecho cometido, resolución e inicio de medida $(n=76)$

En la tabla 3 se presentan los datos unificados y ordenados según el año y trimestre del hecho cometido que originó la medida judicial impuesta, la resolución (decisión judicial o sentencia) y el inicio de la medida (firma del menor y padres, así como el primer esbozo del plan de trabajo de la medida).

\subsubsection{Trimestre y año del hecho cometido}

De las medidas ejecutadas durante el año 1996, con respecto a la fecha del delito cometido, (véase tabla 4) el mayor porcentaje corresponde a hechos que se cometieron durante el año 95 y $96(82,9 \%)$, siendo el $17,1 \%$ restante a hechos que se cometieron anteriores al 95 . Se puede observar un mayor número de delitos cometidos durante el $2^{\circ}, 3^{\circ}$ y $4^{\circ}$ trimestre del 95 . 


\begin{tabular}{|c|c|c|c|c|c|c|c|}
\hline Año & Trimestre & Hecho cometido & $\%$ & Resolución & $\%$ & Inicio & $\%$ \\
\hline 1993 & 1 & 1 & 1,3 & 0 & 0 & 0 & 0 \\
\hline & 2 & 1 & 1,3 & 0 & 0 & 0 & 0 \\
\hline & 3 & 0 & 0 & 0 & 0 & 0 & 0 \\
\hline & 4 & 1 & 1,3 & 0 & 0 & 0 & 0 \\
\hline TOTAL 1993 & 3 & 3,9 & 0 & 0 & 0 & 0 \\
\hline 1994 & 1 & 2 & 2,6 & 0 & 0 & 0 & 0 \\
\hline & 2 & 4 & 5,3 & 0 & 0 & 0 & 0 \\
\hline & 3 & 2 & 2,6 & 1 & 1,3 & 1 & 1,3 \\
\hline & 4 & 2 & 2,6 & 5 & 6,6 & 1 & 1,3 \\
\hline TOTAL 1994 & 10 & 13,2 & 6 & 7,9 & 2 & 2,6 \\
\hline 1995 & 1 & 4 & 5,3 & 5 & 6,6 & 0 & 0 \\
\hline & 2 & 21 & 27,6 & 5 & 6,6 & 4 & 5,3 \\
\hline & 3 & 11 & 14,5 & 2 & 2,6 & 1 & 1,3 \\
\hline & 4 & 12 & 15,8 & 14 & 18,4 & 16 & 21,1 \\
\hline \multicolumn{2}{|r|}{ TOTAL 1995 } & 48 & 63,2 & 26 & 34,2 & 21 & 27,6 \\
\hline 1996 & 1 & 9 & 11,8 & 20 & 26,3 & 15 & 19,7 \\
\hline & 2 & 5 & 6,6 & 12 & 15,8 & 24 & 31,6 \\
\hline & 3 & 1 & 1,3 & 3 & 3,9 & 3 & 3,9 \\
\hline & 4 & 0 & 0 & 9 & 11,8 & 11 & 14,5 \\
\hline
\end{tabular}

TABLA 3

\begin{tabular}{|l|c|c|c|c|}
\hline Año & ${\text { Trimestre } 1 .^{\circ}}^{\circ}$ & ${\text { Trimestre } 2 .^{\circ}}^{\circ}$ & ${\text { Trimestre } 3 .^{\circ}}^{\circ}$ & ${\text { Trimestre } 4 .^{\circ}}^{\circ}$ \\
\hline 93 & 1 & 1 & 0 & 1 \\
\hline 94 & 2 & 4 & 2 & 2 \\
\hline 95 & 4 & 21 & 11 & 12 \\
\hline 96 & 9 & 5 & 1 & 0 \\
\hline TOTAL & 16 & 31 & 14 & 15 \\
\hline
\end{tabular}

TABLA 4

Si miramos estos datos de año y trimestre $(n=76)$, relativos al hecho cometido en agrupaciones trimestrales, obtenemos la tabla 4 de distribución de los casos.

Hay una mayor incidencia acumulativa de hechos cometidos durante los segundos trimestres del año - meses de abril, mayo y junio-. Es un dato sugerente pero que necesitará mayor comprobación, sobre todo teniendo en cuenta que son los años $94 \mathrm{y}$, sobre todo, 95 los que marcan esta tendencia. El año 93 no facilita datos valorativos, y el año 96 manifiesta una tendencia distinta 


\subsubsection{Trimestre y año de la resolución}

De las medidas ejecutadas durante este periodo, más de la mitad $(57,9 \%)$ corresponden a resoluciones emitidas durante 1996, destacando el $1^{\mathrm{er}}$ y $2^{\circ}$ trimestre del mismo. También resalta el número de resoluciones emitidas durante el $4^{\circ}$ trimestre de 1995 . No existe ninguna resolución anterior al $2^{\circ}$ semestre de 1994 , lo cual se debe al hecho, comentado en la ambientación (epígrafe 1), de que el primer año del programa comienza con un periodo del Juzgado de Menores de la Provincia de Alicante sin Juez en ejercicio.

\subsubsection{Trimestre y año de inicio de medidas}

Durante 1996 se han iniciado 53 medidas $(69,7 \%)$ de las medidas ejecutadas durante este periodo, destacando el $1^{\text {er }}$ semestre y el $4^{\circ}$ trimestre del mismo, habiendo un descenso significativo durante el $3 \mathrm{er}$. trimestre. También resalta el número de medidas iniciadas en el $4^{\circ}$ trimestre del año 1995. No se ejecutaron medidas judiciales anteriores al $2^{\circ}$ semestre de 1994, por la misma razón de juzgado vacante que hemos indicado antes. Al inicio del año evaluado 23 medidas $(30,2 \%)$ habían sido iniciadas con anterioridad a 1996.

\subsection{Relación de medidas respecto al tiempo transcurrido (en meses)} entre el hecho cometido y la resolución $(n=96)$

\begin{tabular}{|c|c|c|}
\hline Tiempo transcurrido en meses & TOTAL & $\%$ \\
\hline 1 & 1 & 1,3 \\
\hline 2 & 2 & 2,6 \\
\hline 3 & 2 & 2,6 \\
\hline 4 & 12 & 15,8 \\
\hline 5 & 17 & 22,4 \\
\hline 6 & 12 & 15,8 \\
\hline 7 & 7 & 9,2 \\
\hline 8 & 4 & 5,3 \\
\hline 9 & 8 & 10,5 \\
\hline 10 & 2 & 2,6 \\
\hline 11 & 1 & 1,3 \\
\hline 12 & 4 & 5,3 \\
\hline 14 & 2 & 2,6 \\
\hline 20 & 1 & 1,3 \\
\hline 21 & 1 & 1,3 \\
\hline TOTAL & 76 & 100 \\
\hline
\end{tabular}

TABLA 5 (tiempo medio -en meses-: 6,41) 
Del total de medidas ejecutadas durante este periodo, podemos observar que el tiempo medio de demora entre el hecho cometido y la resolución oscila en la mitad de las medidas (54\%) entre 4 y 6 meses, siendo un $6,5 \%$ de las medidas las que poseen una menor demora. En el resto de medidas $(39,5 \%)$ es superior a 6 meses, y aquéllas que superan el año constituyen el $5,2 \%$.

Estos datos son importantes de resaltar, puesto que al tratar con menores es de vital trascendencia que el tiempo entre hecho cometido y resolución sea lo más breve posible, para que la medida sea realmente educativa y el menor pueda establecer con claridad la conexión entre hecho delictivo y sus consecuencias.

\begin{tabular}{|c|c|c|c|}
\hline MEDIDA & DURACIÓN & TOTAL & $\%$ \\
\hline \multirow[t]{2}{*}{ Fines de semana } & 2 & 2 & 2,6 \\
\hline & 3 & 5 & 6,6 \\
\hline \multicolumn{2}{|l|}{ TOTAL lines de semana } & 7 & 9,2 \\
\hline \multirow[t]{12}{*}{ Libertad vigilada } & I semana & 1 & 1,3 \\
\hline & curso escolar & 7 & 9,2 \\
\hline & 2 meses & 2 & 2,6 \\
\hline & 3 meses & 2 & 2,6 \\
\hline & 4 meses & 2 & 2,6 \\
\hline & 6 meses & 13 & 17,1 \\
\hline & 8 meses & 3 & 3,9 \\
\hline & 9 meses & 6 & 7,9 \\
\hline & 1 aก̃o & 16 & 21,1 \\
\hline & 2 años & 1 & 1,3 \\
\hline & hasta 16 años & 1 & 1,3 \\
\hline & hasta 18 años & 1 & 1,3 \\
\hline \multicolumn{2}{|l|}{ TOTAL libertad vigilada } & 56 & 73,7 \\
\hline \multirow[t]{4}{*}{ Prestación servicios comunidad } & 10 horas & 1 & 1,3 \\
\hline & 15 horas & 4 & 5,3 \\
\hline & 20 horas & 4 & 5,3 \\
\hline & 30 horas & 1 & 1,3 \\
\hline \multicolumn{2}{|l|}{ TOTAL prestac. serv. com. } & 10 & 13,2 \\
\hline Libertad vig. + prest. serv. com. & 1 año +30 horas & 1 & 1,3 \\
\hline \multicolumn{2}{|l|}{ TOTAL lib. vig. + prest. serv. com. } & 1 & 1,3 \\
\hline \multirow[t]{2}{*}{ Post-medida } & 1 mes & 1 & 1,3 \\
\hline & 4 meses & 1 & 1,3 \\
\hline \multicolumn{2}{|l|}{ TOTAL post-medida } & 2 & 2,6 \\
\hline
\end{tabular}




\subsection{Tipo de medidas y duración $(n=76)$.}

Hay que destacar que, de entre todas las medidas ejecutadas durante 1996 (véase tabla 6), la medida más impuesta en medio abierto es la libertad vigilada $(73,7 \%)$. En cuanto a la duración impuesta en libertad vigilada destacan los 6 meses y el año, siendo éste el periodo más adecuado, a juicio de este equipo, para poder establecer un plan de intervención y poder llevarlo a cabo con ciertas garantías, así como para poder establecer vínculos con el menor y su familia que faciliten dicha intervención. Hemos podido observar que libertades vigiladas que tienen una menor duración no son demasiado positivas por la brevedad de tiempo, y aquéllas que exceden de este tiempo se hacen difíciles de llevar, ya que se hacen muy largas en el tiempo y el chaval llega a perder la perspectiva de la medida y su relación con su conducta, llegando a plantearse el plan de intervención y perdiendo su función educativa.

Queda manifiesto que la medida de libertad vigilada en el programa actual no tiene equivalencia con la libertad vigilada ejecutada en cumplimiento de la Ley de 1948.

En cuanto a la medida de prestación de servicios en beneficio de la comunidad, es la segunda medida de medio abierto más impuesta $(13,2 \%)$. Su duración oscila entre las 10 y 30 horas. Esta medida se ha visto muy positiva en la intervención de los menores, obteniéndose muy buenos resultados por la fácil conexión entre la conducta del menor y su posterior reparación. También hay que resaltar que el perfil de chavales que tienen esta medida difiere de los de libertad vigilada.

Respecto al internamiento en domicilio durante los fines de semana, también hay que resaltar los mismos comentarios que los realizados para la prestación de servicios en beneficio de la comunidad.

Resaltar el hecho de que tan sólo en un caso una misma resolución impone dos medidas diferentes.

En cuanto a la post-medida, los casos ejecutados han sido de chavales que han tenido muy buena respuesta en medidas en ejecución y que al finalizar la medida y al comprobarse que los objetivos no han sido concluidos, y con la voluntariedad del menor y de su familia, se continúa trabajando con él.

\subsection{Distribución de medidas por tipo de delito y sexo $(n=76)$}

El delito más común es el de robo con fuerza $(27,6 \%)$ cometido únicamente por chicos (véase tabla 7). 


\begin{tabular}{|l|c|c|c|}
\hline TIPO DELITO & SEXO & TOTAL & $\%$ \\
\hline Agresión sexual & Chicos & 1 & 1,3 \\
\hline Contra salud pública & Chicos & 1 & 1,3 \\
\cline { 2 - 4 } & Chicas & 3 & 3,9 \\
\hline TOTAL contra salud pública & & 4 & 5,3 \\
\hline Falta & Chicas & 1 & 1,3 \\
\hline Falta contra el régimen de poblaciones & Chicos & 1 & 1,3 \\
\cline { 2 - 4 } & Chicas & 1 & 1,3 \\
\hline TOTAL falta contra el régimen de poblaciones & & 2 & 2,6 \\
\hline Falta de hurto & Chicos & 10 & 13,2 \\
\hline Robo con fuerza & Chicos & 21 & 27,6 \\
\hline Robo con intimidación & Chicos & 6 & 7,9 \\
\cline { 2 - 4 } & Chicas & 1 & 1,3 \\
\hline TOTAL robo con intimidación & & 7 & 9,2 \\
\hline Robo con violencia & Chicos & 7 & 9,2 \\
\cline { 2 - 4 } & Chicas & 4 & 5,3 \\
\hline TOTAL robo con violencia & & 11 & 14,5 \\
\hline Robo en grado de frustación & Chicos & 1 & 1,3 \\
\hline U.I.V.M & Chicos & 2 & 2,6 \\
\hline TOTAL U.l.V.M & Chicos & 6 & 7,9 \\
\hline Robo con intimidación + Falta de hurto & Chicas & 1 & 1,3 \\
\hline Quebrantamiento de medida & Chicos & 1 & 1,3 \\
\hline Quebrantamiento de medida + UIVM + Robo con & Chicos & 1 & 1,3 \\
\hline Receptación & Chicos & 1 & 1,3 \\
\hline Falta de hurto + Incendio + UIVM & Chicos & 2 & 2,6 \\
\hline Robo con violencia + Robo con intimidación & Chicos & 1 & 1,3 \\
\hline Post-medida & Chicos & 1 & 1,3 \\
\hline Cambio de medida & Chicos & 2 & 2,6 \\
\hline TOTAL & & 76 & 9,2 \\
\hline
\end{tabular}

TABLA 7

El segundo delito más cometido es el de robo con violencia $(14,5 \%)$. Este delito es el que más han cometido las mujeres.

La falta de hurto es el tercer delito más cometido $(13,2 \%)$ y es sólo cometido por hombres.

Siguiendo en orden descendente, la utilización ilegítima de vehículos a motor (U.I.V.M.) es el cuarto delito cometido con mayor frecuencia, siendo en casi su totalidad hombres y tan sólo una mujer; 
también en la misma proporción y con el mismo número de casos es el robo con intimidación.

En cuanto a los delitos contra la salud pública $(5,3 \%)$ destaca el grupo de mujeres frente al de hombres.

Hay que resaltar que las resoluciones que recogen varios delitos constituyen el 5,2\% de los casos y son en su totalidad hombres.

Destacar que respecto al periodo anterior (1995) los tipos de delito se han visto ampliados (casi duplicados), con la característica añadida de que, en algunos casos, para una misma resolución y un mismo menor, se corresponden varios tipos de delito.

3.7. Distribución de menores según el criterio de estructuración familiar (responsable/s educativo/s) $(n=73)$

\begin{tabular}{|l|r|r|}
\hline ESTRUCTURACIÓN FAMILIAR & TOTAL & $\%$ \\
\hline Pareja constituida de manera estable & 43 & 58,9 \\
\hline Mujer soltera habitualmente sola & 2 & 2,7 \\
\hline Mujer separada habitualmente sola & 17 & 23,3 \\
\hline Mujer viuda habitualmente sola & 2 & 2,7 \\
\hline Hombre habitualmente solo & 1 & 1,4 \\
\hline Abuelo/a & 5 & 6,8 \\
\hline Hermano/a mayor & 1 & 1,4 \\
\hline Emancipado & 2 & 2,7 \\
\hline TOTAL & 73 & 100 \\
\hline
\end{tabular}

TABLA 8

El mayor número de casos se refieren a familias estructuradas en torno a parejas estables $(58,9 \%)$. El criterio seguido para calificar una pareja como estable ha sido el de la convivencia en el mismo núcleo familiar, sin embargo, tal estabilidad, en gran número de casos, es muy relativa, debido a problemáticas individuales de cada pareja. Otro dato reseñable es el alto porcentaje de mujeres separadas, y habitualmente solas como responsable educativo.

Los dos casos de emancipación corresponden a menores que han formado su propio núcleo familiar, aunque siguen conviviendo en el domicilio de alguno de los progenitores.

\subsection{Distribución de menores por condiciones de la vivienda $(n=73)$}

Los criterios que hemos seguido para evaluar las condiciones de las viviendas (tabla 9) han sido los siguientes: 
- Condiciones precarias (falta de higiene, hacinamiento, infraestructura interna y externa insuficiente).

- Condiciones mínimas (deterioro de la infraestructura interna y externa, esto es, mobiliario inadecuado en función de la composición familiar, humedad, grietas, etc.).

- Condiciones adecuadas (infraestructura externa cuidada, mobiliario ajustado a las necesidades del núcleo familiar, higiene suficiente, ausencia de hacinamiento, etc.).

\begin{tabular}{|l|c|c|}
\hline CONDICIONES DE LA VIVIENDA & TOTAL & $\%$ \\
\hline Adecuadas & 53 & 72,6 \\
\hline Mínimas & 13 & 17,8 \\
\hline Precarias & 7 & 9,6 \\
\hline TOTAL & 73 & 100 \\
\hline
\end{tabular}

TABLA 9

3.9. Características del menor al inicio de la medida $(n=73)$

\begin{tabular}{|l|c|c|}
\hline CARACTERÍSTICAS del menor al inicio de la medida & N. ${ }^{\circ}$ CASOS & $\%$ \\
\hline Consumo de sustancias tóxicas & 23 & 31,51 \\
\hline Salud física o enfermedad importante & 1 & 1,37 \\
\hline Salud mental & 6 & 8,22 \\
\hline No escolarizados & 26 & 35,62 \\
\hline Absentismo & 17 & 23,29 \\
\hline Conducta escolar inadaptada & 17 & 23,29 \\
\hline Graves dificultades en lectura y escritura & 19 & 26,03 \\
\hline En paro con edad laboral & 19 & 26,03 \\
\hline No participa en activ. formativas y de ocio y t. & 54 & 73,97 \\
\hline Grupo de amigos conflictivo & 54 & 73,97 \\
\hline Ha estado internado en centro de protección & 7 & 9,59 \\
\hline Ha estado internado en centro de reforma & 12 & 16,44 \\
\hline Malos tratos físicos/psíquicos & 9 & 12,33 \\
\hline
\end{tabular}

TABLA 10

En la tabla podemos ver que el mayor porcentaje de características comportamentales asociables al hecho delictivo se halla en los aspectos referentes a las relaciones con iguales ("grupo de amigos conflictivo") y al hecho de la no ocupación del tiempo libre de modo positivo para su desarrollo personal. También aparecen unos porcentajes elevados de menores no escolarizados $(35,62 \%)$ y de menores que consumen sustancias tóxicas $(31,51 \%)$. En este punto conviene matizar que 
el porcentaje real es mucho mayor, pero se trataría básicamente de consumidores de drogas de síntesis (éxtasis, speed, etc.), porros y alcohol, especialmente en fines de semana. Un porcentaje muy bajo estaría referido a heroinómanos y consumidores habituales.

\subsection{Características de la familia al inicio de la medida $(n=73)$}

\begin{tabular}{|l|c|c|}
\hline CARACTERÍSTICAS de la familia al inicio de la medida & N. ${ }^{\circ}$ CASOS & $\%$ \\
\hline Consumo drogas padre/madre & 8 & 10,96 \\
\hline Alcoholismo padre/madre & 7 & 9,59 \\
\hline Encarcelamiento padre/madre & 13 & 17,81 \\
\hline Prostitución manifiesta o encubierta & 2 & 2,74 \\
\hline En paro crónico & 20 & 27,40 \\
\hline En paro temporal & 16 & 21,92 \\
\hline Responsable educativo distinto de padres & 8 & 10,96 \\
\hline Problemas de salud física responsables educativos & 9 & 12,33 \\
\hline Problemas de salud responsables educativos & 10 & 13,70 \\
\hline Problemas de salud física en hermanos & 4 & 5,48 \\
\hline Problemas de salud mental en hermanos & 4 & 5,48 \\
\hline Familia permisiva / Falta de límites & 44 & 60,27 \\
\hline Usuaria habitual de servicios sociales & 31 & 42,47 \\
\hline Problemática delictiva en hermanos & 22 & 30,14 \\
\hline Internamiento de hermanos en centro de reforma & 6 & 8,22 \\
\hline Consumo de alcohol/drogas en hermanos & 19 & 26,03 \\
\hline
\end{tabular}

TABLA 11

Si observamos la tabla y extraemos los datos más significativos, resulta fácilmente deducible el entorno familiar poco normalizado en el que se desenvuelven la mayoría de los menores objeto de esta memoria.

Se trataría, en gran número de casos, de familias permisivas o incoherentes, con ausencia de límites educativos $(60,27 \%)$ y usuarias habituales de servicios sociales $(42,47 \%)$. Además, podemos destacar el porcentaje importante de familias con problemática delictiva en hermanos $(30,14 \%)$ y con una situación cronificada de paro $(27,40 \%)$. Respecto a los aspectos de consumo de alcohol y drogas, las cifras reales siempre son mayores de las que aparecen en la tabla, ya que la recogida de este tipo de datos resulta más complicada, dado que las familias tienden a ocultarlos.

A partir de esta tabla y la anterior podríamos definir el perfil de los menores como: 
- chico (varón),

- entre 14 y 16 años,

- que suele relacionarse con grupo de amigos conflictivo,

- con escasa participación en actividades formativas y de ocio y tiempo libre,

- no escolarizado o con problemática escolar manifiesta (absentismo, conducta desadaptativa, etc.),

- que consume sustancias tóxicas, sobre todo en fines de semana y del tipo de síntesis, "blandas" y alcohol.

Esta descripción, unida a las características de estructuración familiar y vivienda, nos hace pensar que son los valores y actitudes, pautas de conducta habituales en el medio socio-familiar, las circunstancias que mejor explicarían la aparición de las conductas delictivas.

\section{IV.NIVEL DE INTERVENCIÓN (OBJETIVOS).}

De manera global, podríamos afirmar que los objetivos fundamentales o generales del PEI (Programa Educativo Individualizado) que se repiten en cada una de las medidas son:

- Evitar la reincidencia en el menor.

- Lograr la implicación del menor y la familia con el PEI y con el/la educador/a.

\subsection{Libertad vigilada}

TABLA 12

\begin{tabular}{|l|c|c|c|c|}
\hline OBJETIVOS TRABAJADOS EN LIBERTAD VIGILADA & Prop.* $^{*} \%$ & Logr.** $^{*} \%$ \\
\hline Lograr conocimiento y valoración de sí mismo y de su situación & 76 & 100 & 31 & 62 \\
\hline Adquirir autonomía y responsabilidad & 76 & 100 & 32 & 64 \\
\hline Lograr implicación del menor con el PEI y con el educador & 76 & 100 & 42 & 68 \\
\hline Retomar escolarización & 10 & 13,16 & 3 & 6 \\
\hline Reducir absentismo & 11 & 14,47 & 4 & 8 \\
\hline Aumentar colaboración e implicación en actividades escolares & 19 & 25 & 5 & 10 \\
\hline Obtener certificado de escolaridad & 2 & 2,63 & 1 & 2 \\
\hline Obtener el graduado escolar & 6 & 7,89 & 3 & 6 \\
\hline Ocupar el tiempo libre en una actividad formativa & 38 & 50 & 7 & 14 \\
\hline Adquirir conocimientos y hábitos para el desarrollo de un trabajo & 17 & 22,37 & 4 & 8 \\
\hline Planificar y participar en circuitos laborales adecuados a su capacidad & 19 & 25 & 9 & 18 \\
\hline Reforzar y mejorar actitudes para el mantenimiento del puesto de trabajo & 3 & 3,95 & 2 & 4 \\
\hline Participar en actividades de integración en el barrio & 5 & 6,58 & 3 & 6 \\
\hline Desarrollar una actividad organizada de carácter lúdico-deportivo & 25 & 32,89 & 12 & 24 \\
\hline
\end{tabular}




\begin{tabular}{|l|c|c|c|c|}
\hline Evitar la reincidencia & 76 & 100 & 45 & 90 \\
\hline Lograr que la familia asuma la problemática del menor & 76 & 100 & 31 & 62 \\
\hline Lograr inplicación y colaboración de la familia con el PEl y el/la educador/a & 76 & 100 & 45 & 90 \\
\hline Potenciar actitudes en la familia que mejoren su relación con el menor & 76 & 100 & 32 & 64 \\
\hline Sensibilizar a la familia de la problemática que mejoren su relación con el menor & 76 & 100 & 28 & 56 \\
\hline Ofrecer orientación prelaboral/laboral & 24 & 31,58 & 24 & 48 \\
\hline Adecuar los recursos al interés y las necesidades del menor & 76 & 100 & 42 & 84 \\
\hline Facilitar el acceso a los recursos comunitarios & 76 & 100 & 40 & 80 \\
\hline
\end{tabular}

*Objetivos propuestos: $n=76 . * *$ Objetivos logrados: $n=50$.

En este apartado interesa destacar, como aspectos positivos, la buena implicación de las familias con el PEI y el/la educador/a (90\%), el logro de cambios favorables en la actitud de las familias respecto a los menores $(64 \%)$, la adecuación de los recursos al interés y necesidades del menor (84\%) y la facilitación del acceso a los recursos comunitarios $(80 \%)$.

Como aspectos negativos mencionar que se da un escaso nivel de logro en el objetivo de potenciar la adquisición de hábitos para el desarrollo de un trabajo y también en el objetivo de potenciar actitudes que fomenten la constancia para desarrollar una misma actividad.

\subsection{Prestación de servicios en beneficio de la comunidad}

\begin{tabular}{|c|c|c|c|c|}
\hline TABLA 13 & $(n=10)$ & & $(n=10)$ & \\
\hline OBJETIVOS DE P.S.B.C & Prop. & $\%$ & Logr. & $\%$ \\
\hline Tomar conciencia del daño causado & 9 & 90 & 9 & 90 \\
\hline Participar en la actividad propuesta & 10 & 100 & 10 & 100 \\
\hline Lograr implicación del menor con la actividad y con el/la educador/a & 10 & 100 & 10 & 100 \\
\hline Evitar reincidencia & 10 & 100 & 10 & 100 \\
\hline Lograr implicación de la familia con la actividad y con el/la educador/a & 2 & 20 & 2 & 20 \\
\hline Sensibilizar de la problemálica y necesidades del menor donde se realice la prestación & 10 & 100 & 9 & 90 \\
\hline Ofrecer orientación prelaboral/laboral & 1 & 10 & 1 & 10 \\
\hline
\end{tabular}

\subsection{Internamiento en domicilio durante fines de semana}

Respecto al internamiento en domicilio durante fines de semana, cabe destacar como aspectos positivos la buena implicación tanto del menor como de la familia con el PEI y el/la educador/a. Como aspectos negativos, hay que mencionar la falta de recursos comunitarios para cumplir las horas de prestación de servicios y la dificultad de 
112 Javier Domínguez - José Brocal - José Cases - Virginia Tovar - Agustín Bueno

TABLA 14
\begin{tabular}{|l|c|c|c|c|}
\hline OBJETIVOS TRABAJADOS EN INTERNAMIENTO EN DOMICLLIO DURANTE FNNES DESEMANA & Prop. & $\%$ & Logr. & $\%$ \\
\hline Lograr conocimiento y valoración de sí mismo y de su situación & 6 & 85,7 & 4 & 57,14 \\
\hline Lograr la implicación del menor con el PEI y con el/la educador/a & 7 & 100 & 6 & 85,71 \\
\hline Orientar al menor en ocupación del tiempo libre y actividades formativas & 1 & 14,29 & 1 & 14,29 \\
\hline Permanecer en el domicilio & 7 & 100 & 6 & 85,71 \\
\hline Participar en tareas domésticas & 3 & 42,86 & 3 & 42,86 \\
\hline Evitar reincidencia & 7 & 100 & 7 & 100 \\
\hline Lograr la implicación y colaboración de la familia con el PEI y el/la educador/a & 2 & 28,57 & 1 & 14,29 \\
\hline Facilitar el acceso a los recursos comunitarios & 5 & 71,43 & 4 & 57,14 \\
\hline
\end{tabular}

ajustar el horario de tiempo libre del menor al funcionamiento de la entidad prestadora del servicio.

Otro punto importante es que tanto en P.S.B.C. como en internamiento de F.S. el éxito del PEI es mayor debido a que el perfil de familias y de menores es distinto a los de Libertad Vigilada. Se trata de familias y menores bastante normalizados (menores escolarizados, con un ritmo escolar aceptable, familias estructuradas, etc.).

\section{RECURSOS UTILIZADOS}

TABLA 15

\begin{tabular}{|l|r|}
\hline RECURSOS UTILIZADOS & $\mathrm{N}^{\circ}$ \\
\hline Familias acogedoras & 1 \\
\hline Centros escolares & 23 \\
\hline EPAS & 10 \\
\hline Cursos de alfabetización & 6 \\
\hline Módulos de garantía social & 13 \\
\hline Talleres prelaborales & 11 \\
\hline Academias de enseñanza escolar & 1 \\
\hline Academias de F. Profesional & 3 \\
\hline Centros jóvenes & 7 \\
\hline Empleados en puesto laboral & 5 \\
\hline Gimnasios & 11 \\
\hline Asociaciones de ocio y tiempo libre & 2 \\
\hline O.N.Gs & 4 \\
\hline Actividades deportivas organizadas & 15 \\
\hline Empresas de prestación de servicios & 10 \\
\hline
\end{tabular}


El recurso más utilizado es el de centros escolares. Esto es debido a que el perfil de la población estudiada, como ya se ha comentado, responde principalmente a una franja de edad entre 14 y 16 años, edad propia de la última etapa de escolarización obligatoria.

Otro porcentaje importante de recursos utilizados es el correspondiente a la franja de edad de más de 16 años (talleres pre-laborales, EPAs, Módulos de Garantía Social).

En cuanto a la ocupación del Tiempo Libre, la tabla también refleja un porcentaje elevado de recursos utilizados para este fin (Gimnasios, Asociaciones, etc.).

Hay que aclarar que estas cifras corresponden exclusivamente al dato de utilización del recurso, y no al nivel de aprovechamiento del mismo por el menor. Es éste precisamente uno de los problemas fundamentales que encontramos a diario: lograr constancia y continuidad de los menores en las actividades propuestas en el PEI.

Hay que destacar también como recurso de la intervención, aunque no aparecen en la tabla:

- El Equipo de Medio Abierto, como eje principal de la intervención en su labor de apoyo y tutorial.

- Los profesionales de los distintos Centros Sociales del Ayuntamiento.

- Los recursos propios del Centro Social.

- Otros recursos por derivación (p.e. Centros de Salud, etc)

- La propia familia del menor .

\section{VI.VALORACIÓN.}

6.1. Distribución de menores por actitud ante delito, educador y medida (casos de baja) $(n=50)$

Los criterios que hemos seguido para evaluar la actitud del menor ante el delito han sido:

- Positiva (el menor reflexiona adecuadamente sobre las consecuencias del hecho cometido y de su actitud).

- Indiferente (el menor no se plantea las consecuencias de su conducta).

- Negativa (el menor se muestra reforzado en su autoestima por la conducta desarrollada).

Los criterios que hemos tenido en cuenta para evaluar la actitud de la familia ante el delito han sido los siguientes: 
TABLA 16

\begin{tabular}{|l|r|r|r|r|r|r|r|r|r|r|r|r|}
\hline & \multicolumn{4}{|c|}{ MENOR } & \multicolumn{5}{|c|}{ FAMILIA } \\
\cline { 2 - 14 } & + & $\%+$ & $=$ & $\%=$ & - & $\%-$ & + & $\%+$ & $=$ & $\%=$ & - & $\%-$ \\
\hline Actitud ante el delito & 24 & 48 & 21 & 42 & 5 & 10 & 36 & 72 & 11 & 22 & 3 & 6 \\
\hline Actitud ante el educador/a & 38 & 76 & 9 & 18 & 3 & 6 & 37 & 74 & 11 & 22 & 2 & 4 \\
\hline Actitud ante la medida & 28 & 56 & 15 & 30 & 7 & 14 & 36 & 72 & 10 & 20 & 4 & 8 \\
\hline
\end{tabular}

Claves de la tabla anterior: "+" actitud positiva; "=" actitud indiferente; "-" actitud negativa.

- Positiva (la familia apoya al menor en su proceso de reflexión sobre la conducta negativa desarrollada y sus consecuencias).

- Indiferente (la familia no interviene ni apoya al menor en su proceso de reflexión sobre el hecho cometido).

- Negativa (la familia no da importancia al hecho y, de alguna manera, refuerza la conducta delictiva del menor).

Los criterios de evaluación según la actitud del menor ante el educador/a han sido:

- Positiva (el menor acepta al educador/a como figura de referencia).

- Indiferente (No acepta al educador/a como referente educativo, sino como figura coercitiva y de control).

- Negativa (el menor rechaza al educador/a).

Los criterios evaluativos para valorar la actitud de la familia ante el educador/a han sido los siguientes:

- Positiva (la familia acepta el rol del educador/a y colabora).

- Indiferente (la familia no entiende/asume el rol del educador/a).

- Negativa (la familia rechaza la figura del educador/a).

Los criterios que hemos seguido para evaluar la actitud del menor ante la medida (PEI) son:

- Positiva (el menor acepta la medida como una consecuencia válida a su conducta delictiva y colabora activamente en el desarrollo del PEI).

- Indiferente (el menor no entiende/asume la medida como consecuencia al hecho cometido y muestra una actitud pasiva ante el desarrollo del PEI).

- Negativa (el menor rechaza la medida y cualquier actividad que se proponga en el PEI).

Los criterios para evaluar la actitud de la familia ante la medida han sido:

- Positiva (la familia acepta la medida como consecuencia válida a la conducta del menor y se implica en el desarrollo del PEI).

- Indiferente (la familia no asume/entiende la medida y se muestra pasiva ante el PEI). 
- Negativa (la familia rechaza la medida como consecuencia válida a la conducta del menor y no colabora ni se implica en el desarrollo del PEI).

\subsection{Apreciación global del pronóstico de los menores $(n=50)$}

TABLA 17

\begin{tabular}{|l|c|r|}
\hline PRONOSTICO & TOTAL & $\%$ \\
\hline Muy positivo & 10 & 20 \\
\hline Positivo & 14 & 28 \\
\hline Dudoso & 16 & 32 \\
\hline Negativo & 10 & 20 \\
\hline
\end{tabular}

Los criterios que hemos tenido en cuenta en este apartado se han basado en una apreciación global del menor al finalizar la medida y en base a cómo ha desarrollado el P.E.I.

Por ello, consideramos un pronóstico muy positivo de evolución del menor después de la firma del cese de la medida en los casos en los que el menor ha desarrollado un P.E.I. de manera provechosa, cumpliendo la mayoría de los objetivos propuestos, ha aceptado en todo momento la figura del educador/a y la familia es capaz de apoyar y reforzar actitudes positivas en el menor. El pronóstico sería positivo si de los factores mencionados sólo se dan algunos, como, por ejemplo, que el menor haya desarrollado un P.E.I. adecuado, aceptando el rol del educador como referente educativo, aunque por parte de la familia no se haya conseguido un cambio positivo de actitudes respecto al menor. Hemos valorado como pronóstico dudoso los casos en los que el menor ha cumplido una parte del P.E.I. propuesto, pero no se aprecia un cambio real en sus actitudes, dentro de un ambiente familiar permisivo. Por último, hemos considerado un pronóstico negativo en los casos en los que el menor no ha desarrollado un P.E.I. de manera adecuada y desde la familia no hay apoyo suficiente para reforzar actitudes positivas en aquél.

6.3. Nivel de logro de la intervención según criterios de "evitar la reincidencia" y "lograr implicación en las actividades propuestas en el P.E.I."

TABLA 18

\begin{tabular}{|l|c|c|c|}
\hline NIVEL DE LOGRO & LIBERTAD V. & P.S.B.C. & INTERN. F.S. \\
\hline No reincidencia & $90 \%$ & $100 \%$ & $100 \%$ \\
\hline Implicación con el PEI & $68 \%$ & $100 \%$ & $85,71 \%$ \\
\hline
\end{tabular}


Según refleja la tabla, y sobre la base de los criterios que hemos considerado como fundamentales para medir el período de intervención, resulta más que evidente que el nivel de logro alcanzado ha sido muy alto durante el año 96 , lo cual avala considerablemente la validez y eficacia del programa.

\section{VII.COMENTARIO GENERAL Y CONCLUSIONES}

Como primera observación, mencionaremos que en la memoria del año 95 se contabilizaron 63 medidas ejecutadas y 60 menores atendidos, mientras que en la memoria de 1996 se han contabilizado 76 ejecutadas y 73 menores atendidos; por lo tanto, el incremento de un año para otro ha sido de 13 medidas y menores más.

Respecto a las medidas impuestas desde el Juzgado de Menores, la Libertad Vigilada sigue siendo la más utilizada, aunque no debemos olvidar que ha habido un notable aumento de las Prestaciones de Servicios en Beneficio de la Comunidad (de 3 casos en 1995 a 10 en 1996). Sin embargo, no se ha dado un aumento paralelo de entidades colaboradoras para la realización de dichas prestaciones.

Reseñar también que en 1995 se producía una demora de 4 a 5 meses entre el hecho cometido y la fecha de la resolución judicial. En 1996, lejos de acortarse este tiempo, se ha generado un aumento a una media de 6,41 meses entre ambas circunstancias, con lo que supone de pérdida de efectividad educativa con vistas a plantear al menor un proyecto socializador basado primariamente en la responsabilidad del hecho cometido. El tiempo transcurrido entre el hecho cometido, la resolución judicial y el inicio de la ejecución de la medida debería ser el menor posible dada la importancia educativa que posee para el menor la inmediata conexión entre su conducta delictiva y la medida que se desprende de la resolución.

El perfil del menor infractor y el de la familia de éste sería el de un chico de unos 15 años de edad, sin escolarizar, con grupo de amigos conflictivo, que consume sustancias tóxicas de las que se podrían calificar como "blandas" y de "síntesis" (sobre todo, en fines de semana), que convive en un núcleo familiar de pareja relativamente estable, con situaciones de paro crónico y nivel económico, por tanto, más bien bajo, usuarias habituales de servicios sociales y con hermanos que consumen también sustancias tóxicas y han manifestado conductas delictivas (cfr. Distinta tipología de familia según el tipo de medida).

El EMA (educador de medio abierto) sigue siendo la figura relevante en la intervención con el menor y, en gran número de casos, el 
único recurso educativo válido, ejerciendo funciones de tutoría social. Esto se da, sobre todo, en los casos que llegan durante el primer semestre del año, debido a que los talleres pre-laborales y demás cursos de formación general ya están iniciados desde el último trimestre del año anterior.

Resaltar también la dificultad de encontrar recursos adecuados para chicos menores de 16 años, para los que la escuela no es ya un recurso válido y tampoco pueden acceder a talleres pre-laborales ni al mercado laboral reglado por falta de edad. Todo esto nos puede conducir al riesgo de agotamiento del EMA como único recurso, especialmente, en los casos en los que la libertad vigilada se prolonga más allá de 8 ó 9 meses. En tales casos, se cuestionaría la efectividad y eficacia de las medidas de libertad vigilada de larga duración, ya que resulta complicado mantener el interés del menor dada la situación de escasez de recursos anteriormente descrita.

Cada vez es mas frecuente la necesaria coordinación con distintas entidades con las cuales tiene relación el educador debido a la concreción del PEI de cada menor (cfr. ver tabla de recursos utilizados.) Especial mención merece la relación con los profesionales de los distintos centros sociales del Excmo. Ayuntamiento de Alicante, donde el trabajo conjunto es bastante satisfactorio y la utilización de servicios gradualmente ira a más (sesiones terapéuticas y diagnósticas con el psicólogo/a, tratamientos de toxicomanías, ayudas puntuales económicas, intervenciones familiares, etc.)

El programa de seguimiento de medidas judiciales de medio abierto, se convierte en un buen catalizador de «destape» de necesidades (tanto del propio menor como de su entorno) que conlleva al incremento del nivel de intervención. En el caso del menor, es el EMA el profesional indicado para dar respuesta a la problemática presentada. En el caso de la familia, el EMA derivará al centro social la problemática para su conocimiento y actuación.

Es preocupante el incremento del numero de menores con problemática de toxicomanías. Este es un tema que no habrá que perder de vista en su evolución de cara a una intervención específica.

Otro aspecto que se hace cada vez mas necesario, en la intervención con el menor, es la necesaria implicación de la familia en el proceso resocializador. Implicar a la familia en tal proceso supone trabajar con ella y, en muchos casos, descubrimos otras carencias sobre las que hay que actuar.

Al finalizar el año, desde la Dirección General de Asuntos Sociales, se ha planteado un cambio en el procedimiento de derivación de los casos por parte de la Dirección Territorial. Sería deseable que una 
vez adaptado el funcionamiento no se produzcan desfases en la formalización del acta de inicio de la medida, estando presentes el menor y sus responsables educativos.

El programa de Seguimiento de Medidas Judiciales en Medio Abierto, según los datos aportados, ofrece una respuesta bastante apropiada a la realidad de los menores infractores (cfr. ver tabla de nivel de logro de la intervención) que otras actuaciones (internamientos cerrados) menos económicas y, en muchos casos, no mas idóneas para los objetivos pretendidos (responsabilización, no reincidencia, inserción, normalización social del menor).

Queda pendiente la profundización en los distintos temas mencionados (red de recursos, intervención familiar mas específica/especializada, etc.).

\section{PERSPECTIVAS PARA 1997}

I. Continuar con un sistema de evaluación cada vez más preciso, utilizando una base de datos adaptada y mejorada, en base a la hasta ahora utilizada.

II. Según el tipo de medidas ejecutadas en la actualidad, existe una serie de recursos que se han comprobado como válidos, pero insuficientes en bastantes casos. Seguiremos utilizando la oferta publica de los mismos, trabajando una adaptación mejor de estos a lo largo del año, así como sugeriremos otros recursos posibles que favorezcan la inserción social de los menores. Así mismo, según la frecuencia de las medidas, habría que trabajar más para la búsqueda de entidades colaboradoras para llevar a cabo la medida de PSBC.

III.Desarrollar un programa de mediación, dentro del programa general, para menores infractores en colaboración con el Equipo Técnico del Juzgado de Menores y con el/la Juez/a de menores.

IV.Desarrollar un proyecto de intervención grupal (en grupos pequeños) que complemente el trabajo eminentemente individual del programa, según características y necesidades de los menores, incidiendo en temas de comunicación, habilidades sociales, competencia social, resolución de conflictos, etc. que resulta necesario para muchos de estos menores.

V. Establecer un mecanismo fluido entre las distintas instancias que intervienen con el menor (Servicios Sociales Autonómicos, Juzgado de Menores, Ayuntamiento), así como precisar el procedimiento administrativo y funcional para llevar a efecto las medidas (comunicación de la resolución, informes del Equipo Técnico del Juzgado, citaciones, plazos, etc.). 


\section{ORGANIZACIÓN DE LOS SERVICIOS DE PROTECCIÓN A LA INFANCIA EN LA COMUNIDAD VALENCIANA. ANÁLISIS NORMATIVO Y FUNCIONAL}

\section{JOSÉ CONRADO MOYA MIRA}

Psicólogo. Jefe de la Sección de Familia, Infancia y Juventud de la Dirección Territorial de Bienestar Social de Alicante.

\section{INTRODUCCIÓN}

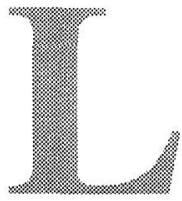

a Constitución Española de 1978 supone el punto de arranque de una nueva concepción de las responsabilidades que, respecto de la protección a la infancia, asumen las Entidades Públicas en nuestro país.

Esta nueva orientación atribuye un papel no sustitutivo de la función paterna y materna, sino que atribuye la responsabilidad de asegurar la protección a la infancia cuando se produzcan situaciones en las que los niños queden o estén en riesgo de quedar en situación de desamparo o desprotección, debiendo disponer los mecanismos necesarios para corregir tal situación.

Así, en el artículo 39 de la Constitución Española, se dice textualmente:

«1. Los poderes públicos asegurarán la protección social, económica y jurídica de la familia.

2. Los poderes públicos asegurarán también la protección integral de los hijos, iguales ante la ley, con independencia de la filiación y de las madres, sea cual sea su estado civil. La Ley hará posible la investigación de la paternidad.

3. Los padres han de prestar asistencia completa a los hijos tenidos dentro o fuera del matrimonio, durante la minoría de edad y en los otros casos en que la Ley obligue.

4. Los niños gozarán de la protección prevista en los acuerdos internacionales que velen por sus derechos».

Se deja en manos de la Entidad Pública competente la adopción de medidas para garantizar la protección de la infancia.

Esta capacitación de las Entidades Publicas para la adopción de medidas de protección se complementa con lo preceptuado en la 
Constitución cuando se posibilita que las distintas Comunidades Autónomas puedan asumir competencias plenas en materia de protección de menores.

En el caso de la Comunidad Autónoma Valenciana, la entrada en vigor del Estatuto de Autonomía (1982) da paso a un proceso de transferencias en materia de servicios sociales y, por tanto, de protección a la infancia, asumiendo en la actualidad competencias plenas en esta materia.

\section{ESTRUCTURA ORGÁNICA Y PROTECCIÓN A LA INFAN- CIA}

El proceso progresivo de asunción de competencias, por parte de las Entidades Públicas de Comunidades Autónomas, iniciado, en el caso de la Comunidad Valencia, en 1982, supone la recepción no sólo de centros y servicios, sino de los organismos por los que venían siendo gestionados, por ejemplo, las Juntas de Protección de Menores, el I.N.A.S., etc.

La necesidad de integrar en una estructura orgánica única todas las competencias en materia de Servicios Sociales y de Protección a la Infancia ha constituido un criterio asumido por la Generalitat Valenciana que, utilizando distintos modelos organizativos (Dirección General, Instituto Valenciano de Servicios Sociales, etc.), atribuye en la competencia exclusiva en materia de protección y guarda de menores a la Consellería de Bienestar Social.

De forma simultánea a la creación de una estructura única, se inicia un proceso de descentralización y desconcentración, que supone la organización de competencias relacionadas con los Servicios Sociales y con la Protección a la Infancia, atendiendo a dos niveles:

1. El nivel de Atención Primaria, que supone intervenciones de carácter preventivo y generalizado y cuya competencia es asumida por los Ayuntamientos o agrupaciones de Ayuntamientos.

2. El nivel de Atención Especializada, que supone intervenciones técnicas y complejas cuya competencia es asumida por la Generalitat y por algunos Ayuntamientos, cuando el ámbito de actuación sea local.

Este principio de descentralización se combina con el de globalización de la intervención, fijándose tres modalidades de intervención que pretenden configurar un modelo continuo basado en el desarrollo de medidas de carácter preventivo, asistencial y rehabilitador. 


\section{III.EL PAPEL DE LAS ENTIDADES PÚBLICAS CONFORME LA NORMATIVA BÁSICA DE PROTECCIÓN A LA INFANCIA A NIVEL ESTATAL.}

\subsection{LA LEY 21/87, de 11 de noviembre, por la que se modifican de- terminados artículos del Código Civil y de la Ley de Enjuicia- miento Civil en materia de adopción.}

La Ley 21/87, de 11 de noviembre, por la que se modifican determinados artículos del Código Civil y de la Ley de Enjuiciamiento Civil en materia de adopción, va a suponer una profunda transformación no sólo en la regulación de la adopción sino en el establecimiento de nuevas instituciones que inciden profundamente en la protección a la infancia, así como en lo referente a la organización competencial en esta materia.

La actuación para garantizar la protección a los menores en situación de desamparo (definido en el art. 172 del C.C.) pasa a ser competencia de las Entidades Públicas, a las que, en el respectivo territorio esté encomendada la protección de Menores, pudiendo ésta asumir la tutela de los mismos por ministerio de la ley, pasando el control judicial a un segundo término en caso de que fuera necesario la resolución de conflictos producidos por esta primera actuación.

Con la entrada en vigor de la Ley $21 / 87$, se produce una modificación muy importante de orden competencial, dado que queda suprimida la llamada «facultad protectora» de los Tribunales Tutelares de Menores, quedando ésta asumida por la Administración Autonómica.

Esta asunción de competencias por parte de la Entidad Pública Autonómica no supone la derogación expresa de la Ley de Tribunales Tutelares de Menores de 1948, cuestión que ha quedado resuelta con la entrada en vigor de la Ley Orgánica 1/96 de Protección Jurídica del Menor que, en su Disposición derogatoria única, dice textualmente: "Queda derogado el Decreto de 2 de julio de 1948 por el que se aprueba el texto refundido de la legislación sobre Protección de Menores y cuantas normas se opongan a la presente Ley".

Igualmente, atribuye al Ministerio Fiscal la superior vigilancia de la tutela, guarda o acogimiento resueltos por la Entidad Pública.

En cuanto a los principios que deben informar la actuación de las Entidades Públicas competentes en protección de menores, se establecen:

- El carácter prioritario del interés del menor.

- La necesidad de mantener al menor en su medio familiar siempre que sea posible. 
- La configuración de las instituciones de guarda, acogimiento y adopción como instrumentos de integración familiar.

- La utilización del recurso de internamiento sólo cuando sea indispensable y por el menor tiempo posible.

3.2. LA LEY ORGANICA 1/96, de 15 de enero (B.O.E. 17 de enero de 1996) de Protección Jurídica del Menor, de modificación parcial del Código Civil y de la Ley de Enjuiciamiento Civil.

La Ley Orgánica 1/96 viene a intentar dar respuesta a las lagunas que la aplicación de la Ley $21 / 87$ había puesto de manifiesto en sus ocho años de aplicación. Se aborda una reforma profunda de las instituciones de protección a la infancia partiendo del reconocimiento del menor de edad como sujeto participativo y activo, incidiendo en la idea de que la mejor forma de garantizar la protección a la infancia es promover su autonomía como sujetos.

La Ley Orgánica 1/96 establece los principios rectores que deben regular la actuación de la Entidad Pública, definiendo los siguientes:

1. La supremacía del interés del menor.

2. El mantenimiento del menor en el medio familiar de origen, salvo que no sea conveniente para su interés.

3. Su integración social y familiar.

4. La prevención de todas aquellas situaciones que puedan perjudicar su desarrollo personal.

5. Sensibilizar a la población ante situaciones de indefensión del menor.

6. Promover la participación y solidaridad social.

7. La objetividad, imparcialidad y seguridad jurídica en la actuación protectora, garantizando el carácter colegiado e interdisciplinar en la adopción de las medidas.

El artículo 14 de la L.O. 1/96 determina, igualmente, el principio de colaboración, que obliga a que "en toda intervención, se procurará contar con la colaboración del menor y de su familia y no interferir en su vida escolar, social o laboral".

En relación a las actuaciones de la Entidad Pública ante situaciones de desprotección social del menor, se definen dos tipos de situaciones:

a. Situación de riesgo. Definida como aquélla que pueda perjudicar el desarrollo personal o social del menor que NO requieran de la asunción de tutela por parte de la Entidad Pública.

b. Situación de desamparo. Definida como aquélla que se produce de hecho, a causa del incumplimiento, o del imposible o inadecuado ejercicio, de los deberes de protección establecidos por las leyes 
para la guarda de los menores, cuando éstos queden privados de la necesaria asistencia moral o material.

Ante las situaciones de riesgo, la Entidad Pública debe poner en marcha las actuaciones pertinentes para reducirlas y realizar el seguimiento de la evolución del menor en la familia.

Ante las situaciones de desamparo, la Entidad Pública debe adoptar las medidas de protección, asumiendo la tutela del menor/es y poniéndolo en conocimiento del Ministerio Fiscal.

La Entidad Pública asumirá la guarda del menor bien cuando previamente haya sido declarado en desamparo o bien a solicitud de los padres, cuando concurran circunstancias graves que impidan a aquéllos el cuidado de su/s hijos/s o en los casos en que sea determinado por el Juez competente.

La guarda de un menor podrá ser ejercida a través de las siguientes figuras:

A. ACOGIMIENTO FAMILIAR, que podrá adoptar las siguientes modalidades:

1. Acogimiento familiar simple: de carácter transitorio, bien porque se prevea la reinserción al núcleo familiar de origen bien hasta garantizar una medida de protección más estable.

2. Acogimiento familiar permanente, cuando la edad u otras circunstancias del menor así lo aconsejen.

3. Acogimiento familiar preadoptivo, formalizado por la Entidad Pública cuando eleve propuesta de adopción, o considere necesario establecer un periodo de adaptación del menor a la familia.

4. Acogimiento familiar provisional, posibilitando que la Entidad Pública resuelva en interés del menor, en los casos de no consentimiento u oposición de los padres, el acogimiento familiar en tanto se produce una resolución judicial.

B. ACOGIMIENTO RESIDENCIAL, procediendo al internamiento de un menor, procurando que tenga la menor duración posible, salvo que convenga al interés del menor.

Los centros u Hogares funcionales deberán estar autorizados y acreditados por la Entidad Pública, debiendo prestar especial atención a la seguridad, sanidad, número y cualificación profesional de su personal, proyecto educativo, participación de los menores en su funcionamiento interno y demás condiciones que contribuyan a asegurar sus derechos.

Se prestará especial atención a la obligación establecida en el artículo 22 de la Ley Orgánica 1/96 de informar a los padres, tutores o guardadores sobre la situación de los menores internos, cuando no exista Resolución Judicial que lo prohiba. 
C. $L A A D O P C I O N$. La tramitación de la adopción tanto nacional como internacional compete a las Entidades Públicas, pudiendo delegar determinadas funciones de mediación a Entidades acreditas.

En el caso de la Adopción Internacional, se estará a lo dispuesto en el Convenio Relativo a la Protección del Niño y a la cooperación en materia de adopción internacional (Convenio de la Haya).

No obstante esto, y a expensas de la regulación por parte de las Comunidades Autónomas de normativa que regule la acreditación de las Entidades de Mediación en materia de adopción Internacional, la Ley Orgánica 1/96 determina las funciones que podrán ser asumidas por éstas y que serán:

1. Información y asesoramiento a los interesados en materia de adopción internacional.

2. Tramitación de expedientes ante las autoridades españolas y extranjeras.

3. Asesoramiento y apoyo a los solicitantes de adopción.

Las Entidades Públicas deberán asegurar, en todo caso:

1. La recepción y tramitación de solicitudes, ya sea directamente o a través de Entidades acreditadas.

2. La expedición de los certificados de idoneidad y compromiso de seguimiento en los países que se requiera.

3. La acreditación, control, inspección y elaboración de directrices de actuación de las Entidades que realicen funciones de mediación en sus respectivos territorios.

La emisión de los certificados de idoneidad se realizarán a partir de la elaboración de los preceptivos informes psicosociales, pudiendo incorporar procesos de formación de familias que así lo deseen.

Indicar a este respecto que en la tramitación de Adopción Internacional hay países que ponen como requisito la existencia de un Certificado de acreditación de haber recibido formación, por lo que la Dirección General de Servicios Sociales ha implantado los referidos cursos a partir de septiembre de 1996.

IV.NORMATIVA BÁSICA DE PROTECCION DE MENORES A NIVEL DE LA COMUNIDAD AUTONOMA VALENCIANA.

Con anterioridad a la publicación y entrada en vigor de la Ley $21 /$ 87 en la Comunidad Valenciana, se había regulado una modalidad de acogimiento familiar con finalidad de retorno, conocido como familias educadoras. 
Igualmente, se publica el llamado Libro Blanco del Menor (1987) que pretende organizar las prestaciones, servicios y recursos dispuestos para la protección a la infancia de una manera eficaz.

En la Comunidad Valenciana, la Ley 21/87 fue desarrollada a través del Decreto 23/88 sobre medidas de protección de menores desamparados, modificado parcialmente con posterioridad por el Decreto $31 / 91$.

El Decreto 23/88 establece los criterios que orientan la actuación de la Administración Pública Valenciana en materia de protección de menores en situación de desamparo, los procedimientos que regirán la actuación de la Administración a fin de evitar la arbitrariedad de los Poderes Públicos y regula las medidas aplicables para garantizar las protección de menores.

Como consecuencia del desarrollo legislativo llevado a cabo tanto a nivel estatal como autonómico, el Gobierno Valenciano considera necesario dar rango de Ley a toda la normativa que de una manera dispersa había ido regulando el sector de infancia.

De esta manera se publica en D.O.G.V. de 16-12-94 la Ley $7 / 94$ de la Infancia de la Generalitat Valenciana, que tiene por objeto ordenar las competencias atribuidas a la Generalitat Valenciana, tanto en materia de protección de menores como en reforma de menores.

Así, se desarrollan los programas de atención a la infancia que deberán ser implantados para el cumplimiento de estas competencias, siguiendo los principios y criterios organizativos que a continuación se exponen.

\section{PROGRAMAS DE PROTECCIÓN A LA INFANCIA EN LA COMUNIDAD VALENCIANA.}

Como ya he indicado anteriormente, los programas de protección a la infancia vigentes en la Comunidad Autónoma Valenciana se rigen por una organización que distingue dos niveles de intervención:

1. El Nivel de Atención Primaria, recayendo la responsabilidad de su implantación en los Ayuntamientos, a través de los Servicios Sociales Generales.

2. El Nivel de Atención Especializada, competencia de la Generalitat Valenciana y de los Ayuntamientos, en los casos recogidos en la Ley de Servicios Sociales.

Estos niveles de intervención estructuran secuencias de prestaciones y servicios que configuran programas en torno a una concepción de necesidades de la infancia agrupadas en cinco grandes esferas: 
1. Necesidades de información.

2. Necesidades de accesibilidad.

3. Necesidades de cooperación.

4. Necesidades de convivencia.

5. Necesidades de reinserción.

Sin entrar detalladamente a cada uno de ellos enunciaré el desarrollo previsto en la Ley $7 / 94$.

\subsection{Programas de información.}

a. Nivel Primario:

- Campañas informativas y de sensibilización.

- Servicios de asesoramiento y primer diagnóstico.

b. Nivel Especializado:

- Campañas autonómicas de información y sensibilización.

- Servicios de diagnóstico especializado.

\subsection{Programas de accesibilidad.}

a. Nivel Primario:

- Seguimiento del absentismo escolar.

- Promoción de la salud infantil.

- Fomento de la inserción prelaboral.

b. Nivel Especializado:

- Prevención de los malos tratos.

- Integración escolar.

- Medidas laborales de inserción.

- Eliminación de barreras arquitectónicas y de comunicación.

\subsection{Programas de cooperación.}

a. Nivel Primario:

- Promoción de la autoayuda.

- Fomento del voluntariado social.

- Promoción de organizaciones solidarias.

b. Nivel Especializado:

- Acreditación de centros y servicios.

- Regulación del régimen de cooperación.

- Reconocimientos de las instituciones colaboradoras de integración familiar. 


\subsection{Programas de convivencia.}

a. Nivel Primario:

- Ayuda familiar (económica, educativa, etc.).

- Acogimiento familiar de carácter primario (f. educadora/ext.).

b. Nivel Especializado:

- La terapia familiar.

- El acogimiento familiar de carácter especializado.

- El acogimiento en Residencias.

- La emisión de Propuestas previas para adopción.

\subsection{Programas de reinserción.}

Estos programas van dirigidos a jóvenes que presentan problemas de inadaptación y que se encuentran cumpliendo medida judicial dictada por el Juzgado de Menores.

En su desarrollo entraremos con posterioridad, cuando tratemos la intervención de la Entidad Pública en materia de ejecución de medidas judiciales impuesta a jóvenes infractores.

De las secuencias de prestaciones y servicios que permiten el desarrollo de Programas de Atención a la Infancia, se puede concluir que la Ley no entiende la protección a la infancia como la implantación de un sistema dicotomizado en medidas de internamiento o de acogimiento familiar, sino que, por el contrario, se estructura un continuo de programas que garanticen una estructura sólida de Prevención, asistencia y reinserción.

En el desarrollo de estos Programas no sólo está implicado y reponsabilizado el sistema de Servicios Sociales, sino que se reconoce como indispensable la integración y articulación de las acciones promovidas desde el resto de sistemas de atención a la infancia (Educación, Sanidad, ocio y tiempo libre, etc.).

Así, en el Preámbulo de la Ley 7/94, se dice textualmente:

«Las nuevas necesidades de los niños, la calidad de los servicios de la infancia y la promoción de nuevas oportunidades requieren de una articulación adecuada de las administraciones educativas, sanitarias, sociales, culturales y de preparación al mundo laboral.» 
VI.PRINCIPIOS QUE ORIENTAN LA ORGANIZACIÓN DE RECURSOS PARA EL DESARROLLO DE PROGRAMAS DE PROTECCIÓN A LA INFANCIA.

Para entender la organización e implantación actual de los recursos dispuestos para promover el desarrollo de los Programas de Protección a la Infancia es necesario analizar su proceso de configuración íntimamente relacionado con el desarrollo de los Servicios Sociales en nuestra Comunidad Autónoma.

Así, los recursos con los que la Generalitat Valenciana contaba en el momento de asumir las competencias de protección de menores se reducían a dos posibilidades:

1. El mantenimiento del niño/a en su domicilio con algunos apoyos de índole económica (en el mejor de los casos).

2. El ingreso en un centro de internamiento.

De forma paulatina se operaron cambios profundos en el sistema de protección a la infancia que pasaban necesariamente por:

1. Objetivar los procedimientos de valoración de solicitudes de utilización de servicios especializados.

2. Ampliar los recursos disponibles en la red básica de Servicios Sociales (Atención Primaria), de forma que fuera posible desarrollar y diversificar actuaciones preventivas eficaces y sistemas de detección precoz de los casos.

3. La mejora de las prestaciones de los centros de infancia a partir de cambios que afectarán a la organización, infraestructura, profesionalización...

4. El desarrollo de los programas de acogimiento familiar dispuestos, tanto con finalidad de retorno al núcleo familiar de origen como de proporcionar una alternativa familiar a menores pertenecientes a familias cuyo pronóstico de recuperabilidad fuese negativo.

5. La diversificación de otros programas de atención especializada que fueran capaces de no bipolarizar el tipo de respuesta (acogimiento familiar-acogimiento residencial) ofertada a la infancia en situación de desprotección social.

Entraré en el desarrollo de los puntos concernientes al acogimiento residencial.

\subsection{Objetivar procedimientos de utilización de servicios especiali- zados.}

Las medidas de protección a la infancia hasta principios de la década de los años 80 estaban basadas fundamentalmente en medidas de 
internamiento o de mantenimiento en domicilio con algunos apoyos económicos.

Los niños/as eran acogidos en instituciones de forma poco objetiva, produciéndose una falta de rigurosidad en los procesos de valoración de problemáticas que aconsejaban el internamiento. De esta forma, podíamos encontrarnos en los centros menores cuyo único problema familiar era la falta de recursos económicos, junto a otros cuyas problemáticas eran mucho más agudas (malos tratos, abandono, etc.).

La implantación progresiva de la red de atención primaria de nivel municipal, el establecimiento de equipos de recepción de nivel provincial capaces, los primeros, de detectar, prevenir y prestar un primer nivel de asistencia generalizado a las situaciones de riesgo en las que pudiera encontrarse un menor $\mathrm{y}$, los segundos, de objetivar y unificar criterios de utilización de recursos de nivel especializado, han provocado efectos positivos, entre los que destacaría:

- Una mayor especialización de los equipos de atención primaria que trabajan con infancia (todavía no suficiente).

- Reducción del número de plazas de internado.

- Fomento de programas de apoyo a la familia, con carácter preventivo.

Igualmente, y como en cualquier proceso, se detectan efectos no deseables, consecuencia de la aplicación de los nuevos criterios de tratamiento de la problemática infantil. Entre ellos, destacaría:

- La mayor complejidad de los casos que llegan a los internados, dado que se atienden casos que han experimentado situaciones de grave deprivación, abandono o maltrato en sus propias familias.

- El agrupamiento de menores que acceden a los internamientos en dos bloques de edades, primera infancia y adolescentes.

- Aparición de nuevas problemáticas, como, por ejemplo, el consumo de tóxicos, agresividad y falta de control extremo, absentismo escolar persistente, aislamiento y dificultad para responder a los demás, etc.

De forma paulatina, los acogimientos residenciales pierden su carácter de contraposición al resto de posibles medidas a adoptar y entra a formar parte de un continuo de alternativas posibles que, además, es recomendable para determinado tipo de problemáticas que no pueden mantenerse en acogimientos familiares o en familia biológica.

En definitiva, la mejora de los procesos de objetivación y valoración de casos de menores que puedan encontrarse en situación de riesgo o desamparo es un objetivo permanente, necesario, para: 
1. Dar cumplimiento a lo dispuesto en el art. 11 y 16 de la Ley Orgánica 1/96 que establece "que la Entidad Pública regirá su actuación garantizando la objetividad, imparcialidad y seguridad jurídica en la actuación protectora, garantizando igualmente el carácter colegiado e interdisciplinar en la adopción de las medidas.

2. Que la Entidad Pública deberá verificar la situación denunciada y adoptará las medidas necesarias para resolverla en función del resultado de aquella.

3. Posibilitar la utilización de los recursos y prestaciones que a cada caso convenga, individualizando en lo posible, el tratamiento del caso".

\subsection{Ampliación de recursos en el nivel de atención primaria.}

El desarrollo del sistema de protección a la infancia ha estado íntimamente relacionado con la implantación de la red de Servicios Sociales en nuestro país.

El criterio de municipalización de los recursos ha sido determinante en la organización y desarrollo de los Servicios Sociales y, por tanto, del sistema de protección infantil.

Con su aplicación, se ha dado una importancia relevante al desarrollo del nivel de atención primaria de los servicios sociales. Este nivel de atención primaria garantizará la implantación de las llamadas prestaciones básicas de carácter polivalente y generalizado.

El carácter polivalente de la atención primaria pretende acabar con la extrema sectorización de la red de servicios sociales existentes en los primeros años de la década de los ochenta.

La implantación de los Servicios Sociales de nivel primario es potenciado desde las propias Comunidades Autónomas con la colaboración de las Entidades locales y reciben un impulso definitivo con la implantación, en el año 1988 y por parte del Ministerio de Asuntos Sociales, del llamado Plan Concertado.

Las medidas previstas dentro de los distintos programas a nivel de atención primaria pretenden un triple objetivo:

a. Garantizar el acceso al sistema de servicios sociales de la población en general, así como la detección temprana de casos que se encuentren en posible situación de desprotección.

b. Garantizar la implantación de un nivel de prestaciones básicas que aseguren la atención de los usuarios sin necesidad de separación innecesaria del núcleo familiar de convivencia.

c. Elaborar los informes técnicos pertinentes que diagnostican y fundamentan una solicitud de atención del caso desde los servicios de nivel especializado. 
En el nivel de atención primaria, aparece, como especialmente necesario, la implicación de los sistemas que intervienen en la protección infantil, sobre todo de Educación, Sanidad, Servicios Sociales, así como de otros organismos judiciales, o incluso del ámbito policial, que asegure la rapidez en las actuaciones y la objetividad e imparcialidad que debe regir en la actuación de las Entidades Públicas en materia de protección de menores.

Respecto de los tres objetivos que se pretenden con el desarrollo del nivel de atención primario de protección infantil, podríamos indicar lo siguiente:

- Que comienzan a estructurarse fórmulas de coordinación intersistemas que permiten la detección precoz de situaciones de riesgo o desamparo, aunque sigue siendo necesario ampliar el conocimiento que respecto de los procedimientos de protección a la infancia tienen los ciudadanos en general y los profesionales en particular.

- La existencia de equipos técnicos interdisciplinares garantizan procedimientos ágiles de elaboración de diagnósticos que asegurando la objetividad de las medidas propuestas a adoptar con los menores, resulten ágiles y eficaces.

- Sin embargo, el nivel de asistencia a casos, promoviendo medidas que den respuesta integral a la situación de desprotección en la que se encuentra o puede encontrarse un niño, procurando su integración familiar, es, en mi opinión, todavía muy insuficiente y debe ser el objetivo básico a conseguir en los próximos años.

El insuficiente desarrollo de los servicios de intervención familiar, desde el nivel primario de actuación, provoca, en ocasiones, el acceso innecesario de algunos casos a servicios de nivel especializado.

Las medidas de atención primaria han sido dispuestas de forma jerárquica, así, en lo referente a los Programas de Convivencias, se han dispuesto medidas que van desde los apoyos económicos a la familia hasta programas de acogimiento temporal con finalidad de retorno al núcleo familiar de origen (acogimiento provisional según L.O. 1/96), pasando por los programas de intervención familiar de carácter educativo o de ayuda a domicilio.

Sin embargo, denotamos que estos programas han recaído sobre los Equipos Municipales de Servicios Sociales Generales que tienen como encargo la implantación del resto de medidas previstas con carácter general y polivalente para todos los sectores de población.

Este hecho provoca que no exista la necesaria especificidad en el desarrollo de los programas de nivel primario destinados a la protección a la infancia y se produzcan situaciones no deseadas como las anteriormente referidas. 
Es por ello que parece oportuno potenciar la creación de un nivel intermedio entre la atención primaria y la atención especializada capaz de abordar situaciones específicas de menores en situación de riesgo, diversificando de esta manera la secuencialización de prestaciones y servicios.

\subsection{La mejora en la organización y prestaciones de los centros.}

Respecto del trabajo realizado en centros de infancia, ha pasado por abordar procesos de normalización de la atención a los menores allí atendidos, evitando la dinámica de Institución Total y procurando la incorporación a los servicios de la redes ordinarias de Educación, Sanidad, Servicios Sociales, culturales, etc.

Se han realizado actuaciones dirigidas a mejorar la infraestructura de los centros, las dotaciones de personal, la diversificación de tipologías de centros y, en definitiva, la delimitación de condiciones necesarias que debe cumplir un Centro para autorizar su funcionamiento en el territorio de la Comunidad Valenciana. Para ello, se desarrolló normativamente el llamado plan de ordenación de los servicios sociales de la Comunidad Valenciana, en los que quedaban incorporados los centros y servicios de atención a la infancia.

Se aborda el desarrollo de Proyectos Educativos, Regalamentos Régimen Interior que deben incorporar dinámicas de funcionamiento interno de los centros que garanticen los derechos reconocidos a la infancia en los tratados internacionales y la legislación nacional.

Todos estos procesos deben entenderse en un continuo cuya consecución pasa por distintos niveles y en cuyo desarrollo aparecen situaciones favorecedoras o que dificultan su implantación.

Revisaré a continuación cada uno de los puntos citados.

\section{3.a. Aplicación del criterio de normalización en los centros.}

El criterio de normalización debe entenderse en relación a:

- La utilización de la red ordinaria de servicios (Educación, Sanidad...) por los menores internos. Este aspecto podemos decir que está prácticamente cubierto, dado que es muy difícil encontrar centros que mantengan servicios internos para los menores atendidos. Sin embargo, habría que plantearse las condiciones en las que vienen siendo atendidos estos menores u otros que, sin estar en internados, requieren de una actuación compensatoria desde los recursos normalizados.

- Las condiciones estructurales que disponen los lugares de convivencia en los que se desarrolla el niño que permanece interno en 
una institución. Teóricamente, los equipamientos residenciales deberían ser lo más similares posibles a los que viven la mayoría de los niños, en cuanto a tamaño, emplazamiento, etc. Sin embargo, hemos visto como políticas de potenciación de uso de viviendas normalizadas como recursos de internamiento han fracasado fundamentalmente por criterios económicos.

- Las dinámicas de vida cotidiana deben asegurar un sistema de relaciones interpersonales lo más parecidas posibles a las del resto de los niños. Igualmente, nos encontramos aquí ante organizaciones institucionales especialmente rígidas que impiden aprendizajes que desarrollen niveles de autonomía personal suficiente.

\section{3.b. Mejora de la infraestructura de los centros.}

La infraestructura de los centros transferidos obedecía a unas finalidades que son totalmente diferentes a las que actualmente se pretenden. Para resolver esta cuestión ha sido necesario acometer remodelaciones internas que aseguraran la posibilidad de desarrollar programas educativos ajustados a las necesidades de los menores en ellas atendidas. Por ejemplo, reducir la capacidad de los dormitorios promoviendo capacidad individual o doble, adecuar el edificio a las necesidades de menores con dificultades de movilidad, etc.

\section{3.c. El establecimiento de condiciones mínimas para autorizar el funcionamiento de los centros.}

La necesidad de ordenar y diversificar los equipamientos residenciales dedicados a la protección de menores ha requerido que, en un primer momento, se establecieran la tipología de equipamientos institucionales, definir su funcionalidad, determinar sus prestaciones y establecer las dotaciones de personal (en número y cualificación) necesaria para un correcto funcionamiento. Estas serían las condiciones necesarias para que la Entidad Pública autorizara el funcionamiento de un centro de protección a la infancia.

\section{3.d. Diversificación de las tipologías de centros.}

Los centros de la Comunidad Valenciana han sido clasificados en función de la tarea a desarrollar y la edad de los usuarios en Centros de Recepción y Acogida, Residencias Comarcales, Residencias Infantiles, Residencias Juveniles y Centros de Reeducación.

Esta tipología de recursos deberá ser revisada, dado que no parece adecuado seguir manteniendo criterios como mantener en un mismo 
tipo de centros a menores de edades entre 6-18 años o resolver el debate de si pueden ser atendidos en los mismos centros menores de protección y reforma.

\section{3.e. La profesionalización de los centros vs. el voluntarismo}

Uno de los criterios en los que se ha basado la reorganización de los centros de infancia ha sido el mejorar la profesionalización de las prestaciones. En este proceso de profesionalización ha sido fundamental la situación de falta de reconocimiento y formación específica de la figura profesional del educador, que ha mantenido en una permanente e innecesaria situación de conflictividad a los centros de infancia. Este hecho, junto con la falta de definición del papel del voluntariado en los programas de atención a la infancia, provoca, en ocasiones, debates que no esconden, en mi opinión, sino intereses de tipo económico.

En este momento, la entrada en vigor de la Ley del Voluntariado y el reconocimiento como titulación universitaria de Grado Medio de los estudios de educador social crean las condiciones idóneas para acometer una ordenación eficaz que regule la participación del voluntariado de los centros de infancia sin necesidad de confrontación con la siempre deseable mejora de la profesionalización de los mismos.

Igualmente necesario, en mi opinión, es la incorporación de equipos técnicos a las residencias de menores, dado que el aumento de la complejidad de los casos allí atendidos así lo requiere.

Por último, hacer referencia a la necesidad de mantener sistemas de formación continua que posibiliten una adecuación de la práctica cotidiana a las necesidades de la población atendida.

\section{3.f. Incorporar en los centros dinámicas internas que aseguren el} ejercicio de los derechos reconocidos a la infancia.

El desarrollo de la normativa reguladora del funcionamiento de los centros, a través del Estatuto Básico de los Centros de Infancia y Juventud, la obligación de que los equipos profesionales definan objetivos generales de la institución, a través de los Proyectos Educativos, o que se establezcan las estrategias organizativas y de funcionamiento interno de los centros, a través de los Reglamentos de Régimen Interior, son los mecanismos utilizados para asegurar un sistema de garantías en el ejercicio de los derechos de los menores internos.

No obstante estos esfuerzos, es necesario seguir profundizando en la concreción de desarrollos normativos que aseguren sistemas de fun- 
cionamiento interno participativos, orientados a potenciar la autonomía personal, que tomen como objeto de intervención no sólo al niño sino, y fundamentalmente, a la familia, y, en definitiva, que aseguren de forma inequívoca el ejercicio de los derechos reconocidos a la infancia.

\section{3.g.}

Por último, me gustaría destacar la necesidad de encuadrar los equipamientos residenciales en la red de protección infantil, evitando su consideración como recurso aislado. Por el contrario, es necesario potenciar la creación de redes que permitan el desarrollo de procesos coherentes y globales de evaluación-atención y retorno a domicilio o a otra medida de protección de carácter permanente integrando recursos previstos en los niveles de atención primaria y especializada.

\subsection{Desarrollo de programas de acogimiento familiar.}

La medida de acogimiento familiar, entendida como el confiamiento de un menor a una familia distinta a la suya, para que le cuide y eduque, ha sido una de las formas de autoauyuda más antiguas como forma de atender a una familia que atraviesa dificultades.

Se reconoce como una medida de apoyo entre familias que disponen de una red social suficientemente amplia y dispuesta a prestar apoyo en momentos de crisis.

Sin embargo, hay familias que no cuentan con otros adultos en los que puedan confiar suficientemente cuando se encuentran en grave dificultad, por tanto, cuando se encuentran en situación de crisis, requieren de ser apoyados de forma temporal o permanente por otras familias ajenas a su ámbito.

En la evolución que ha seguido el acogimiento familiar, en lo relativo al procedimiento de formalización, se ha pasado de una forma de resolución, a partir del acuerdo mutuo entre partes, a ser necesaria la participación de la Entidad Pública, tanto en procesos de mutuo acuerdo cuando, sobre todo, no existe acuerdo.

La regulación normativa sobre el acogimiento familiar, así como su promoción, han ido unidos a la evaluación que, respecto de las consecuencias negativas de los internamientos de menores, se realizan a partir de la Segunda Guerra Mundial.

Así, en nuestro ordenamiento jurídico, podemos observar:

1. La escasa utilización, y relacionada en la mayoría de los casos con situaciones que no quedan abiertas a la adopción, cuando se apli- 
caba la normativa contenida en el texto refundido de la Ley de Tribunales Tutelares de Menores (1948). Nos referimos a la llamada colocación en familia.

2. El aumento del número de casos atendidos en acogimiento familiar temporal (con previsión de retorno) se produce a partir de 1980 con la implicación de las Entidades Públicas Municipales y de Comunidades Autónomas. En esta ocasión, se utiliza como recurso social dispuesto para la cobertura de un tipo de necesidades para las que no existía un dispositivo adecuado, dado que éstos se reducían a internamientos, adopciones o mantenimiento en domicilio. Las Comunidades Autónomas pioneras en este tipo de programas de Acogimiento Familiar Temporal fueron Cataluña (1983) y Valencia con el programa de Familias Educadoras (1986).

3 . Con la entrada en vigor de la Ley $21 / 87$, se introduce la figura de! acogimiento familiar, siendo posible su formalización a partir de un procedimiento administrativo o judicial. Esto posibilita la aparición de distintas modalidades de acogimiento familiar conforme los desarrollos reglamentarios que aparecen en cada una de las Comunidades Autónomas.

Así, en la Comunidad Autónoma Valenciana se regulan las siguientes modalidades (Decreto 23/88) de acogimiento familiar:

a. El Acogimiento por una Familia Educadora: cuando se trate de desarrollar un proyecto educativo global y se pretenda el retorno del menor a su domicilio. La intervención de la Familia Educadora no se limita al acogimiento del menor sino que se compromete a apoyar procesos de recuperación de la familia biológica.

b. El acogimiento en los casos de suspensión de guarda y educación abiertos a la reinserción familiar.

c. Los acogimientos previos a la formalización de la adopción.

4. Tras la aplicación de estas modalidades de acogimiento familiar, se producen modificaciones importantes tanto a nivel de Comunidad Autónoma Valenciana (Ley 7/94 de la Infancia, Generalitat Valenciana) como muy recientemente las modificaciones incorporadas por la Ley Orgánica 1/96 de Protección Jurídica del Menor. Analizando ambos marcos legales, es posible desarrollar un cuadro comparativo a partir de los siguientes criterios:

- Instancia administrativa a quien compete su implantación.

- Objetivo y finalidad del acogimiento.

- Tipo de acogedor/es.

- Características del menor acogido y su familia.

- Organismo responsable de la Formalización y resolución.

- Tiempo previsto de duración. 
Teniendo en cuenta cada uno de ellos, paso a sintetizar, en los cuadros siguientes, las distintas modalidades de acogimiento actualmente vigentes, no sin antes dejar claro que podrían ser otras muchas variables a partir de las que es posible establecer una clasificación de los acogimientos familiares (naturaleza de la intervención, modalidad de formalización, compensación-retribuido o no retribuido, nivel de participación de la familia origen, etc.).

\subsection{Ampliación de programas de nivel especializado.}

La red de protección infantil necesita de un desarrollo de servicios especializados capaces de diversificar las prestaciones existentes y posibilitar una atención más individualizada a las necesidades infantiles dado que éstas se encuentran en permanente cambio y una estructura bipolarizada de servicios residenciales y de acogimiento familiar aparece como claramente insuficiente.

Esta ampliación de programas de nivel especializado no debe atender exclusivamente a la modalidad de intervención asistencial o rehabilitadora prevista para la atención a la infancia, sino que es indispensable su crecimiento en la modalidad de intervención de carácter preventivo.

En mi opinión, la idea que fundamenta la necesidad de crecimiento de este tipo de programas sería: Toda la legislación vigente en materia de protección a la infancia pone en juego dos principios que deben orientar la actuación de las Entidades Públicas. Estos principios, como ya hemos referido, son "el respeto al supremo interés del niño" y "el mantenimiento del menor en su medio familiar de origen salvo que no sea conveniente para su interés".

En la práctica, lograr que no entren en colisión ambos principios resulta, en ocasiones, muy dificil. Pensemos que limitar las posibilidades de actuación ante situaciones de desprotección infantil a la utilización de programas de atención primaria dispuestos para situaciones no especialmente complejas o a acogimientos familiares o residenciales supone la renuncia a poder atender conflictos que se producen en sistemas familiares multiproblemáticos, atribuyendo el calificativo de no recuperables a familias con las que no hemos sido capaces de desarrollar programas realmente especializados y adecuados a las necesidades planteadas que, asegurando la necesaria protección al niño/a permitan a su vez desarrollar un trabajo de intervención familiar que posibilite iniciar procesos de recuperabilidad de la familia, capacitándola para poder atender a su hijo, haciendo compatible los dos principios básicos de la protección infantil. 
Pero, ¿de qué tipo de programas estaríamos hablando?. Como he indicado anteriormente, sería necesario el desarrollo de estos programas desde las distintas modalidades de intervención, es decir, desde la prevención, la asistencia o la rehabilitación. Citaré algunos ejemplos que, en mi opinión, serían significativos.

DESDE LA PREVENCIÓN, sería deseable la incorporación y desarrollo de programas de mediación familiar. Pensemos que un gran número de los niños/as que se encuentran en situación de riesgo pertenecen a familias que se encuentran, o han pasado, por conflictos derivados de procesos de separación familiar o divorcio. Por este motivo, implantar de forma generalizada programas de mediación familiar, cuya finalidad primordial es el "evitar enfrentamientos inútiles entre la pareja y su incidencia negativa entre los menores, así como fomentar la coparentalidad", parece puede ampliar la red de programas eficaces para la prevención de procesos negativos que afecten al bienestar infantil. Esta modalidad de programas vienen siendo desarrollados en la Comunidad Autónoma de Madrid y, al parecer, las evaluaciones realizadas al respecto desprenden resultados satisfactorios.

DESDE LA ASISTENCIA. Nos enfrentamos, en esta segunda modalidad de intervención, ante situaciones que ya están produciendo un daño en el niño/a, provocando una situación de riesgo o desamparo. Es por ello necesario adoptar medidas que, asegurando la protección del niño/a, permitan desarrollar programas de recuperación familiar. En este sentido, parece muy interesantes experiencias que se han desarrollado tanto en nuestro país como en el extranjero. Me refiero a programas que combinan, simultáneamente, la protección del niño/a, asegurando dispositivos de separación provisional del núcleo familiar biológico (bien en acogimiento residencial o familiar) y programas de intervención (o terapia) con la familia biológica. Cito ejemplos como el Centro para el niño maltratado y el tratamiento de la familia en crisis de Milán o los programas de acogimiento familiar especializado con finalidad de reintegración familiar.

DESDE LA REHABILITACIÓN. Trataríamos, por último, de atender situaciones que, habiendo pasado por procesos intensos de crisis, requieren de apoyos para poder retomar procesos normalizadores de vida cotidiana. Dentro de este tipo de programas, merecería especial importancia los de terapia familiar, llevados a cabo de forma simultánea con programas de incorporación al mundo laboral u otros programas destinados a atender problemáticas específicas de alguno/s miem$\mathrm{bro} / \mathrm{s}$ de la unidad de convivencia (tratamientos de salud, drogodependencias, etc.). 


\section{VII.LA ACTUACIÓN DE LA ENTIDAD PÚBLICA EN MATERIA DE EJECUCIÓN DE MEDIDAS DICTADAS POR LOS JUZGA- DOS DE MENORES.}

Con la entrada en vigor de la Ley Orgánica 4/92 de 5 de junio, sobre reforma de la Ley Reguladora de la competencia y el procedimiento de los Juzgados de Menores, surgida como consecuencia de la Sentencia 36/1991 del Tribunal Constitucional, por la que se declaraba inconstitucional el art. 15 de la Ley de Tribunales Tutelares de Menores de 1948, se viene a cubrir la falta de un procedimiento específico adaptado a la situación del menor, pero en absoluto supone una reforma en profundidad del sistema de Justicia Juvenil existente en nuestro país.

No obstante, la Ley Orgánica 4/92 introduce importantes modificaciones, como, por ejemplo, las siguientes:

- Atribución al Ministerio Fiscal de la defensa de los derechos, la observancia de las garantías y el cuidado de la integridad física y moral del menor.

- Atribución al Ministerio Fiscal la instrucción de los expedientes de los menores a los que se le impute la comisión de un delito o falta.

- Reconocimiento a los menores de los derechos que se establecen en la Ley de Enjuiciamiento Criminal para los adultos.

- Obligatoriedad de requerimiento de un informe sobre situación psicológica, educativa, familiar y social del menor, en el momento resulte imputado.

En relación al papel de la Entidad Pública en la jurisdicción de menores, cabe decir que la Disposición Adicional Tercera de la Ley Orgánica 4/92 dice textualmente: «La ejecución de las medidas adoptadas por los Juzgados de Menores corresponde a las Entidades Públicas competentes en la materia».

Igualmente, se atribuye competencia a las Entidades Públicas en cuanto a la adopción de medidas educativas y formativas respecto de: 1. Menores de 12 años que hubieran cometido delitos o faltas según las leyes penales.

2. Mayores de 12 años y menores de 16 que, habiendo cometido un delito o falta, el Juez de Menores determine su remisión a las Instituciones administrativas, siempre y cuando en la comisión de los hechos no se hubiera utilizado grave violencia o intimidación. 


\section{VIII.PROGRAMAS DE REINSERCIÓN Y EJECUCIÓN DE MEDI- DAS DICTADAS POR LOS JUZGADOS DE MENORES.}

Para la ejecución de las medidas que determina el Juez de Menores, conforme a la Ley Orgánica 4/92, la Generalitat Valenciana ha diseñado los Programas de Reinserción previstos en Ley 7/94 de la Infancia.

Los medidas previstas dentro de los Programas de Reinserción son las siguientes:

A. De Atención Primaria (Competencia municipal).

1. La amonestación.

2. La libertad vigilada.

3. El asesoramiento educativo, terapeútico y ocupacional.

4. La prestación de servicios en beneficio de la comunidad.

5. El internamiento de uno a tres fines de semana.

6. La reparación extrajudicial.

B. Alternativas a la ejecución del nivel primario (competencia municipal).

1. La instrucción de apoyo.

2. La instrucción de tratamiento terapéutico.

3. El asesoramiento educativo.

C. De atención Especializada (Competencia de la Generalitat).

1. El acogimiento por otra persona o núcleo familiar.

2. El tratamiento ambulatorio.

3. El ingreso en un centro de carácter terapéutico.

4. El ingreso en un centro en régimen abierto, semiabierto o cerrado.

La no definición de las medidas en la Ley 4/92 provoca que se definan en la Ley 7/94 de la Infancia, pero esta definición es, también parcial, lo que podría suponer inseguridad jurídica para los menores.

A lo largo de estos cinco años de aplicación de la L.O. 4/92, la imposición de las medidas impuestas por los Juzgados de Menores ha estado fuertemente bipolarizada, utilizándose, fundamentalmente, las de libertad vigilada y la de internamiento en sus distintos regímenes, siendo el tratamiento ambulatorio una medida que se adopta con frecuencia, acompañando a la medida de internamiento. No obstante, es de destacar, en el último año, el aumento de la imposición de medidas de prestación de servicios en beneficio de la comunidad.

Del resto de las medidas, cabría indicar que algunas se han utilizado en muy pocas ocasiones, como, por ejemplo, la reparación extrajudicial, las de acogimiento familiar. 
Algunas de estas medidas, no desarrolladas suficientemente, sí lo han sido en otras Comunidades Autónomas, siendo evaluadas como altamente eficaces. La más destacable, sin duda, son los resultados que están siendo obtenidos con la implantación de servicios de mediación extrajudicial, cuyo objetivo es lograr un tratamiento del menor infractor por fuera de lo que supone la judicialización del expediente.

\section{IX.ORGANIZACIÓN DE RECURSOS PARA LA EJECUCIÓN DE MEDIDAS JUDICIALES}

La Generalitat Valenciana, desde el momento que asume las competencias en esta materia, ha ido promoviendo la organización de recursos que garantizaran el cumplimiento de su responsabilidad.

Así, de forma progresiva, se han ido incorporando profesionales a los Equipos Sociales de Base Municipales que se encargan directamente de ejecutar los programas educativos que dan contenido a las medidas judiciales de orden abierto (libertad vigilada, prestación de servicios en beneficio de la Comunidad, etc.).

El número de profesionales que actualmente están asignados a Equipos Base Municipales de la Comunidad Valenciana lo han hecho en dos modalidades: la primera, ampliándose los equipos de atención primaria, la segunda, creando o concertando con Entidades sin ánimo de lucro servicios que específicamente se dedicaran a la ejecución de estas medidas.

Los recursos utilizados para la ejecución de medidas de orden abierto son, en la mayoría de las ocasiones, los ya existentes en las localidades de residencia de los menores, promoviendo un criterio de normalización e intentando, a su vez, incorporar las adaptaciones individuales que permitan adecuar los programas educativos a las necesidades de los menores.

En relación al cumplimiento de las medidas de prestación de servicios en beneficio de la comunidad, se utilizan, como regla general, la incorporación de los jóvenes a actividades que tengan un beneficio de interés general y social, promoviendo la toma de conciencia del joven sobre las necesidades de otras personas.

La medida de tratamiento ambulatorio, en la mayoría de las ocasiones, ha sido utilizada para la atención a jóvenes con problemas de drogadicción, y unidas a otra medida de internamiento en sus distintas modalidades. 
Esto ha supuesto, por una parte, la apertura de los Centros de Atención a Drogodependientes a casos de menores de 16 años (población que quedaba fuera de los tratamientos ofertados por estos centros) y, por otro lado, que el apoyo educativo en el proceso de tratamiento de la drogadicción deba ser prestado desde los centros de internamiento.

Las medidas de internamiento han sido llevadas a cabo en Residencias Comarcales o en Centros de Reeducación. En los primeros, se ejecutan básicamente las medidas de internamiento en régimen abierto y semiabierto, en los segundos, las medidas de internamiento en régimen semiabierto (reincidentes) y cerrado.

Cuando es necesario la elaboración de informes de diagnóstico en régimen de internamiento abierto o semiabierto, se utiliza el Centro de Recepción.

Tanto el Centro de Recepción como las Residencias Comarcales son establecimientos desde donde se atienden a menores que se encuentran bajo protección de la Administración o cumpliendo una medida impuesta por el Juzgado de Menores.

En los Centros de Reeducación, se atienden menores que se encuentran cumpliendo medida impuesta por los Juzgados de Menores.

La medida de ingreso en un centro terapéutico supone una dificultad importante para su ejecución, dado que, tanto para el tratamiento de problemas de drogadicción como problemas de salud mental, no existen recursos específicos para la atención a jóvenes de edades inferiores a 16 años.

La carencia de centros específicos conlleva, en ocasiones, la necesidad de llevar a cabo la medida en Residencias Comarcales o Centros de Reeducación, buscando apoyos ambulatorios que garanticen un tratamiento lo más adecuado posible.

Me gustaría destacar aquí la importancia de establecer equipos de asesoramientos a la Fiscalía y Juzgado de Menores, suficientes en cuanto a su número y capaces de superar la línea del puro informe de carácter pericial, llegando a configurar modelos de diagnóstico a partir de los cuales puedan desarrollarse programas educativos individuales que den sentido a la medida judicial impuesta. En este sentido, parece necesario potenciar procedimientos que puedan acercar evaluación y atención como partes de un mismo proceso.

Por último, reseñar la importancia que, para el cumplimiento de las medidas impuestas por Juzgados de Menores, va a tener la elevación de la mayoría de edad a los 18 años, ordenada en nuestro nuevo Código Penal, dado que, para la correcta atención a estos jóvenes, se requerirá no sólo de un aumento de los recursos y prestaciones dispo- 
nibles en la actualidad sino una mejora sustancial en la preparación de los profesionales a los que corresponda su atención directa.

Como conclusión de todo lo dicho, quisiera destacar lo que, en mi opinión, es la clave para asumir el reto de ir adecuando la estructura de prestaciones y servicios dispuestos para la protección a la infancia y juventud en nuestra Comunidad Autónoma. Parece imprescindible evaluar los cambios que respecto de las necesidades de la infancia y juventud se han producido en los últimos años y relacionarlos con el sistema legal actualmente vigente, a fin de promover cambios en la estructura de servicios y formación de personal que posibilite un ajuste entre prestaciones y necesidades a atender.

Esta revisión debe ser incorporada al método de trabajo, dado que, de no hacerlo, podría volver a producirse una situación como la actual en la que no se analiza en profundidad el funcionamiento de los recursos, produciéndose un desajuste que, por una parte, genera insatisfacción en los profesionales y, por otra, y lo que es más importante, genera una inadecuada respuesta ante las problemáticas de la infancia y la juventud.

Un excelente momento para adoptar esta medida sería el desarroIlo del Plan Integral de Atención a la Infancia previsto en la ley de la Infancia de la Comunidad Valenciana del año 1994 que, en estas fechas, sigue sin ser desarrollado.

\section{BIBLIOGRAFÍA}

ACTAS DEL IV CONGRESO DE INFANCIA MALTRATADA: Calidad y Eficacia como metas. Sevilla, del 8 al 11 de noviembre de 1995.

BARJAU CAPDEVILA, C.: El acogimiento Familiar, un medio de protección infantil. En Manual de Protección Infantil. Coordina Joaquín de Paul Ochotorena. Edit. Masson, 1995.

CASAS AZNAR, F.: Instituciones Residenciales ¿Hacia dónde?. III Congreso Estatal sobre Infancia Maltratada, 1993.

COLTON, M.J. y HELLINCKX, W.: La Atención a la Infancia en la Unión Europea. Ministerio de Asuntos Sociales, 1993.

ECHEVESTE ALBAITERO, J.A.: Reseña normativa en materia de protección de menores. En Intervención Social con Menores. Coordinado por Agustín Bueno. Edita Universidad de Alicante y Fundación Cultural CAM, 1996.

Estatuto Básico de Centros de Atención a la Infancia.

FUNES Y ARTIAGA, J.: Mediación y Justicia Juvenil. Generalitat de Catalunya. Colección Justicia y Sociedad,1994. 
Ley 5/97 de Servicios Sociales de la Generalitat Valenciana.

Ley 7/94 de la Infancia de la Generalitat Valenciana.

Ley Orgánica 1/96 de Protección Jurídica del Menor.

Ley Orgánica 4/92 sobre reforma de la Ley reguladora de la competencia y procedimientos de los Juzgados de Menores. 


\section{LOS NIÑOS MALTRATADOS \\ Y SUS FAMILIAS.}

ALGUNAS INDICACIONES PARA LA

INTERVENCIÓN DEL TRABAJADOR SOCIAL

\section{MARÍA JOSÉ ESCARTÍN CAPARRÓS}

Profesora titular Trabajo Social. Departamento de Trabajo Social y Servicios Sociales.

Universidad de Alicante.

La paliza no significaba nunca un espontáneo arrebato de cólera. Empezaba con una mirada que me convertía en un mal bicho. Y luego el silencio en el que aún no habia nada decidido y en el que, sin embargo, ya no cabía ninguna escapatoria. No se admitían pretextos, explicaciones o disculpas. El delito estaba alli, desde la mancha de plátano en el vestido, hasta el no querer comer.

Waltraud Anna Mitgutsch, «Entre mujeres».

\section{INTRODUCCIÓN}

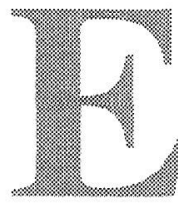

1 párrafo anterior ilustra la terrible desolación y desconcierto de un niño que es apaleado por sus padres. La confusión y la frustración le acompañarán siempre, incluso cuando tenga sus propios hijos.

La violencia doméstica es una verdadera crisis para aquellos que sufren sus consecuencias, hasta el punto que, en 1961, Kempe y Kempe acuñaron el término «síndrome del niño maltratado».

Por otra parte, ninguna comprensión moderna de los malos tratos a los niños fundamenta su existencia en una sola causa: factores como la situación económica y social de un grupo, las características biopsico-sociales de una familia, el temperamento de los padres o la conducta de los niños, cada uno de estos factores aislados, no explican, por sí mismos, las situaciones de malos tratos en nuestra sociedad.

Así, pues, parto de la premisa de que los malos tratos infantiles es un fenómeno multicausal y variado que reviste múltiples formas. Desde este supuesto, se puede afirmar que por malos tratos se entiende toda acción que lesione los derechos del niño, donde quiera que se dé; 
desde los círculos más particulares e íntimos (familia, barrio) hasta el contexto general de la sociedad y el Estado.

La sociedad maltrata cuando las condiciones generadas por la pobreza impiden a la familia y a los padres satisfacer las necesidades básicas de sus hijos; cuando por su forma de organización y estilo de vida permite que en su interior existan situaciones de extrema pobreza en contraste con grupos que gozan y abusan de todos los privilegios. La pobreza y la riqueza extremas facilitan que se den conductas y costumbres que son formas de maltratar a los niños.

Los medios de comunicación maltratan cuando utilizan al niño como objeto de publicidad. Las escuelas, hospitales, centros de protección maltratan cuando las normas de disciplina que aplican lesionan la integridad física o emocional de los niños, o cuando su relación con ellos no es la relación con una persona que piensa, sino con un objeto al que hay que imponer educación, salud o cuidado.

El Estado y los Gobiernos maltratan cuando no definen políticas adecuadas a la defensa y mejora de las condiciones de vida de los niños y sus familias; cuando en sus presupuestos no son aquellas prioritarias; cuando no revisan las legislaciones para castigar a quienes maltratan a los niños y cuando dictan normas que, en lugar de rehabilitar, reprimen.

Pero también, y frecuentemente, maltrata la familia. Es de esta forma de violencia infantil de lo que trata este artículo. Es en el interior de la familia donde se reproducen todas o gran parte de las formas sociales de malos tratos anteriormente apuntadas. Es ahí donde los adultos tomamos nuestra «revancha» para desquitarnos de las múltiples injusticias y violencias de las que somos objeto en los otros ámbitos sociales. Y son los niños, por su indefensión, las víctimas inocentes, objeto de esa «cultura maltratante» de nuestra sociedad.

\section{ALGUNOS CONCEPTOS RELACIONADOS CON LAS FAMI- LIAS ABUSADORAS.}

Los malos tratos físicos o mentales pueden darse en cualquier familia, independientemente de su status social o económico, aunque si bien es cierto que, cuando a unas características psicológicas determinadas se le unen variables de deprivación económica y falta de recursos, el problema se acrecienta. En cualquier caso, lo determinante no es sólo el factor económico, como veremos a continuación.

Diversos autores (Gil, 1973, Steele, 1976, Allen, 1994) coinciden en señalar algunas características que suelen encontrarse de manera 
más o menos coincidente en familias de niños maltratados:

1) Simbiosis: es un lazo físico o emocional con el propósito de la supervivencia. Otros autores (Bowlby, 1969, Ainsworth, 1970, Lamb, 1985) denominan esa tendencia por mantener la proximidad hacia la persona/personas con las que se está vinculado con el término «apego». Un niño pequeño tiene que depender de su madre/padre para sobrevivir. Si ese lazo es insuficiente o inadecuado, el niño crecerá con carencias. Las familias abusadoras se caracterizan por ofrecer un apego lábil o inestable a los niños.

2) Aislamiento: como consecuencia de experiencias dañinas e inadecuadas en sus relaciones con los propios padres, o con la sociedad, en general, los padres golpeadores se caracterizan por el aislamiento social y emocional.

3) Falta de control: los padres que en su infancia fueron a su vez víctimas de malos tratos tienen dificultades para controlar sus reacciones y descargan en sus hijos su rabia y sus frustraciones.

4) Paro: suele ser un acontecimiento que desata los malos tratos hacia los hijos, ya que, generalmente, las personas con situaciones prolongadas de falta de trabajo tienen una autoestima muy baja, se sienten humillados y desesperados, con su competencia en tela de juicio por el resto de personas de la familia, amigos y por la sociedad en general.

5) Comunicación de pareja: en el caso de padres golpeadores también se dan conflictos en la comunicación, fracasando como esposos, ya que no cubren las necesidades y expectativas del uno para el otro.

6) Desarrollo y educación de los hijos: los padres abusadores desconocen que sus hijos tienen diferentes necesidades, demandas emocionales y problemas, según la edad que tengan, y que ellos deben responder de manera flexible a esas diversas necesidades como parte de la educación.

\section{III.INDICADORES DE LOS MALOS TRATOS}

Generalmente, cuando hablamos de malos tratos, evocamos a un niño golpeado, pero el problema es más complejo. Los malos tratos pueden referirse, evidentemente, a la violencia física o al abandono físico que son más o menos detectables desde fuera, pero también significa otras formas de violencia más sutiles y con efectos devastadores para la personalidad y la integridad del niño, esto es, abandono emocional, maltrato y vejaciones emocionales y explotación y abusos sexuales. 
Los niños maltratados presentan una serie de características o indicadores de que son víctimas de malos tratos:

- Hemorragias subdurales y fracturas varias de los huesos largos, debidas a traumas físicos repetidos.

- Quemaduras, contusiones y accidentes viscerales.

- Melancolía, retraimiento y aislamiento social.

- Recelo y desconfianza hacia los adultos.

- Sumisión.

- Comportamientos compulsivos y destructivos en ocasiones.

- Ansia por agradar a los adultos.

- En 1961, Kempe habla del «síndrome del niño golpeado».

\section{IV.CARACTERÍSTICAS PSICOLÓGICAS DE LOS PADRES GOLPEADORES}

El rasgo más frecuente en las historias de familias abusadoras es la repetición transgeneracional de una pauta de actos violentos, negligencia o deprivación del cariño parental.

Los padres que maltratan, generalmente, son jóvenes, inmaduros emocionalmente $y$, frecuentemente, con relaciones inestables y violentas, con un nivel de tolerancia a las frustraciones muy bajo.

Entre las características más importantes, podemos destacar:

1) Falta de confianza básica, en sí mismos y en otros, que da como resultado:

- inseguridad emocional extrema,

- inmenso sentimiento de desvalorización,

- miedo al rechazo,

- vulnerabilidad, por los anhelos de independencia no resueltos

- defensas fuertes, principalmente: hostilidad, negación y apatía.

2) Sentido maternal:

- atienden bien físicamente al niño,

- inhabilidad para «alimentar emocionalmente» y de manera protectora,

- quieren que el niño les compense por su dependencia y ternura emocionales,

- a veces, ven al niño como perseguidor que les critica; otras veces se identifican con el niño llorando y les golpean para castigar su «propio ser malo»,

- a veces, los padres compulsivos y llenos de obsesiones demandan prestaciones irreales por parte del niño en cuanto a su edad y desarrollo. 
3) Identificación con el agresor: estos padres se identifican con sus propios padres sádicos e infligen a sus hijos las heridas que ellos recibieron. Repiten patrones de comportamiento aprendidos en su infancia.

4) Falta de fuerza, de poder:

- nunca percibieron que sus sentimientos y deseos tenían importancia; no creen que ellos puedan influir para mejorar o cambiar sus destinos,

- esto influye sobre la unión del marido con la mujer cuando golpean,

- es muy raro que pidan ayuda, aunque no carecen de autoayuda; atascan incluso a la persona que intenta ayudarles.

5) Escaso poder de control:

- esto es lo que desencadena la reacción repentina de rabia dirigida contra el niño y tiene su raíz en frustraciones de su propia infancia;

- a veces, su agresividad se mantuvo a nivel primitivo, no modificado por experiencias de cariño y control parental;

- los sentimientos y fantasías son «actuado» y no verbalizados.

6) Celos:

- estos padres experimentaron los celos de sus propios padres. Repiten este comportamiento y están celosos ante cualquier señal de cariño dado a sus hijos o cónyuge,

- tienen miedo de establecer alguna relación porque piensan que despertará envidia,

- este miedo es actuado durante el tratamiento.

Además, de todas las características enumeradas, las familias abusivas sostienen a nivel inconsciente una serie de creencias irracionales que mantienen un contexto de malos tratos. Ellis (1973) describe esas creencias como pensamientos erróneos que el profesional deberá trabajar a través de una terapia racional cognitiva para desterrarlos.

Esas creencias irracionales que coadyuvan en la situación de maltrato infantil son las siguientes:

- «Si mi hijo llora o se porta mal, o no hace lo que yo quiero, no me ama y soy un mal padre».

- «Mi hijo debería saber lo que quiero y lo que no quiero».

- «Mi hijo debería cuidarme como yo lo hice con mis padres».

- «Mi marido/mujer debería saber lo que quiero y responder a mis necesidades».

- «Si se lo tengo que pedir, soy un fracasado». 


\section{ALGUNAS INDICACIONES DE TRATAMIENTO}

$\mathrm{El}$ aspecto preventivo es muy importante $\mathrm{y}$, a veces, el profesional que tiene una relación con una familia (por ejemplo, familias dependientes de Servicios Sociales) y que ya ha detectado signos de disfuncionalidad en la misma, puede estar atento al reconocimiento de algunos signos de peligro en las familias:

1. Hay padres que expresan sentimientos extremos de enojo, angustia y malestar cuando el niño llora. Si a esos indicadores conductuales se les une alguna de las características enunciadas acerca de las familias golpeadoras, existe una situación de riesgo, ya que se comportan con:

- accesos de rabia incontrolada y deseos de golpear para que el llanto cese;

- educan al niño para que sea «bueno» demasiado temprano y con una impaciencia agresiva;

- desarrollan un miedo anormal de mimarlo.

Estos padres suelen racionalizar su conducta diciendo que tienen que imponer su autoridad inmediatamente porque si no el niño va a poder con ellos.

2. A veces tienen miedo de quedarse durante la noche solos con el niño. La madre confiesa muchas veces que ella fue la «víctima» en su familia, la mala. Siente que nunca podrá hacerlo «bien» y que su hijo la odia también por esta razón.

3. Cuando el niño es difícil o llora mucho, existen riesgos de golpes en los momentos del baño, biberón, cambio de pañales... Muchas veces el niño «designado» no fue deseado o llegó cuando los padres tenían otros problemas, o es el enfoque para las fuertes proyecciones negativas de los padres.

4. Cuando el cónyuge sufrió privaciones en su familia de origen o en su matrimonio, puede pensar que el niño tiene que darle compensaciones.

5. Cuando el «padre golpeador» es el hombre, suelen ir asociadas situaciones de paro o enfermedad en su historia social, con sentimientos de desvalorización. Cuando el niño llora, puede desencadenar la rabia destructiva y vengadora.

El profesional que interviene en situaciones de maltrato infantil tiene que ser enormemente cuidadoso, ya que el trabajo en este contexto es muy difícil. Carpenter y Treacher (1994) indican algunas formas de comportamiento equivocadas de los profesionales. A veces, adoptan en su relación con estas familias la «norma del optimismo» con la esperanza no realista de que las circunstancias familiares mejo- 
ren y desaparezcan los malos tratos, ya que se sienten inseguros, son los que Dale y colegas (1983) denominan «profesionales peligrosos»; en otros casos, adoptan un papel de salvadores, culpando a los padres, con el riesgo de perderlos para el tratamiento y abandonando la neutralidad terapéutica. Sin embargo, lo que es claro, en mi opinión, es que, en primer lugar, deben socorrer a la víctima, es decir, solicitar a jueces y autoridades competentes que separaren al niño transitoriamente de sus padres para asegurar su integridad física y mental.

A partir de ahí, el trabajador social que interviene en este tipo de situaciones debería tener en cuenta las siguientes consideraciones:

- El trabajador social tiene una gran responsabilidad, ya que puede cambiar el futuro del niño al separarlo de su familia.

- Tiende a identificarse con el niño, por lo tanto, deberá controlar su conducta, usándose a sí mismo para sentir como siente el niño.

- No interesarse demasiado por el niño para no intensificar la rivalidad y hostilidad de los padres.

- El trabajador social tiene que saber que va a trabajar en un clima hostil, camuflado a veces por una complacencia temporal externa de los padres.

- Debe saber usar la capacidad de contención, aceptando la actitud de rechazo de los padres.

- Tiene que ayudar a los padres golpeadores a verbalizar la agresividad, no a actuarla.

- Debe ayudar a los padres a contemplar a su hijo como realmente es, con sus cualidades y sus defectos.

- Debe ayudar a los padres cuando están atormentados por el miedo al castigo, apoyándolos y deshaciendo fantasías.

- Debe trabajar con los padres para ayudarles a experimentar el dolor por la situación de malos tratos infringidos a sus hijos (esto incluye ayudarles a perdonarse a sí mismos).

- Si se consigue romper el círculo de crueldad, el trabajador social pasa a ser un padre de sustitución y puede ofrecer una experiencia de cariño parental más positiva que la que el golpeador tuvo en su infancia.

\section{VI.CONCLUSIONES}

Aunque al principio se ha dicho que los malos tratos se dan en cualquier ambiente y clase social, hay unos factores ambientales que incrementan la rabia y la impotencia y, por tanto, el deseo de golpear y castigar: el paro y las dificultades económicas; la vivienda en malas condiciones; el aislamiento social; el abandono de los mismos padres (real o simbólico) cuando estos eran niños. 
Cuando se empieza a trabajar con estos padres golpeadores y sus hijos, el profesional tiene que ser consciente de que tiene un poder inmenso: el de separar al niño de sus padres y, por tanto, una enorme responsabilidad, ya que la decisión que tome tendrá importantes consecuencias para la vida del niño.

Derivado de lo anterior, es muy necesario, para los profesionales que tratan estos problemas, la supervisión de apoyo y educativa que abarque también las respuestas emocionales del propio profesional, ya que con estos clientes las emociones son muy poderosas (su compasión por el niño, su deseo de castigar a los padres, etc.). Estas respuestas emocionales son una proyección inconsciente de lo que sucede en la mente de los padres.

Estos procesos se verán reflejados en la relación supervisor/profesional y son, básicamente, ansiedad, terror, sexualidad, agresividad...Todos estos sentimientos provienen del cliente que, inconscientemente, llama la atención sobre sus miedos; si el profesional los comprende habrá alivio y menos actuaciones compulsivas. En cualquier caso, hay que subrayar que es muy incómodo recibir estas poderosas proyecciones inconscientes.

Por último, advertir que, para los niños, en estas familias, además de los golpes y los riesgos que implican, existen otros peligros físicos, emocionales y sexuales (delincuencia, drogadicción, abandono, incestos, falta de limpieza, desnutrición...).

Por todo lo expuesto, el trabajo con los niños golpeados y sus padres requiere una gran delicadeza por parte del profesional por la situación de alto riesgo que implican esas problemáticas, por lo que habría que considerar: primero protección y después intervención.

\section{BIBLIOGRAFÍA}

AINSWORTH, M.D.S. y cols. (1978): Patterns of Attachment: A psychological study of the strange situation. Hillsdale, Eribaum Associates, Inc. Publishers.

ALLEN, D. (1994): A Family Systems Approach to Individual Psichoterapy. New Jersey, Aronson, p. 110.

BOWLBY, J. (1969): Attachment and Loss. vol. 1, London, Hogarth Prees.

CARPENTER, J. y TREACHER, A. (1993): Problemas y soluciones en terapia familiar y de pareja. Barcelona, Paidós, p. 152.

ELLIS, A. (1973): «Rational-emotive therapy» en L. Herscher (dir.), Four psychoterapies, N. York, Appelton-Century-Crofts. 
GIL, D. (1973): Violence agaisnt children: Physical Abuse in the United States. Cambridge, Harvard University press, pp. 75-78.

HERTHOGUE, A.M. (1986): Seminario sobre Trabajo Social Familiar (apuntes ciclostilados).

KEMPE, R.S. y KEMPE, C.H.: Niños maltratados. Barcelona, Morata Ediciones.

LAMB, M.E. y cols. (1986): Infant mother atachment: the origins and developmental significance in strange situation behaviour. Hillsdale, Eribaum Associates, Inc. Publishers. 



\section{TRIBUNA LIRRE}





\title{
EL "PROBLEMA DE LA DROGA" Y LA PREVENCIÓN DEL CONSUMO DE DROGAS: MITOS Y ALTERNATIVAS, CON UNA ESPECIAL REFERENCIA AL CONSUMO DE CANNABIS
}

\author{
SALVADOR AMIGÓ BORRÁS
}

Profesor Asociado de la Facultad de Psicología de la Universidad de Valencia.

\section{RESUMEN}

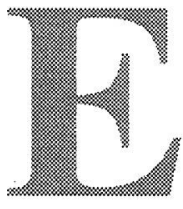

n este estudio se realiza una investigación básica sobre los aspectos que fundamentan los programas de prevención del consumo de drogas y la actual política de drogas, que tiene como objetivo afrontar el "problema de la droga". Así, se estudian los determinantes del consumo, dependencia y abuso de cannabis, así como la aceptación de mensajes y consejos sobre su consumo (permisivos versus punitivos). Se cuenta con una muestra de 70 jóvenes, de los que 33 son consumidores frecuentes de cannabis, 16 son no consumidores, 10 consumidores experimentales y el resto consumidores de otras drogas. Se les administró una amplia encuesta compuesta de dos partes: una batería de pruebas psicológicas (EPQ, inventario de calidad de vida, listado de problemas, inventario de felicidad, cuestionario de modos de afrontamiento y cuestionario de emocionalidad) y un cuestionario de drogas (incidencia del consumo de drogas, patrones de consumo, criterios de dependencia y abuso, efectos a corto y largo plazo, actitudes y motivaciones, y preferencia por mensajes permisivos o punitivos del consumo). Los resultados indican que hay una diferencia significativa entre los consumidores frecuentes y los no consumidores en variables estables como psicoticismo e inconformismo. Por otra parte, los consumidores frecuentes aceptan mucho más los mensajes permisivos sobre el consumo y los consejos para prevenir consecuencias adversas (reducción de daño) que los no consumidores, que prefieren los mensajes punitivos. Además, los consumidores frecuentes de cannabis informan de unos niveles importantes de control del consumo, y unos beneficios percibidos del consumo prolongado en mayor medida que las consecuencias negativas. Estos resultados serán interpretados en el contexto del fracaso de los programas de prevención del consumo de 
drogas y de la actual política prohibicionista de lucha contra la droga, proponiendo alternativas en ambos aspectos.

\section{INTRODUCCIÓN}

Una de las prioridades de los gobiernos occidentales en materia política y sanitaria es la lucha contra la droga. Las medidas que se implementan para ello son tanto legislativas y policiales como preventivas y asistenciales. Es el abordaje preventivo de la drogadicción lo que nos servirá como punto de partida de este estudio.

En la actualidad, proliferan gran cantidad de programas de prevención, aplicados en los ámbitos comunitario y escolar, y que gozan de una gran aceptación en la opinión pública. Normalmente, se entiende, por una parte, que los gobiernos deben promover estos programas, ya que una de sus funciones es afrontar el problema de la droga $y$, por otra parte, que los programas de prevención son eficaces en la consecución de su propósito de reducir el consumo de droga. Ahora bien, esto nos lleva a lo que considero los dos mitos asociados a los programas de prevención del consumo de drogas: la eficacia de los mismos y que exista el problema de las drogas. Digamos algo primero sobre la eficacia de los programas de prevención.

En un principio, hay que señalar que una grandísima proporción de los programas de prevención no presentan los requisitos mínimos para poder ser evaluados, a pesar del énfasis que sus promotores ponen en los aspectos metodológicos (sic) en la implementación de tales programas. De una revisión de 350 programas recogidos para su análisis en los años 1989 y 1990 en España, sólo 100 reunían condiciones mínimas para ser incluidos en las bases de datos, y de estos, sólo el $10 \%$ presentaba resultados relacionados con las hipótesis de la aplicación del programa, y el 5\% hacía una valoración de dichos resultados de acuerdo con sus objetivos (Froján y Santacreu, 1994). En algunos estudios sobre la eficacia de los programas de prevención (Goodstadt, 1978; Goodstadt, Sheppard y Chan, 1982) es difícil extraer resultados concluyentes al contar con errores metodológicos, como el no distinguir los diferentes tipos de programas (específicos vs. inespecíficos, información-cambio de actitud, etc.) que se están comparando (Smart, 1983). Así, parece ser que los programas basados fundamentalmente en la información sobre las drogas y sus consecuencias no son efectivos en modificar las actitudes hacia la droga $\mathrm{y}$, cuando lo consiguen, no siempre es en la dirección esperada (Pickens, 1985). Por ptra parte, los programas educativo-formativos, donde se utilizan fundamentalmente estrategias de información, persuasión y 
otras actividades escolares, sí consiguen un cambio significativo en las creencias y actitudes hacia la droga (Bangert-Drowns, 1988; Escámez, 1990). No obstante, no está claro si estos programas consiguen el cambio no sólo de actitud sino de conducta futura de los jóvenes respecto a la droga (para una discusión del cambio de actitudes y del comportamiento sobre la droga, ver Maciá, 1986). Esto ha hecho que muchos programas incorporen entrenamiento, con modelado y role-playing, para resistir la presión de los pares para consumir, consiguiéndose resultados satisfactorios en la reducción del consumo del tabaco (Biglan, Weissman y Severson, (1985), así como del tabaco y el alcohol desde la perspectiva de la competencia social y la autoestima (Pentz, 1985).

Uno de los programas más importantes en el mundo, diseñado para resistirse a la presión de los pares, aumentar la autoestima y la aceptación de las instituciones, así como la eliminación del consumo de sustancias y el retraso en la edad de la experimentación con alcohol, tabaco y otras drogas, es el DARE (Drug Abuse Resistance Education). Está diseñado para los preadolescentes, poniendo énfasis en los mensajes anti-droga y en las destrezas de resistencia a la presión, antes de acceder a la escuela media. Durante un semestre y una vez a la semana, un policía entrenado para tal propósito, desarrolla el contenido del programa. No hay duda de que el DARE es el programa de prevención del consumo de drogas más difundido en los Estados Unidos (Ennet et al., 1994). De ser un programa de ámbito local en 1983 en Los Angeles ha pasado a ser un proyecto internacional representado en más de 20 países (Becker, Agopian y Yeh, 1992). Es, además, un programa muy bien aceptado y valorado por los preadolescentes y los adultos (Wysong, Anikiewick y Wright, 1994). Por tratarse de un programa tan importante y difundido y por estar constituido por aspectos que se consideran básicos en este tipo de programas (mensajes antidroga, mejora de la autoestima, habilidades para resistirse a la influencia de los amigos, etc.), nos parece especialmente relevante detenernos por un momento en los estudios que desde sus comienzos se han realizado para comprobar la eficacia del mismo.

Una revisión reciente de los programas DARE (Dukes, Ullman y Stein, 1996) concluye que, mientras estos programas han demostrado su eficacia a corto plazo, en el largo plazo (un año o más) no se muestran efectivos. Así, mientras estos autores obtuvieron en 1995 resultados significativos del DARE en un estudio longitudinal de 6 meses, no obtuvieron diferencias en autoestima, resistencia a la presión de los pares y consumo en un estudio posterior de 3 años de seguimiento (Dukes, Ullman y Stein, 1996). Así, estudios como el de Ennett, Rosembaum et al. (1994) encontraron unos efectos del DARE en el 
corto plazo en medidas de conocimiento de drogas, autoestima, habilidades sociales, actitudes hacia la policía y hacia el consumo de droga, así como al propio consumo de droga en el grupo que recibió el programa frente al grupo de control. Cuando se evaluó entre 1 y 2 años después de terminado el programa, no se obtuvieron diferencias significativas ni en el consumo de tabaco ni en el de alcohol. Resultados similares fueron obtenidos por Faine y Bohlander (1989). Estudios como el de Clayton et al. (1991) encontraron que inmediatamente después del DARE, los participantes tenían una actitud anti-droga claramente marcada, pero, un año después (Clayton, Cattarello y Walden, 1991), tan sólo encontraron una diferencia entre el grupo experimental y el de control, y es que los jóvenes que recibieron el programa consumían más marihuana que los controles. Algunos efectos paradójicos más se han obtenido con la implementación del DARE, encontrándose un mayor consumo de alucinógenos en aquellos que participaron en el programa frente a los controles (Wyson, Aniskiewick y Wright, 1994). Autores como Dukes, Ullman y Stein (1996) y Rosembaum et al. (1994) indican que este tipo de resultados ponen de manifiesto la necesidad de llevar a cabo programas más prolongados en el tiempo donde los temas sean tratados con más profundidad. Ahora bien, no sabemos con certeza si esta modificación en la aplicación del programa, independientemente del problema de un mayor coste económico, ofrecerá mejores resultados a largo plazo. Así, el DARE va dirigido a los preadolescentes, de manera que, con el paso del tiempo, la experimentación y el consumo de drogas aumentará en esta población, lo que significa que los efectos madurativos van en dirección opuesta al pretendido efecto de estos programas (Dukes, Ullman y Stein, 1995). Además, con la edad, los adolescentes se hacen más conscientes de la distinción entre uso y abuso de drogas y se vuelven mucho más escépticos a los mensajes anti-droga de estos programas, a los que empiezan a dar una valoración más negativa (Brown y Caston, 1995).

Podemos concluir que, aunque está aceptada socialmente la implementación de programas de prevención del consumo de drogas, y aunque las autoridades sanitarias y los profesionales elogien sus beneficios, el rigor metodológico y la eficacia de estos programas está muy lejos de lo que éstos preconizan. Incluso se ha constatado, como anteriormente hemos señalado, que algunos de estos programas pueden tener efectos contrapreventivos. Así se ha construido el mito de la necesidad y eficacia de los programas de prevención del consumo de drogas sobre un soporte más que inconsistente. No es de extrañar que en este estado de cosas se considere innecesaria la investigación básica y la incorporación de los resultados de investigación en los progra- 
mas de prevención (Dembo, 1979, 1981), lo que a su vez puede explicar el escaso éxito de estos programas.

Precisamente, este es el objetivo fundamental de este estudio: realizar investigación básica que ahonde en los determinantes del consumo y abuso, así como en la preferencia por diferentes mensajes y consejos referidos a las drogas. Espero que este estudio de carácter exploratorio aporte algunas cuestiones concretas que nos alerten sobre las razones del aparente fracaso de los programas de prevención, así como de las posibles soluciones a lo que he llamado problema de la droga y que más adelante será tratado con algún detalle. Si bien este estudio recoge información relevante para varias drogas (cannabis, éxtasis y cocaína), en este artículo sólo se presentarán los resultados de las drogas en general y del cannabis en particular, dejando los resultados referentes al éxtasis y a la cocaína para un futuro escrutinio.

\section{SUJETOS, MATERIALES, PROCEDIMIENTO Y MÉTODO}

De un total de 80 encuestas sobre la droga, se eliminaron 10 casos por errores importantes o datos perdidos, quedando la muestra constituida por 70 personas. La muestra se obtuvo a partir de la colaboración de un grupo de estudiantes de primer año de universidad a los que se encuestó, los cuales a su vez localizaron a personas que consumían o bien cannabis (hachis/marihuana) o bien éxtasis y/o cocaína, para administrarles las pruebas. Así, no se trata de ningún estudio sobre incidencia en el consumo de drogas en una muestra determinada, sino un estudio sobre los determinantes del consumo en una muestra heterogénea en la que hay una mayor proporción de consumidores de la que se obtendría en la población general.

La edad media de estas personas es de 19 años, con una desviación típica de 3,16 y con un rango de 16-36. De ellos, 30 (42,9\%) eran hombres y $40(57,1 \%)$ mujeres. La mayoría eran estudiantes de primer ciclo de universidad $(71,4 \%)$ y de BUP y COU $(15,7 \%)$ siendo el resto estudiantes de FP, trabajadores no cualificados y desempleados.

La encuesta está compuesta por dos partes: batería de pruebas psicológicas y cuestionario sobre drogas.

- Batería de pruebas psicológicas:

- Cuestionario de Personalidad de Eysenck (EPQ-Eysenck y Eysenck, 1975).

- Inventario de Calidad de Vida (ICV-R, García Riaño, en preparación).

- Inventario de Felicidad de Oxford (Argyle y Lu, 1990).

- Listado de Problemas (McKay, Davis y Fanning, 1981). 
- Cuestionario de Modos de Afrontamiento (Holahan y Moosm 1987).

- Cuestionario de Creencias de Control Emocional (NMRCataranzo y Mears, 1990).

- Escala de Afecto Positivo y Negativo (PANAS- Watson, Clark y Tellegen, 1988).

- Cuestionario sobre drogas.

Construido para esta investigación. Consta de varios apartados:

1. Tabla de incidencias de consumo de varias drogas, tanto en el pasado como en el presente, y consumo en el último mes.

2. Patrones de consumo de cannabis, éxtasis y cocaína.

3. Preguntas basadas en los criterios del DSM-IV para el diagnóstico de dependencia y abuso de drogas.

4. Listados de efectos a corto y largo plazo del cannabis, éxtasis y cocaína, así como las motivaciones para el consumo de cada una de ellas y el nivel percibido de control.

5. Listado de actitudes hacia las drogas en general.

6. Mensajes informativos y persuasivos sobre el consumo de drogas. Para cada una de las tres drogas (cannabis, éxtasis y cocaína), se presentan aleatorizados dos mensajes alternativos: uno de ellos da un mensaje negativo sobre la droga e intenta persuadir de su no consumo. El otro mensaje es más permisivo sobre el consumo, dando consejos para evitar consecuencias negativas del mismo. Se trata así de presentar un mensaje punitivo y otro permisivo y de reducción de daño sobre las drogas. A los sujetos se les decía que ambos mensajes son correctos y que ninguno de ellos pretende engañarle. Tras la lectura de los dos mensajes, cada sujeto respondía a las mismas 6 preguntas para cada droga y que son :

- ¿Cuál de los dos mensajes te parece más interesante?

- ¿Cuál estarías, de verdad, dispuesto a seguir?

- ¿Cuál te parece más beneficioso para ti?

- ¿Cuál te crees más?

- ¿Con cuál te identificas más?

- ¿Cuál darías antes a un amigo que consume la droga?

Una vez cumplimentados los cuestionarios, se procedió a realizar una gran cantidad de análisis estadísticos, de los cuales se extraerán únicamente los más relevantes para ser presentados aquí. 


\section{III.RESULTADOS}

En primer lugar, vamos a considerar la incidencia del consumo de drogas en nuestra muestra, tanto en el presente como en el pasado. Hay que resaltar que estas dos categorías son excluyentes. Así, consideramos ANTES como el consumo de una determinada sustancia en el pasado, pero que se interrumpió en algún momento y no persiste en el presente, mientras que en la categoría AHORA incluimos los consumos actuales independientemente de que fueran interrumpidos en el pasado. En el CUADRO 1 se presentan estos datos.

CUADRO 1: Incidencia del consumo de drogas en la muestra de este estudio.

\begin{tabular}{|lrlrl|}
\hline & ANTES & \multicolumn{3}{c|}{ AHORA } \\
Cannabis & 21 & $(30 \%)$ & 30 & $(42,9 \%)$ \\
Extasis & 12 & $(17,1 \%)$ & 7 & $(10 \%)$ \\
Cocaína & 18 & $(25,7 \%)$ & 8 & $(11,4 \%)$ \\
Tabaco & 18 & $(25,7 \%)$ & 39 & $(55,7 \%)$ \\
Alcohol & 14 & $(20 \%)$ & 51 & $(72,9 \%)$ \\
Anfetaminas & 8 & $(11,4 \%)$ & 1 & $(1,4 \%)$ \\
Heroína & 1 & $(1,4 \%)$ & 0 & $(0 \%)$ \\
Opiáceos & 6 & $(8,6 \%)$ & 3 & $(4,3 \%)$ \\
Rohipnol & 1 & $(1,4 \%)$ & 0 & $(0 \%)$ \\
Inhalantes & 8 & $(11,4 \%)$ & 1 & $(1,4 \%)$ \\
Alucinógenos & 18 & $(25,7 \%)$ & 3 & $(4,3 \%)$ \\
Tranquilizantes & 9 & $(12,9 \%)$ & 3 & $(4,3 \%)$ \\
\hline
\end{tabular}

El CUADRO 2 recoge las actitudes sobre las drogas y las respuestas a las preguntas anteriormente formuladas sobre la preferencia de los mensajes sobre drogas, a los que llamaremos PERMISIVO $\mathrm{Y}$ PUNITIVO.

CUADRO 2: Actitudes ante la droga y los mensajes para la muestra total (en \%).

\begin{tabular}{|lr|}
\hline La droga es mala & 42,9 \\
La droga es buena & 1,4 \\
La droga no es buena ni mala & 2,9 \\
Depende de la droga & 14,3 \\
Depende de cómo se utilice & 37,1 \\
(En las siguientes preguntas se permitía más de una respuesta) & \\
Ayuda a mejorar las relaciones & 7,1 \\
Es muy peligrosa para la salud & 64,3 \\
Debería penalizarse su consumo & 12,9 \\
Es difícil controlar su consumo & 41,4 \\
Debería estar legalizada & 37,1 \\
Quien consume es que no sabe divertirse sin droga & 31,4 \\
Hace que te lo pases mejor con los amigos & 15,7 \\
\hline
\end{tabular}




\begin{tabular}{|lcc|}
\hline MENSAJES CANNABIS & PUNITIVO & PERMISIVO \\
1. Interesante & 44,3 & 54,3 \\
2. Dispuesto a seguir & 50 & 48,6 \\
3. Beneficioso & 58,6 & 40 \\
4. Más creíble & 50 & 48,6 \\
5. Te identificas & 45,7 & 52,9 \\
6. Dar a un amigo que consume & 52,9 & 45,7 \\
MENSAJES EXTASIS & PUNITIVO & PERMISIVO \\
1. Interesante & 52,9 & 47,1 \\
2. Dispuesto a seguir & 65,7 & 34,3 \\
3. Beneficioso & 84,3 & 15,7 \\
4. Más creíble & 70 & 30 \\
5. Te identificas & 64,3 & 35,7 \\
6. Dar a un amigo que consume & 65,7 & 34,3 \\
MENSAJES COCAÍNA & PUNITIVO & PERMISIVO \\
1. Interesante & 54,3 & 45,7 \\
2. Dispuesto a seguir & 74,3 & 25,7 \\
3. Beneficioso & 80 & 20 \\
4. Más creíble & $7 I, 4$ & 28,6 \\
5. Te identificas & 70 & 30 \\
6. Dar a un amigo que consume & 71,4 & 28,6 \\
\hline
\end{tabular}

De estos resultados, podemos destacar que para la mitad de los jóvenes de esta muestra la droga es claramente mala, y que para un tercio esto depende de la droga o de cómo se utilice. Más de la mitad cree que las drogas son muy peligrosas para la salud y que es muy difícil controlarlas. En cuanto a los mensajes, lo primero destacable es la mayor aceptación del cannabis frente al éxtasis y la cocaína. Así, mientras que para el cannabis se reparte a partes iguales la aceptación de un mensaje permisivo o punitivo, respecto a la cocaína y el éxtasis, los jóvenes consideran que es más beneficioso para ellos un mensaje punitivo ( 84,3 y $80 \%$ para el éxtasis y la cocaína respectivamente), les resulta más creíble $(70$ y $71,4 \%)$ y están más dispuestos a seguirlo $(65,7$ y $74,3 \%)$. Hasta aquí todo parece indicar que los mensajes punitivos pueden ser, en términos generales, mejor aceptados que los permisivos, sobre todo para drogas como el éxtasis y la cocaína, y que, tal vez, con una insistencia suficiente puedan decantar las actitudes de los jóvenes hacia la droga en una dirección marcadamente negativa.

No obstante, vamos a contemplar este tema desde otro punto de vista. Así, vamos a presentar los porcentajes de respuestas a estas mismas preguntas de dos subgrupos de la muestra. En el CUADRO 3 se presentan los resultados para el grupo de no consumidores y consumidores experimentales del pasado de no más de 3 ocasiones (no consu- 
midores-NC) por una parte, y para el grupo de consumidores actuales o del pasado que consumen o han consumido más de un año (consumo frecuente-CF). Respecto a la preferencia de los mensajes, sólo consideraremos en este caso la categoría PERMISIVO, ya que, al tratarse de una elección forzada de dos alternativas, es suficiente con presentar los resultados de una categoría.

CUADRO 3: Actitudes ante la droga y los mensajes para el grupo de no consumidores (NC) y consumidores frecuentes (CF) (en \%).

\begin{tabular}{|lcc|}
\hline & $\mathrm{NC}$ & $\mathrm{CF}$ \\
La droga es mala & 76 & 15 \\
La droga es buena & 0 & 0,3 \\
La droga no es buena ni mala & 0 & 0 \\
Depende de la droga & 0,3 & 24 \\
Depende de cómo se utilice & 20 & 57 \\
Ayuda a mejorar las relaciones & 0 & 15 \\
Es muy peligrosa para la salud & 88 & 48 \\
Debería penalizarse su consumo & 23 & 0 \\
Es difícil controlar su consumo & 60 & 36 \\
Debería estar legalizada & 0,8 & 54 \\
Quien consume es que no sabe divertirse sin droga & 52 & 15 \\
Hace que te lo pases mejor con los amigos & 12 & 21 \\
(SÓLO PERMISIVO) & & \\
MENSAJES CANNABIS & $\mathrm{NC}$ & $\mathrm{CF}$ \\
1. Interesante & 19 & 81 \\
2. Dispuesto a seguir & 0,4 & 84 \\
3. Beneficioso & 0,4 & 66 \\
4. Más créble & 12 & 75 \\
5. Te identificas & 12 & 81 \\
6. Dar a un amigo que consume & 12 & 72 \\
MENSAJES EXTASIS & & \\
1. Interesante & 38,4 & 57 \\
2. Dispuesto a seguir & 0,7 & 54 \\
3. Beneficioso & 0 & 21 \\
4. Más créble & 0,7 & 45 \\
5. Te identificas & 11,5 & 60 \\
6. Dar a un amigo que consume & 23 & 57 \\
MENSAJES COCAÍNA & & \\
1. Interesante & 38 & 57 \\
2. Dispuesto a seguir & 0,3 & 48 \\
3. Beneficioso & 0,38 & 36 \\
4. Más créble & 0,3 & 51 \\
5. Te identificas & 0,3 & 54 \\
6. Dar a un amigo que consume & 0,7 & 51 \\
\hline
\end{tabular}


Estos resultados nos dan, desde luego, otra visión del tema. Así, mientras la actitud de partida hacia la droga es claramente negativa para los NC, es justo lo contrario para los $\mathrm{CF}$, quienes, aunque reconocen que es peligrosa para la salud $(48 \%)$, piensan que debería legalizarse $(54 \%)$. Una parte de ellos reconoce que la droga sirve para mejorar las relaciones (15\%) o para pasarlo mejor con los amigos $(21 \%)$. En cuanto a la actitud ante los mensajes, los resultados muestran unas diferencias muy evidentes y claras entre los NC y los CF. Los consumidores frecuentes aceptan mejor que los no consumidores el mensaje permisivo (de reducción de daño) que el punitivo para todas las drogas, pero muy especialmente para el cannabis, donde la credibilidad del mensaje permisivo es muy significativa (75 y $12 \%$ para los CF y NC respectivamente). Esto nos hace reflexionar sobre la conveniencia de emplear determinados mensajes en los programas de prevención sin considerar el tipo de droga al que se refieren ni al tipo de jóvenes al que va dirigido. Así, en el caso de la droga que más nos interesa en este estudio, el cannabis, mientras un $96 \%$ de los no consumidores está dispuesto a seguir un consejo punitivo, un $84 \%$ de los consumidores frecuentes están dispuestos a seguir un consejo permisivo con el consumo y de reducción de daño. La diferencia es espectacular. Es difícil pensar que por mucho que se repitan los mensajes punitivos en un programa de prevención, va a cambiar sustancialmente la actitud ante la droga de los consumidores actuales. Es posible también que los no consumidores, con una actitud negativa hacia la droga de partida, no necesiten ser expuestos en demasiadas ocasiones a mensajes negativos sobre las drogas para no consumir. Dicho de otro modo, es posible que los programas de prevención sólo influyan sobre aquellos que ya tienen una actitud negativa y que, de todas formas, no presentan riesgo de consumo futuro, y que, por otra parte, no influyan sobre aquellos que consumen en la actualidad. Ahora bien, los defensores de los programas de prevención argumentarán que el cambio de actitud no es la única vía, ni siquiera la más importante, para conseguir un cambio en el consumo, sino que el entrenamiento en habilidades para resistirse a la presión de los pares a consumir, será lo más eficaz. Ahora bien, hay que contemplar otra cuestión al respecto, y es que entre los jóvenes tiene lugar un proceso de selección interpersonal de amigos con conductas y valores similares (Kandel, 1978a). O sea, que en muchos casos esta selección de amigos con actitudes similares ante la vida, entre las que pueden encontrarse las relativas al consumo de drogas, sería previo al consumo y formaría parte de actitudes y susceptibilidades más arraigadas que las relativas a la droga y que serían especialmente resistentes al cambio. Sigue sin quedar claro que la orientación teórica y práctica de los actuales programas de preven- 
ción del consumo de drogas, tengan un resultado de mayor alcance de lo que supone "convencer a los ya convencidos".

Pero, para seguir este argumento, es necesario realizar más análisis que nos orienten al respecto. Así, si existen diferencias fundamentales entre los dos grupos ( $\mathrm{NC}$ y $\mathrm{CF}$ ) en dimensiones de personalidad, y si estas dimensiones tienen alguna relevancia en cuanto a determinar el consumo y abuso de drogas, o en cuanto a la aceptación de un determinado tipo de mensajes sobre la droga, se confirmaría nuestro argumento de que "se convence a los convencidos". Pero veamos estos resultados.

\subsection{Diferencias en personalidad entre los no consumidores (NC) y los consumidores frecuentes $(C F)$}

Hemos contrastado las medias de las dimensiones de personalidad del cuestionario EPQ (Extraversión, Neuroticismo y Psicoticismo) además del factor Sinceridad de los dos grupos anteriores, pero añadiendo una variante. Así, hemos comparado el grupo $\mathrm{CF}(\mathrm{N}=33)$ con el grupo NC pero excluyendo a los consumidores experimentales de cannabis para aislar cualquier efecto del consumo. Seguiremos llamando a este grupo $\mathrm{NC}(\mathrm{N}=16)$ y sólo cuando se considere oportuno se hará la distinción necesaria. Se han obtenido dos diferencias estadísticamente significativas en $\mathrm{P}(\mathrm{t}=-2.76, \mathrm{p}<.01)$ y en $\mathrm{S}(\mathrm{t}=-5.16$, $\mathrm{p}<.001$ ). La diferencia en Psicoticismo es esperable en cuanto a que los aspectos que componen tal dimensión (impulsividad, agresividad, búsqueda de sensaciones, etc.) están asociados tradicionalmente con el consumo de drogas. Ahora bien, lo que resulta más llamativo es la diferencia en Sinceridad a favor de los consumidores de cannabis. La sinceridad no parece ser un rasgo característico de los consumidores de droga, pero en nuestro estudio es una característica claramente definitoria de los mismos. ¿Cómo podemos interpretar este resultado? Si bien no existe investigación ni consenso suficiente sobre el significado de esta variable, existen indicios de que se trata de un rasgo estable de personalidad, aunque no se sabe muy bien cuál (Eysenck y Eysenck, 1975). Se ha apuntado la posibilidad de que se trate de un factor que mida la no asunción de reglas sociales (Eysenck y Eysenk, 1964), ya que sus ítems se refieren a negligencias en cuestiones que atañen las normas sociales. Si este fuera el caso, sería más adecuado denominar a este factor Inconformidad, haciendo referencia más al no convencionalismo, más que a Sinceridad. Si bien no existe en la investigación general suficiente evidencia para lo que aquí estamos proponiendo, sí es cierto que la validación de este factor puede provenir de estudios como éste, por lo que en principio aceptare- 
mos este razonamiento e interpretación del factor $\mathrm{S}$, al que denominaremos I (inconformismo).

\subsection{Predictores del consumo actual de cannabis}

Si estas dos dimensiones ( $\mathrm{P}$ e I) distinguen a los no consumidores y consumidores frecuentes, es importante considerar si tienen alguna implicación en la conducta de consumir cannabis y en la dependencia y abuso del mismo. Así, se han realizado numerosos análisis de regresión teniendo como variables dependientes el consumo actual de cannabis y la categoría de dependencia y abuso, y como variables independientes las dimensiones de personalidad, introduciendo en posteriores análisis variables circunstanciales y situacionales (calidad de vida, número de problemas y emocionalidad negativa), y actitudes hacia la droga. Todas las regresiones son logísticas, ya que las variables dependientes son dicotómicas y en todos los análisis, la introducción de las variables se realizó "paso a paso". A continuación resumiremos los resultados obtenidos.

En un primer análisis se incluyeron como variables independientes las tres dimensiones de personalidad eysenckianas. $\mathrm{P}$ y $\mathrm{E}$ fueron incluidas en la ecuación, pero $\mathrm{E}$ no resultó significativa al nivel $\mathrm{p}<.05$. Para la variable $\mathrm{P}, \mathrm{B}=.20(\mathrm{p}<.05)$. Cuando se añadió a las dimensiones de personalidad la variable I, ésta fue la única que se incluyó en la ecuación $(\mathrm{B}=.24, \mathrm{p}<.01)$ dejando fuera de la ecuación a las demás. Podemos interpretar de estos resultados que una dimensión de personalidad como $\mathrm{P}$ es buen predictor del consumo actual, pero que el Inconformismo es un predictor mucho más importante del consumo actual.

$\mathrm{Si}$ a las dimensiones de personalidad y al Inconformismo añadimos la variable ACTITUD, obtenemos otra combinación de variables predictoras. Así, la variable ACTITUD es la que se incluye en la ecuación en el primer paso (como esta variable es categórica sólo indicaremos el nivel de significación, $\mathrm{p}<.05)$, seguidas por $\mathrm{I}(\mathrm{B}=.27, \mathrm{p}<.05)$ y por $\mathrm{E}(\mathrm{B}=.25, \mathrm{p}<.05)$. Por tanto, en la predicción del consumo actual de cannabis influye especialmente la actitud que se tenga ante la droga, pero también la actitud general frente a la vida y la sociedad (Inconformismo) y la personalidad (Extraversión). Si los programas de prevención pretenden cambiar las actitudes hacia las drogas con mensajes negativos, es más difícil que consigan cambios de mentalidad a otros niveles o de personalidad, aspectos que, como vemos, están relacionados con el consumo de cannabis. En relación con esto, en un análisis logístico en el que añadimos a las variables anteriores las de CALIDAD DE VIDA, PROBLEMAS y EMOCIONALIDAD 
NEGATIVA, observamos que ninguna de ellas fue incluida en la ecuación, lo que indica que la conducta de consumir cannabis tiene motivos más estables y no transitorios.

Estos resultados se confirman si prescindimos en el análisis de ACTITUD e incluimos las siete actitudes específicas que más arriba enunciamos (esto lo hacemos así para evitar posible colinealidad).

En este caso, 4 variables son incluidas en la ecuación (I, E, DROGAS 5 y DROGAS 6, estas dos últimas categóricas). Las únicas con $\mathrm{B}$ significativas al nivel $\mathrm{p}<.05$ son Inconformidad $(\mathrm{B}=.34)$ y "Quien consume es que no sabe divertirse sin drogas" (B negativa). Próximas a la significación $(\mathrm{p}<.06)$ están Extraversión y "Debería estar legalizado".

Es decir, se confirma que en el consumo actual de cannabis influyen aspectos de personalidad ( $\mathrm{P}$ y E), de actitud general frente a la sociedad (I) y especialmente frente a la droga. Al respecto de esto último, el consumo está asociado con una actitud más favorable hacia la droga, la impresión de que su consumo es una forma más de diversión pero que no cubre todas las formas de diversión (recordemos la $B$ negativa) y que debería estar legalizada. Aparte de la influencia de los demás factores, parece que este tipo de variables forman parte de un sistema de valores amplio y de la comprensión general de la sociedad y las relaciones humanas y no parecen, desde luego, susceptibles de cambio salvo ímprobos esfuerzos de las autoridades sanitarias y políticas.

\subsection{Predictores de la dependencia, abuso y consumo compulsivo de cannabis}

En este grupo de análisis hemos querido constatar si la personalidad y algunos aspectos más transitorios como la cantidad de problemas que uno tiene en la actualidad o la calidad de vida, predicen la dependencia, el abuso o la compulsión del cannabis. Las variables dependientes representan el sumatorio de las respuestas afirmativas a los criterios del DSM-IV, y por tanto no son variables categóricas (dependencia/no dependencia, etc). Lo hemos hecho así para hacer valer la riqueza de información que teníamos al respecto.

Si consideramos como variables independientes las dimensiones de personalidad y el Inconformismo, obtenemos que el Psicoticismo es la única variable incluida en las ecuaciones, tanto para la dependencia (beta $=.39, \mathrm{p}<.001$ ), como para abuso (beta $=.40, \mathrm{p}<.001$ ) y para compulsión (beta $=.46, \mathrm{p}<.001$ ), con una varianza explicada del 12 , 16 y $21 \%$, respectivamente. 
Si añadimos las variables PROBLEMAS y CALIDAD DE VIDA, aparecen algunas variaciones. Así, mientras que para el abuso, $\mathrm{P}$ es la única variable incluida (beta $=.40, \mathrm{p}<.001$ ) (varianza explicada del $16 \%$ ), para la dependencia, la ecuación incluye las variables PROBLEMAS (beta=.35, p<.01) e Inconformismo (beta=.28, $\mathrm{p}<.05$ ) (varianza explicada del 24\%), y para la compulsión las variables $\mathrm{P}$ (beta $=3.28, \mathrm{p}<.01$ ) y PROBLEMAS (beta $=.27, \mathrm{p}<.05$ ) (varianza explicada del 28\%).

Así, se comprueba que mientras la cantidad de problemas y su impacto negativo son buenos predictores de la dependencia y el consumo compulsivo de cannabis, también es cierto que factores más estables como el Psicoticismo y el Inconformismo se relacionan claramente.

\subsection{Predictores de la aceptación de mensajes permisivos sobre el consumo de cannabis}

Una vez hemos visto los mejores predictores del consumo y abuso del cannabis, entre los cuales hay factores estables de personalidad, vamos a realizar el mismo tipo de análisis de regresión múltiple tomando como variable dependiente CAMEP. Esta variable es el sumatorio de todas las respuestas afirmativas de preferencia a los mensajes permisivos a partir de las 6 preguntas sobre los dos mensajes del cannabis que se les presentan a los jóvenes de este estudio, y por lo tanto es una variable continua.

Cuando se utilizan como variables independientes las 3 dimensiones eyxenckianas, sólo la $\mathrm{P}$ es incluida en la ecuación (beta=.26, $\mathrm{p}<.05$ ), la cual explica tan sólo el $0,7 \%$ de la varianza. El Inconformismo es una variable mejor predictora que las de personalidad, ya que, al añadirla a las anteriores, es la única incluida en la ecuación (beta $=.41$, $\mathrm{p}<.001$ ), con una varianza explicada del $16 \%$.

$\mathrm{Si}$ a las anteriores variables añadimos CANAH (consumo de cannabis en la actualidad) y CANAL (consumo de cannabis en el pasado pero interrumpido en el presente), son estas dos variables las únicas incluidas en la ecuación, explicando un $45 \%$ de la varianza.

Si además añadimos las 7 actitudes específicas, las únicas variables incluidas en la ecuación son el consumo actual y pasado de cannabis y "Debería estar legalizado", con una varianza explicada del $49 \%$.

Podemos concluir que, aunque las variables de personalidad y el Inconformismo predicen en alguna medida la aceptación de mensajes permisivos del consumo de cannabis, es el hecho de consumir (tanto 
en el presente como en el pasado) y la actitud favorable a la legalización, los mejores predictores. En el CUADRO 4 se resumen los resultados que acabamos de exponer, de forma que se integren y ordenen los datos a partir de los distintos análisis de regresión con diferentes bloques de variables independientes, y de aquellos análisis que cuentan con todas las variables independientes de una vez.

CUADRO 4: Principales predictores del consumo, dependencia, abuso, compulsión y aceptación de un mensaje positivo sobre el consumo de cannabis.

PREDICTORES (por orden de importancia)

\begin{tabular}{|c|c|}
\hline \multirow[t]{4}{*}{ CONSUMO ACTUAL } & $\begin{array}{l}\text { Actitud general } \\
\text { Inconformismo } \\
\text { Actitud específica (negativa): "Quien consume es que } \\
\text { no sabe divertirse sin } \\
\text { drogas" }\end{array}$ \\
\hline & Psicoticismo \\
\hline & Extraversión \\
\hline & Actitud específica: "Debería estar legalizada" \\
\hline \multirow[t]{3}{*}{ DEPENDENCIA } & Problemas \\
\hline & Inconformismo \\
\hline & Psicoticismo \\
\hline ABUSO & Psicoticismo \\
\hline \multirow[t]{2}{*}{ COMPULSIÓN } & Psicoticismo \\
\hline & Problemas \\
\hline \multirow[t]{5}{*}{ MENSAJE PERMISIVO } & Consumo actual de cannabis \\
\hline & Consumo pasado de cannabis \\
\hline & Actitud específica: "Debería estar legalizada" \\
\hline & Inconformismo \\
\hline & Psicoticismo \\
\hline
\end{tabular}

En este cuadro podemos destacar la gran importancia de la actitud general hacia las drogas y de actitudes específicas a la hora de explicar el consumo actual de cannabis y la aceptación de mensajes permisivos sobre su consumo. También hay que destacar que las variables de personalidad (especialmente P) e I juegan un importante papel en este caso. Hay también que señalar en este punto que las dos variables (Psicoticismo e Inconformismo) están muy relacionadas en nuestra muestra $(\mathrm{r}=.43, \mathrm{p}<.001)$. Por otra parte, la cantidad de problemas que uno tenga y el hecho de consumir o haber consumido cannabis, tiene valor predictivo de la dependencia/compulsión y de la aceptación de mensajes permisivos, respectivamente. Por último, el Psicoticismo, factor estable de la personalidad, es un predictor importante de la dependencia y abuso del cannabis y de su consumo compulsivo $\mathrm{y}$, por tanto, poco controlado. 


\section{IV.LOS PROGRAMAS DE PREVENCIÓN Y EL PROBLEMA DE LA DROGA}

Si una serie de variables de personalidad (P y E), y actitudes frente a la sociedad (I) y frente a las drogas (favorable a la droga y a su legalización) son los mejores predictores del consumo, abuso, y aceptación de mensajes permisivos y de reducción de daños respecto al cannabis, es fácil comprender cómo los programas de prevención han resultado, en general, un fracaso respecto al consumo general de drogas y en particular de cannabis. Como decíamos más arriba, parece ser que aumentar la duración y la intensidad de los programas mejoraría su eficacia. Pero tampoco está claro que esto sea así. Además, esto encarecería todavía más la aplicación de estos programas. La aplicación del DARE en Estados Unidos es de 100 dólares por estudiante (Dukes, Ullman y Stein, 1996). Esto nos lleva a plantearnos si tiene sentido mantener la existencia de estos programas, al menos tal como están enfocados en la actualidad. Y esto, a su vez, nos lleva a plantearnos la posibilidad de proponer un cambio en la política de drogas hacia la no intervención del Estado. Esta propuesta no tiene visos de ser bien aceptada por la opinión pública debido al otro mito del que se hablaba al principio de este artículo: el mito del problema de la dro$\mathrm{g} a$. Este mito puede ser expuesto como la creencia firme e incontestada de que la droga es un gran problema social y sanitario en todos los países, y que hay que erradicar, empezando por convencer a los jóvenes que no consuman. En este apartado hablaremos del problema de la droga a partir de los resultados que hemos obtenido en nuestra muestra, y referidos al cannabis. No es posible generalizar con facilidad a las demás drogas, ni es posible hacerlo a partir de estos resultados. No obstante, la pretensión de mostrar estos resultados es abrir un diálogo que permita realmente la superación del "problema de la droga". Veamos.

Vamos a detenernos en el grupo de CF (consumidores frecuentes). En el CUADRO 5 se presentan las pautas de consumo de cannabis de los jóvenes de nuestra muestra, así como el control percibido del consumo, los efectos percibidos a corto y largo plazo, niveles de dependencia y abuso y las motivaciones del consumo.

Entre los resultados más destacables presentados en el CUADRO 5 encontramos que las pautas de consumo son muy variadas. Así, un $18 \%$ mantienen un consumo ocasional, mientras que el $27 \%$ consumen muchas veces en situaciones concretas (fiestas, etc.) y el $33 \%$ consumen casi todas las veces en esas situaciones concretas. Un 18\% consumen muchos días al margen de esas situaciones concretas, y aunque este consumo no sea necesariamente diario, lo hemos denomina- 
CUADRO 5: Pautas de consumo de cannabis, y otros aspectos relacionados (resultados en porcentajes)

$\begin{array}{lc}\text { Pautas de consumo } & \\ \text { Consumo ocasional } & 18 \\ \text { Consumo circunstancial } & 27 \\ \text { Consumo habitual } & 33 \\ \text { Consumo "a diario" } & 18 \\ \text { Situaciones de mayor consumo } & \\ \text { Discoteca } & 39 \\ \text { Fiesta } & 90 \\ \text { Con la pareja } & 33 \\ \text { Sólo } & 24 \\ \text { Mezclar con otras drogas } & \\ \text { Nunca } & 0,6 \\ \text { Alguna vez } & 33 \\ \text { Frecuentemente } & 27 \\ \text { Siempre } & 33 \\ \text { Sustancias que mezcla } & \\ \text { Alcohol } & 93 \\ \text { Anfetaminas } & 0,6 \\ \text { Tranquilizantes } & 0 \\ \text { Alucinónenos } & 15 \\ \text { Heroína } & 0 \\ \text { Cocaína } & 21 \\ \text { Extasis } & 27 \\ \text { Tian } & \end{array}$

Diagnóstico de dependencia y abuso según criterios del DSM-IV

Dependencia 45

Abuso $\quad 57$

Control percibido del consumo de cannabis

$\begin{array}{lc}\text { Nada } & 0,9 \\ \text { Algo } & 12 \\ \text { Bastante } & 12 \\ \text { Mucho } & 36 \\ \text { Totalmente } & 30\end{array}$

Efectos a corto plazo del cannabis

Bienestar

Nunca A menudo Siempre

Euforia

$\begin{array}{lll}0,3 & 69 & 27\end{array}$

Risas

Sedación

$0,9 \quad 54 \quad 33$

Letargia

Poca memoria inmediata

$30 \quad 39$

Dificultad en los procesos mentales complejos

Poca capacidad de juicio

Percepciones sensoriales distorsionadas

$56 \quad 40$

Deterioro de la actividad motora

$50 \quad 25$

$40 \quad 46$




\begin{tabular}{|c|c|c|c|c|}
\hline Tiempo pasa despacio & 46 & 53 & \multicolumn{2}{|c|}{0} \\
\hline Ansiedad & 75 & 25 & \multicolumn{2}{|r|}{0} \\
\hline Retraimiento social & 81 & 18 & \multicolumn{2}{|c|}{0} \\
\hline Irritación conjuntival & 50 & 28 & & 18 \\
\hline Aumento del apetito & 18 & 46 & & 31 \\
\hline Sequedad de boca & 18 & 18 & & 59 \\
\hline Taquicardia & 81 & 0,9 & & 0,9 \\
\hline Efectos percibidos a largo plazo del cannabis & NADA & POSIT & VO NE & NEGATIVO \\
\hline Estado mental psicológico & 61 & 2 & & 16 \\
\hline Bienestar emocional general & 35 & 6 & & 0,3 \\
\hline Relaciones personales & 38 & 5 & & 0,6 \\
\hline Nivel de comunicación & 45 & 4 & & 0,6 \\
\hline Relaciones con el sexo opuesto & 48 & 4 & & 0,3 \\
\hline Seguridad en sí mismo & 38 & 4 & & 12 \\
\hline Disfrutar más de las cosas & 35 & 48 & & 16 \\
\hline Superar los problemas emocionales & 48 & 3 & & 16 \\
\hline & $\mathrm{DA}$ & LLGO BA & STANTE & E MUCHO \\
\hline Mayor fatiga general & 43 & 40 & 12 & 0,3 \\
\hline Desgaste general & 59 & 25 & 15 & 0 \\
\hline Resfriados y enfermedades & 81 & 15 & 0 & 0,3 \\
\hline Depresión & 71 & 25 & 0,3 & 0 \\
\hline Problemas emocionales & 65 & 28 & 0,6 & 0 \\
\hline Pérdida memoria y facultades intelectuales & 46 & 37 & 12 & 0,3 \\
\hline Dependencia de la droga & 62 & 28 & 0,6 & 0,3 \\
\hline Motivaciones para el consumo de cannabis & & & & \\
\hline Para encontrar un nuevo estilo de vida & & & & 24 \\
\hline Para sentirme libre & & & & 27 \\
\hline Para facilitar el contacto social & & & & 24 \\
\hline Para "desconectar" de problemas emocionales & & & & 57 \\
\hline Para "cargar baterías" y afrontar los problemas & con más & fuerza & & 0,6 \\
\hline Para superar la timidez & & & & 0,9 \\
\hline Para superar el malestar emocional & & & & 36 \\
\hline Para experimentar placer & & & & 51 \\
\hline Para experimentar sensaciones nuevas y difere & ates & & & 54 \\
\hline Para sentirme "colocado" & & & & 51 \\
\hline Para pasar el rato & & & & 39 \\
\hline Por el gusto de hacer algo prohibido & & & & 27 \\
\hline Para disfrutar más de la diversión & & & & 39 \\
\hline Para experimentar con más intensidad las emo & iones & & & 33 \\
\hline Para penetrar en mi interior y conocerme mejo & & & & 18 \\
\hline Porque me da un sentido espiritual de la vida & & & & 21 \\
\hline Porque mis amigos lo toman & & & & 21 \\
\hline Porque produce un efecto positivo en mi vida & n general & & & 18 \\
\hline
\end{tabular}


do "a diario". Ya que la muestra, como dijimos anteriormente, se ha obtenido a partir de la búsqueda de personas que resaltaban por su consumo, cabe esperar que esté sesgada hacia una mayor frecuencia de consumo de lo que encontraríamos en una muestra representativa de la población general de consumidores. No obstante estas matizaciones, que servirán para la interpretación del resto de los resultados de este apartado, cabe decir que la mayor frecuencia de consumo se da en situaciones concretas. Esto se confirma al ser la situación de fiesta donde más se da el consumo $(90 \%)$ con mucha diferencia de las demás y sobre todo del consumo en solitario (24\%), que se presenta en una menor proporción. Si además de un alto control percibido del consumo (el $36 \%$ perciben mucho control y el $30 \%$ total control), el tener reglas para el cuándo y dónde consumir drogas (consumo en situaciones concretas) es un reflejo del control de la misma (ver Cohen y Sas, 1992, para el consumo de cocaína), podríamos concluir que un porcentaje alto de los consumidores de nuestra muestra controlan en buena medida el consumo.

No obstante, los datos sobre los porcentajes de jóvenes con diagnóstico de dependencia (45\%) y de abuso (57\%) no nos hablan precisamente de control de la droga. Ahora bien, a lo largo del estudio y hablando con los consumidores de cannabis, tuvimos la impresión de que los criterios diagnósticos del DSM-IV eran demasiado laxos. Dicho de otra forma, de que "hinchan" la proporción de dependientes y de consumidores que abusan en la población. Para comprobar esto hicimos una prueba. Separamos a los consumidores "a diario" de cannabis $(\mathrm{N}=7)$ y contrastamos las medias de los sumatorios de dependencia y abuso con el resto de los consumidores $(\mathrm{N}=23)$. Obtuvimos una diferencia estadísticamente significativa en Dependencia $(\mathrm{t}=-$ $2.45, \mathrm{p}<.05)$ pero no en Abuso. Así, si consideramos como variable para el contraste no el diagnóstico de dependencia, sino el sumatorio de los puntajes en respuesta a los criterios del DSM-IV, existen diferencias significativas entre los que tienen una pauta de consumo "controlada" y los que consumen a diario en cuanto a la dependencia de la droga. Si bien este resultado debe ser replicado en posteriores investigaciones con muestras mayores, es indicativo de que el DSM-IV puede estar empleando criterios "laxos" para el diagnóstico de dependencia y abuso.

Por otra parte, hay que resaltar que los efectos a corto plazo apenas presentan situaciones de riesgo o peligro. Si bien se presentan algunos inconvenientes en las funciones mentales, con un $27 \%$ señalando dificultad en los procesos mentales complejos y un $25 \%$ percepciones sensoriales distorsionadas, un $75 \%$ nunca presentan problemas de ansiedad y un $81 \%$ nunca presentan retraimiento social. 
Por otra parte, los efectos percibidos a largo plazo son positivos en mucha mayor medida que negativos. Así, la mayor parte de los efectos negativos (mayor fatiga general, desgaste general, etc.) o bien no se presentan como consecuencias a largo plazo del consumo o bien aparecen en poca medida (algo). Ninguno de estos efectos negativos supera la proporción del $15 \%$ en cuanto a que representen una consecuencia bastante negativa del consumo. En cuanto a los efectos del primer bloque (estado mental psicológico, bienestar emocional general, etc.) hay que resaltar que, aunque cerca de la mitad de los consumidores no percibe ningún tipo de efecto a largo plazo, si comparamos las consecuencias positivas con las negativas, el consumo sostenido de cannabis ha tenido un impacto escasamente negativo y claramente positivo, para más de la mitad de los consumidores en bienestar emocional general $(61 \%)$ y relaciones personales $(54 \%)$ y en un $48 \%$ de los consumidores en el nivel de comunicación, relaciones con el sexo opuesto, seguridad en sí mismo y disfrutar más de las cosas. Hay que resaltar que el $35 \%$ reconocen un impacto positivo del consumo continuado respecto a la superación de los problemas emocionales, si bien un $16 \%$ ha respondido en sentido contrario.

En cuanto a las motivaciones para el consumo, hay que destacar las referentes a la búsqueda de sensaciones y diversión, es decir, al aspecto lúdico del consumo de droga, como son: experimentar placer $(51 \%)$, experimentar sensaciones nuevas y diferentes $(54 \%)$, sentirse "colocado" (51\%) y disfrutar más de la diversión (39\%). Ahora bien, el resultado más llamativo es el que se refiere al consumo para "desconectar" de problemas emocionales (57\%). Esto puede significar que más de la mitad de los consumidores se drogan para no afrontar los problemas, para huir de ellos, lo que constituiría un comportamiento inmaduro y de evitación. Ahora bien, esto no está claro que sea así. Veamos. Por otra parte, en una Encuesta Nacional sobre Drogas en Estados Unidos (Timmer, Veroff y Colten, 1985) se concluye que la "relajación" de los problemas que proporciona la droga no es incompatible con otras estrategias activas de coping, como el recurso a la red social y la comunicación, y que, más bien al contrario, las personas con mejor ajuste psicológico son las que consumen drogas de forma moderada frente a las que no consumen nada, que tienen peor ajuste. El consumo excesivo está relacionado con la necesidad de "escapar" a unos niveles altos de estrés y es característico de personas con mal ajuste psicológico, mientras que el consumo moderado resulta saludable como un recurso para "relajarse" en las situaciones de estrés moderado de la vida diaria. También aquellas personas con una mayor vulnerabilidad al estrés, que sienten que las situaciones de tensión sobrepasan sus capacidades de afrontamiento y que poseen una 
baja autoconfianza, son más propensas a consumir excesivamente para afrontar el estrés. Por otra parte, en algunos estudios sobre coping y drogas (Wills, 1985) se concluye que la Distracción (que equivale a nuestra variable "desconectar" de problemas) es una válida y eficaz estrategia para afrontar el estrés. En definitiva, el coping está relacionado de una forma particular con el nivel de estrés y el consumo de drogas. Así, a niveles moderados de estrés, el coping incrementa el consumo de drogas, mientras que con niveles altos de estrés aumenta el consumo de drogas mientras se reduce el coping. Así, el nivel de estrés sería una variable moduladora de la relación entre coping y consumo de drogas. El hecho de que estas variables pueden covariar positivamente lo muestra el hecho, constatado por Wills, de que el apoyo social está asociado positivamente con el fumar. Cuanto más dependía un estudiante de su grupo de pares para hablar de sus problemas, más involucrado estaba en la conducta de fumar tabaco. Este mismo autor encontró que si bien un factor general de autoestima y de control percibido correlacionaron negativamente con el consumo de tabaco y alcohol, dos subescalas de ambos constructos, autoconfianza social y control percibido en situaciones sociales, correlacionaron significativamente $(\mathrm{p}<.01)$ con el consumo de alcohol y con el consumo de tabaco y alcohol, respectivamente. Esto da a entender que el consumo de drogas (en este caso legales) puede estar positivamente relacionado con el apoyo social y el incremento de los aspectos sociales de la autoestima y el control percibido.

$\mathrm{Si}$ en nuestra muestra contrastamos las medias de los modos de afrontamiento, que son las Estrategias activas cognitivas (EAC), Estrategias activas comportamentales (EACO) y Estrategias de evitación (EE) entre los consumidores de cannabis actuales $(N=33)$ y el resto de la muestra que no consume en la actualidad ninguna droga ilegal ( $\mathrm{N}=38)$ no encontramos diferencias estadísticas en las estrategias activas y sí un mayor empleo significativo de las estrategias de evitación entre los consumidores actuales $(p<.05)$. Hay que destacar que en el caso de las EACO, los consumidores actuales las emplean más hasta un punto que se acerca a la significación $(\mathrm{p}<.08)$. Si bien no hay diferencias significativas entre los dos grupos en cuanto a cantidad de problemas, sí es cierto que en dos subescalas de calidad de vida (relaciones emocionales e involucración en el trabajo), los consumidores actuales se sienten más insatisfechos. Ahora bien, si comparamos a los consumidores actuales de cannabis con los no consumidores de ninguna droga ilegal en la vida $(\mathrm{NC}=16)$, encontramos los mismos resultados en los modos de afrontamiento que anteriormente hemos citado, pero además vemos que los consumidores actuales tienen más problemas en general $(\mathrm{p}<.05)$ y en particular más problemas 
económicos $(p<.01)$, de vivienda $(p<.01)$ y familiares $(p<.05)$. Además, se sienten más insatisfechos en las relaciones emocionales $(\mathrm{p}<.05)$, familiares $(\mathrm{p}<.01)$, en el área económica $(\mathrm{p}<.05)$ y se apoyan menos en la religión $(\mathrm{p}<.01)$. Podemos ver que en aquellas áreas donde más problemas tienen los consumidores actuales, son las que más insatisfacción encuentran, si bien no hay diferencias significativas en el índice general de calidad de vida ni en felicidad. Estos resultados pueden interpretarse en la línea de los estudios citados sobre coping y consumo de drogas. Así, por una parte, la diferencia significativa en el volumen de problemas pude ocasionar en los consumidores actuales un nivel alto de tensión al que responden con un mayor consumo y más estrategias de evitación. Por otra parte, no utilizan menos estrategias activas que los no consumidores, con lo cual se hace patente que es compatible el uso de estas estrategias con el consumo de drogas. De hecho, para el total de la muestra, los problemas se relacionan significativamente con los 3 tipos de estrategias $(p<.001$ para EAC y $\mathrm{p}<.01$ para EACO y EE). O sea, que cuantos más problemas, más estrategias de afrontamiento se ponen en marcha, tanto de evitación como activas. El que muchos consumidores (57\%) informan del consumo de cannabis como una forma de "desconectar" de los problemas no representa necesariamente una estrategia de huida, sino que, como ya se ha señalado antes, puede representar una válida estrategia de afrontamiento de niveles altos de estrés.

\subsection{La hipótesis de la escalada de drogas}

Si el consumo de cannabis no produce un efecto tan negativo en los jóvenes sobre su salud mental como pudiera pensarse en un principio, el mayor peligro que muchos ven en este consumo, es que lleve inevitablemente al consumo y abuso de otras drogas ilegales y peligrosas (cocaína y heroína principalmente). Es lo que se llama la hipótesis de la escalada de las drogas. En una revisión de la evidencia al respecto, Kandel et al. (1992) concluyen que si bien los consumidores de "drogas duras" empezaron mayoritariamente consumiendo tabaco, alcohol y cannabis, esto no quiere decir que los que consumen cannabis vayan a progresar en la dirección del consumo de drogas más peligrosas. Así, el consumo de cannabis es una condición necesaria pero en modo alguno suficiente para el paso a otras drogas.

Por otra parte, con datos del National Household Surveys (Fishburne et al., 1980), se informa que casi todos los jóvenes entre 18-25 años que son consumidores de cannabis lo son de tabaco y alcohol, pero poco más de una cuarta parte de ellos ha probado cualquier otra droga ilegal. Muy pocos de los que han probado otras drogas son consumidores actuales de las mismas. 
En un estudio muy reciente de consumidores de cannabis de Amsterdam, Cohen y Sas (1996) argumentaron que la teoría de la escalada se confirmaría si el $75 \%$ o más de los que consumen cannabis, presentan algún consumo de otras drogas como la heroína, la cocaína y el éxtasis. En su muestra, en ningún grupo de consumidores de cannabis, ni siquiera en los consumidores "fuertes" se constató un consumo de cualquiera de estas tres drogas que alcanzara la proporción indicada.

La muestra de nuestro estudio es especialmente interesante al respecto, ya que debido al sistema de búsqueda, que anteriormente explicamos, cabría esperar que muchos de los consumidores de cannabis consumieran también otras drogas ilegales. Si sumamos el consumo actual con el consumo pasado interrumpido, independientemente del nivel del mismo, obtenemos que de la muestra de consumidores actuales ( $\mathrm{N}=33)$, el $66 \%$ consume o ha consumido cocaína (de los cuales el $51 \%$ ya la han dejado), el $51 \%$ éxtasis (el $36 \%$ ya lo han dejado) y el $0,3 \%$ heroína. Así, en una muestra de consumidores de cannabis favorable para encontrar confirmación de la hipótesis de la escalada, si nos atendemos a la operacionalización al respecto establecida por Cohen y Sas (1996), se desconfirma tal hipótesis. Así, parece que el cannabis no resulta tan peligroso para la juventud en el sentido de conducirles necesariamente al consumo de drogas "duras".

\section{DISCUSIÓN}

El estado actual de conocimientos sobre la eficacia de los programas de prevención del consumo de drogas muestra, en el mejor de los casos, inconsistencias, cuando no resultados desalentadores. En este estudio se han puesto de manifiesto algunas posibles razones que explican este aparente fracaso. Así, se ha constatado la importancia de factores estables de personalidad (especialmente Psicoticismo) y de actitud frente a la vida y la sociedad (Inconformismo) como determinantes del consumo y abuso de cannabis. Además, los consumidores frecuentes de cannabis muestran una preferencia muy marcada por aquel tipo de mensajes y consejos permisivos sobre el consumo de drogas en general y del consumo de cannabis en particular, resultándoles a la mayoría más interesantes $(81 \%)$, creíbles $(75 \%)$ y a los que están más dispuestos a seguir (84\%), frente a los mensajes antidroga, más aceptados mayoritariamente por los no consumidores. Así, es posible que los programas de prevención estén infravalorando la importancia de los factores estables, como el Psicoticismo e Inconformismo, como factor de resistencia a aceptar estos programas por los 
consumidores de drogas, y que la insistencia en mensajes negativos y anti-droga esté resultando ineficaz con los consumidores (al menos de cannabis, que constituyen la principal representación de nuestra muestra), y que sólo convenzan a los "ya convencidos", es decir, que influyan en la reducción del consumo o en el retraso del primer contacto con la droga en aquellos que nunca serán consumidores problemáticos.

Ahora bien, muchos dirán que si los programas se aplican de forma más prolongada en todos los niveles de edad, la eficacia sería mucho mayor en todo tipo de jóvenes, consumidores o no. También se argumenta que si estos programas tienen un impacto, aunque sea pequeño, en algunos potenciales consumidores futuros de drogas, estaría más que justificada su implementación. Además, el Estado no puede evadir su responsabilidad de afrontar el problema de la droga.

En cuanto al primer argumento, hay que recordar lo que ya dijimos al principio, y es que cuando los chicos se hacen mayores se vuelven más escépticos a los mensajes que les dicen que todas las drogas son igual de perjudiciales y para cualquier nivel de consumo. Los jóvenes perciben que hay una diferencia considerable entre el consumo y el abuso de drogas, de forma que los mensajes que insisten en que todo consumo es peligroso y rechazable, en los que se basan casi todos los programas de prevención, les resultan poco creíbles, de forma que empiezan a valorar más negativamente los programas preventivos que en la preadolescencia valoraban más positivamente (Brown y Caston, 1995). En cuanto al segundo argumento, no está claro por qué está justificado que el Estado deba promover los programas de prevención de drogas aunque sólo se beneficie una minoría de jóvenes. Si nos atenemos al cannabis, que es el centro de interés de este artículo, no parece razonable que "salvar" a una cantidad determinada de jóvenes del consumo de esta droga compense el dispendio económico que supone su puesta en marcha. Y esto es así porque no parece que el consumo de cannabis represente, precisamente, un grave problema de salud pública.

Así, en nuestra muestra hemos constatado que, en general, los efectos percibidos a largo plazo de los consumidores frecuentes de cannabis (como mínimo un año de consumo) son en mayor medida positivos que negativos. En particular, la mayoría de los consumidores informa de un mayor bienestar emocional general $(61 \%)$ como consecuencia del consumo de cannabis. También, un 54\% informan de una mejora de sus relaciones personales y un $48 \%$ perciben un efecto positivo del cannabis en el nivel de comunicación, relaciones con el sexo opuesto, seguridad en sí mismo y disfrute de las cosas de la vida. Un $35 \%$ encuentra que la droga le ha ayudado a superar los problemas, mien- 
tras que un $16 \%$ ha percibido lo contrario. Por otra parte, no parece que entre los consumidores de nuestra muestra, el consumo de cannabis haya perjudicado el empleo de estrategias activas de afrontamiento del estrés. Si bien los consumidores frecuentes tienen más problemas que los no consumidores $(\mathrm{p}<.05)$ y emplean más estrategias de evitación $(\mathrm{p}<.05)$, no hay diferencias en el uso de estrategias activas para afrontar los problemas, incluso aunque más de la mitad de los consumidores $(57 \%)$ reconozcan que utilizan la droga para "desconectar" de los problemas. Al respecto hay que recordar que esta estrategia puede ser una forma útil de afrontar el estrés (Wills, 1985).

No obstante, es posible criticar estos resultados de varias formas. Primero, se basan en efectos percibidos de los consumidores, los cuales pueden no ser objetivos. Se tendría que contar, además, con otro tipo de resultados con criterios más objetivos, como análisis médicos y psiquiátricos, o con índices de búsqueda de asistencia médica por problemas agudos del consumo o derivados del consumo prolongado. Segundo, aunque pueda demostrarse en alguna medida que algunos consumidores de cannabis pueden en parte controlar su consumo y no informan de efectos negativos a largo plazo, esto no es extrapolable a los efectos muy negativos de las "drogas duras" como la cocaína y la heroína. Y tercero, la muestra es pequeña para extraer conclusiones definitivas sobre los efectos beneficiosos del cannabis.

En cuanto a la primera crítica, que faltan datos objetivos médicos y psiquiátricos, hay que decir que, al respecto, es clarificadora una magnífica revisión de las consecuencias del consumo de cannabis realizada en 1982 por el Institute of Medecine de los Estados Unidos y que, hasta la fecha, no se han obtenido resultados que alteren en una medida significativa sus conclusiones. Una lectura detenida de los resultados recogidos por el Institute of Medecine nos muestra que hay una importante diferencia entre el consumo y el exceso o abuso de cannabis. Así, mientras no se ha encontrado prácticamente ninguna consecuencia negativa del consumo de cannabis, el abuso de los consumidores "a diario" puede llevar a procesos inflamatorios crónicos en los bronquios y úvula, frecuentemente asociados con sinusitis crónica, pero que son reversibles al cesar el consumo. No hay resultados consistentes respecto a los potenciales daños sobre la función reproductiva masculina, teratogeneidad, efectos genéticos y sobre el sistema inmunitario. En cuanto a los consecuencias negativas del sistema cardiovascular, sólo se han constatado en personas con graves alteraciones de este sistema, que normalmente pertenecen a un grupo de edad distinto del de los consumidores. De especial relevancia son las consecuencias negativas sobre la conducta social y la salud mental. Así, se han descrito reacciones de pánico y fuerte ansiedad y 
descoordinación tras el consumo de dosis normales, pero estos síntomas remiten al poco tiempo (unas 4 horas) y el número de admisiones hospitalarias por este motivo es despreciable. En cuanto a fuertes reacciones disfóricas o síndrome cerebral agudo, sólo se ha constatado en grandes consumidores y con dosis muy elevadas, especialmente de hashis. La ocurrencia de "flashbacks" o de brotes psicóticos tras el consumo se ha observado en consumidores previos de LSD o en personas altamente predispuestas (esquizofrénicos) respectivamente.

Esta distinción fundamental entre las consecuencias del consumo y del abuso se pone también de manifiesto en otra serie de estudios. Así, Newcomb y Bentler (1988), en un estudio que pretendió especialmente establecer relaciones causales entre el consumo de drogas y sus consecuencias, no encontraron un impacto negativo años después del consumo de drogas (donde estaba muy representado el consumo de cannabis) en salud mental ni en relaciones sociales, pero sí unas consecuencias negativas de los grandes consumidores en aspectos particulares de la salud mental, como el aumento de la tendencia psicótica o la ideación suicida, y un mayor aislamiento social y soledad. Es curioso observar que estos autores encontraron que el consumo de alcohol, si no se consume con otras drogas ilegales, tuvo efectos muy positivos tanto en salud mental (reducción de la depresión y mejora del estado de ánimo) como en las relaciones sociales (aumento de las relaciones sociales y reducción de la soledad). Nuevamente se pone de relieve que consumir cannabis tiene unas consecuencias a largo plazo muy diferentes al hecho de abusar del cannabis.

¿Pero qué pasa con las correlaciones altas que se encuentran continuamente en la literatura científica entre la delincuencia y el cannabis, y entre el fracaso escolar, el menor interés por los estudios y la falta de interés por los proyectos futuros y el cannabis? Si bien no podemos extendernos en estas cuestiones, sí al menos daremos una sucinta respuesta aclaratoria. Así, sí es cierto que la delincuencia y las demás actitudes citadas hacia la escuela y el futuro (todo lo cual recibe el nombre de "síndrome amotivacional") se relacionan con el consumo de cannabis. Ahora bien ¿Esto dice algo de la relación causal? ¿Es la droga la que provoca estos problemas, o más bien son las actitudes previas las que conducen al consumo? Entre los numerosos estudios longitudinales de estudiantes entre 12-21 años, revisados por Kandel (1978b, c , 1980), se muestra que una serie de factores tradicionalmente relacionados con el consumo de cannabis, como son bajo rendimiento académico, delitos, baja autoestima, humor depresivo, rebeldía y otras características de personalidad, en realidad preceden al consumo de cannabis. Un estudio (Jessor y Jessor, 1977) demostró, además, que el consumo de marihuana podía agravar o exagerar cier- 
tas conductas, como la delincuencia o el bajo interés académico. No obstante, el aumento de la conducta desviada y el bajo interés escolar cambiaron más bruscamente el año que precedió al consumo.

Como conclusión de esta revisión de los efectos a largo plazo del consumo y de los antecedentes del mismo, podemos concluir que muchos males que se asocian con el consumo de cannabis (delincuencia, fracaso escolar, etc.) son parte de un sistema de valores que en realidad preceden al consumo y no son su consecuencia. En este grupo de jóvenes, el consumo de drogas ilegales es un aspecto más de su conducta desviada, y una forma más de mostrar su inconformismo con las normas sociales establecidas por los adultos. Por tanto, no es extraño que los programas de prevención del consumo de drogas no sean muy efectivos, ya que focalizar sus esfuerzos en combatir el consumo de droga supone atacar un comportamiento que forma parte de un sistema más amplio y complejo de valores y actos sociales, que además están relacionados con variables de personalidad estables. Recordemos que en nuestra muestra, el Psicoticismo y el Inconformismo están muy relacionados $(\mathrm{r}=.43, \mathrm{p}<.001)$. Por otra parte, ha quedado claro que el consumo de cannabis no tiene especiales consecuencias a largo plazo, incluso puede resultar beneficioso para una buena parte de los consumidores, mientras el abuso y exceso puede ser perjudicial a corto y largo plazo. Ya que, de alguna forma, los jóvenes reconocen esta realidad (Brown y Caston, 1995), la insistencia de los programas de prevención en los mensajes anti-droga de cualquier nivel de consumo representan más una apreciación moral sobre el consumo de drogas por parte de quienes los llevan adelante y de los responsables políticos que una actitud fundamentada científicamente.

Por todo lo dicho, y con especial referencia al cannabis, la necesidad y eficacia de los programas de prevención del consumo de drogas y las consecuencias negativas para la salud son más un mito que una realidad. $\mathrm{Ni}$ se ha comprobado suficientemente que los programas preventivos sean eficaces ni que el cannabis represente un problema de salud pública. El reconocimiento de que las consecuencias a largo plazo pueden ser negativas si se abusa del cannabis pero no si se consume, y la percepción ajustada a la realidad que los jóvenes tienen al respecto, nos tiene que hacer reflexionar sobre la conveniencia de afrontar el "problema de la droga" desde la información veraz de las consecuencias negativas del abuso de drogas y, en particular, del cannabis (los llamados programas de "reducción del daño") mientras se reconoce su inocuidad e incluso el beneficio de un consumo ocasional o moderado. 
Esta conclusión que acabamos de esbozar nos lleva a la propuesta de una nueva política de drogas, con programas de información de las consecuencias del mal uso y el abuso de drogas y con la no injerencia de los organismos públicos en el consumo y distribución a escala reducida del cannabis. Tal vez el modelo holandés de no intervención respecto al consumo y la permisividad y control parcial de su distribución, sea un modelo muy apropiado que se ajusta a los resultados extraídos de este estudio. La despenalización de su consumo y la permisividad de la venta a pequeña escala ha permitido alejar a esta droga de la criminalidad, pero sin aumentar desproporcionadamente su consumo. Así, si comparamos la prevalencia de vida del cannabis en Amsterdam (1987) con el de Nueva York (1988) en jóvenes de 18 años y mayores, observamos que es menor en Amsterdam $(23,7 \%)$ que en Nueva York (29\%) a pesar de la fuerte actuación policial sobre el consumo y venta de cannabis en esta última ciudad. También hay diferencia si consideramos el consumo reciente, donde encontramos un $11 \%$ en Nueva York frente a un 9,4\% en Amsterdam (Cohen, 1989). Por otra parte, no se ha constatado que la despenalización de su consumo en Amsterdam a principios de los años 70, haya conducido en el presente a un "explosión" de consumo ni a un aumento considerable del consumo de otras drogas (Cohen, 1995 ; Cohen y Sas, 1996). Al comparar muestras de 1987, 1990 y 1994 de consumidores de cannabis en Amsterdam, estos autores encontraron una estabilidad en porcentajes de prevalencia de vida por grupos de edad, alrededor de un $3 \%$ entre $12-15$ años y de un $25 \%$ entre 16 y 19 años. Sólo se ha producido un aumento del $40 \%$ en 1987 al 50\% en 1994 del grupo de edad 19-24 años, pero el patrón de consumo de estos jóvenes permanece estable, es decir, aunque ha aumentado la proporción de consumidores, lo que aumenta es el consumo ocasional y moderado, no el continuado. A partir de los 24 años decrece progresivamente el interés por el cannabis. El consumo continuado (consumo en el mes anterior a la encuesta) representa entre $20-25 \%$ del total de los que han experimentado con la hierba, pero sólo el $4 \%$ son fumadores "fuertes" (más de 20 veces al mes). Curiosamente, la edad promedio del primer consumo es 20 años (no se ha reducido la edad del primer contacto con el cannabis) y la del abandono del consumo es 26 años. Además, la cantidad total de jóvenes que han solicitado tratamiento por problemas relacionados con el consumo de cannabis aumentó de 27 en 1988 a 54 en 1994. Si calculamos unos 60.000 consumidores de cannabis en Amsterdam, no se puede hablar precisamente de un problema de salud pública (Cohen, 1995). Así, parece que una política más permisiva con el consumo de cannabis y su distribución a pequeña escala (lo cual reduce su adulteración ya que los pequeños vendedores tienen que mantener un buen producto para ser "competitivos") junto con 
campañas de información de los efectos negativos del mal uso y consejos para evitar estos inconvenientes, merece una mayor atención y reconocimiento en nuestro país.

Ahora bien, si esto puede ser cierto con el cannabis, ¿qué pasa con las demás drogas? Esto nos lleva a responder a la segunda pregunta que nos hacíamos más arriba, referente a que los resultados obtenidos, de este y otros estudios y revisiones sobre el cannabis, pueden no ser aplicables a otras "drogas duras". En principio, hay que aclarar que para la mayor parte de las autoridades políticas y sanitarias que promueven las campañas de prevención contra la droga, no hay distinción entre drogas duras y drogas blandas. Así, el cannabis sería una droga igual de peligrosa que la cocaína o la heroína, sino por sus efectos, sí porque el consumo de cannabis conduce claramente al consumo de las otras drogas. Hay que recordar que ni en este estudio ni en los que se han realizado para valorar la hipótesis de la escala de las drogas desde el cannabis, se ha encontrado la confirmación de tal hipótesis. Además, en este estudio hemos constatado que los consumidores frecuentes de cannabis informan de un nivel importante de control del consumo y de beneficios a largo plazo derivados del mismo, lo cual parece inverosímil para las demás drogas. No obstante, hay una creciente evidencia de que entre los consumidores de cocaína que no están implicados en actividades delictivas ni están en centros de tratamiento, el control del consumo y la ausencia de problemas a largo plazo derivados del consumo, parece ser la norma más que la excepción (Cohen y Sas, 1992 ; Cohen y Sas, 1994 ; Erickson y Weber, 1994, Reinarman, Murphy y Waldorf, 1994 ). Estos mismos autores concluyen que estos resultados apuntan a la necesidad de estudiar políticas de drogas alternativas a la política prohibicionista extendida en todo el mundo. No obstante, más investigación es necesaria sobre esta cuestión.

La tercera crítica a las conclusiones extraídas de este estudio, a la que hicimos referencia más arriba, se refería a que no es posible sacar conclusiones importantes de una muestra relativamente reducida. Ahora bien, este estudio cumple la función de explorar desde otra óptica distinta de la tradicional el estudio del "problema de la droga", obteniendo resultados congruentes, en buena parte, con la evidencia experimental existente y que aquí ha sido sucintamente expuesta. Además, abre nuevas estrategias de investigación que ya están dando su fruto. Así, los primeros resultados que están siendo evaluados en este momento de un estudio en marcha en un Instituto de BUP y COU, en el que se ha administrado la encuesta que aquí se propone, están replicando los resultados más sobresalientes que se han obtenido aquí. Así, entre los consumidores actuales de cannabis $(\mathrm{N}=46)$ de un total 
de 360 alumnos que respondieron a la encuesta, se está encontrando que la mayoría acepta mejor los mensajes permisivos sobre el consumo que los punitivos, siendo que la mayoría de los no consumidores, prefiere los punitivos. Además, los consumidores informan, en general, de consecuencias favorables del consumo prolongado de cannabis más que de consecuencias negativas. También se han replicado las diferencia significativas en Psicoticismo e Inconformismo entre los consumidores y no consumidores, al igual que el poder predictivo de estas variables sobre el consumo, abuso y preferencia de mensajes permisivos. Los datos están todavía analizándose y que serán presentados en un futuro, pero, como podemos ver, los resultados están replicando lo aquí encontrado.

\section{BIBLIOGRAFÍA}

ARGYLE, M. y LU, L. (1990): The happiness of extroverts. Personality and Individual Differences, 11, 1011-1017.

BANDERT-DROWNS, R.L. (1988): The effects of school-based substance abuse education. A meta-analysis. Journal of Drug Education, 18, 243264.

BECKER, H.K., AGOPIAN, M.W. y YEH, S. (1992). Impact evaluation of Drug Abuse Resistance Education (DARE). Journal of Drug Education, 22, 283-291.

BIGLAN, A., WEISSMAN, W. y SEVERSON, H. (1985): Coping with social influences to smoke. En S. Shiffman and T.A. Wills (Eds.), Coping and substance abuse. New York and London: Academic Press. pp 95-116. BROWN, J.H. y CASTON, M.D. (1995): On becoming "at risk" through drug education. How symbolic policies and their practices affect students. Evaluation Review, 19, 451-492.

CATTARANZO, S.J. y MEARNS, J. (1990): Measuring Generalized Expectancies for Negative Mood Regulation: Initial Scale Development and Implications. Personality Assessment, 54, 546-563.

CLAYTON, R.R., CATTARELLO, A., DAY, L.E. y WALDEN, K.P. (1991): Persuasive communications and drug abuse prevention: An evaluation of the DARE program. En L. Donohew, H. Sypher y W. Bukowsky (Eds.), Persuasive communication and drug abuse prevention. Hillsdale, NJ: Lawernce Erlbaum. Pp 295-313.

CLAYTON, R.R., CATTARELLO, A. y WALDEN, K.P. (1991): Sensation seeking as a potential mediating variable for school based prevention interventions: A two year follow-up of DARE. Journal of Health Communications, 3, 229-239.

COHEN, P. (1989): Cocaine use in Amsterdam in non-deviant subcultures. Amsterdam: University of Amsterdam. 
COHEN, P. (1990): Cocaine and Cannabis: An identical policy for different drugs? En P. Cohen (Eds.), Drugs as a social construct. Amsterdam; CEDRO.

COHEN, P. (1995): Cannabis users in Amsterdam. Presentación en la Conference on Urban Softdrugs Tolereance Polivy, Jaarbeurs Conference Center, Utrecht.

COHEN, P. y SAS, A. (1996): Cannabis use, a stepping stone to other drugs? The case of Amsterdam. Amsterdam: CEDRO.

COHEN, P. y SAS, A. (1992): Loss of control over cocaine, rule or exception? Paper presented at the American Society of Criminology, New Orleans.

COHEN, P. y SAS, A. (1994): Cocaine use in Amsterdam in non deviant subcultures. Addiction Research, 2, 71-94.

DEMBO, R. (1979): Substance abuse prevention programming and research: A patnership in need of improvement. Journal of Drug Education, 9, 189208.

DEMBO, R. (1981): Critical issues and experiences in drug treatment and prevention evaluation. International Journal of Addictions, 16, 1399-1414.

DUKES, R.L., ULLMAN, J.B. y STEIN, J.A. (1996): Three-year follow-up of Drug Abuse Resistance Education (DARE). Evaluation Review, 20, 4966.

DUKES, R.L., ULLMAN, J.B.y STEIN, J.A. (1995): An evaluation of D.A.R.E (Drug Abuse Resistance Education) using a Solomon four group design with latent variables. Evaluation Review, 19, 409-435.

ENNET, S.T., ROSEMBAUM, D.P., FLEWELLING, R.L., BIELER, G.S., RINGWALT, C.L. y BAILEY, S.L. (1994): Long-term evaluation of Drug Abuse Resistance Education. Addictive Behaviors, 19, 113-125.

ENNET, S.T., TOBLER, N.S., RINGWALT, C.L. y FLEWELLING, R.L. (1994): How effective is Drug Abuse Resistance Education? A metaanalysis of project DARE outcome evaluations. American Journal of Public Health, 84, 1394-1401.

ERICKSON, PG. y WEBER, T.R. (1994): Cocaine careers, control and consequences; results from a canadian study. Addiction Research, 2, 3750.

ESCÁMEZ, J. (1990): Drogas y escuela: Una propuesta de prevención. Madrid: Dykinson.

EYSENCK, H.J. y EYSENCK, S.B.G. (1964): Eysenck Personality Inventory. London: Hodder and Stoughton, Educational.

EYSENCK, H.J. y EYSENCK, S.B.G. (1975): Manual of the Eysenck Personality Questionnaire (junior \& adult). London: Hodder and Stoughton.

FAINE, J.R. y BOHLANDER, E. (1989): DARE in Kentucky schools 198889; An evaluation of the Drug Abuse Resistance Education program. Bowling Green, KY: Western Kentucky University Social Research Laboratory. 
FISHBURNE, P.M., ABELSON, H.I. y CISIN, I. (1980): National Survey on Drug Abuse: Main Findings:1979. DHHS Publication No. (ADM) 80976. Washington, D.C.: U.S. Government Printing Office.

FROJÁN, M. y SANTACREU, J. (1994): Evaluación de programas de prevención del consumo de drogas. Adiciones, 6, 283-299.

GOODSTADT, M.S. (1978): Alcohol and drug education: Models and outcomes. Health Education Monographs, 6, 263-279.

GOODSTADT, M.S., SHEPPARD, M.A. y CHAN, G.C. (1982): Relationships between drug education and drug use. Carts and horses. Journal of Drug Issues, 431-442.

HOLAHAN, C.J. y MOOS, R.H. (1987): Personal and contextual determinants of coping strategies. Journal of Personality and Social Psychology, 52, 946-955.

INSTITUTE OF MEDECINE (1982): Marihuana and Health. Washington: National Academy Press.

JESSOR, R. y JESSOR, S.L. (1977): Problem Behavior and Psychological Development: A Longitudinal Study of Youth. New York: Academic Press.

KANDEL, D.B. (1978a): Homophily, selection, and socialization in adolescent friendship. American Journal of Sociology, 84, 427-436.

KANDEL, D.B. (1978b): Longitudinal Research on Drug Use: Empirical Findings and Methodological Issues. Washington, D.C.: Hemisphere Publishing Corp.

KANDEL, D.B. (1978c): Convergences in prospective longitudinal surveys of drug use in normal populations. En D.B Kandel (Eds.), Longitudinal Research on Drug Use: Empirical Findings and Methodological Issues. Washington, D.C.: Hemisphere Publishing Corp. Pp 3-38.

KANDEL, D.B. (1980): Drug and drinking behavior among youth. Annual Review of Sociology, 6, 235-285.

KANDEL, D.B., YAMAGUCHI, K. Y CHEN, K. (1992): Stages of progression in drug involvement from adolescence to adulthood: further evidence for the Gateway Theory. Journal of Studies on Alcohol, 447-452.

MACIÁ, D. (1986): Método conductual de prevención de la drogodependencia. Valencia: Promolibro.

MCKAY, M., DAVIS, M. y FANNING P. (1981): Thoughts and Feelings, the Art of Cognitive Stress Intervention. New Harbinger Publications.

NEWCOMB, M.D. y BENTLER, P.M. (1988): Consequences of adolescent drug use. Impact on the lives of young adults. London: Sage Publications.

PENTZ, M.A, (1985): Social competence and self-efficacy as determinants of substance abuse in adolescence. En S. Shiffman and T.A. Wills (Eds.), Coping and substance abuse. New York and London: Academic Press. pp 117-142.

REINARMAN, C., MURPHY, S. y WALDORF, D. (1994): Pharmacology is not destiny: The contingent character of cocaine abuse and addction. Addiction Research, 2, 21-36. 
ROSEMBAUM, D.P., FLEWELLING, R.P., BAILEY, S.L., RINGWALT, C.L. y WILKINSON, D.L. (1994): Cops in the classroom: A longitudinal evaluation of Drug Abuse Resistance Education (DARE). Journal of Research in Crime and Delinquency, 31, 3-31.

SMART, R.G. (1983): The Nature, Treatment and Prevention of Illicit Drug Abuse. Toronto: Adiction Research Foundation.

TIMMER, S.G., VEROFF, J. y COLTEN, E.E. (1985): Life strees, helplessness, and the use of alcohol and drugs to cope: an analysis of National Survey Data. En S. Shiffman and T.A. Wills (Eds.), Coping and substance abuse. New York and London: Academic Press. pp 171-198.

WATSON, D., CLARK, L.A. y TELLEGEN, A. (1988): Development and validation of brief measures of positive and negative affect: the PANAS Scales. Journal of Personality and Social Psychology, 54, 1063-1070.

WILLS, T.A. (1985): Stress, coping, and tobacco and alcohol use in Early adolescence. En S. Shiffman and T.A. Wills (Eds.), Coping and substance abuse. New York and London: Academic Press. pp 67-94.

WYSONG, E., ANISKIEWICZ, R. y WRIGHT, D. (1994): Truth and DARE: Tracking drug education to graduation and as symbol politics. Social Problems, 41, 448-472. 



\section{MARCO OPERATIVO DE LAS INTERVENCIONES DE INSERCIÓN ASOCIADAS A LA PERCEPCIÓN DE RENTAS MÍNIMAS}

$M^{\mathrm{a}}$ JOSÉ SALVADOR PEDRAZA

EVA DOMÍNGUEZ SÁNCHEZ

RAQUEL CARRACEDO MANZANERA

Técnicos de la Consejería de Sanidad y Bienestar Social de la Junta de Castilla y León.

\section{RESUMEN}

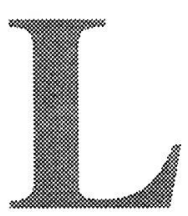

os profesionales relacionados con los programas de Rentas Mínimas de Inserción se encuentran, en el marco de la normativa existente en las distintas Comunidades Autónomas, con el reto de articular intervenciones que, asociadas a la percepción económica de unos ingresos mínimos de garantía, supongan medidas de apoyo para lograr, desde criterios promocionales y con la participación activa de los sujetos beneficiarios de estas prestaciones, itinerarios de inserción sociolaboral. Por ello, se precisa sistematizar e intercambiar experiencias sobre los criterios, objetivos y aspectos múltiples relacionados con los procesos operativos dirigidos a dicho objetivo, que suele materializarse a través de proyectos individualizados, adaptados al diagnóstico de cada situación y a las características de cada contexto, sobre todo en el ámbito de actuación de la Red de Servicios Sociales Básicos o Generales. Este artículo pretende servir como elemento de reflexión y aportación de referencia, tanto conceptual como metodológica, en este sentido, facilitando algunos apuntes, basados en la experiencia e investigación, respecto de criterios metodológicos, procedimiento a seguir, elementos a considerar, coordinación necesaria, entre otros aspectos.

\section{INTRODUCCIÓN}

A pesar de las controversias sobre el futuro del modelo del Estado del Bienestar en su vertiente de Protección Social y del coste presupuestario que sus prestaciones conllevan en el capítulo de gastos sociales, es innegable que en la actualidad, en todos los países democrá- 
ticos occidentales, la generalización de derechos sociales ha sido un presupuesto fundamental de las políticas de integración y cohesión social.

En efecto, dichas políticas han contribuido a corregir los efectos de los mecanismos generadores de procesos de exclusión, a través de la transferencia de recursos y del desarrollo de prestaciones, cada vez más diversificadas, desde el sector público a los colectivos más necesitados, fundamentalmente a través del Sistema de Seguridad Social y del específico de los Servicios Sociales.

En el marco de estas estrategias para la cobertura de las situaciones de desigualdad o exclusión social, suponen un instrumento importante las llamadas Rentas Mínimas de Inserción, que se crean al objeto de cubrir las necesidades socio-económicas básicas de las personas o núcleos de convivencia que carecen de ingresos de otro tipo, como consecuencia, sobre todo, de la dinámica selectiva de los mercados laborales.

Estos ingresos mínimos de protección para los que se ha extendido, no muy acertadamente, en nuestra opinión, el uso del término Salario Social, suelen llevar asociadas al contenido económico de la prestación, siguiendo el modelo francés, medidas adicionales que pretenden favorecer o mejorar las condiciones promocionales de inserción social y laboral de las personas perceptoras.

Tratar en breves páginas un tema tan complejo como el de la forma de abordar las actuaciones relacionadas con el desarrollo de los proyectos individualizados para favorecer, en el escenario descrito anteriormente, itinerarios de inserción de las personas perceptoras de rentas mínimas de garantía, objeto principal de este artículo, es un reto difícil y complejo con múltiples dimensiones asociadas.

Por ello, en esta aportación, sólo pretendemos, con base en la propia experiencia profesional en esta materia y desde una complementaria investigación documental y de intercambio técnico, describir algunas notas sobre los criterios y elementos a tener en cuenta en el proceso de intervención e introducir puntos de reflexión sobre los distintos aspectos y variables relacionados con aquél.

El debate sobre las Rentas Mínimas de Inserción y las intervenciones sociales complementarias, a partir de su progresiva implantación en las distintas Comunidades Autónomas, está aún abierto en nuestro país y entorno al mismo se han realizado numerosos encuentros, seminarios, jornadas de trabajo y documentos. Lo importante es que cada vez se considera más necesario, desde el realismo y datos de la experiencia acumulada, profundizar en lo relativo a los procesos de inserción o integración que, complementariamente al reconocimiento del 
derecho a la prestación de rentas mínimas, deberán ser definidos a nivel individual y adaptados a las peculiaridades de cada persona y de cada contexto social.

Es preciso tener en cuenta, en este sentido, que en España las Rentas Mínimas de Inserción nacieron y se han desarrollado por iniciativa de la Administración Autonómica, existiendo en cada Comunidad Autónoma una normativa y una realidad diferente respecto de las condiciones relativas a estas prestaciones. En consecuencia, nos encontramos, según cada territorio, con modalidades singulares, tanto en lo relativo a la propia percepción económica para garantizar un determinado y desigual nivel de ingresos, que actúa como instrumento de seguridad mínima en cuanto a recursos de subsistencia básica, como en lo relativo a los programas diseñados para favorecer itinerarios de integración o inserción, en el marco del desarrollo de medidas institucionales frente a la pobreza y la exclusión.

La heterogeneidad es tan grande que es difícil, en la pluralidad existente, deducir elementos comunes, sobre todo en lo que respecta a las medidas de acompañamiento, resultando muy complejo extraer una línea clara sobre su aplicación.

Un aspecto curioso a resaltar es que aunque la inserción constituye, en la práctica totalidad de las normativas autonómicas, un imperativo y un objetivo básico complementario al derecho a la percepción de la Renta Mínima, se da una gran indefinición sobre aquel término, por lo que se origina una diversidad de interpretaciones.

Ante esta realidad, en este artículo nos parece interesante tratar de delimitar no sólo los aspectos relativos a la caracterización de las Rentas Mínimas, sino también las dimensiones y perfiles asociados a los procesos de inserción, fundamentalmente de carácter socio-laboral, que guardan estrecha relación con los principios de normalización e igualdad en las oportunidades de participación e integración de los ciudadanos en la vida social.

\section{CARACTERIZACIÓN DE LAS RENTAS MÍNIMAS DE INSERCIÓN}

Podemos definir las Rentas Mínimas de Inserción como prestaciones periódicas de carácter temporal e individualizado, dirigidas a luchar contra las situaciones de necesidad económica y de exclusión social más extremas. Constituyen un instrumento básico de seguridad y de protección, en su vertiente de garantía, tanto de unos recursos económicos mínimos para la subsistencia material, como de medidas idóneas para promover estrategias de inclusión o integración social. 
En su nivel de protección, inciden sobre las personas adultas en edad laboral pero que, por sus dificultades para acceder al mercado de trabajo, tienen una situación de precariedad socio-económica y vulnerabilidad.

Históricamente, los orígenes de las Rentas Mínimas de Inserción se sitúan en Francia, tras la creación en 1988 del Révenu Mínimun d'Insertión, prestación que añadió a la asignación económica de protección el mandato a los poderes públicos y a la sociedad para desarrollar mecanismos que permitiesen a los ciudadanos ejercitar el derecho a un espacio de integración.

Podemos afirmar, aunque con ciertas reservas, que en la actual caracterización de las Rentas Mínimas de Inserción, se combinan dos tipos de derechos o cuasiderechos: el respectivo a la propia prestación económica y el correspondiente a la inserción, que tiene posibilidad de ejercitar una población cada vez más heterogénea en sus características y numéricamente reducida, en este último aspecto fundamentalmente por razones de limitación presupuestaria.

El desarrollo de las distintas modalidades de Rentas Mínimas de Inserción en nuestro país, desde el inicio de su andadura, vinculada como primer antecedente al Decreto 39/1989, de 28 de febrero, sobre «Ingreso Mínimo Familiar del Gobierno Vasco», ha supuesto un incremento importante, aunque todavía claramente insuficientemente, del presupuesto público destinado a los Servicios Sociales y dentro de este Sistema a los sectores más excluidos, así como un aumento proporcional en el área de la Red Básica de los respectivos recursos humanos.

El mayor avance, no obstante, podemos afirmar que se ha producido respecto de las intervenciones dirigidas a la integración-inserción social, donde se ve la necesidad de que tanto técnicos, como instituciones y la sociedad en general, continúen desarrollando su capacidad innovadora para reorientar y racionalizar los recursos y prestaciones en favor de la integración.

Las Rentas Mínimas de Inserción son una solución parcial ante una situación concreta, teniendo, en su propia naturaleza o configuración, el fin último de su desaparición, a partir de procurar el restablecimiento de las condiciones normalizadas de autonomía económica o integración socio-laboral.

No se puede hablar de un modelo unificado de Rentas Mínimas de Inserción en Europa, ni en España, como ya hemos señalado, y esto se aprecia no sólo en la vertiente económica, sino en las condiciones de acceso, tiempo de disfrute u obligaciones y compromisos individualizados para la inserción, asociados a dichas prestaciones. 
Una característica importante de las Rentas Mínimas de Inserción es que permiten detectar y conectar, desde las redes de protección social establecidas, con las personas y familias en situación de mayor desventaja o vulnerabilidad para promover su integración social normalizada con estrategias y medios diversos. Permiten, así pues, hacer visible un sector de población que a menudo, pese a sus graves condiciones de precariedad socioeconómica, queda al margen de los mecanismos tradicionales de protección social y del empleo. A este respecto hay que tener en cuenta que, según los datos del informe del Consejo Económico y Social sobre la exclusión en España', en nuestro país hay más de siete millones de personas en situaciones de pobreza, es decir, cuyas rentas están por debajo del cincuenta por ciento del salario mínimo interprofesional, de los cuales cerca de ochocientos mil tienen una situación de pobreza severa (línea inferior al $25 \%$ del salario mínimo interprofesional) y aproximadamente 6.200 .000 se encontrarían en situación de pobreza moderada (línea existente entre el 25 y el 50\% del salario mínimo interprofesional).

En este sentido, el balance y evaluación de los Programas de Rentas Mínimas de Inserción en las distintas Comunidades Autónomas, así como de las funciones que respecto de participación en la cofinanciación, homologación, etc, pudiera jugar la Administración del Estado, es necesario, pero consideramos especialmente urgente sistematizar las experiencias y avanzar en lo relativo a la vertiente de apoyo social que estas prestaciones conllevan para una parte de los ciudadanos, que de otro modo quedarían desamparados y sin posibilidad efectiva de acceder a procesos de inserción social, cronificándose y agravándose las situaciones de exclusión o vulnerabilidad que padecen o tienen riesgo de padecer.

\section{III.RELACIONES ENTRE LAS RENTAS MÍNIMAS DE INSERCIÓN Y LAS MEDIDAS DE APOYO PARA EL ACCESO AL EMPLEO}

En el marco de las transformaciones que en las últimas décadas ha sufrido el mundo del trabajo, asociadas a las modificaciones en la estructura ocupacional, la desvinculación entre crecimiento económico y empleo, entre producción y ocupación, así como al cambio de una economía productiva hacia una predominantemente de servicios, se han producido ciertos desajustes en las relaciones socio-laborales y en

Informe n. ${ }^{\circ} 8$ del Consejo Económico y Social (CES) aprobado en sesión extraordinaria del pleno del 27 de noviembre de 1996. Documento editado pro CES en 1997. Madrid. 
las posibilidades de inserción en el mercado de trabajo, que es preciso tener en cuenta al tratar el tema relativo a los aspectos relacionados con las Rentas Mínimas de Inserción.

Las dimensiones que alcanza en la actualidad el fenómeno del desempleo, su carácter estructural y persistencia, constituye un factor determinante en el desarrollo de procesos de exclusión y vulnerabilidad socio-económica. En efecto, las tasas de desempleo de los sectores con menor especialización duplica las de otros parados con experiencia laboral constatando que en estos casos se dan, así mismo, los mayores índices de eventualidad.

Así pues, parece de interés reflexionar y profundizar en la relación existente entre las acciones llevadas a cabo en el marco de la protección social, (sobre todo en lo que respecta a las prestaciones por desempleo y las Rentas Mínimas de Inserción) y las medidas activas para favorecer el acceso al empleo de las personas y colectivos con más dificultad en la inserción laboral.

Aumentar las posibilidades individualizadas de acceso al mercado laboral, en condiciones normalizadas y de igualdad de oportunidades, implica promover procesos favorecedores de inclusión. Es decir, poner en marcha, frente a los simples mecanismos de protección asistencial y pasiva, políticas activas que combinen la garantía de cobertura de unos ingresos mínimos, con la necesaria formación ocupacional, el desarrollo de habilidades personales o socio-laborales y la promoción de nuevas alternativas de empleo. Deberá darse prioridad, por tanto, a la participación de las personas perceptoras de Rentas Mínimas en actividades formativas, así como de técnicas de búsqueda de empleo u otras que favorezcan su inserción socio-laboral.

Se hace necesario, por todo ello, avanzar en la búsqueda de un equilibrio entre las acciones de protección vinculadas a los Programas de Rentas Mínimas de Inserción y el correspondiente esfuerzo de los poderes públicos y de la sociedad para la promoción del acceso al trabajo, en condiciones normalizadas, siempre en el marco de las estrategias globales y transversales vinculadas a las políticas de carácter socio-económico.

Complementariamente, habrá que buscar fórmulas para que las medidas de protección social en las personas y colectivos más vulnerables no lleguen a convertirse, en el plano individualizado, en un factor de desincentivación para el acceso al mercado de trabajo, sino que por el contrario favorezcan itinerarios favorecedores para la inserción socio-laboral. Esto sin olvidar que siempre el mantenimiento de un nivel mínimo de rentas garantizadas para la cobertura de las necesidades más elementales, la permanencia en el entorno habitual, así como el mantenimiento de la autoestima, del equilibrio personal y de las rela- 
ciones de convivencia, serán aspectos fundamentales que condicionarán, en mayor o menor grado, tanto las posibilidades de acceso al trabajo como el desarrollo o mantenimiento de posibles situaciones de marginación, pobreza o exclusión social.

$\mathrm{Si}$, a los factores expuestos, se añade el contenido, consensuado con los propios interesados, respecto de aquellas acciones que se consideren idóneas para desarrollar itinerarios individualizados de inserción socio-laboral (siempre ajustados a las necesidades y capacidades de la persona perceptora de rentas mínimas), estaremos potenciando, sin excluir la necesaria responsabilidad de los poderes públicos, la respectiva de los propios ciudadanos en el esfuerzo para participar y promover, en la medida de lo posible, la superación efectiva de sus dificultades a fin de alcanzar la deseada igualdad de oportunidades cara a la normalizada integración socio-laboral.

Desde estas premisas, la formación ocupacional, la mejora en la información, las acciones positivas para favorecer el acceso al trabajo de los colectivos en riesgo de exclusión del mercado laboral, junto con las respectivas acciones en materia de política de trabajo, se convierten en ejes fundamentales de la articulación entre las políticas activas de empleo y las respectivas de protección en el área de acción social.

En relación con este planteamiento, será básico impulsar los mecanismos de coordinación entre las administraciones públicas y los agentes sociales, pues se precisa del esfuerzo común para superar las meras intervenciones asistenciales y favorecer la adecuada inserción sociolaboral de las personas perceptoras de estas prestaciones.

La corresponsabilidad, la cooperación y la transversalidad desempeñan en este tema un papel fundamental para obtener resultados eficaces, no siendo suficientes las soluciones sectoriales, sino que es preciso movilizar otras de carácter horizontal donde el principio de proximidad juega un protagonismo especial.

También, en esta línea de acción, es preciso reforzar los nexos de colaboración entre los distintos Sistemas de Bienestar Social, así como entre la iniciativa pública y la privada, sobre todo en el marco de desarrollo de programas integrados de base local que permitan afrontar las situaciones de vulnerabilidad social, desempleo y exclusión en cada ámbito territorial, existiendo en este sentido algunas experiencias referenciales de interés como, por ejemplo, la desarrollada en el proyecto piloto de intervención integral en municipios de menos de 20.000 habitantes promovido por la Junta de Castilla y León en el ámbito de los municipios de Sahagún (León), Villada (Palencia) y Villalón de Campos (Valladolid), durante los años 1995/96².

2 Experiencia publicada en el libro de varios autores: La intervención integral de municipios 
En este sentido tienen un importante papel, no solo la Red de Servicios Sociales u otros recursos institucionales, sino también las llamadas Empresas de Economía Social que incluyen sociedades anónimas laborales, cooperativas de trabajo asociado, iniciativas de empleo autónomo, asociaciones y fundaciones sin ánimo de lucro, etc., que pueden generar nuevos yacimientos de trabajo. Complementariamente, habrá que tener en cuenta el papel que pueden jugar las denominadas Empresas de Inserción., cuya finalidad es facilitar la integración laboral de personas en desventaja para que puedan alcanzar una formación y socialización a través del trabajo que les facilite habilidades ocupacionales para el desarrollo posterior de una actividad laboral ordinaria, aún pendientes de regulación jurídica en nuestro país.

\section{IV.PERFILES DE LA INSERCIÓN}

A lo largo de este artículo se ha mencionado varias veces la palabra «inserción» y también ha sido comentada la diversidad de sus interpretaciones, en el tratamiento normativo de las Rentas Mínimas de Inserción en las distintas Comunidades Autónomas, pero aún queda por abordar la definición de este término. Por ello, a continuación, vamos a hacer un esfuerzo de identificación terminológica sobre los perfiles que caracterizan a la inserción, esto puede ser útil para unificar criterios y servirnos de base para fijar el marco conceptual en el que se sustentan nuestras reflexiones.

La inserción social implica la posibilidad personal de poder desempeñar, en condiciones normalizadas, desde la propia autonomía o con los oportunos apoyos para la adquisición de habilidades y conocimientos necesarios, un papel activo de participación en la sociedad en el plano económico, de convivencia, cultural, sanitario, de relaciones socio-laborales..., siempre desde un óptimo aprovechamiento de las capacidades y recursos individuales que se precisan para el normal desenvolvimiento e integración en la vida social de un determinado contexto.

Desde este perfil, las intervenciones profesionales e institucionales, así como de la propia sociedad y agentes sociales, en favor de la inserción, deberán dirigirse a reducir las situaciones de desigualdad y a propiciar la participación y cohesión social. Son factores básicos, en este sentido, las relaciones familiares y sociales, las alternativas para la promoción individual, el desarrollo de las capacidades personales, la cualificación profesional, la realidad cultural, socio-económica, sa-

menores de 20.000 habitantes. (1996), editado por la Junta de Castilla y León-Consejería de Sanidad y Bienestar Social. 
nitaria, de vivienda, etc., que en cada caso inciden como elementos favorecedores de la movilización de mecanismos de inclusión o exclusión social, según su grado.

Las intervenciones profesionales para promover itinerarios de inserción se efectuarán siempre bajo el principio de estimular el esfuerzo personal y familiar de los sujetos de las acciones de apoyo y no suplir su potencial.

La inserción social es una de las finalidades que, en el marco de las distintas Leyes Autonómicas de Servicios Sociales, se atribuye a la Red Básica de Servicios Sociales que, en nuestro país, está descentralizada y vinculada a la Administración Local. En este sentido, deberá tratarse de evitar la progresiva burocratización y carga de trabajo, sin medios proporcionales, de este tipo de equipamientos con relación a la gestión de la prestación de Rentas Mínimas y, por el contrario, potenciar los recursos técnicos para desarrollar, en condiciones eficaces, las intervenciones profesionales relacionadas con la inserción.

La normativa reguladora de las Rentas Mínimas en cada Comunidad Autónoma suele establecer la necesidad de alcanzar ciertos compromisos u obligaciones, relativos a promover la inserción personal, social o laboral de los perceptores y/o sus unidades de convivencia. Como referencia entre la amplia gama de posibilidades para facilitar dicha inserción, podemos distinguir, entre otras:

- Las medidas relacionadas con la educación o formación cultural básica.

- Las orientadas a la formación ocupacional y el reciclaje profesional.

- Las dirigidas a la participación social y a la integración o mantenimiento en el mercado laboral.

- Las relativas al desarrollo de actividades solidarias o de interés social, orientadas a la adquisición de habilidades y al apoyo, atención o cuidado de otras personas o, en su caso, del entorno.

- Las respectivas para favorecer la rehabilitación y promoción personal, así como a mejorar las condiciones de convivencia.

- Las destinadas a potenciar habilidades básicas o a establecer mejoras en este área.

En el campo de las actuaciones con objetivos de inserción sociolaboral existe el reto de generar una reformulación de las medidas de carácter asistencial o de protección pasiva, hacia otras estrategias activas de inserción. Esto supone instaurar procesos, no sólo de movilización personal sino también social, que serán diferentes en cada contexto, según su realidad y las características que en el mismo alcancen las situaciones de vulnerabilidad, pero, sobre todo, según las posibili- 
dades efectivas de integrar o reinsertar a las personas con mayores dificultades en el mercado de trabajo.

\section{DELIMITACIÓN DE LOS PROYECTOS INDIVIDUALES DE INSERCIÓN}

Una vez que nos hemos acercado a los perfiles de la inserciónintegración social, es importante, conforme el objeto principal de este artículo, determinar la delimitación o marco conceptual relativo a los proyectos individualizados de inserción. Podemos decir que éstos consisten en un conjunto programado y articulado de acciones que, elaboradas con criterios profesionales, a partir del estudio diagnóstico de cada situación y adaptándose a las circunstancias de cada caso, tienen como fin último facilitar una mejora en las condiciones normalizadas de integración personal, familiar laboral o social, de los perceptores de rentas mínimas de garantía.

El proyecto individualizado de inserción se convierte, en este marco, en un instrumento al servicio del derecho efectivo que tienen todos los ciudadanos a la participación e inserción social.

En el marco de estas premisas, el proyecto individualizado persigue, en última instancia, desarrollar de un modo formalizado, desde los necesarios refuerzos y apoyos técnicos e institucionales, itinerarios de inserción a la medida de cada caso. De hecho, puede afirmarse que este tipo de proyectos materializan el vínculo entre rentas mínimas y procesos de inserción.

Los proyectos individualizados no pueden imponerse, sino establecerse, de forma consensuada, con los sujetos que son sus destinatarios, lo que implica nuevos retos para la intervención social, tanto de los profesionales como de las instituciones, públicas o privadas, que pueden colaborar en su elaboración, ejecución o seguimiento, en el marco que permita la normativa aplicable en cada caso en las distintas Comunidades Autónomas.

Hay que tener en cuenta que los procesos que se pretenden movilizar a través de los proyectos individualizados de inserción suelen ser largos y muy lentos, por lo que se requiere una sensibilización de la sociedad para organizar el desarrollo de las adecuadas respuestas, en un marco de solidaridad y justicia social.

También es preciso avanzar en la formación de los profesionales, así como sistematizar criterios y procedimientos para el desarrollo de estos proyectos que tienen peculiaridades propias, no pudiendo perder de vista que las medidas de inserción sociolaboral, aparte de su com- 
ponente individualizado y socio-familiar, implican otras variables de carácter estructural que no siempre podrán abordarse en el marco de gestión y desarrollo de las rentas mínimas de inserción.

\section{VI.CRITERIOS METODOLÓGICOS EN EL DESARROLLO DEL PROYECTO INDIVIDUAL DE INSERCIÓN}

Las intervenciones dirigidas a promover itinerarios de inserción se sustentarán, con carácter general, en los siguientes criterios:

a) Enfoque ecológico, según el cual existe relación de reciprocidad entre las personas y su entorno, lo que condiciona su situación a nivel individual, familiar, social y laboral.

b) Flexibilidad, que supone respetar las características, necesidades y dinámica de cada persona o contexto.

c) Enfoque preventivo-formativo para promover una mayor competencia personal y social, evitando situaciones de riesgo o cronificación de problemáticas, y posibilitando, por el contrario, el desarrollo tanto individual como de entornos socio-familiares y de organizaciones sociales más capaces para abordar sus necesidades de integración.

d) Participación de los destinatarios, que no sólo deberán estar implicados en la asunción de responsabilidades sino aceptar previamente el itinerario de inserción del que serán sujeto activo.

e) La coordinación y la colaboración para unir esfuerzos desde un planteamiento interinstitucional, y de cooperación entre los distintos agentes sociales.

f) La complementariedad, propiciando y apoyando la asunción de las responsabilidades personales, familiares o institucionales existentes, en su caso, y actuando los profesionales e instituciones vinculados al proyecto de inserción sólo de forma subsidiaria como elementos de apoyo técnico y de refuerzo.

g) La solidaridad, por lo que las intervenciones movilizarán los resortes de apoyo social del entorno familiar o social, la autoayuda, la acción del voluntariado, los recursos comunitarios...

h) La globalidad, desde una consideración total de la persona y no sólo de aspectos parciales.

\section{VII.OBJETIVOS BÁSICOS DE LOS PROYECTOS INDIVIDUALES DE INSERCIÓN}

El objetivo general será promover unas mejores condiciones de integración social y laboral, si bien esta meta sólo podrá alcanzarse, en 
la mayoría de los casos, a través de objetivos y logros parciales, lo que hace necesario poner en claro en las intervenciones profesionales las reglas de preferencia sobre la urgencia respectiva de dichos objetivos parciales en cada situación concreta.

Dado que la provisión de unos mínimos a nivel de soporte material y económico no garantiza las condiciones de vida digna, ni de integración social, habrá que considerar en los proyectos individuales de inserción otros objetivos que podrían agruparse en los siguientes:

- Promoción personal y mantenimiento en el propio entorno social.

- Mejora de las relaciones sociales en sentido más amplio.

- Aumento de las habilidades y competencias a nivel personal, familiar, laboral y social.

Los objetivos de los proyectos individuales de inserción se basarán en el previo análisis de necesidades para la integración social y laboral normalizada y en las posibilidades o potencial de cambio de cada persona y contexto, debiendo ser objetivos precisos, realistas y medibles, dirigidos, de forma selectiva, entre otros, a los aspectos siguientes:

a) Mantenimiento del estado de salud física y de las condiciones mínimas de subsistencia digna.

b) Desarrollo educativo, potenciando, en caso necesario, la alfabetización, la coherencia de formación con las demandas laborales, el incremento de conocimientos y del nivel de instrucción, la mejora cultural, etc.

c) Promoción de las condiciones de integración-participación social, a través de la mejor utilización de las capacidades individuales, el aumento de habilidades personales, la facilitación de la armonía en el seno familiar y en las relaciones sociales.

d) Mejora en las condiciones para la participación en la actividad económica y acceso al mercado de trabajo, superando posibles obstáculos respecto de baja cualificación, déficits de habilidades sociolaborales y destrezas profesionales, etc.

\section{VIII.PROCESO A SEGUIR EN LAS INTERVENCIONES DIRIGI- DAS A PROMOVER ITINERARIOS DE INSERCIÓN ASOCIA- DOS A LA PERCEPCIÓN DE RENTAS MÍNIMAS}

La intervención social en estos casos implica un proceso de apoyo técnico programado a partir de un diagnóstico, tanto de las necesidades como de las capacidades, y que culmina en la aplicación de un proyecto individualizado de inserción, unida a su posterior evaluación. Se trata de un proceso continuo y organizado, debiendo estar las personas interesadas implicadas en el mismo desde el diagnóstico a la evaluación. Las fases del proceso serán las siguientes: 
FASE I: Recepción inicial de la demanda, generalmente en la Red Básica de Servicios Sociales, e información-orientación sobre la prestación de rentas mínimas si procede, así como sobre la necesidad de cumplimiento de determinados compromisos. Complementariamente, se brindará, si es preciso, asesoramiento sobre otros posibles recursos existentes.

Es una fase, previa a la tramitación del expediente de rentas mínimas, que va unida al diagnóstico social o psicosocial cuando proceda y que permite la valoración sobre la situación personal o socio-familiar del solicitante.

Esta fase supone el primer nivel de acceso al programa.

FASE II: Desarrollo paralelo a la tramitación del expediente de solicitud de rentas mínimas de una serie de actuaciones dirigidas a la toma de conciencia y autodiagnóstico de la persona solicitante respecto de su propia situación, e inicio de un proceso de motivación para su progresiva implicación en la búsqueda de alternativas posibles o de soluciones a su problemática.

FASE III: Selección, en base al diagnóstico y valoración profesional del técnico o equipo que actúa en el caso, de las posibles medidas de intervención y compromisos abiertos pero limitados, a cumplir por la persona solicitante o su unidad familiar, y que supondrán la base del contenido del proyecto individualizado específico para ese caso, delimitando previamente y de forma participada los objetivos generales y específicos a lograr.

FASE IV: Elaboración técnica, por parte de los profesionales responsables de las intervenciones para la inserción, del Proyecto Individualizado que deberá incluir las acciones o en su caso los compromisos a cumplir por parte de la persona perceptora de la prestación para participar en el desarrollo de su propio itinerario de inserción, así como los objetivos, actividades y recursos previstos.

FASE V: Definición complementaria a nivel técnico, de los apoyos profesionales que se prestarán, así como del sistema para el seguimiento y evaluación de los resultados del itinerario individualizado previsto. 
FASE VI: Resolución del expediente de solicitud de rentas mínimas en la unidad administrativa competente, donde así mismo se desarrollarán los aspectos formales del acuerdo para facilitar las medidas de inserción socio-laborales y la respectiva firma de los compromisos individuales, con información a la persona sobre el marco de su cumplimiento, dentro de los determinados plazos de tiempo que se establezcan, según proceda.

FASE VII: Notificación a la persona solicitante de la concesión de la prestación de rentas mínimas a través de la unidad respectivamente competente iniciándose el correspondiente trámite para el pago de la prestación, así como la respectiva ejecución del proyecto de inserción.

FASE VIII: Revisión por parte de los técnicos competentes del cumplimiento de los objetivos de inserción perseguidos y realización del Informe de Resultados a lo largo del proceso y fundamentalmente al finalizar los periodos de concesión y prórrogas de la prestación de rentas mínimas.

\section{VARIABLES A CONSIDERAR EN LAS INTERVENCIONES PARA FACILITAR LA INSERCIÓN}

Los técnicos implicados en las prestaciones de inserción asociadas a las rentas mínimas procederán a valorar, de una forma general, la situación personal, familiar, laboral y socio-económica que rodea a los solicitantes de la prestación. Para ello, entrevistarán a las personas interesadas y estudiarán sobre todo las siguientes variables:

\subsection{Características personales}

Se valorarán aquellas características personales que impidan a la persona integrarse en su entorno o en el mundo laboral de una forma normalizada, como son el nivel de instrucción, las habilidades sociales, posibles déficits, conductas antisociales, creencias, actitudes y expectativas, etc. 


\subsection{Características del entorno familiar}

Se valorarán aquellas características del entorno familiar que estén propiciando una desestructuración o que impidan el correcto cumplimiento de sus roles y funciones, como son la atención básica de necesidades de los miembros, la transmisión de valores, disciplina, educación escolar obligatoria de los hijos, habilidades parentales, relaciones sociales, etc. Es importante el estudio de la dinámica familiar en este sentido y la utilización de técnicas como el ecomapa o genograma, entre otras.

\subsection{Vivienda}

Se valorará la situación de la vivienda en cuanto a régimen de tenencia, coste mensual, tamaño en proporción a los miembros que la habitan, condiciones de habitabilidad e higiene, distribución, déficits de equipamiento, etc.

\subsection{Aspectos socio-económicos y laborales}

Se recogerá información sobre aspectos económicos relacionados con el nivel de ingresos, hábitos en la economía familiar, historia laboral de los miembros hasta el momento, cualificación profesional y expectativas futuras.

\subsection{Situación sanitaria}

Se recogerán datos sobre cobertura sanitaria, hábitos higiénico-sanitarios, drogodependencias $\mathrm{u}$ otras informaciones relacionadas con esta materia.

Las técnicas aplicables en esta fase para obtener una valoración y diagnóstico que oriente a una intervención determinada dirigida a la consecución de los objetivos serán fundamentalmente:

- La revisión documental a partir de la solicitud de documentos u otros informes de interés, tanto a la persona solicitante de la prestación como, en su caso y, si procede, a otros profesionales que tengan conocimiento del caso.

- Entrevista individual y/o familiar.

- Visita domiciliaria.

- Protocolos estandarizados o elaborados a este fín.

- La observación directa.

- Otras técnicas adecuadas a cada situación. 


\section{X. ÁREAS POSIBLES DE INTERVENCIÓN EN LOS PROYEC- TOS INDIVIDUALIZADOS DE INSERCIÓN}

Una vez valorada la situación de la persona solicitante de la prestación de rentas mínimas y establecido un primer diagnóstico sobre cuáles son sus deficits y necesidades en el marco de la integración social y laboral, se podrán establecer criterios para intervenir en una o varias de las siguientes áreas:

a) Area personal: En ella se incluyen las actuaciones que van dirigidas directamente a la persona solicitante y, en su momento, perceptora de la prestación de rentas mínimas, tratando, según proceda, de movilizar sus recursos personales, destrezas y habilidades para cubrir mejor sus necesidades de integración socio-laboral y prevenir situaciones de exclusión o su agravamiento.

b) Area familiar: Incluye las actuaciones dirigidas a la unidad de convivencia para que sus miembros se responsabilicen de la búsqueda de alternativas optimizando las redes y los sistemas de apoyo natural, teniendo en cuenta que el entorno familiar es una de las vías más normalizadas para canalizar las necesidades de sus miembros, si bien precisa de los adecuados apoyos institucionales y sociales para cumplir adecuadamente esta función.

c) Area comunitaria: Incluye las acciones dirigidas a la comunidad o ámbito más próximo a la que pertenecen una o varias unidades familiares perceptoras de rentas mínimas de inserción, con el fin de fomentar la tolerancia y la solidaridad hacia este colectivo, así como potenciar acciones directas dirigidas a los beneficiarios de las prestaciones con el fin de favorecer una mejor integración en su medio.

d) Area socio-laboral: Incluye acciones dirigidas, tanto a nivel individual como familiar, o comunitario, que fomenten mayores posibilidades de acceso al mercado laboral de aquellas personas o grupos que se encuentren excluidos del mismo, en desventaja o con especial dificultad, con respecto al empleo, como suele ser el caso de los perceptores de rentas mínimas en general.

e) Area institucional: Incluye aquellas acciones dirigidas a las instituciones, tanto públicas como privadas, y a los agentes sociales en relación a las personas que perciben rentas mínimas para movilizar los necesarios recursos de apoyo para su inserción. 


\section{XI.PARTICIPACIÓN DE LOS PERCEPTORES DE RENTAS MÍNIMAS EN LOS ITINERARIOS DE INSERCIÓN INDIVIDUALIZADOS}

Los sujetos de los programas relacionados con rentas mínimas de inserción tendrán que tratar de cumplir las medidas o, en su caso, los compromisos acordados en el marco del proyecto individualizado que haya sido elaborado en base al diagnóstico previo de su situación. Asimismo, deberá cuidarse, con carácter general, el cumplimiento de los siguientes aspectos:

- Aplicar la ayuda económica a la finalidad para la que haya sido otorgada.

- No rechazar oferta de empleo.

- No ejercer la mendicidad.

- Intentar colaborar activamente en superar la situación en la que se encuentran.

- Garantizar la escolarización de los menores a su cargo, con asistencia normalizada y regular a los centros correspondientes, cuando estén en edad de asistencia obligatoria.

\section{XII.PAUTAS BÁSICAS EN EL PROCEDIMIENTO DE INTERVENCIÓN}

Pueden considerarse, en los procesos de intervención profesional para promover itinerarios individualizados de inserción, las siguientes pautas operativas:

- Detección inicial: Se realizará a partir del estudio de las situaciones de necesidad captadas ante las que se valorará la conveniencia de gestionar la prestación económica de rentas mínimas, dentro de un programa global de actuación individualizada, en cada caso respectivo.

- Cumplimentación básica de la información y documentación necesarias para dar inicio al expediente, que motivará las actuaciones.

- Estudio personalizado de la situación con datos a nivel individual, familiar, laboral y socio-económico para su diagnóstico.

Serán aspectos importantes a considerar, según proceda, las siguientes situaciones:

- Madres solteras con cargas familiares.

- Mujeres separadas con cargas familiares.

- Mujeres separadas sin cargas familiares.

- Mujeres solas (separadas, solteras).

- Idem que en epígrafes anteriores en el caso de varones. 
- Parejas con problemas de inserción socio-laboral con hijos a cargo.

- Parejas sin hijos a cargo.

- Situación de desempleo de los miembros de la unidad familiar y tiempo sin trabajo respectivamente.

- Deficits de cualificación profesional o de instrucción básica.

A partir del diagnóstico y de la definición de los objetivos generales y parciales a alcanzar, en base a perfiles de las personas perceptoras de la prestación, se establecerán los criterios tanto para desarrollar la intervención como para descartar ésta.

- Diseño de un proyecto técnico individualizado para favorecer itinerarios de inserción a partir de actuaciones de intervención familiar o sociolaboral en función del diagnóstico realizado.

- Aplicación, previo compromiso y aceptación de la persona interesada del proyecto individualizado que ha sido elaborado, para promover itinerarios de inserción.

- Desarrollo de sesiones de motivación y orientación de carácter personal o familiar, si procede.

- Implicación con participación activa de los destinatarios y recursos de su entorno en las actuaciones para la integración socio-laboral.

- Seguimiento y evaluación de las actuaciones y resultados obtenidos.

Serán instrumentos técnicos importantes en el procedimiento de intervención:

- Protocolo de recogida de información personal, familiar y sociolaboral.

- Ficha personal de seguimiento de la intervención.

- Proyecto individualizado específico.

- Instrumentos para el seguimiento y evaluación.

- Modelos formalizados para el acuerdo entre los técnicos y perceptores de rentas mínimas sobre el marco del proyecto individualizado de inserción consensuado.

- Protocolo de intervención para la programación individualizada de itinerarios de inserción. 


\subsection{Propuesta de Modelo de Protocolo de Intervención para la Pro-} gramación Individualizada de itinerarios de inserción

\begin{tabular}{|l|l|l|l|}
\hline Areas de intervención & Necesidades detectadas & $\begin{array}{l}\text { Alternativas posibles pa- } \\
\text { ra mejora o superación de } \\
\text { necesidades específicas }\end{array}$ & $\begin{array}{l}\text { Posibles compromisos o } \\
\text { medidas individualizadas }\end{array}$ \\
\hline PERSONAL & & & \\
\hline FAMILIAR & & & \\
\hline SOCIO-COMUNITARIA & & & \\
\hline SOCIO-LABORAL & & & \\
\hline INSTITUCIONAL & & & \\
\hline
\end{tabular}

Calendario de ejecución y seguimiento

\section{INTERVENCIÓN DE LOS PROFESIONALES DE TRABAJO SOCIAL EN EL PROCESO DE INSERCIÓN}

Todas las normativas autonómicas sobre rentas mínimas de inserción ponen el acento en la necesaria inserción social de las personas perceptoras. De ahí que se conceda a este tema especial papel a la Red de Servicios Sociales Básicos, desde sus competencias de integración social en las que los trabajadores sociales desempeñan, a veces con escasos recursos de apoyo, importantes funciones relacionadas con:

1. El desarrollo del estudio y diagnóstico de la situación específica de cada caso, profundizando en los factores que confirman las deficiencias para la inserción, en el plano socio-económico, educativo, de vivienda, formación profesional, higiene, convivencia familiar, etc.

2. La planificación del proceso de inserción adaptado al diagnóstico donde se efectuará la adecuada selección de las medidas de inserción y la secuenciación de actividades a llevar a cabo a través del proyecto individualizado que se aplique.

3. El desarrollo de estrategias para favorecer la implicación del destinatario, lo que supone el diseño de procesos de desarrollo de la participación, así como el seguimiento de los casos y la evaluación, no sólo técnica sino conjunta, con los propios interesados, del resultado de la intervención.

4. Llevar a cabo funciones de apoyo técnico y de acompañamiento, lo que implica no dar por finalizado el proceso hasta tener cierta seguridad de que se han completado los objetivos para favorecer al inserción o que se han realizado todas las medidas posibles para 
facilitarla, teniendo presente siempre, en la intervención, el criterio metodológico de no crear dependencia ni cronificar situaciones generadoras de marginación o exclusión.

En todo este proceso, los profesionales del Trabajo Social tendrán que tener en cuenta la persona sujeto del itinerario de inserción como sistema individual y como sistema de relaciones familiares, socio-laborales, etc.

Por otro lado, en ningún caso, se suplantará la autonomía y soberanía personal, pese a que los desajustes, crisis, sentimientos de dificultad, desvalimiento y dependencia puedan ser fuertes.

La tarea se centrará en trabajar con las potencialidades personales y de la red de recursos del entorno, usar las oportunidades del medio para la inserción socio-laboral normalizada con criterios promocionales y en favorecer el mecanismo de apoyo técnico, desde la intervención profesional específica o en colaboración con otros profesionales que trabajan también en el ámbito de lo social, para lograr los objetivos previstos en el diseño del itinerario de inserción.

Es deseable, en todo el proceso de intervención, asegurar una alianza estable de colaboración entre el técnico y la persona sujeto del itinerario individualizado de inserción y combatir, en su caso, siempre con realismo, la posible apreciación negativa que las personas perceptoras de rentas mínimas de inserción pueden tener sobre sus posibilidades de éxito en la solución de su situación, avanzando hacia una integración socio-laboral normalizada.

Los trabajadores sociales deberán ser capaces en este proceso de saber anticipar e informar sobre el efecto de las medidas o acciones previstas en el proyecto individualizado de inserción y de ayudar a los destinatarios a comprender las consecuencias de los cambios que se intentan promover.

Se deberá evitar que la gravedad en la situación de dificultad material, social o laboral lleve al profesional a sentir impotencia, para lo que se requiere una formación especializada en este tipo de intervenciones y habilidades técnicas que posibiliten avanzar en intervenciones positivas desde las limitaciones de la realidad y la conciencia explícita de aquellas dificultades.

Será también importante potenciar el intercambio de experiencias y el debate profesional sobre las necesidades, instrumentos y formación que reclama la intervención en itinerarios individualizados de inserción, así como profundizar en los retos que, no sólo a este nivel sino en el marco institucional y de la sociedad, se plantean progresivamente en esta materia. 


\section{BIBLIOGRAFÍA}

ALONSO TORRENS, F. (1994): "Pobreza acumulada y marginación o exclusión social." Documentación Social, 96.

BANDRÉS, I.: “La integración como meta”. Cáritas, 349. 1995.

B.O.C y L. (1995): Plan Regional de Acciones Frente a la Exclusión Social. Decreto 65/1995. Boletín Oficial de Castilla y León de 25 de mayo de 1995.

CASADO, D.: "Sectores y Factores de la pobreza reconceptualizada en España". Documentación Social, n 96, 1994.

GARCÍA ROCA, J.: Lo público y lo privado frente a la exclusión social en VVAA. Inserción Socio-Laboral a debate. Generalitat de Valencia, 1993.

VVAA.: La intervención integral en municipios menores de 20.000 habitantes. Junta de Castilla y León. Valladolid, 1996. 



\section{LA REALIDAD RURAL: SITUACIÓN EN UNA REGIÓN. LA ORGANIZACIÓN DE EQUIPAMIENTOS.}

\section{JESÚS MORAGÓN NAVA}

Trabajador Social. Centro de Salud de Atención Primaria. INSALUD (Albacete).

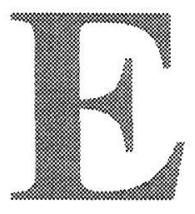

1 presente artículo no pretende ser un estudio exhaustivo de las características definitorias de lo que se entiende por Mundo Rural.

Este documento pretende aportar una visión general sobre algunos aspectos del medio rural, para concretar después esas características en la situación de una región donde lo «rural» tiene un peso importante.

Por último, nos centraremos en cómo la práctica profesional se ve condicionada por las características del medio en el que se desarrolla, haciendo especial referencia a los Centros de Servicios Sociales, como equipamiento básico de atención a la población.

\section{ALGUNOS NÚMEROS SOBRE EL MUNDO RURAL EN ESPAÑA. UNA APROXIMACIÓN.}

La población total de derecho en nuestro país es de 38.872 .268 habitantes; 3.079 .079 viven en municipios de menos de 2.000 habitantes y 6.581 .871 en municipios de entre 2.000 y 10.000 habitantes.

Dadas estas cifras, el número de personas que viven en núcleos rurales (considerando como tales los de menos de 10.000 habitantes) es de 9.660 .958 , lo que representa un $24,85 \%$ del total nacional. Por tanto, más de un $75 \%$ de la población vive en núcleos considerados urbanos.

Resulta evidente que el número de personas que vive en zonas rurales es minoritario respecto a la población urbana, si bien se trata de una minoría importante que necesariamente ha de tenerse en cuenta.

Aunque estos son los datos en un momento determinado, censo de 1991, habría que resaltar ciertas tendencias. Se produce una reducción de la población rural, siendo ésta de casi 400.000 habitantes menos que en el año 1986 (según censo de ese año). Así mismo, en el medio 
rural hay más hombres que mujeres, ya que, si bien las cifras globales son muy similares (debido a la mayor esperanza de vida de la mujer), en edades jóvenes las diferencias se acentúan, lo que confirma una mayor tendencia de la mujer rural a salir de su territorio en esas edades.

Otro hecho que resulta determinante, aunque no es exclusivo del medio rural, es el envejecimiento de la población, provocado por un descenso sostenido de la natalidad, así como por el aumento de la esperanza de vida ${ }^{2}$.

Hasta aquí algunas cifras que nos acercan a la dimensión del fenómeno. Sin embargo, hablar del medio rural es hablar de una realidad compleja, compuesta de diferentes sectores y grupos de población, que, analizados uno a uno, nos proporcionan una visión más detallada de ese mundo. En cualquier caso, ese análisis, hecho de forma individual, es únicamente a efectos de estudio. Esa diversidad hay que entenderla de forma global y en continua interconexión, que es como se da en la realidad.

\section{ACTIVIDAD PRODUCTIVA.}

Al hablar de lo «rural» existe una tendencia a identificarlo con lo «agrario». Esto es así porque históricamente la agricultura ha sido la base de las comunidades rurales. Sin embargo, la situación ha cambiado profundamente y hoy no se puede identificar lo «rural» con lo «agrario» ${ }^{2}$.

El panorama actual nos muestra una agricultura mucho más eficaz, en cuanto al rendimiento, que la que existía hace unos decenios. La actividad agraria se ha modernizado, se ha dado una progresiva mecanización y estamos en un tiempo en el que las altas tecnologías están marcando el ritmo de producción. La modernización de la agricultura no es un fenómeno exclusivo de este momento. Se inició alrededor de los años 60 hasta desembocar en la situación actual. Esa mecanización tiene como consecuencia un incremento importante de la efectividad de las tierras, pero ésta no es la única, y así vemos como cada vez absorbe menos mano de obra, por lo que se produce un desplazamiento de población, hasta entonces ocupada en el sector primario, hacia otros sectores que empiezan a tener una mayor importancia.

Datos obtenidos en «Fondo Documental del Mundo Rural». Tema 1. La Población Rural. Pág. 2. AGANZO TORIBIO, Andrés y Otros. Cáritas Española. Madrid.

? VACA, José María. «Análisis de la realidad rural». Ponencia: La Acción Social de Cáritas en el Mundo Rural. Cáritas Española. 
«La situación de paro es cada vez más acusada y tiende a agravarse. Apuntamos algunas causas:

- El 58\% de los propietarios de las explotaciones tienen 55 años o más.

- Cese de actividad y jubilación anticipada, propuestas desde las nuevas políticas de la CE.

- Cierre de las pequeñas explotaciones familiares, que no pueden ser competitivas a nivel europeo e internacional.

- No existe relevo generacional. A los jóvenes les resulta difícil «permanecer» ante la dureza e incertidumbre por la que atraviesa el sector agrario y las dificultades económicas en la creación de empleos alternativos.

- La preparación y formación personal y profesional es escasa o nula, si se quiere hacer frente a las exigencias que plantea el Mercado Único, la Política Agraria Común (PAC) y los acuerdos del GATT (Acuerdos Generales sobre Aranceles y Comercio), exigencias y acuerdos comerciales entre países. $\gg^{3}$

El análisis de las cifras de población activa en el sector agrario, en relación con lo que representan en el total nacional, vienen a confirmar lo expuesto hasta ahora.

\subsection{Evolución de la población activa en el sector agrario ${ }^{4}$}

Población activa del sector agrario

\begin{tabular}{|llll|}
\hline Año 1974 & $22 \%$ & de la población activa española \\
Año 1980 & $17,8 \%$ & de la población activa española \\
Año 1988 & $14,3 \%$ & de la población activa española \\
Año 1991 & $10,2 \%$ & de la población activa española \\
\hline
\end{tabular}

Dadas las cifras, se aprecia la constante disminución de la población activa en el sector. Además, las previsiones son que la reducción continúe. Ante este descenso ocupacional de la agricultura, en los pueblos se han ido generando una serie de alternativas laborales, ya que si no, estarían condenados a desaparecer. Actualmente, la diversidad laboral es infinitamente mayor que la de hace medio siglo, por lo que ya no es posible identificar lo «rural» con lo «agrario».

3 MARCOS, Purificación. «Manifiesto por un Mundo Rural vivo». Cáritas Española. 1993. Pág. 8.

4 AGANZO TORIBIO, Andrés y Otros. «Fondo documental del Mundo Rural». Tema 8. Los pequeños agricultores. Cáritas Española. Pág. 3.

VACA, José María. «Análisis de la realidad rural». Ponencia: La Acción Social de Cáritas en el Mundo Rural. Cáritas Española. 
Debido a las profundas transformaciones habidas en la producción agrícola, la productividad de las tierras es mucho mayor, sin embargo, la importancia de la riqueza que se genera ha disminuido comparativamente respecto a otros sectores. Los datos nos muestran que:

- En 1972 la agricultura representa el 11,2\% del PNB del país.

- En 1989 representa solamente el 7,5\% del PNB.

Esto se debe a que, aunque la productividad ha aumentado, el crecimiento y la evolución de otros sectores ha sido mucho mayor ${ }^{5}$, por lo que el sector ha perdido peso específico dentro del conjunto de la economía del país, si nos atenemos a las cifras de P.N.B.

\section{III.LA EMIGRACIÓN}

Un hecho, que ya hemos mencionado, estrechamente relacionado con la evolución de la actividad productiva es el de la emigración. Este es un fenómeno paralelo a los procesos de transformación agraria, que aún hoy se sigue produciendo. No se trata de un movimiento que afecte por igual a todos los grupos de edad y sexo, sino que se caracteriza por afectar fundamentalmente a población joven y femenina.

«En el grupo de 14 a 24 años hay 863.686 mujeres y el número de hombres es de 924.776 , lo cual nos indica una mayor tendencia de la mujer rural a salir de su territorio en edades jóvenes» ${ }^{6}$.

Este proceso migratorio, además de la lógica disminución del número de habitantes, trae consigo otra consecuencia, que ahora pasaremos a comentar: el envejecimiento de la población rural.

\section{IV.UNA POBLACIÓN ENVEJECIDA}

El envejecimiento de la población es un hecho que está presente en los países desarrollados, entre ellos España, que ha pasado en los últimos años a la categoría de país envejecido, con más de un $10 \%$ de población considerada anciana. Se trata de un reto para estos países, que han de dar respuesta a las necesidades que surgen en estos grupos de edad.

5 VACA José María. «Análisis de la realidad rural». Ponencia: La Acción Social de Cáritas en el Mundo Rural. Cáritas Española.

" AGANZO TORIBIO, Andrés y Otros. «Fondo documental del Mundo Rural». Tema 1. La Población Rural. Cáritas Española. Pág. 2. 
Algunos datos de lo que supone el fenómeno del envejecimiento en cuanto al presente y el futuro más cercano son: ${ }^{7}$

- En el grupo de edad de 65 y más años, según la proyección realizada por el INSERSO en 1988, para el período 1986 a 2010, observamos un fuerte incremento de este grupo de edad hasta el año 2000 , tendencia que se suaviza desde ese momento hasta el año 2010.

- Los mayores de 80 años aumentan proporcionalmente más que el resto de la población mayor. El ritmo de crecimiento de una población no se incrementa, ésta tiende a envejecer, y esto ocurre también con la población de más edad.

- Mayor presencia de la mujer en estas edades, siendo aún mayor a edades más avanzadas, por lo que se puede hablar de una «ancianidad feminizada».

- En lo que llevamos de siglo se ha duplicado la esperanza de vida de la población al nacer. Actualmente se sitúa alrededor de 80 años para las mujeres y algo menos para los varones.

- En todas las Comunidades Autónomas se ha producido un incremento de la esperanza de vida, sin embargo, los índices de envejecimiento son bastante dispares entre unas y otras. Actualmente, las poblaciones más jóvenes se encuentran en Canarias, País Vasco y Madrid, y las más envejecidas en Aragón, las dos Castillas, Galicia y Extremadura.

- Esta disparidad, que en estos momentos es bastante elevada, tenderá a equilibrarse. Las Comunidades que más van a ver crecer su población anciana van a ser las de Madrid, País Vasco y Canarias, entre otras, mientras que las que presentan una población más envejecida aumentarán su número en menor proporción. La explicación de este fenómeno se debe a que las Comunidades que presentan altos índices de envejecimiento perdieron población en edades jóvenes y adultas a causa de las migraciones, presentando «vacíos demográficos» en determinados grupos de edad, por lo que el incremento de la población anciana será reducido.

Hasta ahora hemos hablado del envejecimiento de la población española en general, pero este fenómeno se agudiza al contemplar los datos de las zonas rurales. «Mientras que los mayores de 65 años de la población total eran 4.689.410, según el padrón de 1986, representando un $12,2 \%$ de la población, los mayores, que según esta misma fuente vivían en municipios de menos de 10.000 habitantes, eran 1.423.942, representando un $14,2 \%$ de la población rural.

7 MUÑOZ, Cristina Catalina. «Los ancianos en el Mundo Rural». Seminario de trabajo, El Escorial, 1991. Cáritas Española. Pág. 3-10. 
De los mayores rurales, 965.468 vivían en municipios de 2.000 a 10.000 habitantes y, el resto, 620.339 en municipios de menos de 2.000 habitantes; en estos municipios la población mayor representa el 19,6\%. Existen núcleos en los que la población de más de 65 años supone entre el 50 y el $100 \% » .{ }^{8}$ Los datos nos aportan otra de las características que definen a los pueblos de nuestra geografía, se trata de núcleos donde el número de personas mayores es comparativamente mucho mayor que en las zonas urbanas.

Esto, que en principio solamente son datos estadísticos, nos muestra que va a ser en estos pequeños núcleos donde surgirán el mayor número de necesidades relacionadas con la ancianidad, por lo que esas Comunidades han de crear los mecanismos necesarios para dar cobertura a las situaciones que lo precisen. Los requerimientos y necesidades de los mayores rurales van a coincidir con los que estos plantean en la sociedad con carácter general, aunque al mismo tiempo, van a presentar características propias del medio en el que habitan:"

- Los procesos de envejecimiento originan, en ocasiones, pérdida de autonomía personal, por lo que la persona pasará a depender de otros.

Al mismo tiempo, suelen convivir únicamente con su cónyuge, o solos ( 3 de cada 4), situación que agravará el proceso de deterioro mencionado.

- En los núcleos rurales, además de las necesidades comunes a todos los mayores, surgen otras relacionadas con la disponibilidad de servicios y recursos, menor que en núcleos no rurales, de tal forma que la solución de determinadas gestiones supone un desplazamiento, $\mathrm{o}$ ante determinadas situaciones problemáticas el anciano ha de trasladarse, con el desarraigo que esto origina. «Como hecho positivo, el anciano rural sigue viviendo en su entorno habitual, en contacto con sus vecinos $y$, en ocasiones, en contacto con actividades de su anterior vida laboral, lo cual facilitará en algunos casos el paso del mundo laboral al mundo jubilado».

\section{OTROS GRUPOS DE POBLACIÓN.}

El análisis podría extenderse a los distintos grupos de población que componen el medio rural. Sin llegar a profundizar, algunas de las

* AGANZO TORIBIO, Andrés y Otros. «Fondo documental del Mundo Rural». Tema 6. Los ancianos y jubilados. Cáritas Española. Pág. 2.

9 AGANZO TORIBIO, Andrés y Otros. «Fondo documental del Mundo Rural». Tema 6. Los ancianos y jubilados. Cáritas Española. Pág. 3-4. 
características que se dan en estos grupos y que complementan la visión sobre la realidad rural son:

- «La ausencia de oferta laboral en el sector industrial ha estabilizado en términos generales la población rural en los últimos años, provocando un aumento del paro.

- Desde la infancia se capta una visión negativa del mundo rural, que provoca una permanente actitud de huida o de obligada resignación.

- Población agraria joven dependiente de los padres hasta edades avanzadas, sin responsabilidad directa en la gestión familiar.

- La composición de la mano de obra agrícola difiere de la de los sectores secundario y terciario, siendo minoritaria la población asalariada frente a la de los trabajadores independientes y familiares». ${ }^{10}$

- En el caso de la mujer, su participación en las actividades agrícolas es, excepto en determinadas Comunidades Autónomas, muy inferior a la del varón. Su actividad productiva se contempla como algo secundario y complementario, estando infravalorada respecto a la actividad del hombre. Por otro lado, en la mayoría de las ocasiones, además de las tareas de explotación, tienen que realizar las faenas domésticas como amas de casa. Este es el grupo de mujeres más numeroso, el que desempeña diversos roles dentro de la actividad familiar. ${ }^{11}$

\section{UNA REGIÓN DONDE LO «RURAL» ES IMPORTANTE.}

Hasta ahora hemos hecho un repaso por algunas de las características que están presentes en el ámbito rural de todo el país. Son circunstancias que se dan en mayor o menor medida en las distintas Comunidades Autónomas, ya que si bien en todas hay núcleos de población de gran importancia, ${ }^{12}$ no es menos cierto que también existe un número más o menos elevado de núcleos pequeños que, en conjunto, daría lugar al panorama descrito con anterioridad.

Por tanto, lo hasta ahora enunciado no es privativo de determinadas Comunidades, sino que es algo propio de lo que se entiende por «MUNDO RURAL», presente por toda nuestra geografía, incluso en aquellas Comunidades con mayores núcleos de población.

10 AGANZO TORIBIO, Andrés y Otros. «Fondo documental del Mundo Rural». Tema 1. La Población Española. Cáritas Española. Pág. 3.

1 AGANZO TORIBIO, Andrés y Otros. «Fondo documental del Mundo Rural». Tema 6. Las mujeres rurales. Cáritas Española. Pág. 3.

12 No hay que olvidar que más del $75 \%$ de la población del país vive en núcleos de más de 10.000 habitantes, siendo la población que vive en núcleos rurales algo menos de un $25 \%$. 
Vamos ahora a analizar en qué medida lo expuesto para definir las zonas rurales tiene su aplicación en una determinada región donde todo esto tiene un peso específico importante, como es Castilla-La Mancha. ${ }^{13}$

Castilla-La Mancha está situada en la sub-meseta meridional de la Península. En extensión es la tercera Comunidad Autónoma del país. Se trata de una región interior con un clima típicamente continental.

En lo referente a la población, ésta representa el $4,4 \%$ del total nacional, mientras que el territorio supone el $15,7 \%$ de la superficie. Se trata de una región con una baja densidad de población, 21 habitantes por kilómetro cuadrado, frente a los más de 74 como media del territorio español. ${ }^{14}$

En cuanto a la distribución, alrededor de 1.000 .000 de personas viven en núcleos de 10.000 habitantes o menos, mientras que son unas 648.000 las que viven en zonas que se consideran urbanas (censo de 1981). A diferencia del resto del país, la población que vive en núcleos considerados rurales (menos de 10.000 habitantes), representa más de un $60 \%$ del total, mientras que para el conjunto español estos núcleos suponen un $24,85 \%$ de la población. Estas cifras muestran la importancia del Mundo Rural dentro de la región.

En lo referente a la evolución que ha experimentado la población, desde 1950 se ha producido un descenso importante y continuado. «Podemos constatar que no sólo se produce una pérdida de población en términos relativos -respecto al conjunto nacional- sino que se ha operado un descenso real de la población, al pasar la población regional de 2.059.700 habitantes en 1960 a 1.648 .600 habitantes el 1-31981, lo que se traduce en una variación negativa del $20 \%$, mientras que España obtuvo una variación positiva del $34,4 \%$. (...) El origen de esta negativa evolución de la población regional tiene su raíz en los flujos migratorios que ha venido soportando la región y que la han caracterizado como tradicional zona de expulsión». ${ }^{15}$

Actualmente, la tendencia es a la estabilización del movimiento migratorio, al igual que en el resto del territorio español, ya que la crisis económica hace que se produzca una reducción de la demanda

13. Se trata de un ejemplo, donde se pretende mostrar en qué medida lo expuesto en la primera parte del artículo coincide o no para esta determinada región. El análisis podría realizarse sobre otras Comunidades, apareciendo situaciones distintas a las aquí expuestas en determinados apartados, ya que la evolución puede resultar diferente, variando de una zona a otra.

14 CARRIÓN, José y Otros. «Realidades a lo claro, Castilla-La Mancha». Editorial Popular. Pág. 26-36.

15 «Programa de desarrollo regional de Castilla-La Mancha; 1986-1988». Servicio de Publicaciones, Junta de Comunidades de Castilla-La Mancha. Pág. 27-28. 
de mano de obra en las zonas industriales, por lo que hay una mayor tendencia a permanecer en los lugares de origen.

Algo estrechamente relacionado con los movimientos migratorios, y que también caracteriza a esta región, es el envejecimiento de la población.

En general, puede afirmarse que la población castellano-manchega es una población más envejecida que la media nacional ${ }^{16}$. Mientras que en España 14 personas de cada 100 tienen más de 60 años, en Castilla-La Mancha son 19 de cada 100 las personas que están en ese grupo de edad. La constante salida de población de determinados grupos de edad ha provocado, además de una importante pérdida en el número de habitantes, un envejecimiento de la población de la región. Al realizar un análisis de las pirámides de población, se observa un estrechamiento de los grupos de edad más jóvenes, al tiempo que un ensanchamiento en los escalones más elevados ${ }^{17}$ (en las provincias de Cuenca y Guadalajara, la población de más de 60 años representa un $23,4 \%$ y un $22,1 \%$ respectivamente, muy por encima de la media en la región).

Si realizamos un análisis de la población activa en Castilla-La Mancha y su distribución ${ }^{18}$, los datos nos muestran que la mayor parte de la población trabaja en el sector servicios -al igual que en el resto del país-. Después se observa como en agricultura trabaja un $28 \%$ de la población, frente a un $18 \%$ en industria. ${ }^{19}$

Con estos datos, sobre todo al compararlos con los del resto del país, se observa que se trata de una región con una actividad productiva fundamentalmente agraria. Por esto, en la región se han dado los procesos de reconversión y de cambio a los que aludíamos, y que tan importantes modificaciones han ocasionado en el sector. Entre ellos, cabe destacar ${ }^{211}$ :

- Fuerte trasvase de mano de obra del campo a la ciudad ante la aparición de grandes grupos industriales, con las consecuencias que esto origina (envejecimiento poblacional, etc.).

16 CARRIÓN, José y Otros. «Realidades a lo claro, Castilla-La Mancha». Editorial Popular. Pág. 38.

17 «Programa de desarrollo regional de Castilla-La Mancha, 1986-1988». Servicio de Publicaciones, Junta de Comunidades de Castilla-La Mancha. Pág. 29-33.

it CARRIÓN, José y Otros. «Realidades a lo claro, Castilla-La Mancha». Editorial Popular. Pág. 41 .

19) Estos porcentajes se invierten para el conjunto español: la población activa ocupada en el sector industrial es de un $28 \%$, frente a un $18 \%$ en agricultura.

20 «Programa de desarrollo regional de Castilla-La Mancha, 1986-1988». Servicio de Publicaciones, Junta de Comunidades de Castilla-La Mancha». Pág. 33. 
- El sistema de producción agrícola entra en ese proceso de modernización. Se impone la mecanización e importantes transformaciones en los factores de producción (se intenta responder a los nuevos hábitos alimenticios, etc.).

- Se produce un aumento de la superficie de las explotaciones, reduciéndose al tiempo el número de las mismas.

Hasta aquí un repaso por algunas de las situaciones que conforman una parte de la realidad de esta región.

\section{VII.SERVICIOS SOCIALES: SERVICIOS INTEGRADOS EN UNA REALIDAD.}

En el plano de los Servicios Sociales, un hecho que cabe destacar es la extensión/universalización que se ha dado en los últimos años. En la actualidad las prestaciones básicas son un derecho reconocido en todas las Comunidades Autónomas, fruto de la cooperación, a través del Plan Concertado, entre la Administración Central y la Autonómica. Esta mayor presencia de los Servicios Sociales es algo que se ha producido tanto a nivel urbano como en las zonas rurales.

Lo visto hasta ahora son algunas de las situaciones que, si no de manera específica, sí que cobran especial importancia en el medio rural, y que conforman una realidad no exenta de problemas y necesidades. Los Servicios Sociales tratan de dar respuesta a estas necesidades. Lo que resulta evidente es que esa respuesta ha de ser distinta en el medio rural y en el urbano. La concepción de los servicios ha de adecuarse a las características del lugar donde se van a desarrollar, de tal forma que las soluciones que se ofrezcan sean realistas y respondan de manera eficaz a las situaciones de carencia.

Actuaciones que pueden ser acertadas en un determinado espacio, dando lugar a la solución del problema, pueden resultar totalmente ineficaces en otro con una realidad distinta, por lo que han de diseñarse acorde con las peculiaridades del medio, teniendo en cuenta, además, que lo que se entiende por «Mundo Rural» presenta una gran disparidad de situaciones, no tratándose de una realidad homogénea que se extienda a lo largo de nuestra geografía.

«La tipología y manifestación de necesidades sociales en el medio rural es muy variada y requerirá tratamiento acorde con sus características, en igualdad de condiciones respecto al medio urbano, lo que implicará incrementar los esfuerzos en la dotación de equipamientos y que estos tengan un diseño y planificación adecuada a las zonas rurales. 
Es imprescindible que el Sistema de Servicios Sociales articule una completa Red de Equipamientos para dar respuesta a las necesidades de Servicios Sociales.» ${ }^{2 !}$

\section{EQUIPAMIENTOS EN EL MEDIO RURAL.}

La Red de Equipamientos supone el soporte necesario para desarrollar las actividades encaminadas a dar cobertura a las necesidades que se presentan en ese determinado espacio.

Pilar Navío Masegosa y otros definen los equipamientos como «un conjunto estructurado e integrado de recursos físicos, humanos, técni$\cos$, financieros y materiales que permiten llevar a cabo una serie de atenciones y medidas para posibilitar que se hagan efectivas una $o$ varias de las prestaciones del Sistema Público de Servicios Sociales».22

Se trata de una definición con una concepción global de Equipamiento, que abarca todo lo necesario para el desarrollo de las Prestaciones Básicas.

Estos han de ser de diferentes tipos, distinguiendo dos niveles: ${ }^{23}$

- Un primer nivel de equipamientos comunitarios, son los Centros de Servicios Sociales y en ellos estarán ubicadas las unidades de Trabajo Social y los equipos interdisciplinares.

- El segundo nivel hace referencia a los equipamientos específicos. Por tales se entiende los de carácter residencial (viviendas tuteladas, albergues,...), los encaminados a la inserción social (centros ocupacionales, etc.), así como los de relación social (hogares y clubes).

\section{LOS CENTROS DE SERVICIOS SOCIALES.}

Los Centros de Servicios Sociales están encuadrados dentro de ese primer nivel fundamental de equipamientos que hemos definido como Comunitarios, suponiendo la primera referencia para la atención de las demandas planteadas por la población. Entre las funciones a desarrollar, destaca la gestión de las prestaciones básicas, además de la

21 Varios Autores. «Los Centros de Servicios Sociales en el Medio Rural». Dossier Mundo Rural y perspectivas de futuro. Cáritas Española. Pág. 148.

22 VV.AA. «Los Centros de Servicios Sociales en el Medio Rural» Dossier Mundo Rural y perspectivas de futuro. Cáritas Española. Pág 139.

2.3 VV.AA. «Los Centros de Servicios Sociales en el Medio Rurai». Dossier Mundo Rural y perspectivas de futuro. Cáritas Española. Pág. 139. 
función planificadora y de coordinación, sin las cuales no podrían desarrollarse las demás. ${ }^{24}$

Vamos ahora a hacer referencia a los recursos con los que deben contar los Centros, estableciendo las peculiaridades producto del medio en el que están ubicados.

Los recursos mínimos para el correcto funcionamiento de los Centros se estima deben ser los siguientes: ${ }^{25}$

- Instalaciones físicas.

- Otros recursos materiales.

- Plantillas.

- Recursos financieros.

- Técnicas de intervención.

\subsection{Instalaciones físicas.}

No cabe duda que contar con un lugar adecuado para el desempeño de la actividad resulta totalmente necesario.

En el Medio Rural, el profesional, la mayor parte de las veces, no va a desarrollar su trabajo en un único núcleo de población, sino que su actividad va a ser desempeñada en varios núcleos que conforman una determinada zona de actuación. Por esta razón, los profesionales no dispondrán de un único edificio en toda la zona de trabajo, sino que en cada uno de los núcleos tendrán a su disposición las instalaciones necesarias para el desempeño de su actividad.

Los edificios distribuidos por los diferentes municipios de la zona, además de las instalaciones dirigidas a Servicios Sociales, albergarán, en la mayoría de los casos, otros servicios de otras áreas, es decir, se tratará de edificios compartidos.

Este es un hecho propio del Medio Rural, a diferencia del Medio Urbano, donde para el desempeño del trabajo el equipo suele contar con un edificio destinado a tal fin.

Aunque las instalaciones han de ser varias y distribuidas por los distintos municipios, en uno de ellos estará ubicado el edificio de referencia. Este quedará delimitado como la sede administrativa, así como el lugar de confluencia de todos los miembros para la realización de las actividades comunes de programación, coordinación, etc.

25 VV.AA. «Los Centros de Servicios Sociales en el Medio Rural». Dossier Mundo Rural y perspectivas de futuro. Cáritas Española. Pág. 142-145. 


\subsection{Otros recursos materiales.}

Por las especiales características de movilidad de los profesionales, se deberá pensar en dotar a los centros de:

a) Vehículos. Se entiende que debe formar parte de la dotación del centro. Si esto no fuera posible, se establecerá la compensación económica adecuada por la utilización del vehículo particular.

b) Sistemas de información. Los profesionales trabajan en diferentes lugares, por lo que estos sistemas han de ser ágiles, adaptándose a esta característica del trabajo. Ante esta situación, algunas Comunidades Autónomas están dotando de ordenadores portátiles a sus unidades de Trabajo Social, ya que resulta fundamental tener un fácil acceso a la información en el desempeño de la actividad.

c) Mantenimiento de instalaciones. Ha de tenerse en cuenta que por este tipo de equipamiento, el mantenimiento es sensiblemente más costoso que en Centros urbanos. Esto ha de reflejarse en la elaboración del presupuesto del Centro.

\subsection{Plantillas.}

El número de componentes de las plantillas en los centros estará determinado por la población a atender y el volumen de trabajo que se genere.

Los componentes de las plantillas serán los necesarios para el desempeño de las siguientes funciones:

- Atención directa y gestión de programas.

- La Administración. Se requiere apoyo administrativo a nivel central y en los distintos lugares de trabajo.

- El staf. Dentro del equipo técnico, el Centro contará con un psicólogo y la posibilidad de una consulta jurídica.

- La dirección. La burocracia que se genera en el Centro, es menor que la de otros con mayor número de profesionales, por lo que la persona que realice estas tareas podrá estar implicada en la gestión de programas, etc.

La atención directa, que se presta a través de las unidades de Trabajo Social, presenta en el medio rural algunas situaciones características.

En cuanto al número de habitantes de referencia de una U.T.S., la media en las zonas rurales sería aproximadamente de 5.000, y, si la zona es muy dispersa, menos aún, mientras que ese número estaría muy por encima en las zonas urbanas. El porqué de estas cifras, que supone un mayor número de profesionales para atender una determinada población, viene determinado por dos situaciones: 
1. Los profesionales han de realizar sus funciones en diferentes núcleos de población, con las dificultades de comunicación que esto origina.

2. La demanda que se recibe en el Medio Rural no es en muchas ocasiones específica de Servicios Sociales. Se trata de demandas correspondientes a otras áreas que no tienen centro ubicado en la zona. El Trabajador Social trata de dar respuesta a esos requerimientos en su función de facilitar el acceso a los recursos.

En el medio urbano, existe una mayor facilidad de acceso a los recursos por parte de la población, por lo que el profesional puede canalizar una determinada demanda no específica de Servicios Sociales, sin que esto suponga un desplazamiento para el usuario.

\subsection{Recursos financieros.}

Los Centros de Servicios Sociales en el Medio Rural han de contar con un presupuesto estable que permita garantizar una adecuada atención a la población.

A la hora de presupuestar se ha de tener en cuenta, por las situaciones vistas hasta ahora, que el coste, en términos proporcionales, es sensiblemente superior al de las zonas urbanas.

\subsection{Técnicas de intervención.}

Se han considerado las técnicas como otro de los recursos con los que ha de contar un Centro para el desempeño de su actividad.

Las situaciones a tratar tienen unas determinadas características, por lo que los profesionales ha de desarrollar técnicas de intervención adecuadas para la puesta en práctica en esa zona. En ese sentido, la formación de profesionales ha de adecuarse a las características del medio. «Debemos hacer un esfuerzo por definir esas técnicas en el medio rural, y no mimetizar las del medio urbano que casi siempre terminan en fracaso.»

Se ha hecho especial referencia a los Centros de Servicios Sociales, ya que estos resultan fundamentales, constituyendo la puerta de acceso de los ciudadanos al Sistema Público de prestaciones. Sin embargo, no han de ser los únicos recursos, debiéndose crear todos aquellos equipamientos específicos, dentro del segundo nivel, necesarios para dar cobertura a las necesidades de la zona, acorde con sus peculiaridades. ${ }^{26}$

26. VV.AA. «Los Centros de Servicios Sociales en el Medio Rural». Dossier Mundo Rural y perspectivas de futuro. Cáritas Española. Pág. 140. 


\section{CONCLUSIONES.}

Después de lo visto hasta ahora, no cabe duda que en el Medio Rural se han producido una serie de transformaciones importantes que han cambiado la fisonomía de una realidad, que en estos momentos presenta algunas situaciones preocupantes.

Aunque la población rural continúa descendiendo respecto al total nacional, lo cierto es que constituye una realidad importante, que no puede ser olvidada, y sobre la que se ha de trabajar para potenciar sus capacidades, como se está haciendo en algunos lugares.

Por todo esto, los Servicios Sociales no pueden permanecer ajenos al lugar donde se encuentran y, en ese sentido, constituyen otro de los elementos que han de contribuir al desarrollo de la zona, intentando dar cobertura a las distintas necesidades, en una realidad no exenta de ellas.

Lógicamente, la organización de los mismos ha de presentar unas características propias, de cara a responder de forma eficaz a esa problemática, y aunque el coste por persona es ligeramente superior, resultan totalmente necesarios para que no se acentúen las diferencias entre dos realidades que presentan situaciones tan distintas.

\section{BIBLIOGRAFÍA}

AGANZO TORIBIO, A. y otros: «Fondo documental del Mundo Rural». Cáritas Española. Madrid.

CARRIÓN, J. y otros: «Realidades a lo claro, Castilla-La Mancha». Editorial Popular. Madrid.1987. $2^{\mathrm{a}}$ edición.

MARCOS, P.: «Manifiesto por un Mundo Rural vivo». Cáritas Española. Madrid. 1993.

MUÑOZ, C.C.: «Los ancianos en el Mundo Rural». Seminario de Trabajo, EI Escorial, 1991. Cáritas Española.

«Programa de desarrollo regional de Castilla-La Mancha, 1986-1988». Servicio de Publicaciones, Junta de Comunidades de Castilla-La Mancha. Toledo. 1986.

VACA, J.M.: «Análisis de la realidad rural». Ponencia: La Acción Social de Cáritas en el Mundo Rural. Cáritas Española. 1989.

Varios autores: «Los Centros de Servicios Sociales en el Mundo Rural». Dossier Mundo Rural y perspectivas de futuro. Cáritas Española. Madrid. 1990. 



\section{EL DEBATE SOBRE LA PROVISIÓN PLURALISTA DE LOS SERVICIOS SOCIALES}

\section{TRINIDAD BANDA GALLEGO}

Profesora titular de la Escuela Universitaria de Trabajo Social. Universidad de Huelva.

\section{RESUMEN}

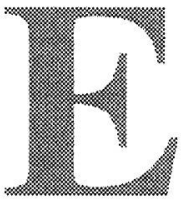

1 artículo que me propongo desarrollar versa sobre un tema de gran actualidad, la provisión pluralista de Servicios Sociales, planteado en tono de debate, porque en lo que se vislumbra respecto a este tema lo que existe son tendencias, pero aún no hay nada decidido sobre el giro que tomará la provisión de servicios. Se tratan aspectos sustanciales que dan cuerpo al debate, tales como las propuestas ideológicas que lo determinan, la relación entre Estado y sociedad civil, la diferencia entre los sectores que ya, de hecho, están presentes, para ver, por último, las ventajas y los límites que tienen cada uno de ellos. Es un debate fructífero al que habremos de contribuir todos los que, de alguna manera, estamos relacionados con la provisión de servicios de bienestar y, quizás, llegar al planteamiento de la necesaria complementariedad entre cada uno de los sectores implicados, porque ninguno de ellos reúne, en sí mismo, los requisitos necesarios para ofrecer una efectiva provisión de los servicios necesarios.

\section{PALABRAS CLAVE}

Pluralismo del bienestar, sociedad civil, Estado, iniciativa social, complementariedad, equidad, voluntariado, mercado.

\section{INTRODUCCIÓN}

La provisión pluralista de Servicios Sociales puede ser utilizada para expresar el hecho de que la atención social que un individuo recibe puede ser obtenida, y de hecho se obtiene, a través de cuatro sectores diferentes: 
- el sector público,

- el sector privado no lucrativo (voluntario),

- el sector privado lucrativo (comercial),

- y el sector informal.

No obstante, este tema hay que inscribirlo en el debate más amplio del «pluralismo del bienestar» que es un debate relativamente reciente, y es un debate anglosajón, iniciado y mantenido en países como Gran Bretaña y Estados Unidos. En España también se habla de él, por parte de autores como Rodríguez Cabrero' y García Roca, aunque éste último le denomina sistema mixto. Los pluralistas parten de unas situaciones básicas y es que el «bienestar» deriva de las cuatro fuentes que hemos nombrado con anterioridad, por tanto, el bienestar social, como responsabilidad de todos, debe ser la suma de esos cuatro sectores, dando lugar a una gran variedad de modos de provisión de recursos. El pluralismo del bienestar trata de transferir responsabilidades, principalmente de producción y gestión de servicios, desde el Estado a los otros sectores, manteniendo el primero funciones muy concretas. Entre todos ellos existen diferencias importantes en cuanto a la razón fundamental que justifica la distribución de recursos; se pueden señalar entre otros, la equidad, la lealtad familiar, el altruismo, la capacidad de pagar, etc.

La frontera entre los dominios público y privado es polémica, cambiante y se halla mal definida. Cada cultura, guiada por los valores de los que ella misma se dota, construye sus propias estructuras institucionales para crear y distribuir riqueza y bienestar. Esta estructura institucional se ve muy influenciada por la tradición, la ideología y la inercia, aunque a veces también entren en el proceso, el análisis y un deseo intencional. En las sociedades capitalistas pueden distinguirse tres principios organizativos para la producción y el intercambio ${ }^{2}$.

El Gobierno, donde son las decisiones políticas, respaldadas por la autoridad, más que por la benevolencia o los precios, las que determinan qué se produce y cómo se distribuye. En una cultura democrática, el gobierno es un mecanismo de coordinación, un dispositivo para detectar necesidades y asignar recursos. Nos comprometemos a pagar mutuamente por lo que todos nosotros necesitamos.

El sistema de precios, donde el principio organizativo es el intercambio recíproco, en interés propio y en cuya interdependencia me-

RODRIGUEZ CABRERO, G., «Entre la protección social y el bienestar social» en Varios Autores: Reflexiones sobre política esconómica, Popular, Madrid, 1990, pp.228-229.

2 DONAHUE, J.D., La decisión de privatizar. Fines públicos, medios privados, Paidós, Barcelona, 1991, pp.31-35. 
dia un precio - el mercado- que opera en todas las culturas. Dame lo que yo quiero y te daré lo que tú quieres.

El voluntarismo, por el que la gente actúa en interés de otros, sin compensación y sin coerción, impulsada ya sea por la tradición, ya sea por un sentido del deber familiar, social o religioso, por simple empatía o por la emoción que brinda el poder implícito de la propia generosidad. El voluntarismo no espera reciprocidad en la transacción. Por lo que te doy no espero nada a cambio.

El debate amplio sobre el pluralismo del bienestar o sistema mixto surge en el contexto de la crítica al Estado de Bienestar y los problemas planteados por la crisis del mismo, aunque otros prefieren llamarlo crisis en el Estado de Bienestar, que comienza a partir de los años 70 , en que comienza a haber un recorte de los gastos sociales, y es a partir de ese momento cuando comienza a surgir una corriente de pensamiento que propugna la necesidad de que todos los sectores mencionados con anterioridad participen en la producción y gestión del bienestar, que si bien han existido siempre, ahora se trata de hacer su presencia más efectiva, ya que esperar que la administración pública suministre todos los servicios necesarios es una utopía. Más concretamente, el pluralismo del bienestar implica que el estado juegue un papel menos dominante, no viendo a éste como el único instrumento posible para dar una provisión colectiva de servicios sociales y mantener y maximizar el bienestar.

Son numerosas las críticas feroces que se alzaron contra el mismo, porque con su intervención no había conseguido incrementar la solidaridad y la igualdad como se había esperado.

Algunas de esas críticas tienen el siguiente tono:

Watzlawick, en su libro El arte de amargarse la vida, dice «como los directores de un zoológico en dimensiones reducidas, en grandes dimensiones los Estados se han propuesto la tarea de configurar la vida de los ciudadanos de manera que ésta, desde la cuna a la tumba, sea segura y chorreante de felicidad. Pero esto es sólo posible mediante una educación sistemática del ciudadano que le haga incompetente en la sociedad» ${ }^{3}$.

Reacciones como ésta, que se han concentrado sobre los fallos de la provisión estatal, son las que intentan devolver el protagonismo y la responsabilidad a la población, intentando impulsar organizaciones sociales, grupos de ayuda mutua, y recuperar las redes naturales, familiares y comunitarias como principal vía de apoyo, ayuda y asistencia. Pero un sistema pluralista conlleva también un papel para el sec- 
tor comercial (mercado privado), aunque los pluralistas más moderados, aún cuando acepten la provisión mercantil, se muestran más entusiastas con la provisión por parte de organizaciones voluntarias. Estas críticas están insertas en la tesis de que con el Estado de Bienestar los individuos lo esperan todo de los estados y poco de la sociedad en la que viven. Se potencia el individualismo (pasividad), se reduce la sensibilidad ante las desigualdades, se pierde el sentido cívico, y se hacen reivindicaciones categoriales, más que el mantenimiento de una actitud estrictamente reivindicativa.

Hay otro motivo por el que se propugna un sistema de provisión pluralista y es por el fundamento antropológico y moral del mismo, en cuanto a diferenciar entre el concepto de necesidad que se contrapone a aspiraciones ${ }^{4}$, deseos y preferencias ${ }^{5}$. Las necesidades son básicas, fundamentales e inmutables; no pueden ser elegidas y no pueden eludirse. Las preferencias, aspiraciones y deseos son secundarias, instrumentales, son demandas subjetivas que responden a imperativos funcionales. Una vez satisfechas las necesidades por parte del Estado, la sociedad es libre para facilitar la satisfacción de estas últimas.

Aunque hacer la distinción entre ambas no es tarea fácil, ya que están sometidas a criterios de valoración, que son necesariamente subjetivos; por ello, al no ser las necesidades, ni objetivas ni neutras, ni inequívocas, no pueden ser la instancia principal para la definición el bienestar, pero, a juicio de Harris, es su componente esencial ${ }^{6}$.

Dos temas estrechamente ligados con el Pluralismo del bienestar son la descentralización y la participación. El término descentralización significa el desplazamiento de las responsabilidades del gobierno central al regional y de este al local, porque la filosofía del pluralismo está en que es cada localidad la que ha de estudiar el equilibrio concreto de servicios que se adecúe mejor a sus necesidades, y estarían más al tanto de las ayudas voluntarias e informal. La descentralización está vinculada con la participación, de la que Rodríguez dice que es un instrumento del principio de solidaridad y se fundamenta en que la persona, a través de la actividad responsable de la participación se perfecciona a sí misma, asumiendo las consecuencias de sus actos. En la medida en que el marco social es manipulable por el hombre, ya que no le viene impuesto con el rigor del medio físico y natural, la persona puede influir sobre él, bien sea por la vía de la simple

4 DOYAL, L y GOUGH, I., Teoría de las necesidades humanas, Icaria, Barcelona, 1994, pp.6768.

5 HARRIS, D., Justificación del Estado del Bienestar, Instituto de Estudios Fiscales, Madrid, 1987, pp.303 y ss.

6 HARRIS, D., op.cit. pp. 316. 
intervención positiva, o bien modificando las instituciones concretas. Los ámbitos donde ha de darse la participación no sólo han de existir, sino que han de llevar una vida activa y no ser aprisionados por la acción indiscriminada de entes sociales superiores?

\subsection{Propuestas determinantes en el debate}

Para García Roca, la construcción del pluralismo del bienestar o sistema mixto se diseña sobre tres propuestas que se muestran insuficientes y determinan el actual debate ${ }^{8}$ :

La Conservadora: que focaliza la política social sobre los grupos primarios (la familia, el voluntariado, las organizaciones solidarias), ya que la intromisión del Estado daña y erosiona la fortaleza de las otras instituciones. Proponen una reducción de los gastos sociales, disminuyendo las demandas hacia el sector público. Esta postura sugiere que la iniciativa social pueda desempeñar las funciones del sector público en el ámbito del bienestar social con una mayor eficacia. Aunque a esta postura se le puede hacer una objeción y es que el Estado de Bienestar surge, precisamente, y entre otros motivos, porque ni el sector mercantil ni el sector no lucrativo satisfacían adecuadamente las necesidades sociales sentidas por los ciudadanos.

La Liberal: que se opone por principio a cualquier regulación de la actividad económica por parte del Estado. Se interesan básicamente por el mercado, en el que descubren la panacea de la creación de riqueza y de protección social, siendo el puro mecanismo del mercado el que resolverá todos los problemas.

La Estatista: que focaliza la atención social sobre la exclusiva responsabilidad del Estado que se reviste de magia y se sitúa por encima de todas las instancias sociales, potenciándose las estructuras normativas que se organizan en burocracias e instituciones estatales. Se oponen a cualquier iniciativa que suponga una promoción del papel de la iniciativa social o el mercado; el argumento es que ello supondría una intromisión en el campo de la competencia del sector público, cuyos efectos más generales entrarían en conflicto con una política de bienestar eficaz y equitativa. La objeción a esta postura es que ello supondría una forma de «totalitarismo social», contrario a los principios democráticos y al pluralismo social.

Pero estas posturas no son tan radicales como García Roca expone, pienso que se van aproximando y emerge la cuestión de la relación

7 RODRÍGUEZ, F., Introducción a la política social, Fundación Universidad Empresa/Cívitas, Madrid, 1979, pp. 381-383.

* GARCÍA ROCA, J., Público y privado en la acción social. Del Estado de Bienestar al Estado Social, Popular, Madrid, 1992, pp. 62-63. 
entre lo gubernamental y lo no gubernamental o entre lo público y lo privado. La separación comienza a romperse cuando las instituciones públicas deciden recurrir a las instituciones no gubernamentales para ofrecer un servicio determinado a través de la contratación externa, de la que hablaremos posteriormente. También se rompería cuando los poderes públicos deciden reforzar la capacidad de transferencia de recursos de las otras instituciones, actuando sobre el lado de la demanda, en la que los ciudadanos, a través de una reducción de los impuestos comprarían u organizarían su propio bienestar. El Estado sólo apoyaría, con una transferencia en dinero, a aquéllos que no pudieran manejarse con esas instituciones. O bien habría un tercer tipo de relación, por la que el Estado ofrecería un mínimo universal, y más allá del mismo, las instituciones no gubernamentales serían las encargadas de responder a las expectativas de cada uno.

El pluralismo del bienestar ocupa un lugar central en este momento, ya que hay argumentos para toda clase de matices. Tiene una ventaja y es estar basado en un sistema que ya es mixto; se trataría de combinarlos en distintas proporciones; «los ingredientes serían los mismos, pero la receta sería diferente» (Aliena Miralles, 1992). La corriente conservadora puede verlo como:

- Una fórmula políticamente conveniente para hacer frente a la sobrecarga del gobierno y la crisis fiscal, al reducir el papel del Estado.

- También puede ser visto como una oportunidad de transferir los servicios públicos hacia el mercado privado, introduciendo así lo que piensan que es un saludable elemento de competencia y elección, lo que fomenta un espíritu de confianza y de independencia.

- Otro factor que se señala puede ser la regeneración de la asistencia familiar, suponiendo que haya habido una degeneración de la misma. En este sentido, Friedman dice «Creemos que uno de los costos mayores del actual sistema de bienestar es que no sólo mina y destruye la familia, sino que también envenena los impulsos de las actividades asistenciales privadas»".

La corriente progresista también verá gustosa las implicaciones antiburocráticas, anticentralistas y antiprofesionales del pluralismo, sin embargo, rechazan la provisión por el mercado y la provisión por las amplias y tradicionales organizaciones voluntarias. Desde esta corriente se reclama el pluralismo del bienestar desde un sentido democrático cuyas ventajas residirían en un estilo más participativo en la provisión de los servicios que respondería de forma más rápida y sensible a las necesidades de la gente. 
Mishra piensa que, por el momento, es la primera de las corrientes la que se está imponiendo, lo que significa" más mercado, más privatización, mayor libertad económica y mayor desigualdad.

Estos son los que forman parte de lo que Galbraith llama la «mayoría satisfecha», de la que da cuatro características ${ }^{11}$ :

1. Están convencidos de que lo que reciben es lo que merecen en justicia, ya que es el producto de su esfuerzo, su inteligencia y su virtud personales. La equidad no debe justificar ninguna acción que reduzca lo que disfrutan o podría disfrutarse. La reacción habitual es la indignación contra lo que usurpa aquello que tan claramente se merece.

2. La segunda característica es su actitud hacia el tiempo; prefieren siempre que el gobierno no actúe, aún a riesgo de que las consecuencias puedan ser alarmantes a largo plazo; puesto que éste puede no llegar y el costo de la actuación del presente recaería (con una subida de impuestos) sobre esa mayoría satisfecha. Los costos actuales son específicos, y el beneficio futuro difuso. Prefieren el beneficio a corto plazo.

3. El Estado es visto como una carga, porque consideran que es inadmisible que se intervenga en algo que está previsto que salga bien; el compromiso con el «laissez faire» es una actitud, es el convencimiento de que, por la propia naturaleza de las cosas, al final todo funciona bien $(1992,69)$. Galbraith lo expresa como «quitar al Estado de las espaldas de la gente», aunque a esta condena hay significativas excepciones. Lo que se considera una carga para el Estado son todas aquellas medidas que benefician precisamente a los intereses de los grupos no privilegiados: gasto en servicios sociales, en viviendas de protección oficial, instalaciones de infraestructura, deportivas, culturales y recreativas en los barrios más pobres, etc.

4. La última característica es la tolerancia que muestran los satisfechos respecto a las grandes diferencias de ingresos: prevenirse contra cualquier ataque a la propia renta es tolerar una mayor cuantía para otros. La opulencia esplendorosa de los muy ricos es el precio que paga la mayoría electoral satisfecha para poder retener lo que es menos, pero que de todos modos está muy bien. Lo expresa del siguiente modo: «Para ayudar a la clase media y a los pobres se deben reducir los impuestos de los ricos» que se corresponde con la teoría vulgar, de que si se alimenta al caballo generosamente

10 MISHRA, R., «El Estado de Bienestar después de la crisis: Ios años 80 y más allá» en Varios Autores: Crisis y fituro del Estado de Bienestar, Alianza, Madrid, 1993, pp. 121.

"GALBRAITH, J.K., La cultura de la satisfaccioin, Ariel, Barcelona, 1992, pp.32-34. 
con avena, algunos granos caerán en el camino para los gorriones» ${ }^{12}$.

\section{RELACIÓN ESTADO-SOCIEDAD CIVIL}

Pero en este debate lo que se está planteando realmente es la relación existente entre el Estado y la sociedad civil o el retorno de esta última, que significa un replanteamiento de las relaciones entre ambas, reinyectando en el cuerpo social las responsabilidades que se han hecho recaer sobre el Estado.

Para ver esta relación, yo me he servido de un libro de Víctor Pérez Díaz, que lleva por título, precisamente, «El retorno de la sociedad civil» ${ }^{13}$ donde, a través de una metáfora, el flujo y reflujo de las mareas, el flujo alternado de avances y retrocesos del mar y de la tierra establece dicha relación. Hegel pensaba que el mar es la infinitud y la inquietud: siempre, aún cuando calmo, en estado de agitación y zozobra. El mar es, por excelencia, el escenario para la acción de las gentes de costas, de sociedades dedicadas a tareas de descubrimiento y explotación del mundo, dedicadas al comercio, la ciencia, la exploración y la piratería. Parece el símbolo propio de una sociedad civil impulsada por las pasiones y los intereses de miles de individuos y grupos pequeños, siempre renovados y cambiantes. Sobre la tierra compacta, en cambio, se proyectan típicamente los sueños de dominación y estabilidad de hombres de estado, funcionarios y militares; en ella, se fijan y se guardan las fronteras de un territorio de dominación; se construyen los grandes edificios y monumentos que son símbolos y expresión de una voluntad de estabilidad y permanencia. «Flujo y reflujo», metáfora que nos sirve para ver una semejanza entre la relación cambiante de tierra y mar y de Estado y sociedad civil.

A su juicio, sociedad civil y Estado, aunque etimológicamente sean términos próximos, se han llegado a convertir en términos que denotan realidades muy distintas, piensa que la gente cada vez más entiende la sociedad civil como en oposición al concepto de Estado, y se usa en el contexto de debates centrados en el problema de cómo definir las fronteras apropiadas y las relaciones adecuadas entre ambos. $\mathrm{La}$ sociedad es civil en tanto que sus agentes son ciudadanos y no meros súbditos de un déspota o una casta dominante, $y$, por tanto, miembros de una sociedad civilizada, y no de una sociedad bárbara o atrasada.

GALBRAITH, J.K., op.cit. pp.39.

PÉREZ DÍAZ, V., El retorno de la sociedad civil, Instituto de Estudios Económicos, MAdrid, 1987, pp.14-16. y PÉREZ DÍAZ, V., La primacía de la sociedad civil, Alianza Editorial, Madrid, 1994, pp.86. 
Cobo Suero, da un concepto de sociedad civil que desde mi punto de vista engloba bastante bien lo que actualmente es o quiere ser: «un conjunto heterogéneo de individuos, grupos organizados, movimientos sociales e instituciones de carácter económico, social, cultural y religioso no mediados o apenas mediados por partidos o instituciones políticas, que aportan su creatividad y trabajo para responder a los retos que ha de afrontar la sociedad» ${ }^{14}$.

En este debate no se trata de enfrentar al Estado con la sociedad civil sino que se redefina su relación complementaria y suplementaria. No se trata de menos estado y más sociedad civil, pues, como dice Rodríguez Cabrero, si el monopolio estatal de la producción del bienestar se convierte en burocratización, cabe pensar que el predominio de la sociedad civil en sociedades industriales llegue a ser una sociedad incivil donde los grupos sociales menos organizados y hábiles quedarán en los márgenes o extrarradios de la sociedad.

Y esta relación complementaria pienso que ya se está dando, desde el momento en que el Estado acuda cada vez más a la contratación externa de servicios que significa hacer con medios privados actividades que son fines públicos y abarca diversas realidades:

1 La contratación específica propiamente dicha: tras una convocatoria pública, el poder público contrata con una entidad privada la producción de un determinado servicio.

2. El reembolso, que consiste en pagar un precio previamente acordado por unidad de servicio.

3. Contratar con agencias delegadas, que asumen la responsabilidad total en la satisfacción de las necesidades de un grupo de clientes específicos a cambio de un pago que cubra todos o parte de los servicios de los costos del contratista.

4. Ayudas públicas a entidades voluntarias o privadas para que provean servicios que complementen o sustituyan la provisión estatal.

Esta modalidad de contratación externa de servicios (que es una privatización) trae dos consecuencias importantes:

1. La reestructuración del papel del estado que ha de aumentar su capacidad reguladora. Se entiende que un gran número de servicios propios constituye un estorbo para la verdadera función de un gobierno, que es tomar decisiones políticas. Un gobierno debe proveer servicios, no necesariamente producirlos. Menos producción gubernamental, significa más tiempo para evaluar qué servicios deben ser provistos, dónde y cómo.

14 COBO SUERO, J.M., Contribución a la crítica de la política social, Universidad Pontificia de Comillas, Madrid, 1993, pp.132-133. 
2. La disolución de las fronteras entre lo público y lo privado. Los proveedores privados asumen inevitablemente un poder de decisión política, aún cuando no les corresponde, y a partir del momento en que una entidad privada recibe fondos públicos, queda sujeta a un mayor control público, perdiendo una parte de sus rasgos más distintivamente privados.

Tradicionalmente, ha habido dos tendencias en torno a la diferenciación entre el sector público y el privado: una que identificaba el servicio público con aquel servicio realizado directamente por un órgano de la Administración, y la privatizadora, que identifica el servicio probienestar con la búsqueda de ganancias y con ánimo de lucro.

García Roca propone elaborar el concepto de servicio público que permita distanciarse de ambas posturas ${ }^{15}$.

El que un servicio sea público no viene determinado por la forma jurídica en que se organiza, sino básicamente *por la naturaleza de su función, *por el origen público de los recursos que lo financian y *por la igualdad de todos los ciudadanos en el acceso.

Así, el término «servicio público» queda definido en el Seminario Taxonómico ${ }^{16}$ como «servicio técnico regulado por el Estado, prestado o producido directamente por este o mediante gestión indirecta, para garantizar la oferta de ciertos bienes de interés general».

\section{III.DIFERENCIAS ENTRE LOS SECTORES}

Veamos ahora más detenidamente las características y diferencias entre los sectores que intervienen en los servicios sociales, desde estructuras institucionales (véase cuadro de la página siguiente).

\subsection{Sector público}

Está representado por las administraciones públicas, así como sus organismos autónomos. El control de estas corresponde a los representantes elegidos por la sociedad, o por individuos o grupos legitimados por el poder político. Las formas de intervención pública son varias: la acción propia directa, acción concertada, subvenciones, desgravaciones, etc.

16 VARIOS AUTORES., Conceptos básicos de Bienestar Social. Seminario Tuxonómico, Colegio Oficial de Doctores y Licenciados en Ciencias Políticas y Sociología, Madrid, 1987, pp. 205. 


\begin{tabular}{|c|c|c|c|}
\hline & $\begin{array}{c}\text { SECTOR PÚBLICO } \\
\text { PODER }\end{array}$ & $\begin{array}{l}\text { SECTOR PRIVADO } \\
\text { NOLUCRATIVO } \\
\text { SOLIDARIDAD }\end{array}$ & $\begin{array}{l}\text { SECTOR PRIVADO } \\
\text { MERCANTIL } \\
\text { MERCADO }\end{array}$ \\
\hline Filosofia & Justicia & $\begin{array}{c}\text { Filantropía, } \\
\text { Solidaridad } \\
\text { Altruismo }\end{array}$ & Beneficio \\
\hline Representa & Mayoría & Minoría & Propietarios \\
\hline $\begin{array}{l}\text { Base legal del } \\
\text { servicio }\end{array}$ & Derecho & Gratuidad & $\begin{array}{c}\text { Cuota por el } \\
\text { servicio prestado }\end{array}$ \\
\hline $\begin{array}{l}\text { Fuente de } \\
\text { financiación }\end{array}$ & Impuestos & $\begin{array}{c}\text { Cuotas, } \\
\text { Subvenciones }\end{array}$ & $\begin{array}{c}\text { Pago de clientes } \\
\text { o terceros }\end{array}$ \\
\hline $\begin{array}{l}\text { Determinación } \\
\text { de funciones }\end{array}$ & Prescrita por ley & $\begin{array}{l}\text { Seleccionada } \\
\text { por grupo }\end{array}$ & $\begin{array}{l}\text { Elegida por } \\
\text { propietarios } \\
\text { directivos }\end{array}$ \\
\hline Objetivo & Interés general & $\begin{array}{l}\text { Limitada por } \\
\text { ubicación o } \\
\text { ideología }\end{array}$ & $\begin{array}{c}\text { Limitada a } \\
\text { aquellos que } \\
\text { pueden pagar }\end{array}$ \\
\hline $\begin{array}{l}\text { Fuente de } \\
\text { autoridad }\end{array}$ & Cuerpo legislativo & $\begin{array}{l}\text { Reglamento o } \\
\text { estatutos }\end{array}$ & Propietarios \\
\hline $\begin{array}{l}\text { Estructura } \\
\text { administrativa }\end{array}$ & $\begin{array}{l}\text { Amplia, } \\
\text { Burocrática }\end{array}$ & $\begin{array}{c}\text { Pequeña, } \\
\text { Burocrática }\end{array}$ & Burocrática \\
\hline Responsabilidad & $\begin{array}{l}\text { Ante el electorado } \\
\text { a través de un } \\
\text { cuerpo legislativo }\end{array}$ & $\begin{array}{l}\text { Ante los miembros } \\
\text { a través del consejo } \\
\text { de dirección y ante } \\
\text { los fundadores }\end{array}$ & $\begin{array}{c}\text { Ante los } \\
\text { propietarios }\end{array}$ \\
\hline
\end{tabular}

Fuente: Adaptación de Knapp, M., La economía de los servicios sociales, EUGE, Barcelona, 1990, pp. 183.

\subsection{Sector privado mercantil (comercial)}

Representa el mercado y el dinero. Desarrolla actividades con fin lucrativo y son controladas por propietarios privados.

\subsection{Sector privado no lucrativo (voluntario)}

Representa la solidaridad, que constituye en palabras de Pérez Díaz, el «cemento emocional y moral de la integración social, que implica un sentimiento y un compromiso moral con una identidad colectiva. Ahora bien, los sentimientos y los compromisos morales tienen como 
sujetos en último término a los individuos, de ninguna forma a las organizaciones ${ }^{17}$. Victoria Camps dice de la solidaridad que es una virtud, que debe ser entendida como condición de justicia y como aquella medida que viene a compensar las imperfecciones de esta, y que serían tres: ${ }^{18}$

1. Porque debe atender las necesidades e intereses generales y toma cuerpo en la ley; esto es, en la intransigencia, la uniformidad y el castigo.

2. La justicia nunca es total ni llega a realizarse del todo, ha de ser compensada con sentimientos de ayuda, amistad, colaboración, reconocimiento del otro, etc.

3. Porque la vida misma es injusta y la igualdad natural es un mito. A este respecto Cobo Suero distingue dos tipos de solidaridad:

- Subjetiva, que nace de la persona misma, que se compromete en acciones solidarias porque se siente interiormente impelida a ello y decide hacerlo libremente. Esta sería una responsabilidad individual y colectiva que correspondería a la sociedad civil, que ha de completar las carencias dejadas por la solidaridad objetiva en materia de justicia social. Esta es la misma idea de Victoria Camps, que comentamos anteriormente.

- Objetiva: por la que se impone a los ciudadanos algo que han de cumplir, con independencia de que se sientan o no solidarios con los demás a hacerlo. Esta es responsabilidad del Estado ${ }^{19}$.

\section{MARCO LEGISLATIVO}

Vamos a ver a continuación el marco legislativo a través del cual es posible que todos los sectores puedan participar y desarrollarse. El primer referente es el marco constitucional y en él hemos de tener en cuenta:

- El artículo 9.2: «Corresponde a los poderes públicos promover las condiciones para que la libertad y la igualdad del individuo y de los grupos en que se integra sean reales y efectivas; remover los obstáculos que impidan o dificulten su plenitud y facilitar la participación de todos los ciudadanos en la vida política, económica, cultural y social».

- El artículo 22: «Derecho de asociación».

- El artículo 34: «Derecho de fundación, para fines de interés general».

17 PÉREZ DÍAZ, V., El retorno de la sociedad civil, Instituto de Estudios Económicos, Madrid, 1987, pp.37.

I* CAMPS, V., K., Virtudes públicas, Espasa Calpe, Madrid, 1990, pp.34-35.

(1) COBO SUERO, J.M., op.cit. pp.135. 
- El artículo 38: Libertad de empresa.

- En cuanto a la legislación autonómica, hemos de tener en cuenta el marco de las leyes de Servicios Sociales. He tenido en cuenta lo que dice la mayoría y lo que dice la minoría, que es el fiel reflejo, pienso, de las nuevas condiciones que se están dando y que tiene mucho que ver con este debate ${ }^{20}$.

\subsection{Iniciativa social}

Todas las leyes de servicios sociales contemplan la iniciativa social, que colaborará con el sistema público de servicios sociales que se está regulando (iniciativa privada sin fin de lucro). Aunque los ser-

LEY 6/1982, de 20 de mayo sobre Servicios Sociales, B.O. del País Vasco de 2 de junio de 1982.

LEY FORAL 14/1983, de 30 de marzo sobre Servicios Sociales, B.O. de Navarra, de 8 de abril de 1983.

LEY 1 l/1984, de 6 de junio de Servicios Sociales, B.O. de la Comunidad de Madrid, de 23 de junio de 1984.

LEY 8/1985, de 9 de diciembre de Servicios Sociales, B.O. de la Región de Murcia, de 19 de diciembre de 1985.

LEY 26/1985 de 27 de diciembre de Servicios Sociales, D.O. de la Generalidad de Cataluña, de 10 de enero de 1986.

LEY 3/1986, de 16 de abril de Servicios Sociales de Castilla-la Mancha, D.O.C.M. de 20 de mayo de 1986.

LEY 9/1987, de 11 de febrero, de Acción Social de Baleares, BOE $n^{\circ} 53$, de 28 de abril de 1987.

LEY 4/1987, de 25 de marzo, de Ordenación de la Acción Social de Aragón, BOE n 86, de 10 de abril de 1987.

LEY 5/ 987, de 11 de abril, de Servicios Sociales del Principado de Asturias, BOE $n^{\circ} 137$, de 9 de junio de 1987.

LEY 5/1987, de 23 de abril, de Servicios Sociales, D.O. de Extremadura ${ }^{\circ} 37$, de 12 de mayo de 1987.

LEY 9/1987, de 28 de abril, de Servicios Sociales de Canarias, BOE n 126, de 27 de mayo de 1987.

LEY 2/1988, de 4 de abril, de Servicios Sociales de Andalucía, BOJA no 29 , de 12 de abril de 1.988.

LEY 18/1989, de Acción Social y Servicios Sociales de Castilla-León, en Boletín Informativo.

LEY DE LA GENERALITAT VALENCIANA 5/1989, de 6 de julio de Servicios Sociales de la Comunidad Valenciana, DOGV de 12 de julio de 1989.

LEY $2 / 1990$, de 10 de mayo, de Servicios Sociales de la Comunidad Autónoma de la Rioja, BOE $n^{\circ} 132$, de 2 de junio de 1990.

LEY 5/1992, de 27 de mayo, de Acción Social de Cantabria, BOE n ${ }^{\circ}$ 181, de 29 de julio de 1992.

LEY 4/1993, de 14 de abril de Servicios Sociales de Galicia, en Cediss n ${ }^{\circ} 45$, Legislación sobre Servicios Sociales, pp. 6-22. 
vicios sociales sean de responsabilidad pública, ello no puede suponer que la titularidad y la gestión de los mismos no pueda ser ostentada por la iniciativa social. Ahora bien, la intervención de esta última ha de desarrollarse dentro de las coordenadas establecidas por las administraciones públicas.

La iniciativa social se contempla en las leyes como subsidiaria ${ }^{21}$ y complementaria de las actuaciones de la administración pública.

Aunque con algunas matizaciones, todas las leyes coinciden en que la administración pública colaborará con la iniciativa social cuando esta cumpla con una serie de requisitos, quedando, por tanto, sometida a determinadas limitaciones:

a) Prestar el servicio o la actividad en el territorio de la Comunidad Autónoma de referencia.

b) Su fin primordial ha de ser el cumplimiento de una función social.

c) Ausencia de ánimo de lucro.

d) Sometimiento al control e inspección de sus actuaciones por parte de la Administración Pública.

e) Adecuación a las normas y a la planificación general de lo que determine la Administración Pública.

f) Funcionamiento interno democrático y garantía de que es así.

g) Inscripción en un Registro de Entidades y Centros, que a tal efecto se establecerá en los órganos correspondientes.

\subsection{Iniciativa privada con fin lucrativo}

Respecto a la intervención de la iniciativa privada con fin lucrativo, las leyes guardan un silencio casi absoluto, excepto en algunas de ellas, aunque de ello no se puede deducir que se prohíba su actuación dentro del campo de la acción social.

Haremos referencia a la ley de Galicia que es la más reciente, concretamente de 1993. Es producto de la derogación de la existente desde 1987, justificándose en su introducción los motivos de dicha derogación: «la propia evolución de la realidad que trataba de ordenar la anterior y las limitaciones del propio texto que se deroga y especialmente la ordenación de las entidades prestadoras de servicios sociales y del voluntariado social, y que hace referencia a que, si bien los servicios sociales se constituyen como un servicio público, no puede

21 La subsidiariedad hace referencia a la necesidad de cubrir las lagunas que se producen en la prestación de servicios. Para Beltrán Aguirre (1992, 365), el término «subsidiariedad» no debe entenderse como secundario, provisional o subordinado, sino que ha de entenderse en una relación de complementariedad ya que ambas aportan algo propio y diferenciado que se complementa. 
«ahogar la creatividad e iniciativa de la sociedad sino, muy al contrario, que la fomente, coordine, regule y colabore, como una parte más integrante en el conjunto, que, considerado en su globalidad, es de responsabilidad pública». Así, de un modo explícito, se reconoce no sólo la iniciativa social carente de fin de lucro, sino también la iniciativa privada lucrativa, lo RECONOCE también en sus principios inspiradores, quedando ambas reguladas como entidades prestadoras de servicios sociales junto con la administración autonómica y las entidades locales.

\section{VENTAJAS / LIMITACIONES DE CADA UNO DE LOS SECTORES}

Estas ventajas y limitaciones de las que hablaremos es lo que justifica el que la provisión de Servicios Sociales no pueda o no deba hacerse casi exclusivamente por uno de ellos, sino por la combinación adecuada de todos, ya que la política social del Estado del Bienestar hay que entenderla en un contexto más amplio, donde puedan existir una gran variedad de combinaciones económicas y organizativas para la prestación, financiación y regulación de los sistemas de bienestar.

\subsection{El sector público}

El sector público se enfrenta a la necesidad de compatibilizar un conjunto de demandas sociales que implican la extensión y la calidad de los servicios públicos y su aceptación a las nuevas necesidades de los 90 , con la contención global del gasto público, para evitar disfuncionalidades. López y Utrilla piensan que este desafío se ha comenzado a abordar a través de distintos planteamientos generales:

1. Revisando los objetivos y prioridades existentes en los programas de gasto público.

2. Mejorando la eficiencia de los provisión de bienes y servicios públicos.

3. $\mathrm{Y}$ atribuyendo un mayor protagonismo a la iniciativa privada en la solución de las necesidades colectivas ${ }^{22}$.

La administración tiene un carácter instrumental, puesta al servicio de los intereses generales de los ciudadanos; pero, aunque tenga la responsabilidad, no interviene en todos los sectores de actividad de los servicios sociales; por tanto, si ésta no interviene, alguien lo tiene

22 LÓPEZ, M.T. y UTRILLA, A., El sector puiblico español (Organización, gestión y aspectos económicos), Actualidad Editorial, Madrid, 1991, pp.110. 
que hacer. Es ahí donde hay espacio para la intervención de los otros sectores, a través de distintas fórmulas. Nos podríamos preguntar qué factores o qué hechos motivan que los poderes públicos intervengan en unos problemas y en otros no.

1. Escasez de recursos personales, económicos y materiales de la administración que tendría responsabilidad de hacerlo.

2. Falta de voluntad o interés político por los problemas sobre los que debe actuarse. Se ha señalado que una causa podría estar en la falta de capacidad intelectual o técnica de los funcionarios políticamente responsables del diseño de políticas públicas.

3. Una legislación o reglamentación defectuosa o inexistente sobre el tema que impide o dificulta una actuación eficiente.

4. La presión por parte de los medios de comunicación o de sectores afectados por un problema particular y singular, que insisten en traspasar al sector público los costes de su problemática sectorial ${ }^{23}$. En general, un problema nuevo forma parte de la actuación pública cuando:

a. El tema ha llegado a una situación crítica y es difícil que siga siendo ignorado.

b. El tema provoca una situación emotiva que atrae la atención de los medios de comunicación.

c. El problema adquiere una importancia global, teniendo en sus inicios unas dimensiones y efectos muy limitados.

d. Los problemas alcanzan gran notoriedad pública por conectar con tendencias o valores vigentes en la sociedad.

En relación a las ventajas de los servicios estatales, Jhonson señala, entre otros ${ }^{24}$ :

1. La oportunidad para una planificación social amplia. El Estado está en situación de adoptar, mejor que ningún otro sector, una visión completa de la dirección de la política social y de establecer prioridades para su desarrollo futuro. La igualdad, por ejemplo, es más probable que se logre mediante la planificación social que a través de actividades no planificadas realizadas por miles de proveedores, ninguno de los cuales está interesado especialmente en ella. La redistribución no ocurrirá por sí misma, es preciso que sea deliberadamente planificada.

2.3 SUBIRATS, L., Analísis de políticas puiblicas y eficacia de la Administración, Ministerio para las Administraciones Públicas, Madrid, 1989, pp.53. y SALA PRAT, G., El negocio de la pobreza o la Utopia del Bienestar, Asociación para la Defensa de la Igualdad Social, Barcelona, 1994, pp. 127.

24 JHONSON, N., El Estado de Bienestar en transición. La teoría y la p'ractica del pluralismo del bienestar, Ministerio de Trabajo y Seguridad Social, Madrid, 1990, pp.214-220. 
2. La ventaja de lo anterior es que al haber una planificación específica puede ser cuestionada y evaluada. Se pueden exigir responsabilidades a los que son responsables del mismo. El término responsabilidad sugiere la idea de "tener en cuenta» las consecuencias de las acciones de uno sobre el bienestar de los demás. La importancia que ha de concederse a los intereses de los demás dependerá de la cultura, el contexto y la naturaleza de la relación. Pero los poderes públicos, según señala Donahue, han de ser responsables por tres motivos ${ }^{25}$ :

a. Porque algunas funciones cruciales para la sociedad deben desarrollarse de forma colectiva.

b. Porque el público, en general, está expuesto a descuidos por parte de las autoridades, en relación a que estas se tomen debidamente en cuenta sus intereses.

c. El individuo es vulnerable ante los poderes públicos, aspecto que la historia ilustra en abundancia y que las constituciones de los distintos países tratan de remediar.

La responsabilidad es una característica de los servicios estatales en general, y es una ventaja de los servicios públicos sobre los servicios proporcionados por otros sectores. Aunque la responsabilidad en los servicios estatales no funcione, es una útil salvaguarda y existen procedimientos para presentar quejas y luchar contra las decisiones que se adoptan.

3. Otras característica, y que comparte con los sectores voluntario e informal, es que sus actuaciones normalmente responden a las necesidades, lo que se contrapone con el sector comercial, que responde a la demanda, a la capacidad de pagar.

4. El Estado puede asegurar una cobertura más amplia y más igualitaria que cualquiera de los otros sectores.

5. Puede actuar sobre las causas de los problemas sociales y hacer frente a los costes sociales que surgen de los cambios tecnológicos, industriales y económicos. Ello no lo hace el sector comercial, porque lo más probable es que la prevención funcione en contra de sus intereses comerciales al reducir el número de sus clientes. Las organizaciones voluntarias podrán adoptar estrategias preventivas, pero la prevención requiere, para tener éxito, una aproximación coordinada y cooperativa, que no es precisamente una de las características de la provisión voluntaria.

6. Otra característica distintiva de los servicios públicos es que generalizan el altruismo, permitiéndonos tener comportamientos altruistas para con los extraños. Titmuss se refiere a esto como una 
«amabilidad anónima». Aunque el altruismo supone de antemano la libertad de decidir si dar o no dar y al estar incrita esta idea en que la política de bienestar se considera repuesta a los derechos sociales, la misma despoja al donante de esa libertad, al suponer que es un deber, una obligación para quienes poseen recursos suficientes, dar a quien se halla en estado de necesidad.

\subsection{Sector privado no lucrativo}

Este es lo que para Ugo Ascoli constituye el ámbito de las «relaciones privado-sociales», son los sujetos formales y constituyen el área de las «solidaridades asociativas» ${ }^{26}$, que tienen un reconocimiento público y donde es posible también encontrar una relación contractual. En general, este sector es muy complejo y heterogéneo y las entidades que lo componen suelen definirse por exclusión de la provisión pública y el mercado. Las entidades pertenecientes a este sector tienen denominaciones muy diversas: entidades privadas sin fin de lucro, organizaciones no gubernamentales (esta es la denominación que parece haberse impuesto en el ámbito internacional), entidades de iniciativa social, tercer sector, entidades sociovoluntarias, entidades asistenciales, entidades solidarias, y, además, pueden tener una naturaleza jurídica muy variada, ya que pueden constituirse en asociaciones, fundaciones, federaciones, cooperativas, etc.

Tradicionalmente, este sector se ha identificado con la prestación se servicios que ni el interesado, ni el sector público, pueden proveer de forma satisfactoria, por la incapacidad de pago de aquellos a los que va destinado el servicio, bien por insuficiencia de recursos o voluntad política por parte del sector público ${ }^{27}$.

Seguimos, para el desarrollo de este sector, la clasificación que hace Ugo Ascoli, que dice nos podemos encontrar con tres tipos de sujetos formales: las organizaciones voluntarias, los grupos de autoayuda y el voluntariado social ${ }^{28}$. límites de una cooperación» en Documentación Social n 71 , abril-junio 1988, pp.85-86.

27 ROVIRA I FORNS., «Contribución de las entidades no lucrativas al bienestar social» en Documentación Social $\mathrm{n}^{\circ} 71$, abril-junio, 1988, pp. 178.

2s ASCOLI, U., «Estado de bienestar y Acción voluntaria» en Revistu Española de Investigaciones Sociológicas, $\mathrm{n}^{\circ} 38,1987, \mathrm{pp} .134$. 


\subsubsection{Organizaciones voluntarias}

Las organizaciones voluntarias han desempeñado siempre un papel de gran importancia en la sociedad europea, en la prestación de servicios sociales y humanos en general.

$\mathrm{Y}$ tienen una serie de características:

1. Su sistema de formación es voluntario.

2. Su sistema o modo de gestión es el autogobierno a través de sus propios órganos y en cuanto a sus actividades y el modo de distribuir sus recursos.

3. Su sistema de financiación es a través de aportaciones voluntarias de sus miembros, destinados a mantenerlos; aunque esta característica queda actualmente diluida, por cuanto muchas de las organizaciones funcionan por las subvenciones que perciben de las administraciones públicas.

4. Las motivaciones que guían su funcionamiento no deben perseguir ningún tipo de beneficio de índole comercial.

5. Presentan, por lo general, un alto grado de especialización, correspondiendo al sujeto público la obligación de proporcionar los servicios básicos o generales.

\subsubsection{Grupos de ayuda mutua}

La autoayuda es una vieja idea reavivada en los últimos años. Los grupos de autoayuda son fruto de iniciativas voluntarias y están formados por personas que tienen un problema o una preocupación compartida, las cuales se unen para el apoyo mutuo y la provisión de servicios a sus miembros y que son conscientes de que sus necesidades no pueden ser cubiertas a través de las instituciones existentes. $\mathrm{La}$ distinción entre proveedores y receptores es vaga e inexistente ya que son los propios miembros los que controlan la organización y la definición de los problemas y las necesidades.

Es difícil hacer una valoración unitaria de estos grupos; no obstante, se afirma que son portadores de una nueva cultura de satisfacer las necesidades que permite superar graves lagunas y deficiencias de los aparatos de bienestar, demasiado rígidos, impersonales, burocráticos y de escasa eficacia.

Los grupos de autoayuda prestan acogida, información, apoyo; aunque pueden prestar también una serie de actividades opcionales como la promoción de servicios, la mentalización social, acciones preventivas, reivindicación ${ }^{29}$.

29 AZUA, P., «Opciones de política interna por parte de las ONGs» en Varios Autores: Organizaciones Voluntarias e intervención social, Acebo, Madrid, 1989, pp.54-57. 
En cuanto a los tipos de grupos de ayuda mutua, hay autores que diferencian entre grupos de apoyo orientados principalmente a la ayuda directa de sus miembros y los que están orientados básicamente a la defensa social y acción política, ya que ambos operan de distinta forma, porque tienen fines diferentes.

Este es un tema popular entre los pluralistas del bienestar, tanto la izquierda como la nueva derecha apoyan la autoayuda, porque es vista como una reacción saludable contra el Estado de Bienestar en que predominan burócratas y profesionales, ya que ésta no es buena aliada para cuando hay que hacer frente a necesidades más personales e individuales y porque es compatible con la descentralización (es una actividad típicamente local) y la participación, ya que por su propia naturaleza es participativa.

\subsubsection{Voluntariado}

El voluntariado, en su sentido más puro, son gentes que no reciben remuneración por lo que hacen, aunque puedan ser reembolsados por los gastos que realicen en el ejercicio de su acción.

Aznar, como jurista y con sus clásicas precisiones conceptuales, advierte de la conveniencia de utilizar más que la expresión «voluntariado» o "voluntario», la de «trabajo benévolo», ya que la voluntariedad no es algo que distinga la actividad no retribuida de la retribuida, sino que es común a ambas, ya que aquella tan sólo se opone al trabajo obligatorio o forzoso ${ }^{30}$.

Actualmente, es un tema muy polémico en España, aunque muchas Comunidades Autónomas se están dotando de Leyes de Voluntariado, así como la Administración Central, no lo es tanto en otros países europeos, donde existe una larga y amplia tradición de voluntariado. Su manifestación más pura es la solidaridad y compartir los problemas sociales. Es preciso, no obstante, que se redefina su papel en la sociedad de cambio actual, y partir de que existen estructuras organizativas e institucionales, y no actuar «por su cuenta».

De todas las maneras, nos podríamos preguntar si el voluntariado forma parte de nuestra cultura civil. Pienso que esa es línea de investigación empírica que está aún por desarrollar.

Pasamos a ver ahora las funciones que desempeña este sector. Aunque son bastantes las he agrupado en cuatro para hacer mas fácil su comprensión:

3) AZNAR, M., «La legislación autonómica de acción social. Análisis jurídico» en $V$ Informe sociológico sobre la situación social en España, $2^{\circ}$ volu. Fundación Foessa, Madrid, 1994, pp. 1872. 
1. Cumplen una función importante en la sensibilización y estímulo de la conciencia ciudadana ante las problemáticas sociales; idea, esta, fundamental para actuar sobre las causas de los problemas sociales y de las desigualdades, función que Jarré denomina de «guardián de los valores» y que consiste en preservar aquellos valores tan desprestigiados y paradójicamente ensalzados actualmente como la solidaridad, la filantropía, la participación, el pluralismo, la protección de las minorías, etc. ${ }^{31}$. Una comunidad dependiente resulta más dócil y controlable, pero conduce al «individualismo comunitario» y a la impermeabilidad frente a los problemas que son vividos y percibidos como «del Estado», y cualquier política de prevención, rehabilitación y reinserción estará condenada al fracaso si no se cuenta con comunidades receptivas.

2. Cumplen una función histórica de denuncia y presión frente a la administración y la sociedad, como único o principal propósito, intentando cambiar las actitudes públicas y haciendo campaña para una mejor provisión de los servicios. A menudo, se convierten en portavoces de grupos sociales marginales, con escasa o nula capacidad de organización, desempeñando una importante acción de defensa de estas personas, vigilando para que las personas obtengan aquello a lo que tienen derecho. Hay grupos que combinan la provisión de servicios con la denuncia y la presión.

A este respecto, dice Pilar Malla que la función de denuncia se hace necesaria desde la situación económica actual y la repercusión que tiene en los sectores menos favorecidos, no debiéndose olvidar que en muy pocas ocasiones una administración ha dado a conocer la pobreza de su propio pueblo ${ }^{32}$. Tenemos el ejemplo del revuelo y las manifestaciones públicas que causó la investigación realizada por Cáritas, cuando dio a conocer a la opinión pública la existencia en España de ocho millones de pobres.

3. Otra función que el sector voluntario realiza es una función complementaria, asumiendo servicios delegados o concertados, bien con sus propios recursos bien como gestoras de recursos públicos, bien con fórmulas mixtas. Cumplen un papel complementario cuando están prestando servicios de distinta naturaleza de aquellos dados por las administraciones publicas y cumplen también una función suplementaria de la provisión estatal cubriendo coyunturalmente servicios o sectores desatendidos o atendidos insuficientemente hasta que sean asumidos por aquella.

3I JARRÉ, D., Boletín del Comité Español para el Bienestar Social, n 16-17, Madrid, 1988. pp.3

32 MALLA, P., «El Trabajo Social en las Instituciones privadas» en Documentación Social $\mathrm{n}^{\circ}$ 64, Madrid, 1986, pp.128. 
Una tercera situación es aquella en la que las organizaciones voluntarias son las únicas o las principales proveedoras de un servicio.

4. Tienen una función innovadora, yendo por delante de los poderes públicos, convirtiéndose en un instrumento de ensayo que permita a aquellos «operar» con más seguridad. A las organizaciones voluntarias se les califica como poseedoras de una mayor agilidado rapidez para movilizar recursos y para despertar iniciativas nuevas, suscitando respuestas alternativas ante nuevas necesidades. Hay que recordar que las organizaciones voluntarias han sido en numerosas ocasiones pioneras tanto en la detección de necesidades, canalizándolas al sector público o bien cubriéndola con sus propios medios; muchos de los recursos actuales, asumidos por la provisión pública (ayuda a domicilio, pisos de acogida, miniresidencias, etc.) fueron introducidos y utilizados por entidades privado-sociales. Así lo confirma Sills: «en muchos países la mayor parte de los servicios cuya responsabilidad asume hoy día el gobierno los iniciaron asociaciones voluntarias ${ }^{33}$.

Ahora entramos a ver las limitaciones o críticas que a este sector se le atañen:

1. Dependencia creciente de la financiación estatal, que da lugar a cuestionarse si ello puede suponer una amenaza para la independencia de las mismas, pero éste es uno de los precios que hay que pagar por ello. Las organizaciones sociales son cada vez más agentes del propio gobierno, aumentando el control sobre las mismas. Esta tendencia ha sido potenciada en parte por el propio sector público, que ha considerado ventajoso fomentar la provisión de servicios a través de entidades sociales, a las que financia en base a subvenciones diversas o conciertos, que es lo que se ha dado en llamar el estado contratante.

Demetrio Casado es uno de los que se muestra un tanto crítico con las organizaciones voluntarias, cuando dice «la mayoría se han enganchado a la ubres subvencionadoras que les ofrecen las administraciones públicas [...]. De este modo se instaura un régimen de dependencia que no contribuye al fomento de las organizaciones voluntarias, sino a su domesticación» o también «cuando el poder público convoca subvenciones orientadas por sus propios criterios y las concede a entidades próximas o satélites no impulsa ni fomenta la iniciativa social, sino que se reproduce a sí misma».

Todo ello da lugar a una serie de fenómenos desnaturalizadores, que esterilizan la creatividad de aquellas al menos en tres sentidos:

i.3 SILLS,D., «Asociaciones Voluntarias» en Enciclopedia Internacional de las Ciencias Sociales, Volumen I, Aguilar, Madrid, 1976, pp.626. 
a. La oferta de recursos suele hacerse de una forma muy reglamentada; ello propicia que las organizaciones voluntarias no se guíen tanto por su apreciación de las necesidades, cuanto por las posibilidades de la oferta.

b. La burocratización de los procedimientos por parte del sector público, en su relación con el sector voluntario, incide en la burocratización de éste.

c. Otras veces, las entidades voluntarias tienden a configurar su demanda o a reconvertirla de acuerdo con las prioridades gubernamentales, para aumentar las posibilidades de lograr las subvenciones, lo cual puede distorsionar sus actividades.

2. Cuando se constituyen en organizaciones de autoayuda parecen gozar de escasa difusión entre las capas más menesterosas y necesitadas de la población, por lo cual parecen constituir un medio más puesto al alcance de los grupos sociales que ya disfrutan de relativas ventajas con respecto al acceso a estructuras profesionales y de servicios y a la utilización de las mismas.

3. Cuanto más consolidada está una organización y más larga tradición tenga, más probable será que haya problemas de fragmentación, despilfarro, duplicidades, burocratización, etc.

4. Lo que comienza siendo un servicio voluntario, con profesional voluntario, acaba profesionalizándose, con lo que se incrementa notablemente el costo de los mismos.

Hay también posturas más críticas que piensan que la función política del sector voluntario es la no solución de problemas. El sector público utilizaría al sector voluntario para hacer políticamente soportable conflictos que, ni él mismo, ni, obviamente, el mercado pueden resolver. El sector público, promoviendo el papel del sector voluntario, diluye o esquiva las responsabilidades que en caso contrario le exigirían los ciudadanos.

\subsection{El sector privado lucrativo (mercado)}

El sector privado lucrativo tiene una característica muy singular respecto a los otros sectores, y es que responde a la demanda solvente (con capacidad de pagar), no a la necesidad. El interés por la ganancia lleva a interesarse por satisfacer cualquier clase de demanda solvente. Es más, puede llegar a correr el riesgo de perpetuar o crear necesidades para autosostenerse.

Una de las virtualidades que se le adjudican al mercado es la libertad de elección, pero ésta realmente sólo la tienen quienes poseen ingresos suficientes, y ello hoy es difícil, por la situación de un desempleo masivo y por la inestabilidad y precariedad de los empleos. 
La libertad de elección sólo existe si hay capacidad económica, quedando excluidos los que no la tienen. Pero si la libertad individual depende de la capacidad de participar en el mercado, ¿qué ocurre con los que están excluidos por falta de recursos?. La libertad política puede sonar a hueco a aquellos que no pueden pagar la factura del médico, de la luz, o que sólo pueden encontrar un alojamiento por debajo del nivel medio. La libertad de hacer sin los servicios esenciales es una libertad a la que la mayoría de las personas no tendrán acceso. La intervención estatal es esencial para garantizar la libertad de los pobres, los desempleados, los enfermos crónicos, la infancia desasistida, los sin techo, etc.

La dinámica y la lógica del mercado tiende a mostrarnos continuamente sus Carencias, no satisface necesidades vitales importantes para todos los ciudadanos: sanidad, educación, servicios sociales, vivienda, protección del medio ambiente, protección civil, transporte públi$\mathrm{co}$, actividades e instalaciones culturales y deportivas, protección del patrimonio histórico, etc., sus Limitaciones, como lo demuestra la competencia desleal, la protección del consumidor, la legislación sobre publicidad engañosa, la legislación antimonopolios, etc., y sus Desigualdades, porque el mercado por sí sólo no garantiza una situación de empleo, o un sistema de subsistencia digno, como tampoco garantiza una enseñanza o salud básica o especializada, para la totalidad de los ciudadanos que la requieran ${ }^{34}$.

Actualmente, desde ninguna postura se propone dejar al mercado para que este reparta bienes y servicios de acuerdo con la capacidad de pago de cada uno, pues esta propuesta sería inviable desde todos los puntos de vista, la propuesta de los que abogan por una mayor presencia de éste iría encaminada a una intervención selectiva por parte de los poderes públicos, no su abstención; esto es, no pagar el bienestar de todos, porque al final son sólo unos pocos los que no se podrían valer frente al mercado, sin dejar que éste provea y pagar la cuota correspondiente a los más débiles y pobres. Consecuencia: pagar menos impuestos aumentaría la eficiencia y la elección. Pero con este sistema queda claro que el que es receptor de esa «cuota» está en condiciones de desigualdad, pero ello, dicen los liberales a ultranza, ya es «normal» en sociedades que han reconocido en sus constituciones el derecho de propiedad y la libre empresa. Este es el debate añejo $y$ actual sobre el universalismo y la selectividad. 


\subsection{Sector informal}

Este sector está compuesto por lo que se denomina las redes de apoyo naturales, constituida por la familia, los parientes, los amigos y los vecinos. Dentro de los dos tipos de ámbitos de las relaciones sociales de los que habla Ugo Ascoli, éste sería el ámbito de los «mundos vitales», representado por los sujetos informales y hace referencia a las relaciones que los individuos mantenemos con otros individuos como simples seres humanos. Es el principal referente para toda persona y ha constituido desde siempre formas privilegiadas de protección social. En la geografía de la protección, se han generado abundantes experiencias que, basadas en la reproducción de un clima familiar, están orientadas a la resocialización (comunidades terapéuticas, viviendas tuteladas, mini-residencias, etc. ${ }^{35}$. También el acogimiento familiar para menores y ancianos va en esta dirección.

Actualmente, la cuantificación precisa de este sector resulta problemática por dificultades de medida y de pruebas no uniformes, ya que existen una gran variedad de tipos de familias y se desconocen muchos aspectos de la misma en cuanto a los lazos de solidaridad existentes entre el círculo amplio de parientes y la unidad familiar, la influencia del ámbito comunitario sobre la vida familiar, etc., tal y como manifiestan Iglesias y Flaquer en su artículo sobre «Familia y análisis sociológico: el caso de España ${ }^{36}$.

Actualmente, se asiste a un interés creciente por el apoyo social, que puede ser prestado por «Redes formales» (autoayuda) y «Redes informales», que son aquellas relaciones sociales que emergen del contexto de forma natural y se comparte una responsabilidad por el bienestar de los otros.

En general, hay tres tipos de apoyo:

- Emocional: que se ha definido como sentimiento de pertenencia, de ser amado, de poder confiar en alguien, disponer de alguien con quien poder hablar.

- Tangible o instrumental: que se ha definido como prestar ayuda directa o servicios (ayuda doméstica, dinero, cuidar de los niños, etc.). Es efectiva cuando el receptor percibe la ayuda como adecuada, pero puede tener efectos negativos si el receptor siente amenazada su libertad o si fomenta sentimientos de estar en deuda.

- Informacional: que es el proceso a través del cual las personas buscan información, consejo y/o guía, que las ayude a resolver sus problemas. Tanto este apoyo como el tangible o instrumental pue- 
den considerarse, asimismo, como apoyo emocional, siempre que no se den por obligación (como cuando es prestado por un profesional).

La contribución de este sector informal del que estamos hablando no cabe duda de que es considerable en el caso de los menores, ancianos y minusválidos. Pero la responsabilidad sobre los mismos no está distribuida de igual manera. Puede decirse que la asistencia es prestada mayoritariamente por mujeres. Finch y Groves ${ }^{37}$ dicen que la asistencia comunitaria=asistencia familiar=asistencia femenina, con el impacto que ello supone para la vida personal de las mujeres. La mujer es la que tradicionalmente ha sido la cuidadora de la familia: las esposas cuidan de los esposos, las madres de los niños, las hijas de los padres ancianos o hermanos incapacitados.

La política social tiende a basarse en una visión tradicional de la familia nuclear: dos adultos casados, con el hombre como principal fuente de ingresos y con dos o tres hijos. Pero esta visión tradicional no se corresponde con la realidad contemporánea, por la amplia participación de la mujer en el mercado de trabajo y los cambios en la estructura familiar (familias monoparentales, incorporación de la mujer al trabajo y la educación, etc.). Las consecuencias de estos cambios ya se están haciendo patentes, porque es difícil que la mujer, con todas las nuevas responsabilidades que está adquiriendo, pueda seguir asumiendo además su papel tradicional. Las políticas que no toman en cuenta estos cambios sólo pueden ser irreales y fracasar a la hora de cumplir sus objetivos. En cualquier caso, Johnson dice que «el objetivo principal de la política social no debería ser presionar a las personas para que se hagan cargo de responsabilidades extra, sino proporcionarles una alternativa realista, de manera que la gente que escoja cuidar de sus familiares más débiles debe recibir todo el apoyo necesario, pues el apoyo que saben que tendrán a su disposición es una de las consideraciones que la gente tiene en cuenta al hacer su elección. Aquellos que eligen no proporcionar una asistencia directa deben tener seguridad en que existen servicios alternativos aceptables, pues si el pluralismo del bienestar tiene algún mérito debe ser el de ampliar el campo de elección, no el restringirlo ${ }^{38}$. Esta idea es también expresa por Doyal y Gouhg ${ }^{39}$.

Respecto a la ayuda prestada por amigos y vecinos, se ha hecho bastante menos investigación, aunque no cabe duda de que es fuente importante de ayuda para muchas personas, pero los amigos se dife- 
rencian de la familia y parientes en que uno los elige, a la familia no, pero el cuidado mutuo no es un elemento inherente en la organización rutinaria de la amistad, ya que no están especialmente bien provistas para suministrar el tipo de cuidados que la asistencia comunitaria conlleva ${ }^{40}$. Además, los servicios proporcionados por vecinos y amigos son tareas simples, que implican tan sólo un compromiso limitado, y que, aunque sean importantes, no sirven de base para constituir un adecuado sustento para el desarrollo de políticas de asistencia comunitaria.

\section{VI.PARA FINALIZAR}

El pluralismo del bienestar o sistema mixto implica el reconocimiento de la complementariedad de cada una de los tres sectores y, a la vez, las imperfecciones e insuficiencia de cada uno de ellos. Cada sector puede resultar eficaz para resolver unas determinadas funciones y puede tener su ámbito, dependiendo de la naturaleza de la necesidad a la que se intente hacer frente o el objetivo que se quiera alcanzar. Ninguno puede ser una alternativa al margen de los otros; sin olvidar que todos tienen sus ventajas y limitaciones, como hemos tratado de exponer.

El Estado, a través de sus administraciones y de las numerosas fórmulas administrativas, tiene que intervenir cuando hay que asegurar la universalidad y la igualdad, propiciando la redistribución, y garantizando un mínimo vital para todos los ciudadanos.

El mercado es necesario para responder a las necesidades que se convierten en preferencias personales a través de medidas individualizadoras, y la competencia en función a la eficiencia de los servicios, pero no resulta eficaz para generalizar la oferta.

El sector voluntario es apropiado para hacer frente a aquellas necesidades que necesitan de proximidad física, ofertada a través de la solidaridad, pero resulta ineficaz para resolver problemas de equidad.

Los que se decantan por el pluralismo del bienestar desean el mantenimiento del Estado del Bienestar, pero quitando peso al Estado como el principal proveedor de servicios, con un mayor peso por tanto de los otros sectores. Su papel seguirá siendo importante en la $f i$ nanciación, planificación, promoción y reglamentación de los servicios. Los pluralistas del bienestar no abogan necesariamente por una reducción del gasto estatal, sino por la redistribución del mismo en 
apoyo de una provisión informal y voluntaria. El pluralismo del bienestar no significa un menor bienestar sino un desplazamiento de la provisión del mismo de un sector a otro, produciéndose no un desmantelamiento del Estado del Bienestar, sino una reestructuración del mismo.

\section{BIBLIOGRAFÍA}

ASCOLI, U., «Estado de bienestar y Acción Voluntaria», en Revista Española de Investigaciones Sociológicas $\mathrm{n}^{\circ} 38,1987, \mathrm{pp} .119-162$.

ASCOLI, U., «Voluntariado organizado y sistema público del «Welfare»: Potencialidades y límites de una cooperación» en Documentación Social $n^{\circ}$ 71, abril-junio, 1988, pp. 183-203.

AZNAR, M., «La legislación autonómica de acción social. Análisis jurídico» en $V$ Informe sociológico sobre la situación social en España. Sociedad para todos en el año 2000, 2 vol, Fundación Foessa, Madrid, 1994, pp. 1737-1875.

AZÚA, P., «Opciones de política interna por parte de las ONGs» en Varios Autores: Organizaciones voluntarias e intervencion social, Acebo, Madrid, 1989, pp. 51-68.

BELTRÁN AGUIRRE, J.L., El régimen jurídico de la acción social pública, Instituto vasco de Administración Pública, Bilbao, 1992.

CAMPS, V., Virtudes Públicas, Espasa Calpe, Madrid, 1990.

CASADO, D., «Las organizaciones sociovoluntarias» en Varios Autores: Organizaciones sociales e intervención social, Acebo, Madrid, 1989., pp. 17-50.

COBO SUERO, J.M., Contribución a la crítica de la política social, Universidad Pontificia de Comillas, Madrid, 1993.

DONAHUE, J.D., La decisión de privatizar. Fines públicos, medios privados, Paidós, Barcelona, 1991.

DOYAL, L. y GOHGH, I., Teoría de las necesidades humanas, Icaria, Barcelona, 1994.

FRIEDMAN, M. y R., Libertad de elegir, Grijalbo, $2^{\mathrm{a}}$ edición, Barcelona, 1980.

GALBRAITH, J.K., La cultura de la satisfacción, Ariel, Barcelona, 1992.

GARCÍA ROCA, J., Público y privado en la acción social. Del Estado del Bienestar al Estado Social, Popular, Madrid, 1992.

HARRIS, D., Justificación del Estado del Bienestar, Instituto de Estudios Fiscales, Madrid, 1987. 
IGLESIAS, J. y FLAQUER, L., «Familia y análisis sociológico: el caso de España» en Revista Internacional de Sociología $\mathrm{n}^{\circ}$ 61, 1993, pp. 57-75.

JARRÉ, D., Boletín del Comité Español para el Bienestar Social, nº 16-17, Madrid, 1988.

JHONSON, N., El Estado de Bienestar en transición. La teoría y la práctica del pluralismo del bienestar. Ministerio de Trabajo y Seguridad Social, Madrid, 1990.

KNAPP, M. ., La economía de los Servicios Sociales. EUGE, Barcelona, 1990.

LEY 6/1982, de 20 de mayo sobre Servicios Sociales, B.O. del País Vasco de 2 de junio de 1982.

LEY FORAL 14/1983, de 30 de marzo sobre Servicios Sociales, B.O. de Navarra, de 8 de abril de 1983.

LEY 11/1984, de 6 de junio de Servicios Sociales, B.O. de la Comunidad de Madrid, de 23 de junio de 1984.

LEY 8/1985, de 9 de diciembre de Servicios Sociales, B.O. de la Región de Murcia, de 19 de diciembre de 1985.

LEY 26/1985 de 27 de diciembre de Servicios Sociales, D.O. de la Generalidad de Cataluña, de 10 de enero de 1986.

LEY 3/1986, de 16 de abril de Servicios Sociales de Castilla-la Mancha, D.O.C.M. de 20 de mayo de 1986.

LEY 9/1987, de 11 de febrero, de Acción Social de Baleares, BOE $n^{\circ}$ 53, de 28 de abril de 1987.

LEY 4/1987, de 25 de marzo, de Ordenación de la Acción Social de Aragón, BOE $n^{\circ} 86$, de 10 de abril de 1987.

LEY 5/1987, de 11 de abril, de Servicios Sociales del Principado de Asturias, BOE n 137, de 9 de junio de 1987.

LEY 5/1987, de 23 de abril, de Servicios Sociales, D.O. de Extremadura $n^{\circ}$ 37, de 12 de mayo de 1987.

LEY 9/1987, de 28 de abril, de Servicios Sociales de Canarias, BOE $n^{\circ} 126$, de 27 de mayo de 1987.

LEY 2/1988, de 4 de abril, de Servicios Sociales de Andalucía, BOJA n 29 , de 12 de abril de 1988.

LEY 18/1989, de Acción Social y Servicios Sociales de Castilla-León, en Boletin Informativo.

LEY DE LA GENERALITAT VALENCIANA 5/1989, de 6 de julio de Servicios Sociales de la Comunidad Valenciana, DOGV de 12 de julio de 1989.

LEY 2/1990, de 10 de mayo, de Servicios Sociales de la Comunidad Autónoma de la Rioja, BOE ${ }^{\circ} 132$, de 2 de junio de 1990. 
LEY 5/1992, de 27 de mayo, de Acción Social de Cantabria, BOE n 181, de 29 de julio de 1992.

LEY 4/1993, de 14 de abril de Servicios Sociales de Galicia, en Cediss $n^{\circ} 45$, Legislación sobre Servicios Sociales, pp. 6-22.

LÓPEZ, Ma T. y UTRILLA, A., El sector público español (Organización, gestión y aspectos económicos), Actualidad Editorial, Madrid, 1991.

MALLA, P., «El Trabajo Social en las instituciones privadas» en Documentación social $\mathrm{n}^{\circ}$ 64, Cáritas Española, 1986, pp.

MISHRA, R., «El Estado de Bienestar después de la crisis: los años 80 y más allá» en Varios Autores: Crisis y futuro del Estado de Bienestar, Alianza, Madrid, 1993.

PÉREZ DÍAZ, V., El retorno de la sociedad civil, Instituto de Estudios Económicos, Madrid, 1987.

PÉREZ DÍAZ, V., La primacía de la sociedad civil, Alianza Editorial, Madrid, 1994.

ROVIRA I FORNS, J., «Contribución de las entidades no lucrativas al bienestar social» en Documentación Social n 71 , abril-junio, 1988, pp. 175181.

RODRÍGUEZ, F., Introducción a la politica social, Fundación UniversidadEmpresa/Civitas, Madrid, 1979.

RODRÍGUEZ CABRERO, G., «Entre la protección social y el bienestar social» en Varios Autores: Reflexiones sobre política económica, popular, Madrid, 1990, pp. 215-236.

SALA PRAT, G., El negocio de la pobreza o la Utopía del Bienestar, Asociación para la Promoción de la Igualdad Social, Barcelona, 1994.

SILLS, D., «Asociaciones voluntarias» en Enciclopedia internacional de las ciencias sociales, Volumen I, Agilar, Madrid, 1976, pp.

SUBIRATS, J., Análisis de políticas públicas y eficacia de la administración, Ministerio para las Administraciones Públicas, Madrid, 1989.

VARIOS AUTORES., Conceptos básicos de bienestar social. Seminario Taxonómico, Colegio Oficial de Doctores y Licenciados en Ciencias Políticas y Sociología, Madrid, 1987.

WATZLAWICK, P., El arte de amargarse la vida, Herder, Barcelona, 1988. 


\section{EL TRABAJADOR SOCIAL EN LA DIRECCIÓN DE UN CENTRO DE SERVICIOS SOCIALES}

\section{VÍCTOR M. GIMÉNEZ BERTOMEU}

Trabajador Social. Coordinador del Centro Social n. ${ }^{\circ}$ 4. Servicios Sociales Municipales del Ayuntamiento de Alicante.

\section{RESUMEN}

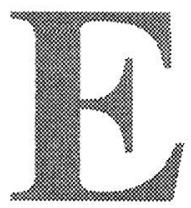

1 presente trabajo pretende acercarse a la figura del trabajador social como director de organizaciones de Servicios Sociales, y más específicamente de Centros Sociales o de Servicios Sociales.

En primer lugar, se encuadra el contexto desde el que se hace la reflexión, delimitando los conceptos de partida y caracterizando las organizaciones donde vamos a situar al trabajador socialdirector.

En segundo lugar, se aborda el contenido de la función directiva en los Centros de Servicios Sociales. Partiendo de la contraposición entre un modelo innovador y una gerencia tradicional, por un lado, se identifican las funciones del director, con especial incidencia en la utilidad de la supervisión en este ámbito, y por otro, las características necesarias para una dirección eficaz.

Por último, se recogen aquellas aportaciones que el Trabajo Social realiza a la función directiva.

\section{PALABRAS CLAVE}

Organizaciones de Servicios Sociales, dirección, supervisión, coordinación, equipo, trabajo en equipo, funciones, capacidades, actitudes, aptitudes y conocimientos del director. 


\section{EL CONTEXTO DE LA REFLEXIÓN}

\subsection{El contexto conceptual.}

El repaso acerca del papel que el trabajador social realiza o puede desarrollar en la dirección de organizaciones prestadoras de Servicios Sociales, ha de partir necesariamente de la identificación de los principales elementos que incluye tal ejercicio.

Consideramos que la dirección de un Centro de Servicios Sociales básicamente consiste en la supervisión y coordinación de los proyectos, objetivos, actividades, técnicas utilizadas y resultados obtenidos por un equipo de trabajo en el desarrollo de las competencias que le han sido encomendadas, y del cual el director es un miembro más con funciones diferenciadas.

Podemos definir el elemento coordinador ${ }^{1}$ como la disposición armónica, funcional y ordenada de un grupo para dar unidad de acción, con vistas a conseguir un objetivo común.

La supervisión, con A. Porcel ${ }^{2}$, la entendemos como un proceso continuo de seguimiento, de análisis, de control y de reflexión, que se hace desde una organización, sobre la intervención social que realizan unos profesionales como agentes de una política social, con la ayuda de un supervisor y un equipo de trabajo.

El equipo de trabajo en Servicios Sociales actúa como una instancia complementaria de supervisión de los profesionales individualmente. El supervisor desarrolla sus funciones características con uno y con los otros.

Es evidente que el hablar de las tareas de supervisión y coordinación que ha de desarrollar un director queda falto de contenido si no se hace referencia al grupo de profesionales del que forma parte y al que denominamos "equipo". Este se diferencia de otros grupos de individuos por utilizar, en un momento determinado, un método de trabajo específico, el "trabajo en equipo"3. Este método de trabajo se caracteriza por acumular necesariamente las condiciones que siguen:

1. Existe trabajo en equipo cuando un grupo define un/unos objeti$\mathrm{vo} / \mathrm{s}$ concretos de producción.

Proyecto de coordinación sanitaria entre Atención Primaria y Atención Hospitalaria. Cabueñes (Asturias).

2 PORCEL MUNDO, A., "La supervisión en Servicios Sociales", en Revista de Servicios Sociales y Política Social n." 25 . Consejo General de Colegios Oficiales de Trabajadores Sociales y Asistentes Sociales. Madrid, 1992. p. 117.

3 PLENCHETTE-BRISSONNET, C., Mètode de Treball en Equip. Ed Pòrtic / INTRESS. Barcelona, 1987. pp. 10-14. 
2. Existe trabajo en equipo cuando la naturaleza de esta producción es compatible con objetivos específicos del trabajo en equipo, como son el ahorro de tiempo y energía, la pluralidad de las respuestas y de las intervenciones, el mejor uso de las competencias individuales, el distanciamiento intelectual respecto a lo cotidiano, el análisis sistemático y la investigación, etc.

Existe trabajo en equipo cuando el grupo de individuos elabora "normas de trabajo" constitutivas de un marco metodológico que permita alcanzar el objetivo o los objetivos fijados. Esta condición para el trabajo en equipo nos remite a la idea de que los miembros del grupo han de compartir un común Esquema Conceptual Referencial Operativo (E.C.R.O. $)^{4}$. En las organizaciones de Servicios Sociales se hace imprescindible tener un conjunto de elementos (valores, conceptos, modelos, técnicas e instrumentos) para el abordaje profesional de la realidad que lleguen a ser comunes a todos los miembros del equipo, que se deben consensuar y crear conjuntamente a partir de los saberes y características de cada uno de los miembros.

Existe trabajo en equipo cuando la calidad o la naturaleza del trabajo individual resultan modificados por la elaboración del método de trabajo en equipo.

Situamos la dirección y al director en un contexto de trabajo en equipo, frente a visiones más tradicionales de la función directiva basadas en la línea jerárquica y vertical de mando, donde el director es un satélite en órbita entre una alta jefatura solar y un equipo planetario. Creemos que es en el marco de un equipo de trabajo donde la dirección cobra gran parte de su sentido y donde más ampliamente se pueden desarrollar las funciones que la caracterizan.

\subsection{El contexto organizacional.}

Para situarnos en la globalidad de la reflexión acerca del papel del trabajador social en la dirección de organizaciones y grupos humanos en el ámbito de los SS.SS., es preciso caracterizar brevemente este ámbito y estas organizaciones.

4 Término acuñado por el psicólogo social E. PICHÓN RIVIERE, Asamblea de evaluación institucional. Escuela de Psicología Social. Buenos Aires, 1972. Citado por GEREZ, M., "Contribuciones para una Formulación del Trabajo Social como Disciplina Científica en América Latina", en Secciones del Servicio Social. Ed. Humanitas. Buenos Aires, 1973. pp. $20 \mathrm{y} s \mathrm{~s}$. 


\subsubsection{Los Servicios Sociales.}

No es el objeto de este trabajo definir amplia y profundamente el ámbito de los Servicios Sociales; por el contrario, nos interesa identificar brevemente sus principales elementos constitutivos.

Los Servicios Sociales son uno de los Sistemas Públicos de Protección Social competente en la cobertura de necesidades específicas 5 .

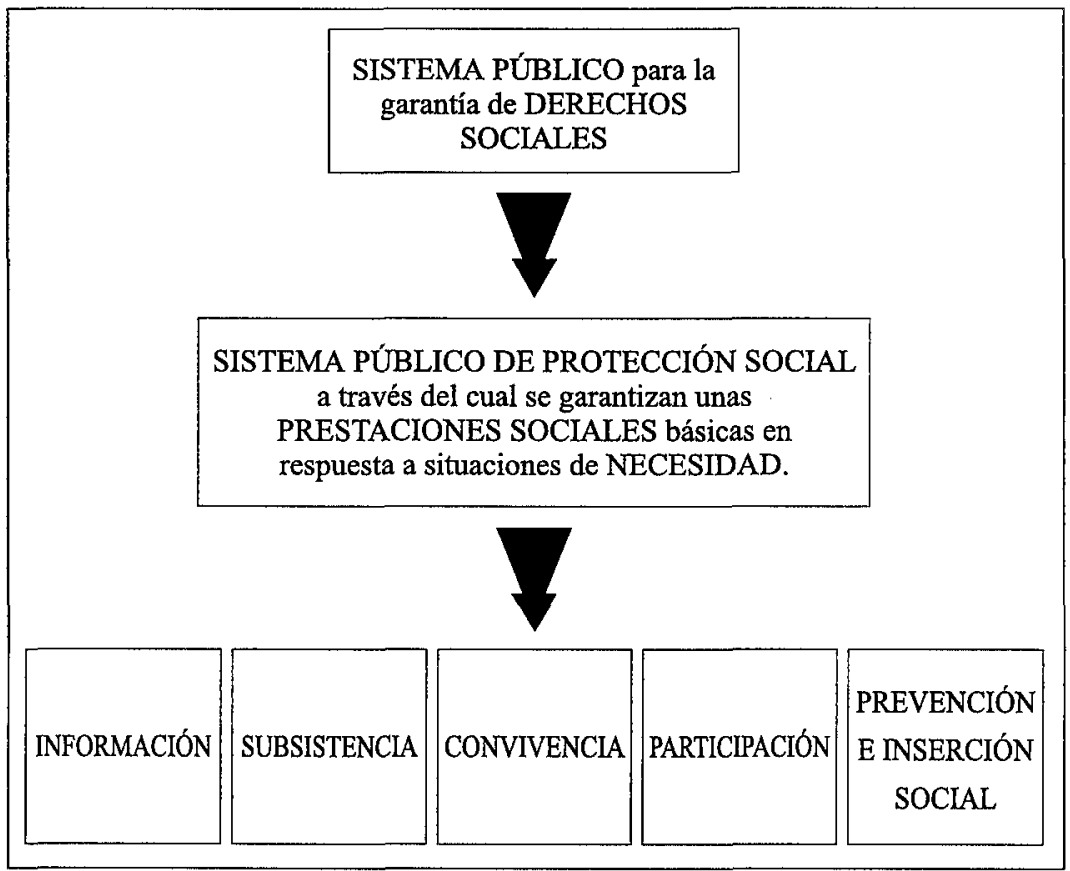

FIGURA 1. El Sistema de Servicios Sociales.

De este modo, y de forma muy sintética, los elementos que definen a los Servicios Sociales son ${ }^{6}$ :

- Un Sistema de PROTECCIÓN SOCIAL.

- Unas necesidades sociales específicas.

- Unas prestaciones sociales específicas.

- Unos equipamientos propios.

- Una normativa, una planificación y unos presupuestos propios.

5 GARCÍA HERRERO, G., Centros de Servicios Sociales. Conceptualización y desarrollo operativo. Ed. Siglo XXI. Madrid, 1988. pp. 18-21.

- GARCÍA HERRERO, G. y RAMíREZ NAVARRO, J.M., Los nuevos Servicios Sociales. Síntesis de conceptos y evaluación. Ed. Certeza. Zaragoza, 1992. pp. 11-15. 
En su desarrollo, este Sistema de Protección Social se ha articulado en dos niveles básicos de intervención:

1. Un nivel generalista, con el carácter de atención primaria, que constituye la "puerta de acceso" al Sistema y se dirige a toda la población por necesidades: los Servicios Sociales Generales, Comunitarios o de Atención Primaria.

2. Un nivel especializado, con el carácter de atención secundaria, dirigido a sectores de población con necesidades específicas: los Servicios Sociales Especializados.

\subsubsection{Las Organizaciones de Servicios Sociales.}

La prestación de los Servicios Sociales se materializa a través de diferentes organizaciones sociales. Éstas comparten elementos comunes a toda organización, y también desarrollan componentes que las singularizan?

Amparo Porcel ${ }^{8}$, basándose en los conceptos aportados por Hasenfeld y English", define las organizaciones de Servicios Sociales como "organizaciones al servicio de la persona (OSP)", e identifica tres características básicas del trabajo que han de realizar:

a. Su input son seres humanos con atributos específicos.

b. Su output o "producción" es cambiar la situación de las personas que atienden.

c. Su mandato es ser un servicio, generalmente derivado de un marco legal que define sus competencias.

Junto a estos rasgos básicos, y con base en los trabajos de Peiró y Medina ${ }^{10}$, Porcel $^{11}$ y Bueno Abad ${ }^{12}$, otros elementos terminan por caracterizar organizacionalmente a los Servicios Sociales:

LÓPEZ CÁBANAS, M. y GALLEGO GALLEGO, A., "Análisis organizacional y propuestas de desarrollo en los Servicios Sociales Comunitarios", en III Jornadas de Intervención Social. Tomo I. Ed. INSERSO. Madrid, 1993. pp. 83-84.

\& POCEL, A. y VÁZQUEZ, C., La supervisión. Espacio de aprendizaje significativo. Instrumento para la gestión. Ed. Certeza / INTRESS. Zaragoza, 1995. p. 158.

9 HASENFELD y ENGLISH citados por PORCEL, A., "La intervención del trabajador social en la planificación, gestión y desarrollo de los Servicios Sociales", en Documentación Social n. ${ }^{\circ}$ 79. Ed. Cáritas Española. Madrid, 1990.

10 PEIRÓ, J.M. ${ }^{a}$ y MEDINA, M., "Aspectos psicosociales de la gestión de organizaciones de Servicios Sociales", en IV Jornadas de Intervención Social. Tomo 2. Ed. INSERSO. Madrid, 1996. pp. 1148-1157.

11 PORCEL, A. y VÁZQUEZ, C. (1995), op. cit. pp. 158-160.

12 BUENO ABAD, J.R., Servicios Sociales: Planificación y organización. Ed. Mestral Llibres. Valencia, 1988. pp. 73-74. 
1. Organizaciones de servicios.

La producción y la entrega del producto son simultáneos y realizados por la misma persona. El consumo se produce también en el mismo acto, lo que no permite la comprobación previa de la calidad del servicio: el cliente lo demanda basándose en la confianza.

No existen stocks. Ello obliga a una gestión diferente de la producción y la entrega.

El servicio combina, además, componentes técnicos y profesionales con componentes ideológicos.

2. Organizaciones públicas, en su mayoría, y privadas.

La Administración es la promotora y proveedora más importante de Servicios Sociales. Ello implica que el servicio público se enfrente a dos tipos de demandas que han de articularse entre sí convenientemente: las demandas e intereses de los ciudadanos y las del proyecto político del equipo que dirige la organización pública.

Coexistiendo con el sector público, se ha desarrollado en gran medida el sector privado $^{13}$, tanto lucrativo como no lucrativo, a través de fórmulas de gestión mixta de los Servicios Sociales: unas veces complementando los servicios públicos; otras, prestando éstos mediante gestión indirecta (convenios, contrataciones, etc.). Al mismo tiempo, la Administración pública ha generado sistemas de autorización de la actividad privada en el ámbito de los Servicios Sociales, para garantizar la calidad de los servicios y de los derechos de los ciudadanos.

3. La misión de las organizaciones de Servicios Sociales.

Estas organizaciones se diseñan y crean con la misión de cambiar las situaciones de las personas que son atendidas mediante la definición de una serie de objetivos generales y estratégicos. Son posibles múltiples formulaciones de esta misión, cuyo contenido va a implicar componentes ideológicos y políticos, además de los componentes técnicos.

Esta multiplicidad, unida a un grado importante de generalidad y ambigüedad, plantea problemas para la concreción de los fines y objetivos, su priorización y su evaluación.

4. El objeto e instrumento de la producción.

Estas organizaciones trabajan con y en las relaciones interpersonales. Muchos de los procesos que emprenden tienen que ver con cambios de actitudes, con la socialización de los individuos, 
con aspectos biográficos de las personas que intervienen en estos procesos y entran en juego valores, ideas, actitudes y hábitos.

5. La tecnología.

La tecnología de las organizaciones de Servicios Sociales no es estándar, ya que está basada en las relaciones interpersonales, que comportan incertidumbre e impredecibilidad sobre el estado del cliente con quien se trabaja.

6. Los profesionales.

Las organizaciones al servicio de la persona emplean profesionales cualificados. Esto es debido a la naturaleza y complejidad de los problemas humanos a que estas organizaciones pretenden dar respuesta. El tipo de trabajo que se requiere es "creativo" y "artesanal" y es complejo.

7. La eficacia y la eficiencia.

La medida de la eficacia (grado de consecución de objetivos) y de la eficiencia (consecución de los objetivos con los resultados adecuados y los menores costes posibles) es compleja en este tipo de organizaciones, por cuanto no puede seguir exclusivamente criterios economicistas. Esta evaluación se complica aún más si consideramos la dificultad para establecer objetivos precisos, la estrecha relación entre la gestión y las decisiones políticas, la dificultad para medir los impactos producidos por determinados programas o proyectos, etc.

Este conjunto de características propias de las organizaciones de Servicios Sociales actúan como elementos definitorios y condicionantes del tipo de estructura organizativa a desarrollar, de la tecnología a utilizar y del modelo directivo y de las estrategias de gestión necesarias para el funcionamiento organizacional.

\subsubsection{Los Centros de Servicios Sociales: estructura, equipo y territorio.}

Participando de las características señaladas para las organizaciones de Servicios Sociales, los denominados "Centros Sociales" o "Centros de Servicios Sociales", desde los Servicios Sociales Generales, son los responsables de la implantación y desarrollo de los programas de Prestaciones Básicas de Servicios Sociales y son la puerta de acceso a la red pública de Servicios Sociales.

De este modo, los Centros Sociales se desarrollan y configuran sobre la base de tres grandes ejes:

- Una estructura integrada y descentralizada de ámbito comunitario, es decir, un lugar de referencia de programas y proyectos, servicios, prestaciones y equipamientos. 
- Un equipo de trabajo, constituido por profesionales de distintas disciplinas con tendencia al trabajo interdisciplinar.

- Un territorio, diana de los programas de Servicios Sociales, que define y limita geográfica y poblacionalmente el ámbito de la intervención del Centro Social.

\section{LA DIRECCIÓN DE UN CENTRO DE SERVICIOS SOCIALES}

\subsection{Pero ¿Por qué...?. TRADICIÓN versus INNOVACIÓN.}

El Centro Social constituye una organización compleja en la que se hace necesario garantizar un desarrollo armónico de funciones y recursos diferentes a través de un profesional con funciones también diferenciadas que asume la dirección del Centro Social.

Hemos de recordar que toda la organización debe ser una cadena de valor añadido, de modo que cada una de las actividades que en ella se realizan debe añadir valor, ya que las tareas o funciones que no añaden valor lo que hacen es añadir coste. Descartamos aquí una figura directiva tradicional que únicamente actúa como enlace informativo y de mando entre el Centro de SS.SS. y su entorno (organizaciones, comunidad, etc.). Optamos, sin embargo, por un modelo de dirección con parcelas propias de decisión; que realiza aportaciones claras con relación a los productos, servicios y actuaciones del Centro Social; que facilita y apoya en su ámbito funcional el trabajo de los profesionales y el funcionamiento del Centro Social y que se orienta hacia la motivación del equipo, al logro de resultados y el fomento de la creatividad e innovación; en definitiva, una figura que actúa estimulando el funcionamiento global del Centro Social.

Entendemos, con G. García Herrero ${ }^{14}$, que el Director no se ha de limitar a ser un superior jerárquico en la estructura, preocupado en exclusiva por el mantenimiento de las normas que le afecten. Por el contrario, éste es el responsable de organizar en la forma más racional (minimizando costes y maximizando resultados) los recursos de los que el Centro dispone, para conseguir con la mayor eficacia y eficiencia posible, los objetivos y metas que esta estructura integrada tiene encomendados.

Por ello, proponemos la superación de la gestión tradicional en la dirección de Centros de Servicios Sociales para dar paso a un modelo más innovador. En esta línea de ideas, es conveniente que pongamos 
en relación los aspectos diferenciales de la gestión tradicional y de la gestión innovadora:

\begin{tabular}{|c|c|c|c|}
\hline & \\
\hline & & Gestión tradicional & Gestion innovadora \\
\hline \multirow{2}{*}{ Criterios } & $\begin{array}{l}\text { Objetivos } \\
\text { del puesto }\end{array}$ & $\begin{array}{c}\text { Gestión de los recursos } \\
\text { disponibles }\end{array}$ & $\begin{array}{l}\text { Creación de nuevos } \\
\text { recursos }\end{array}$ \\
\hline & $\begin{array}{c}\text { Principios de } \\
\text { dirección } \\
\text { (Management) }\end{array}$ & $\begin{array}{l}\text { Principios universales } \\
\text { de gestión }\end{array}$ & $\begin{array}{c}\text { Dirección situacional } \\
\text { Flexibilidad }\end{array}$ \\
\hline \multirow{2}{*}{ de } & $\begin{array}{c}\text { Procedimientos } \\
\text { de trabajo }\end{array}$ & $\begin{array}{c}\text { Orientados a actividades } \\
\text { aisladas }\end{array}$ & $\begin{array}{l}\text { Orientados a procesos } \\
\text { integrados }\end{array}$ \\
\hline & $\begin{array}{l}\text { Criterios de } \\
\text { evaluación }\end{array}$ & $\begin{array}{c}\text { Eficacia } \\
\text { (relac. producción /tiempo) }\end{array}$ & $\begin{array}{c}\text { Eficiencia } \\
\text { (relac. coste /beneficio) }\end{array}$ \\
\hline \multirow{4}{*}{ del } & $\begin{array}{l}\text { Orientación } \\
\text { al mercado }\end{array}$ & $\begin{array}{l}\text { Vende productos o } \\
\text { servicios estándar }\end{array}$ & $\begin{array}{l}\text { Satisface necesidades } \\
\text { de la clientela }\end{array}$ \\
\hline & $\begin{array}{c}\text { Formación } \\
\text { personal }\end{array}$ & Aprendizaje ocasional & $\begin{array}{l}\text { Formación permanente } \\
\text { Descubrimiento personal }\end{array}$ \\
\hline & $\begin{array}{l}\text { Estilo de } \\
\text { mando }\end{array}$ & $\begin{array}{l}\text { Obediencia basada } \\
\text { en el status }\end{array}$ & $\begin{array}{l}\text { Adhesión } \\
\text { Trabajo en equipo }\end{array}$ \\
\hline & Incentivos & $\begin{array}{c}\text { Incentivos extrínsecos } \\
\text { al trabajo }\end{array}$ & $\begin{array}{l}\text { Incentivos intrínsecos } \\
\text { Enriquecimiento de tareas }\end{array}$ \\
\hline
\end{tabular}

FIGURA 2. Gestión Tradicional versus Gestión Innovadora.

Además, hoy las tareas del director en la organización cobran especial relevancia en el modelo mixto de gestión extendido en los Servicios Sociales ${ }^{15}$, en virtud del cual se establece un sistema de corresponsabilidad entre iniciativa pública, privada y social. En este modelo, la Administración pública incorpora al sector privado en los servicios públicos, a través del convenio o el concierto, para la prestación de servicios (Servicio de Ayuda a Domicilio, Programas de Intervención Familiar, Programas de Atención a Colectivos o Necesidades específicas, etc.); y se obliga, entre otras, a realizar una función de inspección y evaluación de los servicios prestados. $\mathrm{Y}$ es al director, desde la estructura descentralizada y cercana al ciudadano que es el Centro Social, a quien le es atribuida esta función de inspección y evaluación en su ámbito territorial.

15 García RoCA, J., Público y Privado en la Acción Social. Del Estado del Bienestar al Estado Social. Ed. Popular. Madrid, 1992. pp. 46, 117-126, 157-161.

GARCÍA HERRERO, G. y RAMÍREZ NAVARRO, J.M. (1992), op. cit. pp. 83-93.

BUENO ABAD, J.R. (1988), op. cit. pp. 81-84. 


\subsection{Funciones y roles del director de un Centro de Servicios Sociales}

Por lo general, los Centros Sociales, por su carácter descentralizado, dependen orgánicamente de las Administraciones locales (Ayuntamientos, Diputaciones o entidades supramunicipales). El director del Centro Social, siguiendo la terminología empleada por Mintzberg ${ }^{16}$, se sitúa en la línea de mando o dirección intermedia, entre el vértice estratégico (Concejal, Diputado, etc.) y el núcleo de operaciones (el personal asignado al Centro Social y a sus unidades dependientes), junto a otros mandos medios de la organización (responsables de Programas Centrales, personal del staff, etc.).

Las funciones de la dirección y los roles que ha de asumir en el ejercicio de aquéllas son, con carácter general, los que la gestión de toda organización implica y son una combinatoria de las mismas funciones organizacionales. Peiró y Medina han elaborado una interesante síntesis de esta combinación de funciones, donde hemos señalado las relaciones que mantienen:

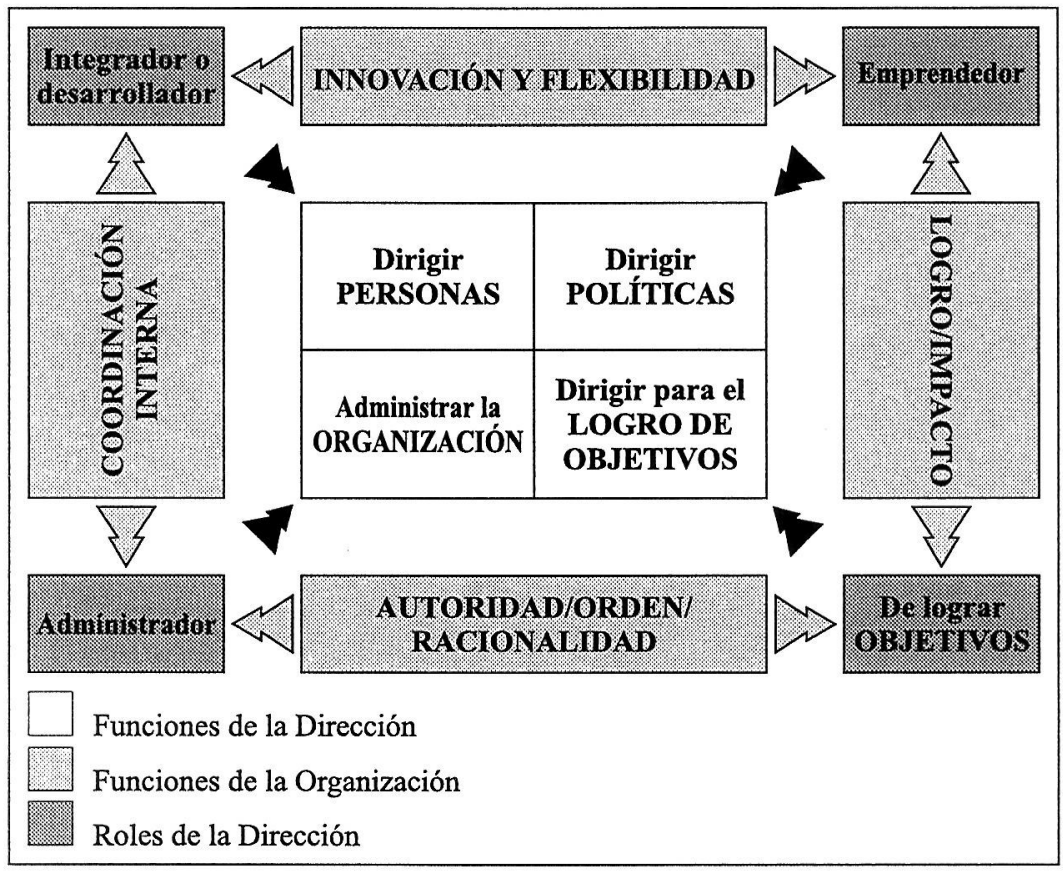

FIGURA 3. Funciones organizacionales y funciones y roles de la Dirección.

16 MINTZBERG, Henry, La estructuración de las organizaciones. Ed. Ariel. Barcelona, 1995. pp. 52-55. 
En virtud de la posición intermedia que ocupa en la organización, le es atribuida una de las funciones vitales para el logro de la misión que la organización tiene encomendada: la función de dirección o "pilotaje", que incluye ${ }^{17}$ :

a. Dirección operacional: desarrollo de las actividades definidas por el ápice estratégico para su unidad y territorio.

b. Enlace vertical: transmisión de la planificación hacia abajo, hacia arriba transmite información para el seguimiento, el control y la evaluación.

c. Enlace horizontal: mantiene la coordinación precisa dentro de la organización con otras unidades y servicios y con el entorno.

d. Mando y dirección de personas, instrucción y motivación.

A. Porcel ${ }^{18}$ ha desarrollado el contenido de esta función partiendo de los trabajos de Mintzberg ${ }^{19}$ y Kadushin ${ }^{20}$.

\subsubsection{Función de dirección operacional.}

Esta función reproduce las actividades del ápice estratégico o alta dirección, pero en el ámbito del Centro Social. Se compone de varias subfunciones:

1. De prospectiva: consiste en conocer la evolución y tendencias tanto del entorno interior (zona, tipo de población, necesidades, demandas, recursos, etc.) como exterior (la organización, otros servicios o departamentos).

2. De relaciones internas y externas: desarrollo de estrategias para mantener el equilibrio en el entorno interior y el clima de colaboración con el exterior.

3. De planificación: pasa por desarrollar la planificación general de la organización en su ámbito territorial.

\subsubsection{Función de dirección de personas.}

Tiene como finalidad guiar los trabajos operacionales, tomando las decisiones oportunas sobre:

- Cuándo y en qué cantidad debe hacerse el trabajo.

- Cómo y en qué condiciones va o está yendo la realización.

- Qué dificultades surgen y qué cambios se precisan.

Es una de las funciones fundamentales para la correcta realización de la producción, y entronca directamente con el uso de la supervisión

17 PORCEL, A. y VÁZQUEZ, C. (1995), op. cit. pp. 135-138.

Is PORCEL, A. y VÁZQUEZ, C. (1995), op. cit. pp. 163-176.

11) MINTZBERG, Henry (1995), op. cit.

20 KADUSHIN, A. Supervision i social work. Columbia University Press. New York, 1985. 
en la dirección de Centros Sociales, sobre la base del necesario soporte que el director ha de prestar a los profesionales.

Dentro de esta gran función, se pueden identificar varias subfunciones del director-supervisor ${ }^{21}$ :

\section{Directiva/Administrativa.}

Consiste en asegurar que el trabajo se lleve a cabo de acuerdo con el encargo. Su objetivo principal es asegurar la coherencia entre planificación y procedimientos.

Incluye las tareas de:

a. Reclutamiento y selección de personal. Esta función en la Administración pública española no es realizada directamente por la dirección del Centro Social. En su lugar, se define el perfil de los puestos necesarios y el de los candidatos, y el número de trabajadores necesario.

b. Iniciación y ubicación del nuevo trabajador.

c. Planificación y asignación del trabajo.

d. Delegación del trabajo.

e. Seguimiento, revisión y evaluación del trabajo asignado y/o delegado.

2. Educativa/Capacitadora.

Es, con la función de apoyo, la característica que diferencia este modelo de dirección de otros. Consiste en dar respuesta a las necesidades de conocimiento del trabajador, de entendimiento conceptual y de desarrollo técnico. Unas veces la respuesta será directa por parte del supervisor, otras indirecta a través de la orientación hacia la formación específica del Trabajador Social. Su objetivo es subsanar las lagunas de conocimiento y mejorar las habilidades.

Complementa la supervisión administrativa ya que ayuda al profesional a comprender cómo ha de realizar las tareas y cómo hacerlas mejor.

3. Apoyo.

Constituye el reconocimiento de que los profesionales de las organizaciones de Servicios Sociales, y especialmente los Trabajadores Sociales, tienen un mayor número de demandas que superan sus recursos personales y emocionales que el que tienen otras profesiones. Tiene que ver con el estado de ánimo de los trabajadores y la satisfacción con relación a la tarea. Su objetivo para el supervisor consiste en ayudar a los supervisados a superar el estrés

21 NICHOLS, J. y CAVE, C., "Supervisión: Algunos principios y consideraciones para la práctica", en Revista de Servicios Sociales y Política Social n. ${ }^{\circ} 25$. Consejo General de Colegios Oficiales de Trabajadores Sociales y Asistentes Sociales. Madrid, 1992. pp. 7-9. 
y la ansiedad inherentes al desempeño del trabajo social e incrementar la moral y la satisfacción en el puesto de trabajo.

4. Evaluadora.

Consiste en el control de la eficacia de la práctica del trabajador utilizando el «feedback» como un medio de apoyo a su desarrollo profesional y para asegurar que el cliente obtenga «el mejor servicio posible». Pasa por la revisión continuada del proceso de trabajo, que ayude a pensarlo y a repensarlo constantemente, valorando los logros, las desviaciones, los imprevistos y facilitando la toma de decisiones.

Como es fácil advertir, estas funciones habitualmente se presentan combinadas en el espacio de la dirección-supervisión, con mayor énfasis en unas o en otras, según las necesidades que se pretende cubrir en cada momento.

\subsubsection{Función de coordinación.}

Las organizaciones de Servicios Sociales, en su calidad de sistemas abiertos, reciben e intercambian información propia y del entorno en un proceso de retroalimentación ${ }^{22}$.

Es función del director posibilitar la conexión vertical y horizontal, la coordinación y la comunicación:

- Entre los miembros del equipo. Ello unifica los esfuerzos de los diferentes trabajadores hacia el logro de los objetivos de la organización.

- Con otras unidades de la organización.

- Con otras organizaciones de Servicios Sociales.

La posición del mando medio en la estructura de la organización es un lugar clave para la recogida, procesamiento y distribución de la información, tanto en sentido ascendente (necesidades y demandas, dificultades de ejecución del trabajo, quejas, etc.), como descendente (directrices, formas de trabajo, etc.) entre, por un lado, el núcleo de operaciones y la población, y, por otro, la alta dirección.

En síntesis, en un Centro de Servicios Sociales, al igual que ocurre en las funciones que ejercen las redes sociales ${ }^{23} \mathrm{o}$ en la intervención profesional con familias, corresponde al director ejercer funciones de dos tipos principalmente ${ }^{24}$ :

22. LÓPEZ CÁBANAS, M. y GALLEGo GALLEGO, A. (1993), op. cit. p. 83.

2.3 VILLALBA QUESADA, C., "Redes sociales: Un concepto con importantes implicaciones en la intervención comunitaria", en Intervención Psicosocial. Vol. II. N. ${ }^{\circ}$. Madrid, 1993. pp. $72-73$.

24 PLENCHETTE-BRISSONNET, C. (1987), op. cit. p. 68. 
a. Funciones de APOYO a los profesionales, orientadas a servir de soporte al trabajo de los miembros del equipo y a resolver las dificultades que de éste se derivan.

b. Funciones de CONTROL de los profesionales, orientadas a vigilar las tareas, actividades, proyectos, etc., para garantizar el logro de los objetivos marcados por el equipo y por la organización.

La organización describe y limita estas funciones directivas generales a través de una definición formal del puesto del directivo intermedio, que da respuesta a sus necesidades de funcionamiento. Junto a ello, encontramos que los miembros de la organización en general, y del equipo de trabajo en particular, someten a la función directiva a un nuevo modelaje, de carácter más específico y detallado que el anterior. Con ello, el equipo y sus integrantes pretenden para dar respuesta a sus necesidades como individuos, como profesionales y como grupo, configurando una definición informal del puesto, dentro de los límites formales atribuidos a éste.

\subsection{Características del director.}

El director de un Centro de Servicios Sociales debería identificarse y actuar como el líder natural del grupo de trabajo al cual pertenece, en calidad de lo cual es limitado en el cumplimiento de sus funciones y le es exigido en mayor medida que al resto de miembros del grupo. Esto no siempre ocurre en las organizaciones de Servicios Sociales. En ellas el liderazgo de la Dirección suele ser formal, por cuanto el director ha sido nombrado o ha accedido al puesto desde el exterior, y es habitual que sea recibido y tratado como miembro ajeno al grupo.

En la realidad organizativa en que nos situamos, no se puede dirigir el esfuerzo de las personas con el mando, ordeno y controlo tradicional. Por el contrario, es necesario un tipo de dirección que en lugar de estar basado en el poder y el rango, lo esté en el respeto y la confianza que el directivo ha de ganarse de los trabajadores. Y por ello, la persona destinada en este puesto ha de reunir unas características específicas y precisa una adecuada formación en management, donde los aspectos humanos son tan importantes como los técnicos.

En los procedimientos actuales de acceso a la Administración pública española no siempre se priman aspectos de vital importancia en el perfil de un director de un Centro de Servicios Sociales, como son el buen ejercicio de la práctica, el conocimiento profundo de los Servicios Sociales (en su teoría y en su práctica), las habilidades necesarias para la dirección de Recursos Humanos y las aptitudes/actitudes personales en relación con el trabajo con personas y con el trabajo en equipo. 
Además, por su situación en la estructura de la organización, el director se encuentra en una posición difícil al situarse en un nivel medio entre la alta dirección y los trabajadores (efecto cartílago). Es por ello, que la dirección requiere una habilidad social considerable además de conocimientos y habilidades técnicas que refuercen la autoridad formal que la organización le atribuye.

Las capacidades, aptitudes, actitudes y conocimientos que consideramos necesarios en el director y que a continuación se relacionan determinan en sí mismos un modelo de dirección.

\subsubsection{Capacidades.}

Para desarrollar las funciones que la organización les asigna, los directores recurren a cuatro tipos de capacidades de administración ${ }^{25}$.

1. Capacidades técnicas.

Son las que permiten dominar los procesos de trabajo, los métodos de producción.

Dado que las tecnologías de las organizaciones de Servicios Sociales no son estandarizables y que puede haber distintos enfoques y formas de intervenir para conseguir resultados similares, el director ha de ser flexible en cuanto a aceptar formulaciones técnicas diferentes por parte del equipo. Para ello, ha de conocer más de un enfoque para así valorar adecuadamente la idoneidad de cada uno con relación al tipo de intervención necesaria.

Incluye también las capacidades para el dominio de técnicas de análisis y estudio de las demandas del entorno, y otras referidas a la producción del grupo ${ }^{26}$.

2. Capacidades administrativas.

Son las que sirven para que todas las partes del servicio encajen unas con otras. Permiten formular objetivos, orientar al equipo hacia la eficacia, facilitar el trabajo en equipo, etc. En definitiva, proporcionan procedimientos claramente estructurados y ofrecen un feedback positivo a los trabajadores sobre sus relaciones con el servicio y sobre su práctica.

3. Capacidades conceptuales.

Son las que se refieren a la capacidad de síntesis, de inferir y de deducir elementos útiles para la intervención a partir de situaciones, hechos y resultados anteriores.

25 HODGETTS, Richard M., El supervisor eficiente. Un enfoque práctico. Ed. Mc Graw Hill. México, 1987, citado en PORCEL, A. y VÁZQUEZ, C. Op. cit. pp. 211-213.

26 Estas técnicas de apoyo a la producción del grupo han sido identificadas por PLENCHETTEBRISSONNET, C. (1987), op. cit. pp. 68-75. 


\section{Capacidades humanas.}

Se basan en las habilidades de comunicación y de relaciones interpersonales. Tienen que ver con su capacidad de liderazgo, con sus habilidades sociales y con su capacidad de empatía. Incluyen:

- Capacidad de escucha.

- Capacidad de comunicación completa y libre con el equipo de trabajo.

- Actuar como facilitador y como línea de comunicación entre la línea operativa y la alta dirección.

\subsubsection{Actitudes}

Estas actitudes orientarán y darán contenido a la actuación del director-supervisor, y definirán el uso de unas técnicas en lugar de otras en el proceso directivo ${ }^{27}$ :

- Confianza y aceptación hacia los profesionales del equipo, a fin de optimizar la autonomía y la facultad de juicio propio y crítico del supervisado.

- Empatía.

- Respeto frente a las opiniones y forma de trabajar de los demás.

- Disponibilidad para consultas de carácter profesional, e incluso personal.

- Compartir conocimientos y enseñar con su práctica y con sus orientaciones.

- Consenso y cooperación para la solución de problemas derivados de la participación democrática más que de los enfoques jerárquicos centralistas.

- Aprender y crecer a partir de la experiencia proporcionada por el trabajo.

- Establecer una relación de liderazgo consultivo más que una relación de subordinación.

\subsubsection{Aptitudes.}

Las aptitudes que recogemos actúan como factores de éxito en el modelo de dirección-supervisión que planteamos. Se basan en las formuladas por Richard E. Boyatzis ${ }^{28}$, Amparo Porcel ${ }^{29}$ y Claudine Plenchette-Brissonnet ${ }^{30}$, incluyendo algunas propuestas del autor.

27 PORCEL, A. y VÁZQUEZ, C. (1995), op. cit. pp. 209.

28 BOYATZIS, Richard E., The competens Manager. Ed. Wiley. New York, 1982, citado en PORCEL, A. y VÁZQUEZ, C. (1985), op. cit. pp. 214-215.

29) PORCEL, A. y VÁZQUEZ, C. (1995), op. cit. p. 215.

30 PLENCHETTE-BRISSONNET, C. (1987), op. cit. pp. 68-74. 
1. Alta capacidad de EXIGENCIA. Un grupo humano sin un líder que practique la exigencia hacia sí mismo y hacia los demás, acabará convirtiéndose en un grupo de incompetentes o en un asilo de burócratas, que sólo trabajan para su propia comodidad y beneficio.

2. CONFIANZA interna y externa y DOMINIO DE SÍ MISMO. Es fundamental que el director tenga confianza en sí mismo, en sus habilidades y en sus conocimientos. Al mismo tiempo, ha de generar confianza en sus colaboradores para optimizar su autonomía y la facultad de juicio propio del trabajador.

La persona con confianza y dominio de sí mismo tiende a aplicarse el concepto de coste-beneficio a sí mismo, al grupo de trabajo y a la organización en general, antes que expresarse o actuar sobre la base de sus necesidades o deseos personales.

3. VISIÓN más amplia y profunda que el resto de trabajadores para:

- Conducir a metas más exigentes.

- Ofrecer seguridad y mover a innovar.

- Romper con la rutina.

4. EMPRENDEDOR. Consiste en analizar constantemente la manera de aprovechar todas las oportunidades que ofrece el cambio, minimizando los efectos de los problemas.

5. FORMADOR. Para lograr mayores objetivos es necesario un mayor grado de formación teórico-práctica, unos conocimientos superiores y una mejora permanente de habilidades.

6. CONTROL POSITIVO. Se trata de un control preventivo o anticipativo que establece parámetros de control antes de que aparezcan los errores.

7. OBJETIVIDAD. Es la habilidad para mantenerse relativamente ecuánime sin dejarse influir por excesivos prejuicios o perspectivas personales. Este factor facilita en mayor medida la consideración de los puntos de vista de los demás.

8. FRANQUEZA. Los supervisores eficientes demuestran tener un alto grado de espontaneidad o habilidad para expresar con libertad, facilidad y seguridad sus sentimientos y emociones.

9. Utilización del PODER INDIVIDUAL. Consiste en el uso de la influencia para obtener obediencia.

10.Utilización del PODER DEL GRUPO. Es el uso de las formas de influencia como las alianzas, las redes, las coaliciones y los equipos para llevar a cabo el trabajo. Las personas que usan el poder socializado tienden a sentirse miembros de un equipo o grupo.

11.MODELAJE de la actuación. Los supervisores acostumbran a su- 
pervisar de la misma forma como ellos son supervisados; y de la misma forma que ellos traten a los miembros del equipo, así actuará el equipo.

12. ACTUAR para integrar las necesidades de producción del servicio con las necesidades socioemocionales de los trabajadores, equilibrando los objetivos del Centro de Servicios Sociales con el ánimo de los profesionales, haciendo las demandas de tareas de acuerdo con los intereses de los miembros del grupo, equilibrando tareas más administrativas e instrumentales con otras más conceptuales, creativas, etc.

13.Ser ANIMADOR DEL EQUIPO. Actuar como garante de la consecución de los objetivos del equipo. Esta aptitud será la que conformará su papel y caracterizará su tarea, sobre todo en las reuniones de equipo.

\subsubsection{Conocimientos.}

El primer conocimiento de este mando medio es el del MANAGEMENT, el de la dirección orientada hacia el trabajo bien hecho y hacia el apoyo a los trabajadores, preocupado por su propia formación permanente y la del equipo de trabajo, y que actúa de forma altamente motivante.

1. Técnicas de MOTIVACIÓN.

Tan importante es motivar a los trabajadores como eliminar los elementos desmotivadores que existen en el área de trabajo.

2. Técnicas de DELEGACIÓN.

La delegación es un instrumento importante para practicar la formación en el puesto de trabajo y para estimular el crecimiento en conocimientos y en responsabilidad de los trabajadores. También es necesaria para eliminar de la línea directiva trabajos de otros niveles que son necesarios, con el fin de disponer del tiempo preciso para las tareas directivas propiamente dichas.

3. Técnicas de GENERACIÓN DE OBJETIVOS en grupo.

4. Técnicas de TRATAMIENTO DE LA INFORMACIÓN.

El director debe dominar la INFORMACIÓN, es decir, la capacidad de sintetizar, extraer y hacer visibles los datos más importantes cuyo análisis servirá de soporte para la toma de decisiones, distinguiendo especialmente la información más útil para el control anticipativo del trabajo.

5. Conocimientos globales de la ORGANIZACIÓN.

Debe poseer un conocimiento general de la organización, y una comprensión global de todas las funciones que se desarrollan en la 
misma, con el fin de facilitar la integración del Centro de trabajo en los objetivos generales de la organización.

6. Conocimientos de las TECNOLOGÍAS de su área de trabajo.

Ha de poseer un buen conocimiento de todas las tecnologías que se precisan en su centro de trabajo. Ello no impide que en algún aspecto puntual y específico, otro trabajador tenga mayores conocimientos.

7. Técnicas de ORGANIZACIÓN MODERNA y de PRODUCTIVIDAD.

Con el fin de aumentar la productividad y los resultados, el director se verá obligado a optimizar constantemente los procesos que dirige. Para ello necesita conocer las técnicas modernas de organización, los sistemas de análisis de tiempos y métodos, así como la racionalización de los procesos. Además, precisa explorar nuevos sistemas de recompensas, reconocimiento profesional y desarrollo profesional.

8. APRENDER a aprender.

Aprender constantemente. Reaprender aspectos olvidados o mal aprendidos. Desaprender el trabajo rutinario, las decisiones basadas sólo en la experiencia, los modos de actuar de la organización jerárquica piramidal y el trabajo individual frente al trabajo en equipo.

\section{III.APORTACIONES DESDE EL TRABAJO SOCIAL A LA DIRECCIÓN DE ORGANIZACIONES Y EQUIPOS DE TRABAJO}

El Trabajo Social como disciplina y como profesión ${ }^{31}$ aporta a la dirección de organizaciones y de equipos de trabajo un sistema integral de abordaje de la realidad, en este caso, de la realidad de la organización, en el que destacamos:

a. El apoyo de una Teoría sistematizada en el ejercicio de la profesión $^{32}$.

b. El uso de un Método sistemático de trabajo.

c. La orientación de sus actuaciones según un Código Internacional de Deontología Profesional ${ }^{33}$, que recoge los principios éticos bá-

31 Estta doble dimensión del Trabajo Social es planteada por BÁÑEZ TELLO, T., "Situación profesional a la que nos enfrentamos hoy", en DI. Aportes desde el Trabajo Social. N. $4 / 5$ (Actas de las Jornadas de Trabajo Social 1995). Colegio Oficial de Diplomados en Trabajo Social y Asistentes Sociales. Alicante, 1995. p. 85.

32 Este elemento y la existencia de un código de ética son esñalados entre los atributos esenciales de una profesión por GREENWOOD, E. (1996), Atributes of a profession.

3. Aprobado por la Asamblea de la Federación Internacional de Trabajadores Sociales en julio 
sicos de la profesión, recomienda procedimientos en situaciones de dilemas éticos, y aborda la ética en las relaciones derivadas del ejercicio de la profesión.

d. Su vinculación y dependencia respecto a los Modelos de Política Social en cuyo marco los trabajadores sociales ejercen su activi$\mathrm{dad}^{34}$.

Acostumbramos a referirnos a este sistema de acercamiento, conocimiento e intervención con la realidad sólo desde la perspectiva de las intervenciones directas que desde las organizaciones de bienestar social realizan los trabajadores sociales con individuos, familias y/o grupos. Sin embargo, este sistema también conserva su vigencia si consideramos la intervención indirecta que realizan los trabajadores sociales a través de funciones gerenciales o de dirección y supervisión de profesionales y organizaciones ${ }^{35}$.

Como aspectos más destacados de este sistema podemos señalar los que siguen y lo singularizan:

- Se basa en el trabajo con personas con necesidades y conflictos, individual o grupalmente considerados. En esta consideración se incluyen el equipo de trabajo y sus miembros.

- Mantiene una actitud de respeto a los valores, ideologías, conductas, etc., de los miembros del equipo de trabajo.

- Sigue criterios de globalidad en el análisis y abordaje de los problemas y necesidades de una organización, puesto que éstos forman parte de una dinámica compleja que ha de considerarse de manera conjunta.

- Pretende la integración de programas, servicios, actividades, profesionales y equipamientos en un todo coordinado que es la organización, y en nuestro caso, el Centro Social.

- Con visión anticipatoria frente a problemas y necesidades de los grupos humanos y la organización, actúa para la prevención de conflictos y dificultades internas y con el entorno.

de 1994 y donde se integran, revisados, documentos anteriores de 1976 y 1990: "La Etica del Trabajo Social: Principios y Criterios". F.I.T.S. Oslo, 1994.

i4 ROSSELL, T., "La formación para el Trabajo Social". VII Congreso Estatal de Trabajadores Sociales y Asistentes Sociales. Barcelona, 1992. Citada por BÁÑEZ TELLO, T. "La formación en el Trabajo Social", en Revista de Servicios Sociales y Política Social N. 30 . Consejo General de Colegios Oficiales de Trabajadores Sociales y Asistentes Sociales. Madrid, 1993. p. 150 .

35 Con relación a la intervención directa / indirecta, nos remitimos al "Dictamen sobre definicion de objetivos y funciones de profesionales" elaborado por el Consejo General de Colegios Oficiales de Trabajadores Sociales y Asistentes Sociales y publicado en la Revistu de Servicios Sociales y Politica Social N. ${ }^{\circ} 30$. Consejo General de Colegios Oficiales de Trabajadores Sociales y Asistentes Sociales. Madrid, 1993. pp. 9-11. 
- Fomenta la participación del equipo y sus miembros en la toma de decisiones y en la resolución de conflictos.

- Se orienta hacia las potencialidades/capacidades de los trabajadores. El arte de la dirección pasa por saber motivar e impulsar a los trabajadores al ejercicio de sus potencialidades profesionales en el contexto organizacional. Este espacio de crecimiento es la supervisión y la formación continuada.

- Por último, se orienta hacia la autonomía de los profesionales. El director actúa como motor y como apoyo para el trabajo autónomo de los profesionales en la organización. Para ello es fundamental el incremento de la confianza recíproca y la elevación del nivel de delegación de tareas hacia los trabajadores como consecuencia directa de la propia labor directiva. Esto no significa el «abandono del profesional», sino el acompañamiento continuo pero oculto y la actuación sólo cuando lo demande el profesional o las decisiones exceden de su ámbito competencial.

\section{BIBLIOGRAFIAA}

BÁÑEZ TELLO, T. "La formación en el Trabajo Social", en Revista de Servicios Sociales y Política Social $n^{\circ} 30$. Consejo General de Colegios Oficiales de Trabajadores Sociales y Asistentes Sociales. Madrid, 1993.

BÁÑEZ TELLO, T., "Situación profesional a la que nos enfrentamos hoy", en Dí. Aportes desde el Trabajo Social. $N^{\circ} 4 / 5$ (Actas de las Jornadas de Trabajo Social 1995). Colegio Oficial de Diplomados en Trabajo Social y Asistentes Sociales. Alicante, 1995.

BUENO ABAD, J.R., Servicios Sociales: Planificación y organización. Ed. Mestral Llibres. València, 1988.

CAMPANINI, A. y LUPPI, F., Servicio Social y modelo sistémico. Ed. Paidós. Barcelona, 1991.

Curso sobre Mandos Medios. Ayuntamiento de Alicante, 1996. Materiales policopiados.

Consejo General de Colegios Oficiales de Trabajadores Sociales y Asistentes Sociales, "Dictamen sobre definición de objetivos y funciones profesionales", en la Revista de Servicios Sociales y Política Social n ${ }^{\circ} 30$. Consejo General de Colegios Oficiales de Trabajadores Sociales y Asistentes Sociales. Madrid, 1993.

Federación Internacional de Trabajadores Sociales, "La Ética del Trabajo Social: Principios y Criterios". F.I.T.S. Oslo, 1994.

GARCÍA HERRERO, G., Centros de Servicios Sociales. Conceptualización y desarrollo operativo. Ed. Siglo XXI. Madrid, 1988. 
GARCÍA HERRERO, G. Y RAMÍREZ NAVARRO, J.M., Los Nuevos Servicios Sociales. Síntesis de conceptos y evolución. Ed. Certeza. Zaragoza, 1992.

GARCÍA ROCA, J. Público y Privado en la Acción Social. Del Estado de Bienestar al Estado Social. Ed. Popular. Madrid, 1992.

KADUSHIN, A. Supervision in social work. Columbia University Press. New York, 1985.

LÓPEZ CÁBANAS, M. Y GALlEGO GALlEGO, A., "Análisis organizacional y propuestas de desarrollo en los Servicios Sociales Comunitarios", en III Jornadas de Intervención Social. Tomo 1. Ed. INSERSO. Madrid, 1993.

MINTZBERG, Henry, La estructuración de las organizaciones. Ed. Ariel. Barcelona, 1995.

NICHOLS, J. Y CAVE, C., "Supervisión: Algunos principios y consideraciones para la práctica", en Revista de Servicios Sociales y Política Social $n^{\circ} 25$. Consejo General de Colegios Oficiales de Trabajadores Sociales y Asistentes Sociales. Madrid, 1992.

PEIRÓ, J.Ma Y MEDINA, M., "Aspectos psicosociales de la gestión de organizaciones de Servicios Sociales", en IV Jornadas de Intervención Social. Tomo 2. Ed. INSERSO. Madrid, 1996.

PLENCHETTE-BRISSONNET, C., Mètode de Treball en Equip. Ed. Pòrtic/ INTRESS. Barcelona, 1987.

PORCEL MUNDO, A., "La supervisión en Servicios Sociales", en Revista de Servicios Sociales y Política Social $n^{\circ} 25$. Consejo General de Colegios Oficiales de Trabajadores Sociales y Asistentes Sociales. Madrid, 1992.

PORCEL, A. Y VÁZQUEZ, C., La supervisión. Espacio de aprendizaje significativo. Instrumento para la gestión. Ed. Certeza/INTRESS. Zaragoza, 1995.

VILLALBA QUESADA, C. "Redes sociales: Un concepto con importantes implicaciones en la intervención comunitaria", en Intervención Psicosocial. Vol. II. $N^{\circ}$ 4. Madrid, 1993 


\section{EL PARADIGMA HUMANISTA COMO SUSTANCIA DEL TRABAJO SOCIAL \\ EL TRABAJO SOCIAL Y EL PARADIGMA HUMANISTA DIALÉCTICO}

Alternativa de reorganización teorética y metodología del trabajo social profesional.

\section{ENRIQUE DI CARLO}

Equipo E.I.E.M.

Universidad Nacional de Mar del Plata. Argentina.

\section{INTRODUCCIÓN}

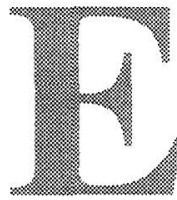

1 trabajo social profesional ha crecido, llamativamente, dentro de un "campo minado". En su despliegue cotidiano siempre estuvo enfrentado a una crisis (económica, social, cultural, política, etc.).

Por otra parte, es una profesión, característica de la sociedad contemporánea, que tiene la especial función de trabajar "cara a cara" con la gente y sus problemas. No cuenta, por la naturaleza de su hacer con elementos sofisticados (verbales, lógicos o materiales) para ejercer su acción, como pueden tenerlos el médico o el psicólogo, por ejemplo.

Está, para expresarlo metafóricamente, "en primera línea de fuego", con capacidades metodológicas, su inteligencia y los conocimientos sobre el hombre y la sociedad que ha adquirido formativamente. Cuenta complementariamente con recursos de la comunidad, aunque cada vez menos importantes.

La clásica defensa burocrática, "su caso será estudiando", tampoco le pertenece, tanto por la variedad social de sus misiones, como por la exigible identificación con el demandante.

Tampoco debe caer en la otra actitud burocrática, aplicando el "no me cuente Ud. su caso", como una actitud que se refugia en las normas rígidas que imponen muchas veces las políticas sociales institucionales (Demetrio Casado, 1981).

La situación profesional siempre se materializa, en esencia, de la siguiente manera: allí está el otro que me demanda y yo que debo responderle. Nada más ni nada menos. 
Los grados de evolución y maduración del trabajo social profesional son diversos de acuerdo al área considerada, y éste no es el tema de la presente exposición.

Entiendo que, más allá de las peculiaridades de cada lugar y tiempo, el trabajo social profesional tiene logros y obstáculos comunes, probablemente provenientes de los mismos condicionantes generales. Consideremos algunos a continuación.

\section{INSUFICIENTE INTEGRACIÓN TEORÉTICA.}

1. Comparte, con el resto de las ciencias sociales, la limitación de las elaboraciones teoréticas disponibles y las fuertes rupturas ideológicas que contiene su comunidad científica. Determinados prejuicios ideológico-políticos han establecido hasta hoy fracturas muy grandes, lo que conspira contra la constitución de una identidad profesional razonablemente admitida por todos.

2. Las elaboraciones teóricas específicas existentes no son suficientemente tenidas en consideración, volcándose, generalmente, la reflexión a comprensiones o técnicas de campos afines.

En muchos casos, dichas comprensiones o técnicas, aún siendo interesantes y enriquecedoras, al no ser reconvertidas (E. Greenwood) al marco de la profesión, pierden sentido y además lo desvirtúan.

3. Las teorizaciones sociales del servicio social son casi siempre volcadas al auditorio interno $y$, por lo tanto, no presentan su aporte (y eventual polémica) a las preocupaciones muchas veces irresueltas, del resto de las ciencias sociales y humanas.

4. También en el plano interno se carece del ejercicio maduro y franco de confrontaciones teóricas, sin las cuales el control del progreso científico dentro del área se hace muy dudoso. Es bastante normal, que distintas visiones profesionales convivan desconociéndose mutuamente o que se conviertan en luchas por el poder institucional.

\section{III.UNA PRÁCTICA TRANSFORMADORA.}

Aunque la comprensión y explicación de los fenómenos sociales constituye una de las motivaciones del trabajo social, su misión principal es la acción de intentar resolver problemas sociales y propiciar cambios mejoradores del sistema de solidaridad existente en una sociedad. Esto es lo que muchas veces, ante todo desde lo externo, produce que la práctica teorética del trabajo social se confunda con su 
programa concreto de acción. Se la puede fácilmente llegar a considerar una simple práctica social.

Por otra parte, muchas veces, la práctica profesional se hace tan exigente por las situaciones mismas a atender, que la elaboración teórica que debe apoyarla queda elíptica; y, en otros casos, peligrosamente, directamente, no existe.

Estos factores considerados constituyen simplificaciones del trabajo social que lo desvirtúan en su realidad y en su imagen profesional. La versión asistencialista del trabajo profesional, muy probablemente, proviene de estas desviaciones. Se lo comienza a considerar entonces, como un administrador de recursos, olvidándose su dimensión científica y transformadora.

Cabe notar, además, que, cuando el trabajador social asume su verdadera actividad y busca incidir en los cambios necesarios a los individuos y a la comunidad, generalmente, encuentra resistencias y oposiciones de distinto tipo. Es siempre mucho más tranquilizador para el sector dominante de la sociedad y para una mentalidad conservadora, que puede estar muy difundida, a veces, que un "técnico" responda a una necesidad con un recurso cualquiera de los disponibles, en lugar de trabajar para que el necesitado encuentre su ser como persona, se descubra igual a todos y sujeto de derechos.

Salvo en condiciones políticas excepcionales de encuadre, donde exista un dinamismo social orientado hacia una democracia cada vez mayor, la acción profesional creadora no es muy bien recibida y debe luchar por su espacio.

"La democracia política y las libertades civiles deben luchar por la conservación de cada pulgada de terreno que ganan; por lo tanto, nadie puede esperar que el camino hacia el bienestar social sea llano. Mientras se piense que "asistencia" significa sólo una benevolencia fácil e incidental; mientras sea el instrumento de un gobierno autoritario, en lo político o en lo industrial, no provocará mucha oposición. En cambio, cuando constituya el esfuerzo de hombres libres que intenten crear sus propias condiciones de bienestar, su progreso será lento y fatigoso." (Gordon Hamilton, 1940).

La defensa de su función genuina es, en general, asumida por la profesión, dentro de muchas dificultades. Sin embargo, como toda lucha, no tiene garantizado el éxito final.

Muchas veces, las dificultades son muy grandes y también en muchos casos se termina aceptando la invitación asistencialista. Como expresaba Aristóteles, la virtud es una práctica (habitus) que, cuanto 
más se ejerce, más se aclara en su sentido inmanente. Inversamente, podemos agregar, nosotros, una práctica caída y pobre, solamente puede producir teorías pobres y justificatorias.

Tales son algunos de los riesgos que afectan a la profesión y a los resultados que la parte sana de la sociedad espera de nuestra acción.

Queremos concluir esta breve introducción expresando que, a nuestro juicio, dentro del campo de las ciencias sociales, el servicio social es la disciplina que mejor ha conservado el ethos humanista igualitario. Pensamos que es hora de que esta orientación humanista, tan poderosa en la vida social moderna y tan desvirtuada ahora, se abra paso racionalmente posibilitando lo que podría llamarse una re-fundación del trabajo social profesional.

Considero, junto al grupo al que pertenezco (EIEM), que, para que esto pueda darse, debemos en parte retomar a nuestros clásicos específicos, a la luz de las conquistas actuales del pensamiento y de la experiencia del siglo.

Creo que la crisis actual de la Sociología proviene, ante todo, de cierta incapacidad explicativa motivada por sus bases paradigmáticas, y que esta circunstancia no ha afectado al trabajo social por su fidelidad teórica al humanismo.

\section{IV.EL HUMANISMO Y LAS CIENCIAS SOCIALES.}

Dejaremos de lado el mal uso en que ha caído el término humanismo. Todo el mundo se declara hoy día humanista, sin tener, generalmente, bien claro lo que esto significa. También, hay que reconocerlo, el concepto de humanismo sirvió muchas veces de refugio para el conservadurismo social.

Volviendo al tema, corresponde señalar que, a nuestro juicio, uno de los errores más básicos de las ciencias sociales es el de haberse constituido como un campo del saber prescindente de las valoraciones como motivos muy centrales de las acciones y de la interacción humana.

De acuerdo a esa visión de las cosas, la realidad humana entera y el hombre dentro de ella con sus capacidades y búsquedas activas, para ser "científicamente relevantes" son tomados como hechos y datos neutros.

"En segundo lugar, hay que advertir que, por muy complicada que sea la relación entre los medios y los fines nunca será más racional de acuerdo con el sentido que hemos dado a la palabra, perseguir un fin en vez de 
otro. Con otras palabras, la palabra racional no puede aplicarse a los motivos independientemente de las creencias. No se puede decir, por ejemplo, que es más racional dedicarse a mejorar la fertilidad del suelo, que dedicarse a destruirla, ambicionar la felicidad universal, que ambicionar la miseria universal o fomentar las buenas causas que fomentar las malas. En cada uno de esos casos el individuo estaría actuando de un modo racional si su conducta respondiera a unas creencias sólidamente fundadas acerca del mejor medio para lograr un fin, conclusión que habría que aplicar sin mirar a la naturaleza de los fines". (Gipson, Q.)

De esta manera, el humanismo quedaría fuera de las ciencias sociales, debiéndoselo considerar, de acuerdo a este enfoque, como una teoría filosófico-social sin otra justificación más que la preferencialirracional.

Hace ya algunos años escribíamos lo siguiente:

"Nosotros debemos tomar posición con respecto a este problema. Si pueden o no haber criterios racionales, sometibles a una crítica, acerca de lo deseable en una práctica social, es decir, acerca de lo que es una vida social buena y satisfactoria. Se ve desde ya que de la contestación a esta pregunta depende la respuesta de si pueden haber criterios racionales para una práctica del Servicio Social". (di Carlo, E., 1983).

Por otra parte, la conocida afirmación: "Por consiguiente debemos considerar los fenómenos sociales en sí mismos, separados de los sujetos-conscientes que se los representan; es decir estudiarlos desde afuera, como a cosas exteriores pues con este carácter se presentan a nosotros" (Durkheim, 1977), expresa bastante claramente el espíritu de una ciencia que rechaza la interpretación de la vida y los acontecimientos sociales en términos humanos.

Igualmente, encontramos una concordancia en este punto, en los esfuerzos teóricos de Max Weber por construir una sociología como "ciencia a-valorativa". Las valoraciones serían respetadas sólo como hechos que se dan, noción bastante difundida.

Más se agrava, a nuestro juicio, el error epistemológico de encare, en las aclaraciones que Durkheim vuelca en el famoso Prólogo de la segunda edición de la citada obra. Nadie puede dejar de compartir la preocupación de objetividad del autor y el cuidado de que la investigación social no se base en prejuicios de cualquier índole y se atenga a los hechos. Sin embargo, no existe ningún cuidado ni ubicación privi- 
legiada que garantice la objetividad de una observación realizada por un científico.

La objetividad alcanzable depende de la posesión de teorías, de la formulación hipotética de explicaciones y del debate intersubjetivo de los hallazgos. Por otra parte, como lo venimos sosteniendo, la interioridad (autodirección racional) no constituye una nota secundaria para los hechos humanos sociales, sino su característica específica. Lo que hace que ellos sean lo que son.

Entiéndase bien que, en nuestra discusión, no nos basamos en una especie de romanticismo por lo humano, que se sentiría lesionado por las tesis antes consideradas. Se trata, para nosotros, aquí, del problema lógico-científico de que no es acertado ni interesante construir un objeto arbitrariamente. $\mathrm{Y}$ entonces hay que comenzar por comprender que la sociedad humana es algo muy distinto a un conjunto corpuscular, por ejemplo.

El programa del positivismo social, que se inició con Comte, se funda en el modelo teórico de la física y pretende crear una "física social". Una forma de investigación que observa a la realidad social en la forma de datos y hechos desde lo externo y "neutralmente". Este estudio de los hechos y sus relaciones (leyes) sería algo independiente de la praxis humana como tal y de las valoraciones que la animan y estructuran.

A nosotros nos parece que, pese a la gran influencia que tuvo y tiene en parte, todavía, este paradigma positivista, se basa en un error y en una simplificación de las cosas. Ni el objeto responde aquí al objeto real, ni la neutralidad del investigador, como ausencia de toda valoración o ideología, son ya sostenibles como hipótesis válidas, desde el actual espíritu crítico alcanzado por la ciencia.

La obra de Carlos Marx es mucho más compleja y contiene algunas interpretaciones de muy difícil refutación. Es indiscutible la inspiración humanista de la primera parte de su obra, para algunos esto es extensible al resto de la misma (E. Fromm, R. Mondolfo). Por otra parte, muchos de sus conceptos están ya integrados al contexto universal de explicación.

Nosotros pensamos que gran parte de la obra de Marx y la de algunos seguidores de renombre $y$, ante todo, su proyección fáctica en el proceso del mundo, expresan un olvido del humanismo y llegan a ser anti-humanistas.

Por otra parte, el marxismo llegó a expresarse como la "única" explicación científica, inaugurando una fractura epistemológica, todavía no superada en muchas conciencias, y que no contribuye al progreso de las ciencias sociales. 
En relación al trabajo social, este paradigma ejerció mucha influencia ante todo en Latinoamérica, principalmente, en la forma del gramscismo.

Pensamos que tuvo el mérito de sacudir a la conciencia profesional frente a rutinas asistencialistas, pero instauró un peligroso corte con las preocupaciones y prácticas cotidianas del hombre, puso en peligro la solidaridad real frente al semejante y desconoció la importancia de la metodología específica transformadora aplicada, propia del trabajo social.

En lo sustantivo, se puede afirmar que, aunque la infraestructura económica contiene aspectos de gran importancia para el hombre y la sociedad, estos aspectos están muy lejos de poder explicar el resto de los fenómenos humanos y sociales.

"Marx no puede entender la metamorfosis del trabajo concreto en abstracto como caso especial de una cosificación sistémicamente inducida de las relaciones sociales, porque parte del modelo del actor que actúa teleológicamente y que, al ser desposeído de sus productos, se ve también privado de la posibilidad de desarrollar las potencialidades de su ser".

"La teoría de la cosificación del capitalismo actual, reformulada en categorías de sistema/mundo de la vida, necesita, pues, ser completada con un análisis de la modernidad cultural que sustituya a la anticuada teoría de la conciencia de clase. El objetivo de ese análisis no sería servir a la crítica ideológica, sino explicar el reconocimiento cultural y la fragmentación de la conciencia cotidiana. En vez de andar ansiosamente tras las evanescentes huellas de una conciencia revolucionaria, su objetivo sería averiguar las condiciones que permitieran la reconección de la cultura racionalizada con una comunicación cotidiana que a menester de tradiciones vivas que la nutran". (Habermas, 1990).

El funcionalismo ,por su parte, se basa en la interpretación de la sociedad como una unidad, cuyas partes (instituciones) están culturalmente armonizadas entre sí para garantizar su desarrollo, perfeccionamiento y la consecución de los medios básicos necesarios a la vida humana. También reconoce el funcionalismo la generación de necesidades asociadas a las básicas, que se incluyen como objeto de las funciones sociales. Las creencias y ritos, por ejemplo, cumplen una función social, reforzando la cohesión del grupo. La noción de anomia es tomada casi exclusivamente en el sentido de lo que entorpece al siste- 
ma, no abriéndose oportunidades para una reflexión sobre el cambio social.

Es innegable la necesidad humana de vivir en una sociedad razonablemente integrada y de cooperar en la producción de bienes a todos necesarios. Sin embargo, a la filosofía propia del funcionalismo le cabe la crítica de todo organicismo. El fin supremo parece ser para el funcionalismo la sociedad, que exige y condiciona compulsivamente al sujeto individual sin chances críticas.

"Bajo el aspecto funcional, los papeles institucionalizados forman el mecanismo merced al cual los tan variados potenciales de la naturaleza humana se integran en un sistema uniforme y global, capacitando a la sociedad y sus miembros para hacer frente a las exigencias de cualquier situación (...) los papeles institucionalizados cumplen dos funciones sumamente importantes: en primer término, la función selectiva gracias a la cual elige entre las posibilidades de comportamiento aquellas que pegan con las necesidades y tolerancias de cierta estructura social, y aparta o corrige a las demás..." (Parsons, T., 1956).

El sujeto humano, la esencia de la sociedad, para esta teoría explicativa, pasa a ser sólo un elemento, interesante, en cuanto contribuye al mantenimiento de lo que se da en el sistema.

El funcionalismo olvida que en el mundo no existe otra instancia de conciencia más que la individual o la individual asociada, que el único testigo y juez válido de que una armonía existe y de que es deseable es la conciencia y no un abstracto-sociedad-que se impondría desde más allá de ella (HABERMAS 1990).

"Si bien, solo algunos pocos son capaces de dar origen a una política, todos nosotros somos capaces de juzgarla". (Popper, K., 1985, citando a Pericles de Atenas).

Nosotros no pensamos que las filosofías o paradigmas considerados (Khun: cosmovisiones) no contengan hipótesis válidas a tener en cuenta, pero parecen no representar las dimensiones científicas que se auto-atribuyen.

La posible construcción científica de las ciencias sociales requiere discusiones más críticas y abiertas, dentro de las cuales no puede faltar el paradigma humanista. 


\section{LA NOCIÓN DE SUJETO}

Sea su alternativa de acción individual, familiar, grupal o más colectiva, es algo reconocido, en el conjunto del servicio social, que lo específico de su actividad es el estar dirigida al hombre como sujeto. Generalmente, se define al objeto profesional como un objeto-sujeto.

Tal centración en el sujeto es lo que hace que el trabajo social se diferencie del asistencialismo y el benefactorismo por un lado y del paternalismo por otro.

Para el trabajador social, el otro al cual se dirige es un ser en sustancia igual a él, es decir, un hombre en debate, más o menos afortunado, con las circunstancias que rodean su existencia.

Este principio de la igualdad humana es un sello característico de la profesión, tanto en lo concerniente a su teoría de la realidad social, como en su organización metodológica. Permite establecer no sólo los principios y los fines, sino también el método comunicativo del trabajo social profesional.

La teoría igualitaria propia de la profesión consiste en el reconocimiento del otro como ser pensante, como ente racional. Un ser que puede hacerse cargo de su vida y que puede, además, darle un sentido moral-social a la misma.

No todos hemos tenido las mismas condiciones materiales y educativas y no todos hemos contado con las mismas chances de desplegar hábitos críticos reflexivos. Es más, determinadas condiciones adversas pueden hasta haber amenazado gravemente el surgimiento o mantenimiento de la capacidad de pensar y comunicarse con otros.

Hoy día hasta se teme que la propia "civilización" nos deshumanice, problema aún más abarcativo que lo que atañe al sujeto marginado económica o existencialmente, con que trabajamos.

$\mathrm{El}$ ejercicio profesional, repetimos, supone que el otro, al cual me dirijo, contiene, real o potencialmente, capacidad de retoma de sí mismo a través del diálogo y la reflexión. Cuando encontramos esta vía cerrada, comprendemos que la situación no pertenece a nuestro ámbito metodológico estricto, aunque siempre podamos colaborar en algo.

Es algo obvio que, en nuestro trato profesional con el otro, incidan y deban tenerse en cuenta aspectos psico-afectivos, sin la consideración de los cuales el vínculo profesional no podría ser establecido ni tampoco podrían ponerse en obra nuevas disposiciones en el atendido. El paso metodológico inicial, por ej., la aceptación del otro en su situación y reacción, reúne ambos aspectos (emocional y racional). Por una parte, la aceptación hace ganar la imprescindible confianza en nosotros al asistido y, por otra parte, hace posible el comienzo del 
análisis de la situación, es decir, que ambos aspectos se dan solidariamente en el proceso, lo que no significa que ambos tengan la misma jerarquía metodológica para el trabajo social.

El encare profesional específico es el de focalizar al sujeto en su capacidad de reflexionar su situación, analizarla y resolverla en la medida de sus posibilidades. Así como el psicólogo pondrá el acento en los aspectos emocionales e inconscientes, el trabajador social lo hace en su dimensión de ser pensante (frónesis).

"Se encuentra el motivo si se examina la manera en que funciona la inteligencia del hombre. El lactante parece equipado en forma menos adecuada que un gatito, un perrito o cualquier otro animalito y su desarrollo mental es mucho más lento. La forma relativamente automática con la cual el animal responde a los estímulos externos sigue caminos bien delineados, es lo que llamamos acciones instintivas. Esto significa que, en el animal, el progreso mental está confinado en un círculo que limita al joven ser y lo hace incapaz de adquirir necesidades progresivas y elevadas. El hombre no está encerrado en este círculo que es reemplazado en él por una espiral. Sus reacciones son mucho más lentas, ya que, desde el comienzo de su carrera, está obligado por una necesidad imperiosa a comparar un concepto con otro y a deducir un tercero, en otros términos debe razonar. Las operaciones del razonamiento y de la formación de las costumbres lo hacen salir del círculo estrecho de las reacciones instintivas para hacer seguir una espiral que se amplia sin cesar con nuevas complicaciones, que agrandan su horizonte y le otorgan la facultad de comunicarse con lo visible e invisible a la vez." (Mary Richmon, 1992).

"Cualquier decisión respecto a lo que ha de ser o hacer, frente al mero ser o hacer a ciegas, requiere la aplicación consciente de las facultades racionales el hombre". (Helen Perlman, 1980).

Toda la bibliografía profesional de base va en esta dirección metodológica. Se destacan, especialmente, por la amplitud analítica de este concepto metodológico, el "Social Diagnosis" de Mary Richmond y el capítulo "El pensamiento en la resolución de problemas" de Helen Perlman (Op. cit.). Un examen más actualizado puede hacerse desde nuestras publicaciones recientes: Enrique Di Carlo y Equipo: "La comprensión como fundamento de la investigación profesional" (Libro Ed. Humanitas, UNMDP, Bs. As., 1995) y "Trabajo social profesional: el método de la comunicación racional" (Idem, 1996/ 97). 
Observamos, entonces, que el trabajo social profesional se ensambla con la tradición filosófica espiritualista-racionalista, que se funda en la autonomía del sujeto como ser pensante y actuante. La hipótesis de base del servicio social es la de que el sujeto social es capaz de reflexionar sobre su situación y desde allí transformar su actitud y disposiciones activas frente a la misma. Si esto no fuera así, si tal posibilidad no existiera, tanto la teoría como la práctica profesional quedarían sin sustancia y sin motivo de actuación.

Para esta reorganización del otro (individuo, grupo o comunidad) por la vía reflexiva, el trabajador social suele utilizar recursos sociales, tanto materiales como profesionales y culturales. Un servicio médico o psiquiátrico, un hogar sustituto, un grupo de referencia, un apoyo económico transitorio o hasta permanente, una beca, una red, una prótesis, etc.

La existencia de recursos disponibles es muy importante para el ejercicio profesional y para la sociedad con necesidades. Pero, pese a desvirtuaciones existentes, el trabajador social está muy lejos de ser un adjudicador de recursos.

$\mathrm{Si}$ alguien, por ejemplo, necesita solamente una silla de ruedas, esto es muy fácil de solucionar, muy claro de resolver si el recurso existe. Nadie puede sostener, para este caso, que hace falta la intervención de un profesional altamente calificado y con especialización científica.

Algo muy diferente sucede cuando la necesidad del recurso viene rodeada de muchos otros factores que comprometen al sujeto humano o cuando el sujeto viene a nosotros con una interpretación de lo que necesita, sin una adecuada captación de sus necesidades y de los determinantes de la misma. Podría sostenerse que estos son los casos más frecuentes para el asistente social.

La reflexión que implica el cambio en la interpretación de las necesidades no es algo fácil de propiciar ni de realizar, y siempre incluye, tácita o explícitamente, la consideración crítica de las valoraciones que orientan a un sujeto dado.

Cuando se trata de reflexionar y modificar la hipótesis, por ej., de la necesidad de ayuda para el pago del alquiler, por la de buscar un trabajo sistemático, capacitarse más o administrar mejor los fondos; cuando en lugar de atender el reclamo muchas veces injustificado, de internar a un anciano en un hogar geriátrico, se propone la reorganización de la red familiar; cuando la pertenencia a un determinado grupo es dañina para alguien y él atribuye sus problemas a la oposición de su familia, etc., para que estas modificaciones se produzcan y sean duraderas es imprescindible la reorganización consciente del cuadro de 
valores y el consecuente cambio en las metas vitales del sujeto involucrado.

Lo que a primera vista y exteriormente solo parecen ser modificaciones "prácticas" de conductas, implican siempre, reiteramos, el costoso esfuerzo de cambiar algunos aprecios y su organización jerárquica (cuadro valorativo), que orientan al sujeto social.

En la mayor parte de los casos, los valores en que busca encauzar al otro reflexivamente el trabajador social son los del tipo que acrecientan la posibilidad de que se asuma como sujeto (apropiación de su yo y del mundo).

Cuando el trabajador social trabaja casi exclusivamente con la moralidad del otro, con sus actitudes sociales y no con recursos, lo expuesto hasta aquí se muestra más nítidamente y sin ningún equívoco. Nos remitimos, como ejemplo paradigmático, al trabajo social con la sordomuda Helen Keller que expone ampliamente Mary Richmond en la Introducción de su libro "Caso social individual". Introducción que concluye así:

"Cuando bajo la palabra enseñanza o servicio social, nos consagramos al servicio de la personalidad -de una personalidad que no es la nuestra-asumimos la tarea más ardua que existe."

"Ci possono essere risposte collettive ai bisogni sociali, ma assolutamente non puó esserci una risposta sociale, né di altri, alla quiestione del desiderio, che é squisitamente soggetiva (non individuale), e que richiede sazi e tempi in cui poter essere articolata, dove anche soggetti normalmente privi di parola possono farsi sentire" (Marzotto, C., 1995).

\section{VI.LA UNIVERSALIDAD}

Desde el ángulo filosófico, el sujeto humano encuentra una de las interpretaciones más acertadas a nuestro juicio, en la teoría de la universalidad.

Esta concepción ha tenido gran influencia sobre el trabajo social profesional desde su inicio y se proyecta hasta nuestros días como una conquista lograda para la estructura teórica de la profesión.

El cartesiano "Pienso, luego soy" inaugura para la conciencia moderna una teoría del hombre según la cual el pensamiento es reconocido como el atributo esencial de la sustancia espiritual, así como la extensión lo es de la sustancia material. 
Esta distinción de base y su enorme influencia cultural deja, por un lado, la tarea de la constitución del sujeto y su mundo sobre bases asumidas (autoconciencia) y críticas. Por otra parte, abre francamente la puerta al programa de la física, como ciencia de la medición. La toma de conciencia del espíritu como espíritu desembruja a la naturaleza que puede ser entonces estudiada como objeto inerte y separado del hombre.

Tanto el Discurso del método, como las Meditaciones metafísicas y las Cartas sobre la moral, son representativas de la toma de conciencia del sujeto humano como sujeto, quedando toda otra alternativa del ser como algo externo, lo que incluye hasta el propio cuerpo ("tengo cuerpo, no soy cuerpo"). La razón es el sentido común en cada uno.

Dentro de la filosofía idealista, es Kant el que desarrolla la antropología más penetrante basada en la idea de universalidad, ya premoldeada desde Descartes.

Para Kant la posibilidad de adoptar puntos de vista generales es constitutiva de la conciencia individual.

La voluntad humana es requerida, por una parte, por los impulsos e inclinaciones (sensibilidad), que representan el ser determinado para la voluntad (heteronomía). El bien supremo está, en cambio, para Kant, en la voluntad buena, es decir, en la voluntad que se rige por la universalidad de la ley racional, que está en cada hombre. Cuando la máxima (principio subjetivo) que decide la acción se basa en el respeto interior a la pura ley racional, prescindiendo de los fines heterónomo, es decir, cuando obro interpretando lo que todo hombre como hombre haría en mi lugar, entonces actúo autónomamente asumiendo mi moralidad potencial. Al tomar como motivo excluyente de la decisión el motivo de la universalidad en mí, que me indica lo que debo hacer y no lo que me conviene hacer, estoy ejerciendo mi libertad en un doble sentido. Soy libre de los mandatos deterministas de la sensibilidad y soy libre porque me someto a ley racional, que es la ley que me doy a mí mismo y que me es propia.

Vemos entonces que la ética kantiana concibe a la autonomía de la voluntad como sujeción a la ley de la universalidad, lo que no significa que para él esto constituya un hecho de experiencia, una certidumbre fundamentalmente empírica. La universalidad es para Kant un principio a priori, que se expresa como imperativo categórico (obligación) para la voluntad libre.

El "debes amar a tu prójimo como a ti mismo" de Mateo, adelanta y expresa exactamente estos mismos motivos.

“... tanto la filosofía natural, como la filosofía moral, pueden tener cada una su parte empírica, porque aque- 
lla debe determinar las leyes de la naturaleza como un objeto de experiencia, y ésta, la de la voluntad del hombre, en cuanto el hombre es afectado por la naturaleza; las primeras consideradas como leyes por las cuales todo sucede, y las segundas, como leyes según las cuales todo debe suceder, aunque, sin embargo, se examinen las condiciones por las cuales muchas veces ello no sucede." (Kant, 1990).

El imperativo categórico es formulado por Kant de la siguiente manera: "obra sólo según una máxima tal que puedas querer al mismo tiempo que se torne ley universal".

La capacidad humana de regirse por fines generales desde la autonomía de la voluntad es lo que da al hombre su dignidad, lo convierte en un fin en símismo.

Mientras que las cosas y los animales están determinados por legalidades externas (inconscientes), el hombre puede ejercer su libertad. Es por esta misma razón que, jurídicamente, cuando no posee en forma accesible esta condición racional, el hombre mismo se hace no imputable de delito.

"Los seres cuya existencia no descansa en nuestra voluntad sino en la naturaleza, tienen, empero, si son seres irracionales, un valor meramente relativo, como medios, y por eso se llaman «cosas», en cambio, los seres racionales llámanse «personas» porque su naturaleza los distingue ya como fines en sí mismos, esto es, como algo que no puede ser usado meramente como medio, y, por lo tanto limita en ese sentido todo capricho, y es un objeto de respeto." (Kant, 1990).

Nos parece casi innecesario, para el lector entendido, realizar un examen detallado de la relación entre los conceptos expuestos y la profesión de asistente social. Por otra parte, ya hemos ofrecido, en los parágrafos anteriores, nuestros criterios epistemológicos y metodológicos acordes con la teoría de la universalidad (humanismo igualitario).

Nos pareció importante la retoma explícita de esta tradición porque, en algunos casos, se la da tan por supuesta que se la olvida y, en otros, se la considera poco relevante frente a la pretensión de los llamados planteos "técnicos". Lo que más generalmente se puede perder de vista es hasta qué punto el humanismo condiciona y hace posible una práctica metodológica de categoría profesional para el trabajador social.

La idea del hombre como un ser respetable por su dignidad de ser 
persona, el derecho de todo sujeto a realizarse y a construir su vida y la de la comunidad a la que pertenece, la autonomía de la conciencia, la solidaridad y la justicia, son valores intrínsecos de la filosofía profesional y principios organizadores de su práctica. Los podemos encontrar dentro del trabajo social profesional, en casi todos los niveles de su desarrollo y, repetimos, nos parece innecesario desarrollarlos aquí.

Sin embargo, pensamos que la idea tan característica del trabajo social, la autodeterminación, merece algún examen a la luz del concepto de universalidad.

La autodeterminación que nosotros buscamos propiciar, a través de la comunicación reflexiva con los sujetos tratados, no es la de la arbitrariedad de la conciencia que se cree libre cuando puede elegir "cualquier cosa". En el trabajo social, se trata de una capacitación vital y moral del otro para el ejercicio autónomo de su existencia, dentro de la cual no toda forma de ser o convivir da lo mismo. Buscamos conscientemente que el otro descubra y ejerza su ser persona frente a sí mismo, los demás y la comunidad, de allí que la tarea no es sencilla.

No nos interesan los "moralismos", ni la sujeción servil a las pautas "dominantes" en el medio. Pero pertenece sustancialmente a nuestros propósitos la orientación valorativa que se basa en el respeto, la solidaridad, la integridad, la comunicación y la cooperación interhumanas. Involucrar al otro en esta dirección implica a su vez ser capaces de ejercer una metodología basada en esos mismos valores. Fines y medios son solidarios.

La forma en la que Gisela Konopka analiza los aspectos señalados nos parece tan expresiva y convincente que no resistimos la tentación de reproducirla, en una larga cita de sus aspectos centrales.

\section{VII."VALOR BASE DEL TRABAJO SOCIAL DE GRUPO"}

“Qué puedo saber?”

"¿Qué debería hacer?"

"¿Qué puedo esperar?"

"Llamo al mundo un mundo moral en tanto esté de acuerdo con las leyes de la ética, lo que en virtud de la libertad de los seres razonables puede ser y lo que de acuerdo con las necesarias leyes de moralidad debería ser".

“...«Justicia», «responsabilidad» y también, aunque menos definido, "higiene mental" son valores éticos, esenciales del trabajo social por su conexión con las relaciones humanas. 
«Justicia» significa aceptación básica de la dignidad de la persona, independientemente de cualquier atributo específico, como raza, sexo, «status» económico, cultura, fuerza física, etc., que pudiera diferenciarla de los demás. Esto no quiere decir que todas las personas sean iguales y deban ser tratadas de la misma manera, sino que tienen derecho a la misma consideración, el mismo afecto y la misma oportunidad.

"Responsabilidad» es el reconocimiento de la interdependencia de los seres humanos, de la aceptación de sus derechos, así como de los propios, y del concepto de hermandad entre todas las gentes (la idea de que cada uno es guardián de su hermano).

«Higiene mental» significa la comprensión de que la persona precisa gozar de un sentimiento de satisfacción y fuerza interior para poder "dar» a los otros.

Estos valores «a priori» constituyen los axiomas de la práctica profesional y están incluidos en los sistemas de valores de un gran número de culturas humanas. Las grandes religiones orientales y occidentales los han incorporado, siendo aceptados también por los humanistas. No pertenecen solamente a una profesión o disciplina, sino a todos los miembros de cualquier sociedad.

Las profesiones que trabajan con individuos han de tener siempre en cuenta estos valores, porque tratan constantemente, como dijo en una ocasión Eduard $C$. Lindeman, "con hechos imbuidos de valores». A veces los trabajadores sociales han vacilado en emplear los términos «bien» $y$ «mal», «bueno»y «malo» cuando se refieren al comportamiento humano, evitando «emitir juicios». Sin embargo, debemos de enfrentarnos con el hecho de que en la actualidad utilizamos estos juicios en cualquier forma de nuestro trabajo, ya sea con individuos, con clientes o con grupos.

¿Por qué enseñamos a un joven a no robar coches? ¿Es únicamente para evitar que sea detenido?. En ese caso, quizá le interese más alguien que pueda enseñarle a robarlo mejor. ¿Por qué exigir un trato, humano para los pacientes de un manicomio? Muchos son incurables, y la forma más cómoda de cuidarles es acogerles en una institución grande y olvidarles después. La dignidad de cada individuo es la única respuesta a estas inquietudes. La idea de una práctica del trabajo social «ausente de valores» apenas ha existido nunca, y cuando se ha de- 
fendido ha sido más bien un intento para evitar una imposición arbitraria de los mismos. Desde los comienzos, esta idea ha perseguido la práctica del trabajo social, especialmente en el campo de la asistencia pública, cuando personas procedentes de una clase media acomodada intentaron imponer su forma de vivir a otros afectados por la pobreza o una vida en disconformidad total con sus costumbres. El trabajador social tuvo mucho que aprender para poder comprender a la gente y apreciar las diferencias de cultura existentes entre ellos, conservando al mismo tiempo una visión clara de los valores éticos. Eduard C. Linderman, uno de los pocos filósofos en el trabajo social, colaboró aportando su distinción entre los valores primarios y los secundarios, representando los primeros exigencias morales básicas y surgiendo los segundos de costumbres culturales que cambian con el tiempo y el lugar. En la práctica no pueden separarse y se reconocen dificilmente.

Entre los trabajadores sociales existe un total acuerdo sobre el origen de los dos valores primarios: la dignidad de la persona humana y la responsabilidad que tienen unos hacia otros.

Los trabajadores sociales de sólida formación religiosa les consideran como valores derivados de un ser espiritual: de Dios. Aquellos de formación más fría los conceptúan emanados de la ley ética. A pesar de esta diferencia de opinión en cuanto a su origen, la aceptación de estos valores como bases de la profesión es general y son reconocidos como absolutos y axiomáticos para su práctica.

También los profesionales están de acuerdo en ciertas traslaciones de estos valores a la práctica, sin discriminación del método que emplean:

1. Todos los trabajadores sociales de grupo están de acuerdo en la importancia de las relaciones positivas entre gentes de distinto color, credo, nación de origen y clase social. Esta es una meta importante en la práctica del trabajo de grupo, aun allí donde se encuentre bajo la protección de alguna secta.

Una persona que practique el trabajo social, empleando el método de trabajo de grupo en una agencia católica, protestante o judía, hará siempre un esfuerzo para que los miembros aprendan a considerar y a vivir con aquellos de otras religiones, siendo una de 
sus principales tareas transformar la cultura de la discriminación racial mediante la enseñanza de la aceptación interior de personas de distintos medios o procedencias (aplicación del valor de la «dignidad de cada individuo»).

2. Todos los trabajadores sociales de grupo están de acuerdo con el valor de la cooperación. En la estructura de una sociedad fuertemente competitiva, el método del trabajo social de grupo incluye en forma consciente la experiencia positiva de cooperar con los demás (la lucha del hombre por obtener el reconocimiento de su individualidad puede destruir el valor de la «responsabilidad hacia los demás»).

3. El sistema de valores del trabajador social de grupo incluye la importancia de la iniciativa individual, que ha de hacer resaltar en el marco de una cooperación creadora. (Aplicación de los dos valores primarios).

4. Otro valor aceptado, y que se deriva de los fundamentales, es el de la libertad de participación. La dignidad del individuo tiene que reflejarse a través de su libertad en expresar sus pensamientos, sus ideas y su derecho a participar en los asuntos concernientes a él y a su comunidad. Este concepto es básico para el método del trabajo de grupo porque le ayuda a distinguir al que lo practica del que entretiene, o del líder autoritario, roles legítimos en otras aspiraciones humanas, pero que han de evitarse en el proceso de ayuda del trabajo social. Este valor aumenta también la necesidad de uno de los procesos más difíciles del trabajo social de grupo como es el de estimular la toma de decisiones en cada individuo. Es competencia del trabajador social de grupo, y una de sus más satisfactorias realizaciones, el ayudar a los individuos a participar de una situación dada en distintas etapas de desarrollo y conforme su capacidad individual.

5. Asimismo existe acuerdo en el valor que se da a la intensa «individualización en el grupo». Una de las principales características del método de trabajo social de grupo es la individualización. Aunque algunas actividades puedan llevarse a cabo sin ella, no pertenecen a la práctica del trabajo social de grupo.

La satisfacción emocional que siente la persona a través de acontecimientos en los que se participa en masa puede tener un importante lugar en la sociedad humana, 
aunque, como se indica anteriormente, no entre dentro del método de trabajo social de grupo que incluye siempre la individualización." (Konopka, G., Trabajo Social de grupo, pág. 87 y ss., 1968).

Hace muy poco tiempo, realizábamos nosotros una reflexión sobre el diagnóstico profesional, en la cual se expresaba esta copertenencia sustancial entre hechos y valoraciones que guía a la profesión.

"El trabajo social pone en obra un tipo de acción (plan de acción) para la resolución de los problemas sociales en un medio dado, que se basa en la investigación cuidadosa del problema y en la formación de un juicio fundado (diagnóstico), sobre sus causas determinantes controlables. Si no existe tal juicio fundado, no existe acción consciente y eficaz.

Esto vale tanto para el trabajo a nivel individualizado, como para el de grupos y comunidades. Y rige también, tanto cuando se busca solucionar un problema existente, como cuando se estudia un plan preventivo o una medida transformadora en la sociedad.

El examen racional de los problemas sociales, tiene para el asistente social su desenlace más característico, en la implementación de acciones prácticas inteligentes y forma parte de ellas. Sin la actividad diagnóstica, el trabajador social no sabría a qué atenerse, ni con qué bases justificaría un plan determinado y no otro cualquiera.

Los problemas sociales se nos ofrecen casi siempre como un conjunto de problemas y con bastante ambigüedad. Todo parece ser causa de todo cuando comenzamos a examinar una situación problemática y si no se ejerce la capacidad de entrar en el problema, analizarlo y comprenderlo, nos quedamos seguramente aprisionados en su cáscara externa, realizando conclusiones sin fundamento (Bea, E. y Di Carlo).

Esta idea del diagnóstico social, ha ido cayendo de alguna manera en desuso junto con el denominado modelo médico y jurídico, en los asuntos sociales. Creo que se trata de un verdadero malentendido.

La profesión debió legítimamente separarse de la medicina y el derecho, que la concebian como una actividad accesoria. Esto tuvo que darse tanto en la práctica profesional, como en el nivel académico, y todavia hoy algunos no lo entienden suficientemente. 
Pero el diagnóstico social está, por su propia naturaleza, muy lejos del correspondiente a la práctica médica. El trabajador social entra en comunicación con el asistido y elabora sus sintesis explicativas en este intercambio con él. De este aspecto nos ocuparemos expresamente en los próximos capítulos.

Nos parece que el rechazo a un modelo clínico de diagnóstico ha llevado a algunos al rechazo total del concepto.

Existen, además, fundamentos ideológicos, que refuerzan a este prejuicio contra la idea de diagnóstico. Por una parte, la bastante legítima disconformidad sobre cómo andan las cosas actualmente en este mundo, han llevado a una radicalización del juicio tan profunda que parecería «improcedente» apelar a algún grado de valoraciones apreciables existentes, y menos a la «osadía aristocratizante» de hacerse cargo uno de ellos como positivas. A esto se agrega el rechazo global al funcionalismo, entendido como subordinación al statu quo.

¿Quién tiene la verdad?. Se dice.

¿Adaptarse, a qué?. Se dice.

Las afirmaciones precedentes tienen sentido en contextos muy especiales y como correcciones críticas ante determinados peligros de la vida social, tales como el fanatismo, la intolerancia, y la esclavitud frente a la presión social. Pero no tienen sentido si pretenden borrar toda diferencia de legitimación entre valoraciones, y si efectivamente pretendieran eliminar algunas de las formas de adaptación sociales, necesarias a toda convivencia creativa.

Nadie considera ni consideró en el trabajo social contemporáneo, que el profesional estuviera tan instalado en la salud moral y social, como para determinar la vida de otros. El servicio social se caracteriza, más bien, por la afirmación y respeto a las diferencias en las búsquedas humanas. Pero esto no significa, que le sea ajena al trabajo social la idea de una vida integrada y los riesgos de la desintegración vital y social.

Que una existencia tome una modalidad $u$ otra no es asunto de las metas profesionales. Que alguien pueda ser más autocentrado y otro más expansivo, que alguien siga tal credo y otro tal otro, que alguien permanezca célibe y otro construya una familia, etc., no constituyen preocupaciones profesionales. 
Es en cambio algo básico en la acción del trabajador social, sea que trabaje con un individuo, un grupo o una comunidad, la estimación acertada de qué actitudes, prácticas y valoraciones contienen riesgos para la integridad del propio sujeto y para la sociedad de que forma parte, y cuáles favorecen su desarrollo. Un diagnóstico social debe basarse, ante todo, en estos criterios, que domina, no como un absoluto, el profesional de trabajo social.

Aunque no siempre nos gusta expresarnos así, de lo expuesto se trata en la profesión y en el diagnóstico social involucrado." (Di Carlo y equipo).

\section{HUMANISMO DIALÉCTICO.}

La filosofía kantiana inicia una trayectoria decisiva para el pensamiento ulterior, que la supera, pero que, constantemente, la presupone (Fichte, Schelling, Hegel), proyectándose hasta nuestros días en la forma de la discusión de la "filosofía de la consciencia" (Husserl, MerleauPonty, Habermas).

Tenemos que comprender que este cambio crítico frente al idealismo kantiano es muy importante y que abrió el camino para la formación de la conciencia contemporánea desde Hegel en adelante, pero también que, a determinado nivel de análisis, es Kant quien todavía tiene las mejores respuestas.

Nosotros pensamos que el trabajo social profesional, que emerge francamente como disciplina social de base científica en la época contemporánea, asimila y se hace cargo de las nuevas comprensiones, en una síntesis teórico-práctica muy interesante.

Esta actual orientación característica de la profesión es llamada por nosotros humanismo dialéctico, en diferenciación del sentimentalismo benefactor, de la filosofía idealista de la conciencia y del materialismo dialéctico.

Concluimos el presente aporte con una muy breve síntesis de algunos de los parámetros principales de esta orientación de la profesión, constituyendo la profundización y desarrollo de la misma, para el trabajo social, nuestra tarea futura.

La antropología kantiana se funda en un individualismo moral, según el cual el sentido de lo humano universal se resuelve en el interior del sujeto. Los otros constituyen lo externo, algo digno y respetable, pero no forman parte ni condicionan efectivamente al debate interior. La universalidad del sujeto se resuelve en definitiva para Kant en la 
interioridad, como asunción y sumisión al órgano de la universalidad (razón).

Tal concepción de la conciencia no le permite a Kant comprender que la universalidad es el producto del diálogo, la deliberación común o razón compartida con el otro. La universalidad se da en el encuentro con los otros y en la comunicación con ellos.

La realidad de un mundo común participativo y comunicativo escapa a la interpretación kantiana y comienza a plasmarse a partir de Hegel, en el pensamiento posterior. También la captación de la forma mediata (social) de constitución del sujeto.

El carácter dialógico-participativo, es una de las notas más representativas de la metodología y los fines últimos del trabajo social profesional y constituye una de los ethos de más peso en nuestra época.

El hombre actual confía cada ves menos en los esquemas tradicionales de conducta y en los mandatos de los "principios" de su conciencia individual, para buscar el entendimiento en el ser en común, dialécticamente asumido. Una comunicación dialéctica que no tiene necesariamente por objeto la eliminación de las contradicciones, ni tampoco de las confrontaciones entre concepciones del mundo y la lucha por intereses sociales antagónicos, pero que abre el espacio para los entendimientos humanizados posibles. El humanismo dialéctico discrimina planos en la vida social y no reduce todos los significados interesantes a un solo principio explicativo y en este punto se hace cargo tanto de la complejidad humana, como de las dificultades del diálogo posible. Que este diálogo lleve a concordias mayores y duraderas o a acuerdos conyunturales (Albert, M. 1992), a lo que el humanismo dialéctico se opone, es a la concepción de la convivencia humana como un ciego conflicto de fuerzas, es decir, a la militarización global de la sociedad.

"La democracia, sin embargo, no es una forma de organización; es un hábito cotidiano". (Richmond, M.).

Que esta orientación dialógica puede deformarse, y hasta tomar modalidades ruines, tramposas o vanales, es algo innegable, pero lo mismo sucede muchas veces con cualquier otra. Puede muy bien existir un uso sádico de las tradiciones y en la aplicación de los principios internos a los demás.

La concepción de la "planificación social participativa" (en oposición a la planificación tecnocrática), expuesta y aplicada por el Trabajador Social Dr. Seno Cornely en Brasil, puede considerarse en su sustancia metodológica muy representativa de un encare posible del punto de vista de la deliberación común, en la construcción de programas en los municipios. Valga este ejemplo de la deliberación común, 
que podríamos tomar también de una infinidad de otros autores del servicio social y desde variados matices ideológicos.

"Un desenvolvimiento más directo de los carenciados en el proceso de planeamiento aumentará su participación real y los capacitará para asumir mayor control sobre las instituciones que hoy deciden por ellos. Ellos aprenderán a participar, decididamente, participando.

Se trata de un ejercicio pedagógico, de aprender en la práctica".

"En la amplia discusión de los propósitos del plan dan razones de sus propuestas y del escalonamiento de prioridades, profundiza las raíces del proceso en la convicción popular".

"La discusión abierta de los diversos intereses motivará al pueblo a participar y ayudará a cada grupo a colocar claramente sus intereses. Eso facilitará la acción negociadora".

"Es de inspiración dialéctica, de sociedad en movimiento y en construcción".

"Es un método de liberación de potencialidades".

"Usa modalidades democráticas, dialogadas, de negociación entre los sectores sociales".

"Se basa en la primacía absoluta del hombre como meta y razón de ser de la acción planificadora y más, de toda organización social.

Aqui ya nos aproximamos a lo que Erich Fromm muy apropiadamente llamó «humanización del planeamiento», al fundamentar su acción en la fe en el hombre, en su potencial de autosuperación y de participar en la construcción de la sociedad, proyecto siempre inacabable y perfeccionable". (Cornely, N., 1986).

"La verdadera comunicación se basa en la capacidad de deliberación común en la cual cada individualidad se entrega anónimamente a un pensamiento que no termina ni comienza en ningún sujeto individual y en el cual se tejen esforzadamente realidades humanas.

No debe inspirarnos ningún optimismo ingenuo, debemos tener muy en cuenta que los progresos de la comunicación son lentos y dificultosos por muchos motivos. La forma misma de pensar en conjunto es una institución históricamente nueva, que necesita llegar a plasmarse mejor y a ser efectivamente experimentada como portadora del bien que promete. 
Sin embargo, tampoco corresponde disminuir el significado de los progresos que gradualmente se van realizando en tal sentido, en todas las esferas de la sociabilidad humana.

La capacidad de deliberación y reflexión común exige un importante grado de libertad en el sentido de no haber desarrollado un egocentrismo fuerte lo que es algo difícil en una sociedad altamente competitiva. En una sociedad crispadamente dividida, la chance de ejercer el pensamiento en común encuentra especiales dificultades. Ahora bien; en cualquier caso, sería erróneo pensar que la comunicación interhumana y grupal consistiría en una comunidad de pensamiento ejercitable sin dificultades inmanentes. La reflexión común se caracteriza por implicar tensiones y conflictos que no se explican suficientemente atribuyéndolos a limitaciones psicológicas humanas o a la organización social en que se vive. Estos conflictos no surgen meramente de una falta de disposición interna de los individuos, sino del hecho de que la reflexión grupal tiene generalmente que ver con asuntos complejos y significativos que siempre permiten enfoques y apreciaciones diversas. El ámbito de reflexión común se nutre tanto de encuentros plenos, como de discrepancias que se saben hacer valer. Si bien es cierto que el mejor destino de un antagonismo legítimo de enfoques es el de llegar a una sintesis rica, en la cual los distintos momentos la verdad se integran, también es cierto que nadie puede desear sensatamente la institución de ámbitos en los cuales toda lucha y toda tensión hayan quedado excluidas.".

"La reflexión común constituye la forma de encarar los asuntos en la cual un querer colectivo, grupal o interindividual es interpretado y desarrollado como una unidad racional y viviente. Muy lejos de anular el individuo, permite que éste encuentre el ámbito en el cual descubre su ser con otros y los horizontes humanos generales en los cuales su particularidad tiene verdadero sentido. La mentalidad grupal que se despliega no es algo ajeno a todos los integrantes, ni tampoco la posición de algunos. Es, al mismo tiempo, lo común y lo de cada uno. No es así que esta racionalidad colectiva es ventajosa como una mera suma de esfuerzos individuales; no es cierto que cuatro ojos ven más que dos como un mero 
asunto cuantitativo, cuatro ojos no ven mejor las mismas cosas, sino que ven cosas diferentes. El ejercicio de la unidad con los otros eleva las miras hacia regiones de otra manera inalcanzables. Surgen de esta manera los motivos sociales como aspiraciones y exigencias significativas y se descubre la solidaridad y la comunicación como la realización humana más prometedora.

Mientras que cada uno se siente aislado junto al otro, no puede surgir ninguna disposición activa grupal. Toda acción grupal, sea cual fuere su amplitud y profundidad, se apoya en la mentalidad colectiva funcionando. Esta mentalidad colectiva puede edificarse sobre puras tendencias agresivas mediante la movilización de las frustraciones del grupo y ser patológica, puede edificarse sobre mitos o consignas indiscriminadas y sentimentales y ser frágil o poco madura, o puede basarse en el ejercicio de la racionalidad y la comunicación y ser la humanidad misma en obra." (Di Carlo, E., 1983)

La crítica al individualismo de la conciencia comienza con la concepción de la implicación dialéctica entre conciencia y realidad.

La dialéctica entre conciencia y realidad descubre al sí mismo autoconsciente, como consecuencia de una relación consigo mismo mediata, es decir, que pasa por el otro y por el mundo (Hegel y G. H. Mead). Encuentro mi ser a través de los demás y de la sociedad.

Es lo externo, lo que se me presenta desde otro ángulo, como lo negativo frente a mí, lo que me da un ser como interioridad pensante (sujeto). Desde el otro polo de esta dialéctica, lo externo social (instituido) es captado ahora como un producto humano histórico, perdiendo su ajenidad.

"El profesor Georges H. Mead, de la Universidad de Chicago, va más lejos todavía cuando afirma que la sociedad no es solamente el medio por el cual se desarrolla la personalidad, sino también la fuente y el origen de ésta. Desgraciadamente ha publicado poco y su obra no es accesible al gran público.

Se ha designado a veces bajo el nombre de "teoría del yo ampliado» esta explicación de la vida y del desarrollo mental del hombre. Es una de las piezas angulares del servicio social de casos individuales (...)." “(...) la mentalidad humana no es fija ni inalterable (...). Por el contrario vive, crece, cambia, es infinitamente sensible a las sugestiones, es capaz de recibir poderosas impresio- 
nes de afuera, formar nuevas costumbres, aprovechar las ocasiones que se presentan, asimilar tanto el bien como el mal. De todos los animales, dice el profesor Hocking, es el hombre en quien menos cuenta la herencia y más las fuerzas constructivas conscientes... La naturaleza puede completar a otras criaturas; la criatura humana debe completarse a si mismo." (Richmond, M., 1962).

Para Hegel, la historia de la humanidad es la historia de la razón colectiva, que se despliega allí en sus distintos momentos progresivos hasta llegar a la autoconciencia en la época moderna, conciencia del sí mismo individual y colectivo. Este aspecto de la teoría hegeliana, ha dado lugar muchas veces a nuestro juicio a interpretaciones erróneas. Aunque Hegel exagera su optimismo en la época en que elaboró su obra, nosotros podemos comprenderla como la comprensión de que la historia (1) no es algo aleatorio, sino que tiene sentido en relación con lo humano, y (2) que la historia no pertenece al dominio de las leyes inconscientes, propias del reino natural (POPPER, K. 1955).

La realidad se constituye desde esta comprensión como un devenir históricamente asumido, como en un movimiento y cambio que es el resultado de las distintas formas de interacción humana y del conflicto de intereses sociales.

Es desde esta filosofía, para nosotros ya clásica, que comienza a formarse la conciencia dialéctica. La conciencia es puesta por el otro, originariamente en la forma del conflicto y la negación, y el mundo es puesto a su vez por la conciencia, también en la forma de la negatividad. El paso siguiente es el reconocimiento de la co-pertenencia activa entre conciencia y realidad. Alienación y extrañeza frente a "lo otro" son dos factores centrales de este movimiento dialéctico, que Hegel expresa muy claramente en la dialéctica del amo y el esclavo.

Carlos Marx retoma exactamente toda esta teoría explicativa dialéctica, pero la aplica casi exclusivamente a la interpretación del proceso de la realidad económica (producción y cambio), en los términos de explotadores y explotados como emergentes de la contradicción esencial en el "trabajo enajenado". El capital que se le presenta al trabajador como lo otro y su enemigo es producto del propio trabajador como acumulación del trabajo enajenado (negatividad), y, por su parte, el trabajador, que emerge de esta misma relación, representa como fuerza revolucionaria la negación del capital(ismo). Lo que parece negar a la otra parte, le da su ser. Contradicción que se resolvería, según Marx, con la abolición del capital (negación de la negación), que surgiría por las condiciones generadas por el desarrollo capitalista. La historia del mundo es la "historia de la lucha de clases", expresa. 
Pensamos que este es el punto decisivo, en la distancia de nuestra visión profesional frente al marxismo, como ya hemos adelantado en general.

Afirmamos que existen diversos niveles de trato y acción en la sociedad humana igualmente significativos: convivencia, vincular preferencial, estético y moral, y que su conjunto configura el mundo humano. Tanto es esto así, que no es fácil para nadie poner en forma absoluta un nivel antes que otro en las propias coyunturas vitales. Que no puede haber libertad si las relaciones de producción nos hacen dependientes, es cada vez menos cierto. Nosotros pensamos que tanto la enajenación como la realización de la existencia se juega en muy diversos planos.

"Marx no puede entender la metamorfosis del trabajo concreto en abstracto como un caso especial de una cosificación sistémicamente inducida de las relaciones sociales, porque parte del modelo del actor que actúa teleológicamente y que, al ser desposeído de sus productos, se ve también privado de la posibilidad de desarrollar las potencialidades de su ser. La teoría del valor está desarrollada en unas categorías de teoría de la acción tales que obligan a situar la génesis de la cosificación por debajo del nivel de la interacción y a tratar la deformación de las relaciones interactivas, es decir, lo mismo la desmundanización de la acción comunicativa, adaptada ahora a medios de control, que la tecnificación del mundo de la vida a que ello da lugar, como si fueran fenómenos derivados: «Esa estructura unilateral del concepto fundamental de acción, que sólo permite entender la acción como actividad productivo-objetiva, se cobra su venganza en una subdeterminación del grado de indiferencia dado con cada reducción del trabajo concreto a trabajo abstracto. Marx resulta, pues, categorialmente demasiado ingenuo a la hora de determinar el grado de indiferencia de la acción necesario para la integración sistémica ...» (Lohmann, 1980).

Las tres debilidades que hemos analizado de la teoría del valor explican por qué la Crítica de la Economía Política, pese a su concepto de sociedad articulado en dos niveles, capaz, por tanto, de combinar sistema y mundo de la vida, no ha permitido una explicación satisfactoria del capitalismo tardio. El planteamiento de Marx fomenta una interpretación de las sociedades capitalis- 
tas desarrolladas reducida en términos economicistas." (Habermas, J 1990).

Pensamos, además, que, aunque el nivel económico-productivo es de gran peso, la lucha de clases tuvo generalmente una desdichada expresión en el siglo, tanto desde el capitalismo como por parte de los sectores proletarios, lo que contribuyó a la tan negativa militarización de la sociedad. Existieron especiales momentos en que, por ejemplo, en el plano académico, pensar de una manera u otra permitía más bien clasificar a las personas, en términos de aliados o enemigos. Todavía hoy el problema no está completamente superado en la comunidad profesional.

Determinadas categorías dejaron de ser utilizadas como formas de presentar, expresar, aclarar, definir o valorar (positiva o negativamente) un punto de vista, para comenzar a ser verdaderas formas de estigmatización (por ejemplo, funcionalismo, reformismo, marxismo, liberalismo, ayuda, asistencia social, caso social, etc.)." (Di Carlo, 1976).

El pensamiento humanista dialéctico está muy lejos de descartar conflictos y tensiones en aras de la igualdad humana, sólo que, por más duras que sean las cosas, los asume en forma humanizada y racional. Por el bien de todos y por la sociedad que se quiere construir, hasta las luchas más exigentes deben seguir siendo fraternas. La solidaridad esencial entre medios y fines no permite otro encare.

El concepto de intencionalidad está en el centro del desarrollo de la fenomenología, que constituye una de las filosofías más importantes de nuestra época. Desde Husserl, la filosofía de la conciencia es superada por la vía de su proyección al objeto, distanciándose del momento de la autoconciencia. La conciencia es intencional, es siempre ante todo conciencia de algo, es siempre, de alguna manera, subsidiaria del objeto.

Heidegger nos habla del ser "a la mano" del mundo, del Dasein y de la angustia o sentimiento metafísico (anonadamiento), como elementos esenciales de su filosofía existencial, que tematiza el concepto de "ser en el mundo", como motivo central.

Merleau-Ponty pone su acento en la percepción como encuentro privilegiado del hombre con la realidad, y destaca al cuerpo como expresividad y predisposición de sentido en este encuentro. Su obra principal, "Fenomenología de la percepción", recuerda la de Hegel, "Fenomenología del espíritu", y la supera en su acento crítico de la filosofía de la conciencia.

Merleau-Ponty exalta la experiencia del "mundo vivido" que cons- 
tituye la experiencia fundamental que posibilita y respalda a todo otro conocimiento. Algo análogo sucede con Habermas en su jerarquización del "mundo de la vida", en el contexto de su crítica de la razón funcionalista.

Casi todo el pensamiento de nuestro siglo supone la reconsideración dialéctico reflexiva de la teoría idealista sobre la relación entre conciencia y realidad. También supone la superación de la antinomia empirismo-racionalismo.

Nosotros estamos muy lejos de sugerir que las ideas que estamos ahora mismo esbozando, ya constituyan conscientemente el cuerpo de la teoría del trabajo social profesional. Nos hemos impuesto la tarea constructiva en esta dirección para los próximos años, en forma compartida con otros.

Sin embargo, no puede dejarse de tener muy en cuenta, que la profesión toma forma por primera vez con Mary Richmond bajo la influencia de, por lo menos, J.Dewey y la cooperación mutua con G.H. Mead de la Escuela de la Universidad de Chicago.

Por otra parte, son innumerables los filósofos sociales citados constantemente en el curso del siglo por los trabajadores sociales constructores de la profesión que se inspiran en las nuevas ideas.

Puede afirmarse que el trabajo social se involucra bastante en la orientación dialéctica, que se basa en el mundo y en la vida como experiencias originarias, que se compenetra con la realidad social en movimiento (Perlman, H.) y cambio (Richmond M.; Hamilton G; Specht H.).

Este, nuestro escrito, solamente busca señalar y fundamentar, claramente, un sendero algo nuevo para la teoría y práctica consciente de la profesión, que nosotros consideramos en parte ya existente y en parte latente dentro de la misma.

Para esto, se nos hizo, además, importante, entrar algo en el debate de las ciencias sociales y clarificar el concepto de dialéctica.

El concepto de dialéctica es de cuño y desarrollo humanista y complementa al más básico de humanismo -humanismo dialéctico- conformando una idea activa de gran importancia para una sociedad tan compleja y móvil, con tantos logros y tantas desorientaciones, como la actual.

El humanismo dialéctico tiene para nosotros mucha confianza constructiva en el orden de la práctica social transformadora, también porque (1) el pensamiento lineal o/y tecnocrático demostró su incapacidad para producir cambios interesantes y (2) porque mantenemos todavía bastante confianza en un mundo de comunicación e igualdad crecientes. 
Concluimos destacando que la orientación transformadora característica de servicio social bien ejercido contiene la retoma enriquecida, por su elaboración práctica concreta, de la tensión dialéctica entre ser y deber ser.

En efecto, la realidad social (individual, grupal y colectiva) en que se trabaja contiene tensiones que la dinamizan. Esto es algo propio de nuestra civilización occidental, en diferenciación de las sociedades tribales, mitológicas y estáticas.

La dinámica de nuestra sociedad se basa en la tensión entre ser y deber ser, entre las tendencias que se apegan a lo existente y las tendencias renovadoras.

Estas tensiones, en cuanto no resueltas, se expresan como contradicciones en el sujeto, en cuanto resueltas constituyen caminos abiertos posibles, que a su vez encontrarán nuevas contradicciones.

Es decir, que la oposición entre ser y deber ser no consiste, para el trabajo social ni para el enfoque dialéctico, en la contradicción abstracta (juvenil, podríamos decir o, más técnicamente, idealista) entre una conciencia que juzga y la realidad a transformar puesta "ante los ojos". Ser y deber ser y la tensión entre los mismos son elementos constitutivos de la realidad social, son inmanentes a ella.

Las posibilidades de cambio, entonces, le pertenecen a la realidad social misma, en cuanto le pertenece a ella un deber ser, más o menos consciente, más o menos asumido.

Una de las tareas más propias del asistente social es la de ayudar, al sujeto con el cual trabaja (una familia, un individuo o grupo o comunidad), a perfilar y comprender mejor su querer, sus proyectos y sus cambios, a razonar sobre sus contradicciones (De Robertis, C., 1988) que siempre involucran valoraciones. El trabajador social coopera así con este proceso dialéctico que constituye la vida en cualquiera de sus niveles y alternativas.

\section{BIBLIOGRAFIA}

BEA, E. Las nociones de acontecimiento y pasado vivo en la epistemología de R.C. Collingwood, en "La comprensión como futuro de la investigación profesional" Humanitas, 1995.

CASADO, D. "El bienestar social acorralado", Ed Humanitas, Bs. AS. 1981.

DI CARLO, E. "El A.S. y el concepto de situación social problemática" en Revista Universitaria de Servicio Social, Universidad del Comahue $N^{\circ} 1$. 
DI CARLO, E. Necesidades básicas y cambio social. Ed. Humanitas, Bs. As., 1983.

GIPSON, Q. "La lógica de la investigación social", Ed. Tecnos, Bs. As.

HABERMAS, J. "Teoría de la acción comunicativa”, T. II. Ed. Taurus. 1990.

HAMILTON, G. "Teoría y práctica del trabajo social de casos", Columbia University Press, NY, 1940.

KANT, E. "Crítica a la razón pura", John Wiley Book Co. New York, 1943.

KANT, E. "Fundamento de la metafísica de las costumbres", Ed. Porrúa, México, 1990.

KONOPKA, G. "Trabajo Social de grupo", Euroamérica, España 1968.

MARZOROTTO, C. "Il Soggetto come fondamento dell'aggira etico", en Ética e servicio sociale. Ed. Vita e Pensiero. Milano, 1995.

PARSON, T. "La situación actual y las perspectivas futuras de la teoría sociológica sistemática". FCU, Uruguay. 1956.

PERLMAN, H. "El trabajo social individualizado", Ed. Rialp, Madrid, 1980.

POPPER, K. "La sociedad abierta y sus enemigos", T. I. Ed. Orbis, 1985.

RICHMON. M. “Caso social individual”, Ed. Humanitas, B.A. 1922/93. 



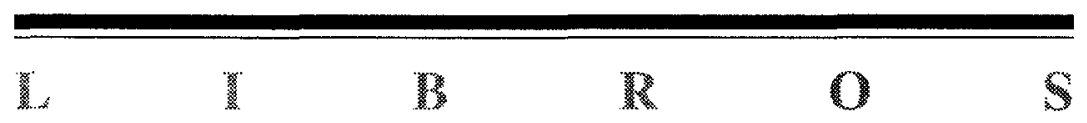



Título: Violencia. Memoria amarga.

Autor: Javier Urra Portillo.

Edita: Siglo XXI de España Editores, S.A., Madrid, 1997, 303 páginas.

El libro de Javier Urra, «Violencia. Memoria amarga», es un abordaje sistemático de la violencia en nuestra sociedad y sus causas desde la experiencia y la reflexión de un profesional que ha dedicado la mayor parte de su quehacer profesional a la Fiscalía de Menores como asesor psicológico.

Este libro es un testimonio de las formas de violencia que se generan en el mundo, pero es también una aproximación al estudio del ser humano y de sus motivaciones e impulsos de agresión y, sobre todo, es un mensaje de esperanza.

El autor analiza la violencia desde múltiples perspectivas: éticas, filosóficas, religiosas, ofreciendo, además, un estudio psicológico de las conductas desviadas y de la agresividad, combinando las tesis ofrecidas con experiencias vividas como profesional, aportando la narración de casos e historias clínicas en las que él ha intervenido como profesional.

Además, reflexiona sobre la violencia en todas las manifestaciones humanas: en la religión, en el arte, en la ciencia, en el deporte, en las instituciones, en definitiva, en todos los ámbitos humanos, bien sea esa violencia expresión de manifestaciones individuales o de masa.

Pero, aunque la lectura de la obra de Javier Urra, en ocasiones, nos inquiete y nos incite a la desesperanza, nos haga revivir experiencias colectivas de la historia negra de la humanidad -violencia, memoria amarga, de ahí el título-, al final, nos ofrece un camino a la fe y a la esperanza: la educación y la prevención pueden ser las claves de la 
transformación, en definitiva, la apuesta por una sociedad más justa y solidaria es posible.

Como dice Javier Urra al finalizar su obra, «inasequibles al desaliento hemos de pedir lo imposible y exigirnos lo inalcanzable».

Un libro imprescindible para la reflexión sobre los hombres y sus acciones y también para la autorreflexión sobre nosotros mismos, para el reconocimiento de nuestras miserias y de nuestras culpas, pero también un libro que nos lleva al convencimiento de que la utopía es posible.

María José Escartín Caparrós.

Profesora Titular del Departamento de Trabajo Social y Servicios Sociales.

Universidad de Alicante. 
Título: Los modelos en Trabajo Social. Intervención con personas y familias.

Autora: Mathilde du Ranquet.

Edita: $\quad$ Siglo XXI de España Editores, S.A., Madrid, 1996. 405 páginas.

Este libro es la traducción española de un texto clásico de la literatura del Trabajo Social, editado inicialmente en Quebec (1981), a partir de una segunda edición francesa actualizada (1991). La autora presenta diferentes modelos de intervención con personas y familias, apoyándose en una serie de teorías psicosociales y en la práctica profesional. En palabras de la autora, «es la aplicación de la teoría a la práctica del trabajo cotidiano y su traducción posterior en una metodología más precisa».

La obra se estructura a partir de dos capítulos introductorios, en el primero de los cuales se efectúa una distinción entre método (conocimientos) y relación profesional (valores), en la que la autora quiere destacar la existencia del componente humano y afectivo que caracteriza la relacional profesional, resultando ser un pre-requisito para la aplicación del método elegido. Un segundo capítulo plantea el marco de referencia sintetizando las teorías del estrés, de sistemas, de la comunicación y del rol, junto a las de la psicología del yo y del crecimiento. El resto del libro se dedica a la exposición de diferentes modelos de la práctica profesional del Trabajo Social: modelos diagnóstico o psicosocial, funcional, centrado en la resolución del problema, de modificación de conducta, intervención en situación de crisis, centrado en la tarea, familiar y de socialización. Cada modelo se plantea con una estructura similar: a partir de una base teórica se describen las etapas del proceso de la intervención, las principales técnicas de tratamiento y las peculiaridades de la relación profesional. Concluyéndose cada descripción de un modelo con un apartado en el que se exponen 
las indicaciones específicas consideradas más adecuadas del modelo en cuestión (ninguno es una panacea) y, a modo de conclusión, una síntesis de lo expuesto en el capítulo.

En su conjunto, estamos ante un interesante libro resultado de un riguroso trabajo de la autora, que consigue integrar teoría y práctica, sistematizando las aportaciones de diferentes teorías psicosociales con los conocimientos adquiridos a través de la aplicación de cada modelo, mediante la práctica profesional del Trabajo Social. Sin embargo, a veces, pesa el tiempo transcurrido desde su primera edición (más de quince años), a pesar de la revisión realizada por la autora para la segunda edición. Los cambios sociales de los últimos diez años han planteado nuevos desafíos al Trabajo Social que no se vislumbran en el libro.

Hay que destacar entre sus aportaciones el reconocimiento de que no se puede limitar la práctica profesional al trabajo con individuos y familias sin incidir en el contexto, remarcando la importante influencia del medio social en las condiciones de vida de las personas y las familias, alertando sobre la tentación frecuente de considerar el «casework» como el único remedio a todos los males, en detrimento de la utilización de los otros métodos clásicos de intervención, trabajo social comunitario y trabajo social de grupo, aún poco utilizados. En efecto, en nuestro contexto profesional se abusa de las intervenciones profesionales individualizadas (sin que ello signifique que no sean necesarias) y cuesta introducir intervenciones grupales y comunitarias, cuando en muchas situaciones las nuevas necesidades sociales lo están demandando.

El peligro de esa tendencia es, como la misma autora advierte, la tentación del tratamiento individualizado de lo social cuando, por el contrario, «el trabajador social pretende menos adaptar a la gente a su medio que liberarla» (pág. 393). Esta cuestión ha sido puesta de manifiesto, recientemente, por Rosanvallon al recordar el riesgo de mantener prácticas de trabajo social del siglo XIX, cuando el objetivo era recualificar moralmente al pobre, incitándolo a una conducta individual juzgada «sana». Por el contrario, las nuevas políticas sociales apuntan más bien al individuo «social»; es la incidencia social de los comportamientos individuales la que está en el punto de mira y no la rectificación moral. La oposición clásica entre individual y colectivo no es operativa; no se pueden separar la reforma de las mentalidades y la reforma de las estructuras ${ }^{1}$. Hay que dirigir la intervención profesional a ayudar al individuo a superar los obstáculos que le impiden lo- 
grar su pleno desarrollo humano y social, sin olvidar que el mismo contexto social suele ser la causa de dichos obstáculos.

En resumen, el libro de Mathilde du Ranquet resulta de indudable interés para la formación de las/os Trabajadores Sociales, tanto para los alumnos de las Escuelas Universitarias de Trabajo Social como para la necesaria formación permanente de quienes ejercen la profesión. En ambos casos, se puede encontrar en él valiosas pistas para la actuación profesional.

M. ${ }^{a}$ Asunción Martínez Román.

Profesora del Departamento de Trabajo Social y Servicios Sociales.

Universidad de Alicante. 

Título: Introducción al Trabajo Social II. Trabajo Social con individuos y familias.

Autoras: Escartín Caparrós, M.J., Palomar Villena, M., Suárez Soto, E.

Edita: Aguaclara. Alicante, 1997. 287 páginas.

Es de agradecer la aparición de esta obra, "Introducción al Trabajo Social II. Trabajo Social con individuos y familias", con que de nuevo nos sorprenden sus autoras, profesoras de la Escuela Universitaria de Trabajo Social de la Universidad de Alicante, porque son escasas estas publicaciones preparadas por autores españoles. Pero es de agradecer, sobre todo, porque esta obra constituye un aporte interesante a la producción de conocimiento de la disciplina del Trabajo Social.

El libro, fruto de un riguroso estudio e investigación, consta de tres partes bien diferenciadas.

La primera hace referencia a la cuestión metodológica en el Trabajo Social, su evolución y planteamientos actuales.

La segunda parte aporta elementos teórico-prácticos necesarios para el ejercicio de la profesión en su relación con las personas, sin olvidar las técnicas específicas, las habilidades y las destrezas que se precisan para un buen hacer profesional.

Se dedica, la tercera parte de este libro, a la intervención profesional con el grupo familiar, aportando nuevas formas de intervención social.

La miradas de estas autoras emergen desde el ámbito de su práctica docente y profesional, por eso, la lectura de sus capítulos acrecienta el respeto por los múltiples esfuerzos y logros alcanzados, al tiempo que abre nuevas perspectivas para comprender, enseñar y ejercer el Trabajo Social. 
Este nuevo texto constituye, además, un paso ineludible para quienes quieran conocer la contribución del Trabajo Social al proceso de ayuda a la familia desde una aproximación más humana y solidaria, tal y como sugieren las propias autoras.

Como expresa la compañera Silvia Navarro, «si escribir el Trabajo Social es un acto valiente de compromiso con uno mismo y con la profesión, leer el Trabajo Social que se va haciendo cada día nos ayuda a no sentirnos solos y a vivir la profesión como reto colectivo».

M. ${ }^{a}$ Victoria Molina Sánchez.

Catedrática de Trabajo Social.

Universidad Complutense de Madrid. 
NUMEROS PUBLICADOS 



\section{NUMERO 1 (1992)}

Jesús Daza Martínez, director.

Presentación

María José Escartín Caparrós. Profesora de Trabajo Social. E.U.T.S. de Alicante

Consideraciones preliminares

\section{Estudios sobre la familia}

Isabel Ramírez de Mingo. Titular de Trabajo Social. Universidad Complutense. Madrid.

El Trabajo Social con familias

María Asunción Martínez Román, María Teresa MiraPerceval Pastor, Hortensia Redero Bellido. E.U.T.S. de Alicante.

Función específica de la Familia en la atención social comunitaria: su valor como recurso para la sociedad.

María José Escartín Caparrós. Profesora E.U.T.S. Alicante. El Sistema familiar y el Trabajo Social

Dr. D. Agustín Bueno Bueno. Profesor del Departamento de Psicología de la Salud. Universidad de Alicante.

Estilos de vida familiar y riesgo social infantil

María Asunción Martínez Román. Profesora de Servicios Sociales. E.U.T.S. Alicante.

Participación de la Familia en el proceso de rehabilitación de los enfermos crónicos: Los Insuficientes Respiratorios Crónicos Graves (I.R.C.G.) y el Bienestar Social

Josefa Lorenzo García, Manuela Palomar Villena, Esperanza Suárez Soto. Trabajadoras sociales. Profesoras de la E.U.T.S. Alicante.

Mujer y Familia. Reflexiones críticas desde nuestra experiencia profesional

Dr. Don Francisco Ortega Beviá. Director Master Terapia Familiar y Profesor Terapia Familiar, Curso Superior 
Psicosociológico. Da Elisa Pérez de Ayala Morenos Santa María. Profesora de Trabajo Social Familiar. Universidad de Sevilla.

La ilusión de las alternativas: vivir en pareja

Antonio Bellido Alonso, Esther Villegas Castrillo. Profesores del Area de Trabajo Social y Servicios Sociales. E.U.T.S., Alicante.

Influencia de la Familia en el desarrollo de pautas inadecuadas de conducta

Josep-Lluís Orts Molines. Profesor de Valencià a l'E.U.T.S. Universitat d'Alacant.

Idees sobre la família a la tardor medieval a través de Lo Libre de les dones de Francesc Eiximenis (1327-1490).

M. ${ }^{a}$ Dolores Vargas Llovera. Profesora del Area de Antropología. Universidad de Alicante.

La función familiar en el actual pluralismo religioso: El caso de los Testigos de Jehová

Jesús Daza Martínez. Catedrático de Derecho Romano. La ley de Divorcio de 1932. Presupuestos ideológicos y significación política

\section{Tribuna Libre}

Manuel Moix Martínez. Catedrático de Trabajo Social y Servicios Sociales.

Problematismo del Bienestar Social

Esther Villegas Castrillo, Antonio Bellido Alonso. Profesores de Trabajo Social. E.U.T.S. Alicante.

La Teoría Sistémica en Trabajo Social. Criterios de aplicación y observaciones críticas

Ana M. ${ }^{\mathbf{a}}$ Herthogue. Trabajadora Social jubilada de la «Family Welfare Association» de Londres.

Relevancia de algunos conceptos y arquetipos de C. Jung para la labor profesional de los trabajadores sociales...

Jorge Garcés Ferrer, M. ${ }^{a}$ José Lahoz Campos, Fco. José Ródenas Riga, Estrella Durá Ferrandis. Profesores de 
SS.SS. en la Escuela de Trabajo Social. U. de Valencia. Valores y características de personalidad en estudiantes de Trabajo Social de la Comunidad Valenciana

\section{Actualidad bibliográfica}

María Asunción Martínez Román, María Teresa MiraPerceval, Hortensia Redero Bellido. E.U.T.S. de Alicante. Jorge Garcés Ferrer. Escola Universitària de Treball Social. Universitat de València.

La familia

IV. Apéndice documental

Decreto 23/1988 de 8 de febrero, del Consell de la Generalitat Valenciana, de medidas de protección de menores en situación de desamparo en la Comunidad Valenciana

Orden de 20 de marzo de 1986, de la Conselleria de Trabajo y Seguridad Social, por la que se establece el recurso de familias Educadoras en la Comunidad Valenciana

Ley $21 / 1987$, de 11 de noviembre, por la que se modifican determinados artículos del Código Civil y de la Ley de Enjuiciamiento Civil en materia de adopción

Decret 23/1988, de 8 de febrer, del Consell de la Generalitat Valenciana, de mesures de protecció de menors en situació de desamparament a la Comunitat Valenciana

Ordre de 20 de març de 1986, de la Conselleria de Treball i Seguretat Social, per la qual s'estableix el recurs de Famílies Educadores de la Comunitat Valenciana 
NUMERO 2 (1993)

Jesús Daza Martínez.

Presentación

\section{Algunas claves del Estado social contemporáneo}

Jorge Hurtado Jordá. Profesor del Departamento de Ciencias Sociales y de la Educación. Universidad de Alicante. Sociedad, Estado, tal vez mercado

Fermín Aliaga Aliaga. Profesor del Departamento de Economía Aplicada y Política Económica. Universidad de Alicante.

Política económica y calidad de vida

Ramón Martín Mateo. Catedrático de Derecho Administrativo.

La cultura del ocio

II. Cuestiones teórico-prácticas sobre el Trabajo Social

M. ${ }^{a}$ José Escartín Caparrós. Profesora titular de Trabajo Social de la EUTSA de Alicante

Influencia de las diferencias culturales en la relación de ayuda

Esperanza Suárez Soto, Manuela Palomar Villena. Profesoras titulares de Trabajo Social en la EUTSA de Alicante. El cliente en Trabajo social. Cuestiones conceptuales y análisis tipológico

Esther Villegas Castrillo. Profesora titular de Trabajo Social en la EUTSA de Alicante.

El Trabajador Social en el trabajo de grupo

Antonio José Bellido Alonso. Profesor titular de Trabajo Social en la EUTSA de Alicante.

La primera entrevista en la relación de ayuda del Trabajo Social Individualizado 
Josefa Lorenzo García. Profesora Titular de Trabajo Social en la EUTSA de Alicante.

La intervención profesional con familias multiproblema desde los Servicios Sociales Municipales

Manuela Palomar Villena y Esperanza Suárez Soto. Profesoras Titulares de Trabajo Social en la EUTSA de Alicante.

El modelo sistémico en el Trabajo Social familiar. Claves teóricas $e$ intervención práctica

III. Problemas y perspectivas de los servicios sociales

Manuel Moix Martínez. Catedrático de Trabajo Social y Servicios Sociales.

«Universalidad» versus «Selectividad» en los Servicios Sociales. La «discriminación positiva»

María del Carmen Alemán Bracho. Catedrática de Servicios Sociales de la EUTS de la Universidad de Granada. Una perspectiva de los Servicios Sociales en España

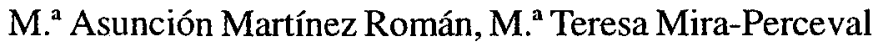
Pastor y Hortensia Redero Bellido. Profesoras titulares de SS.SS. de la EUTS de Alicante.

¿Viejos o nuevos? Orientaciones actuales de los Servicios Sociales en España

Rafael Barranco Vela. Profesor de Derecho Administrativo de la EUTS de la Universidad de Granada.

El principio de participación en las Leyes de Servicios Sociales

\section{Miscelánea}

Manuel Oliver Narbona y M. ${ }^{a}$ Dolores Vargas Llovera. Profesores del Departamento de Humanidades Contemporáneas. Y M. ${ }^{2}$ José Escartín Caparrós, Josefa Lorenzo García, Antonio Bellido Alonso, Roberto Mohedano Menéndez, Manuela Palomar Villena, Esperanza Suárez Soto y Esther Villegas Castrillo. Profesores de la EUTS de Alicante. 
Inmigración y cultura: Reflexiones críticas sobre las diferencias sociales y culturales que produce el hecho migratorio

Carmen Gimeno Escrig, Médica Experta Universitaria en Drogodependencias; M $^{\mathbf{a}}$ Angeles Amérigo Martínez, Trabajadora Social y Experta Universitaria en Drogodependencias; $\mathbf{M}^{a}$ José Martí García, Psicóloga Experta Universitaria en Drogodependencias.

Perfil de los drogodependientes y familias atendidos en el Servicio Municipal de Drogodependencias de la Vila Joiosa

Francisco Martínez Carrasco y M. ${ }^{a}$ Dolores Vargas Llovera. División de Antropología. EUTS de Alicante.

Cultura y salud mental. Influencia del medio institucional en los enfermos profundos adultos

Agustín Bueno Bueno. Departamento de Psicología de la Salud. Universidad de Alicante

Autoconcepto adolescente y clase social

\section{Actualidad bibliográfica}

M. ${ }^{a}$ Asunción Martínez Román, $M^{a}$ Teresa Mira-Perceval Pastor y Hortensia Redero Bellido. Profesoras titulares de SS.SS. de la EUTS de Alicante.

Bienestar Social y Política Social 
NUMERO 3 (1995)

M. a Teresa Mira-Perceval Pastor. Directora E.U. Trabajo Social. Universidad de Alicante.

Presentación

M. José Escartín Caparrós, Esperanza Suárez Soto.

Editorial

\section{Trabajos sobre la mujer}

Jose Manuel Díez Fuentes. Universidad de Alicante.

República y Primer Franquismo: La mujer española entre el esplendor y la miseria, 1930-1950

M. ${ }^{a}$ José Frau Llinares. Departamento Ciencias Sociales y de la Educación. Universidad de Alicante.

La tipificación sexual del trabajo mercantil. El caso valenciano

M.. Dolores Díez García y Sergio Quesada Rettschlag. Catedráticos Matemáticas E.U. Trabajo Social. Departamento de Economía Aplicada. Universidad de Alicante. Silvia M. ${ }^{a}$ Quesada Díez. ICADE. Madrid.

Una empresaria de los 90. Análisis y valoración de un caso

María José Escartín Caparrós. Profesora titular de Trabajo Social. Universidad de Alicante.

Violencia y Mujer. La intervención de crisis con mujeres maltratadas y sus hijos

Trinidad Pablo Cervera, Ruth Pérez Segovia y M. ${ }^{a}$ Dolores Vargas Llovera. Area de Antropología. Escuela Universitaria de Trabajo Social. Universidad de Alicante.

Mujer, Familia y mundo rural. Dos modelos para un cambio social

Yolanda Domenech López. Profesora ayudante del Area de Trabajo Social y Servicios Sociales. Universidad de Alicante.

La situación de la mujer en Honduras 


\section{Tribuna Libre}

Carmen Gimeno Escrig. Médica Servicio Municipal de Alcoholismo y Drogodependencia. Villajoyosa.

Angeles Amérigo Martínez. Trabajadora Social, Servicio Municipal de Alcoholismo y Drogodependencia. Villajoyosa.

Programa de intervención en familias. Evaluación con el cuestionario de salud general de Goldberg

Agustín Bueno Bueno. Profesor titular de Psicología Social de la Escuela Universitaria de Trabajo Social. Universidad de Alicante.

$M^{a}$ Teresa Mira-Perceval Pastor. Profesora titular de Servicios Sociales de la Escuela Universitaria de Trabajo Social. Universidad de Alicante.

Reflexiones ante la Ley de la Infancia de la Comunidad Valenciana

Antonio Gutiérrez Resa. Profesor titular de Servicios Sociales. Universidad de Zaragoza.

Las ONGs y su papel en el futuro de la sociedad

María José Gallego Ayllón. Trabajadora Social.

Estrella Gualda Caballero. Socióloga.

Octavio Vázquez Aguado. Trabajador Social.

Departamento de Filosofía, Sociología y Trabajo Social. Universidad de Huelva.

Las ideas previas de los alumnos de $1^{\circ}$ de Trabajo Social de Huelva respecto a la profesión

Yolanda Domenech López. Profesora ayudante del Area de Trabajo Social y Servicios Sociales. Universidad de Alicante.

Juan Carlos Gómez Díaz. Licenciado en Ciencias Económicas y Empresariales. Universidad de Alicante.

Una alternativa al trabajo social institucionalizado: El trabajo social en la empresa privada 


\section{Apéndice documental}

Ley 7/1994, de 5 de diciembre, de la Generalitat Valenciana, de la Infancia. DOGV n. 2

La Declaración de Pekín. Conclusiones de la IV Conferencia Mundial sobre las Mujeres. Beijing. Septiembre 1995

\section{Libros}

M. ${ }^{a}$ Carmen Santos Aguado. Profesora de la E.U. de Trabajo Social de la Universidad Complutense de Madrid. Título: «Las enseñanzas de Trabajo Social en España: 1932-1983. Estudio socio-educativo». Autora: M. ${ }^{a}$ Victoria Molina Sánchez. 
NUMERO 4 (1996)

Esperanza Suárez Soto. Directora técnica del consejo editorial de la revista «Alternativas. Cuadernos de Trabajo Social».

Presentación

I. Trabajos sobre migración

Abel Albet-Mas. Departamento de Geografía. Universidad Autónoma de Barcelona.

Maria Dolors Garcia-Ramon. Universidad Autónoma de Barcelona.

Joan Nogué-Font. Departamento de Geografía. Universidad de Gerona.

Lluis Ruidor-Gorgas. Facultad de Humanidades. Universidad Pompeu Fabra. Barcelona.

Geografía, ordenación del territorio y colonialismo español en Marruecos.

Mikel de Epalza. Catedrático de Estudios Arabes e Islámicos. Universidad de Alicante

Estructuras de acogida de los moriscos emigrantes de España en el Magreb (siglos XIII a XVIII).

Joan Lacomba. Departamento de Trabajo Social y Servicios Sociales. Escuela Universitaria de Trabajo Social. Universidad de Valencia.

Identidad y religión en inmigración. A propósito de las estrategias de inserción de los musulmanes senegaleses.

M. a Dolores Vargas Llovera. Area de Antropología. Universidad de Alicante.

Inmigración, etnicidad y pluralismo cultural. 
José Cabanes Hernández. Sociólogo.

Luz Vera García. Trabajadora social. Asociación P.G. Arakerando. Alicante.

María Isabel Bertomeu Martínez. Trabajadora social.Asociación P.G. Arakerando. Alicante.

Gitanos: historia de una migración.

D. Ribera, A. Reig, M. Carrillo, J.L. Talavera, A. Caruana, C. Ferrera, A. Majos, R. Climent, C. Clavijo, M. Verdú. Escuela Universitaria de Enfermería. Universidad de Alicante. Hospital General de Alicante. Facultad de Medicina. Universidad de Alicante. Ayuntamiento de Alfaz del Pi (Alicante).

Hábitos y necesidades de cuidados en el colectivo de extranjeros de 80 y más años residentes en la costa mediterránea.

Mercedes González. Octavio Vázquez. Departamento de Filosofía, Sociología y Trabajo Social. Universidad de Huelva.

Trabajo social e inmigrantes. Las intervenciones del trabajo social.

Carmen Santos Aguado. Escuela Universitaria de Trabajo Social. Universidad Complutense de Madrid.

Trabajo social en el campo de actuación de inmigración $y$ refugio.

Socorro Escobar Rubio. Trabajadora social. IRCOSAN. Madrid.

Nieves Gascón Navarro. Trabajadora social. Mancomunidad Intermunicipal de La Encina. Madrid.

Metodología del trabajo social con inmigrantes y refugiados.

Ana M. ${ }^{a}$ Ortiz Duque. Trabajadora social. Ayutamiento de Majadahonda. Madrid. 
M. ${ }^{a}$ Jesús Vega Pascual. Trabajadora social. Alto Comisariado de las Naciones Unidas para los Refugiados (ACNUR). Secretaria de la sección legal.

Fases de la intervención social con refugiados.

\section{Tribuna libre}

Nieves Lillo Herranz. Trabajadora social. Area de bienestar social del Excmo. Ayuntamiento de Elche (Alicante).

El educador gitano, profesional clave para una intervención integral con el pueblo gitano.

Sonia Ródenas Picardat. Trabajadora social. Asociación ciudadana contra el SIDA de la provincia de Alicante.

Grupos de ayuda mutua: una respuesta alternativa en la práctica del trabajo social.

Alfredo Hidalgo Lavié. E.U. Relaciones Laborales - Trabajo Social. Jerez. Universidad de Cádiz.

El marco jurídico-administrativo de los Servicios Sociales de la Comunidad Autónoma Andaluza.

Jorge Hurtado Jordá. Departamento de Ciencias Sociales. Universidad de Alicante.

Lecciones de la informalidad.

Idris M. Iwaki. Hector O. Beaton. Ernesto A. López. Departamento de Sociología. Universidad de Oriente-Santiago. Cuba.

Javier M. Ferrer. Departamento de Trabajo Social. Universidad de Alicante.

Turismo y cambio social en Santiago de Cuba. 


\section{Actualidad bibliográfica}

Carmen Santos Aguado. M. ${ }^{a}$ Jesús Vega Pascual. Socorro Escobar Rubio. Ana M. ${ }^{a}$ Ortiz Duque.

Actualidad bibliográfica sobre inmigración y refugio.......

IV. Libros

Gonzalo Musitu. Coordinador del Area de Psicología Social. Universidad de Valencia.

Título: "Estudio longitudinal de la presencia de la mujer en los medios de comunicación de prensa escita». Cuadernos de Investigación de Psicología Comunitaria. Universidad de Valencia. Nau Llibres. Valencia, 1996.Autor: José Ramón Bueno Abad. 



\section{PAUTAS GENERALES PARA LA PRESENTACION DE ARTICULOS}



1. La Revista «Alternativas. Cuadernos de Trabajo Social» está abierta a aportaciones, investigaciones, trabajos teóricos y metodológicos, de carácter profesional o académico, tanto del trabajo social, política social y servicios sociales, como de otras disciplinas y profesiones que desde un punto de vista multi e interdisciplinar enriquecen y complementan la acción profesional.

2. Contenido de los artículos.

Se exigirán unos mínimos de calidad técnica y científica para la publicación de los artículos. El Comité editorial, ajustándose a los criterios que este órgano tiene establecidos, velará y valorará los mismos.

3. El equipo de redacción revisará los originales recibidos antes de aceptarlos definitivamente. Una vez tomada la decisión, ésta se comunicará a los autores, proponiendo, si es necesario, las modificaciones oportunas. En caso de aceptación, la revista proporcionará un ejemplar a los autores.

Los artículos aceptados serán propiedad de la Revista y para su reproducción total o parcial deberán solicitar la correspondiente autorización al equipo de redacción.

4. Los artículos que no sean inéditos se publicarán bajo la valoración del Consejo editorial y en función de:

- Que su difusión haya sido en algún medio de difícil acceso a la profesión y disciplina del trabajo social.

- Que haya sido publicado en otro idioma.

- Que se consideren de particular relevancia e interés científico profesional.

5. Normas de presentación

- Los artículos deberán ser remitidos a la Redacción de la Revista «Alternativas. Cuadernos de Trabajo Social», Escuela Universitaria de Trabajo Social. Universidad de Alicante. 03690 San Vicente del Raspeig. Alicante.

- Copia escrita y diskette (Word Perfect para Windows v. 5.0 y superiores, Microsoft Word v. 6.0). Mecanografiados en papel tamaño DIN-A4, a doble espacio ( escritura en $12 \mathrm{CPI}$ ), por una sola cara.

- La extensión deberá ajustarse a un mínimo de 10-12 páginas y un máximo de 40. 
- De cada uno de los artículos los autores presentarán las claves conceptuales y un «abstract» de 12/15 líneas al comienzo del trabajo.

- Todos los artículos deberán ir acompañados en folio aparte de los datos personales del autor/res: nombre y apellidos, D.N.I., dirección, teléfono, profesión, actividad, cargo, teléfono de contacto, indicando claramente el título del artículo y si ha sido publicado en algún otro medio.

- Las anotaciones a pie de página se numerarán por orden de aparición en el texto y se mecanografiaran en hoja aparte.

- Las referencias bibliográficas se presentarán al final del texto y por orden alfabético de autores, en la forma siguiente:

- Para los libros: apellidos e inicial del nombre del autor/a/ o autores/as, título de la obra (cursiva), editorial, ciudad, año y número de las páginas a que se hace referencia.

- Para las revistas: Apellidos e inicial del nombre del autor/a o autores/as, título del artículo (entre comillas y en cursiva), nombre de la revista, nombre de la entidad editora, ciudad, año, número de la revista y el de las páginas a que se hace referencia.

- Las tablas y figuras deberán presentarse en hoja aparte numerándose correlativamente e indicando el lugar de colocación en el artículo.

- Los apartados y subapartados se confeccionarán de manera homogénea utilizando la numeración $1,2,3 ; 1.1 .1 .2$, etc.

6. Las normas de publicación podrán ser modificadas si el equipo de redacción lo considera necesario. 
Próxima sección monográfica:

\section{EL MARCO ACTUAL DE LA ACCIÓN SOCIAL ¿SERVICIOS SOCIALES PÚBLICOS O PRIVADOS?}

Plazo para presentación de artículos: 1 de julio 1998.

\section{RECTIFICACIÓN AL NÚMERO ANTERIOR}

El Consejo Editorial de la Revista quiere hacer constar que el artículo publicado en el número 4 de la revista, en octubre de 1996, titulado «Geografía, ordenación del territorio y colonialismo español en Marruecos», que aparece adaptado por D. ${ }^{a}$ M. ${ }^{a}$ José Escartín Caparrós y D. ${ }^{a}$ Esperanza Suárez Soto, debe constar como traductora y adaptadora única $\mathrm{D}$. $^{\mathrm{a}}$ Sonia Ródenas Picardat. 



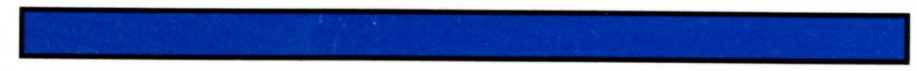

